\title{
Segmentação e reconhecimento de gestos em tempo real com câmeras e aceleração gráfica \\ Daniel Oliveira Dantas
}

\author{
TESE APRESENTADA \\ $\mathrm{AO}$ \\ INSTITUTO DE MATEMÁTICA E ESTATÍSTICA \\ DA \\ UNIVERSIDADE DE SÃO PAULO \\ PARA OBTENÇÃO DO TÍTULO DE DOUTOR \\ EM \\ CIÊNCIAS
}

Área de Concentração : Ciência da Computação

Orientador : Prof. Dr. Junior Barrera

\author{
$\mathrm{O}$ autor recebeu apoio financeiro do \\ CNPq - Conselho Nacional de Desenvolvimento Científico e Tecnológico \\ - São Paulo, marçco de 2010 -
}





\title{
Segmentação e reconhecimento de gestos em tempo real com câmeras e aceleração gráfica
}

\author{
Esta versão contém as \\ correções e alterações sugeridas pela \\ Comissão Julgadora durante a defesa, \\ realizada em 15 de março de 2010
}

Comissão Julgadora:

- Prof. Dr Junior Barrera (orientador) - FFCLRP-USP

- Prof. Dr. Roberto Marcondes Cesar Junior - IME-USP

- Dr. Claudio Santos Pinhanez - IBM

- Prof. Dr. Roberto de Alencar Lotufo - UNICAMP

- Prof. Dr. Siome Klein Goldenstein - UNICAMP 

to boldly go 



\section{Agradecimentos}

Agradeço a todos que me acompanharam durante os anos em que estive matriculado no programa de Doutorado em Ciência da Computação do IME-USP.

Em particular,

David Martins, pela grande ajuda na compra das câmeras e da placa de vídeo, ferramentas fundamentais no decorrer do trabalho.

Thiago Paixão, pela força, inclusive muscular carregando equipamentos, no primeiro experimento de captura.

Silvio Rodrigues e Elier Broche Cristo, pela ajuda com o R. Silvio Rodrigues novamente, pela ajuda com o algoritmo de Viterbi.

Alexandre Noma pelas discussões e pelas dicas sobre belief propagation.

Thiago Santos e Marcelo Hashimoto, pelas discussões sobre visão computacional tridimensional.

David Pires e Jesus Mena, pela ajuda com o $\mathrm{LATEX}_{\mathrm{E}}$ e na revisão do texto.

Obrigado à escola de goleiros "Fechando o Gol" de Zetti, em particular Rodrigo Domingos Barrera e seu instrutor Felipe Rodrigues Silva, que geraram os dados do experimento de captura e aparecem em diversas imagens nesta tese.

Obrigado aos funcionários do IME pela força com a burocracia, em especial ao pessoal do áudio-visual, da biblioteca e da CPG. Valeu aí Pinho, Emerson e sua equipe!

Obrigado à amiga Camilla Ishikawa por me ensinar que existe um turno de trabalho entre o jantar no bandejão e o último ônibus. 
Obrigado a Frédéric Chopin, pelas polonaises, valsas e concertos, e a Red Hot Chilli Peppers, Led Zeppelin, Metallica, Pink Floyd, Queen, Sublime, Molotov, Manu Chao, Raimundos e Chico Buarque por comporem a trilha sonora que eu ouvia enquando programava.

Aos professores do grupo de visão computacional pelas discussões e sugestões, Roberto Cesar, Roberto Hirata, Nina Hirata, Carlos Hitoshi Morimoto.

Ao meu orientador, Junior Barrera pela confiança e por acompanhar todo o trabalho, do princípio ao fim.

E a todos os demais que de alguma forma participaram deste trabalho, mas que por esquecimento meu não foram citados.

A todos vocês, muito obrigado! 


\section{Resumo}

O objetivo deste trabalho é reconhecer gestos em tempo real apenas com o uso de câmeras, sem marcadores, roupas ou qualquer outro tipo de sensor. A montagem do ambiente de captura é simples, com apenas duas câmeras e um computador. O fundo deve ser estático, e contrastar com o usuário. A ausência de marcadores ou roupas especiais dificulta a tarefa de localizar os membros. A motivação desta tese é criar um ambiente de realidade virtual para treino de goleiros, que possibilite corrigir erros de movimentação, posicionamento e de escolha do método de defesa. A técnica desenvolvida pode ser aplicada para qualquer atividade que envolva gestos ou movimentos do corpo.

O reconhecimento de gestos começa com a detecção da região da imagem onde se encontra o usuário. Nessa região, localizamos as regiões mais salientes como candidatas a extremidades do corpo, ou seja, mãos, pés e cabeça. As extre-

midades encontradas recebem um rótulo que indica a parte do corpo que deve representar. Um vetor com as coordenadas das extremidades é gerado.

Para descobrir qual a pose do usuário, o vetor com as coordenadas das suas extremidades é classificado. O passo final é a classificação temporal, ou seja, o reconhecimento do gesto. A técnica desenvolvida é robusta, funcionando bem mesmo quando o sistema foi treinado com um usuário e aplicado a dados de outro. 


\begin{abstract}
Our aim in this work is to recognize gestures in real time with cameras, without markers or special clothes. The capture environment setup is simple, uses just two cameras and a computer. The background must be static, and its colors must be different the user's. The absence of markers or special clothes difficults the location of the users limbs.

The motivation of this thesis is to create a virtual reality environment for goalkeeper training, but the technique can be applied in any activity that involves gestures or body movements.

The recognition of gestures starts with the background subtraction. From the foreground, we locate the more proeminent regions as candidates to body extremities, that is, hands, feet and head. The found extremities receive a label that indicates the body part it may represent.

To classify the user's pose, the vector with the coordinates of his extremities is compared to keyposes and the best match is selected. The final step is the temporal classification, that is, the gesture recognition. The developed technique is robust, working well even when the system was trained with an user and applied to another user's data.
\end{abstract}




\section{Sumário}

1 Introdução 1

2 Fundamentos de Visão Computacional 3D 5

2.1 O modelo de câmera pinhole . . . . . . . . . . . . . . 6

2.2 Distorção radial . . . . . . . . . . . . . . . . . . . . . . . . . 8

2.3 Mapa de profundidade e disparidade . . . . . . . . . . . . . . . . 9

2.4 Restrição epipolar . . . . . . . . . . . . . . . . . . . . . . 11

2.5 Matriz fundamental . . . . . . . . . . . . . . . . . . . 12

2.6 Retificação . . . . . . . . . . . . . . . . . 15

2.7 Visão estéreo . . . . . . . . . . . . . . . . . . . . . 17

2.8 Processo de calibração . . . . . . . . . . . . . . . . . . 18

3 Trabalhos relacionados $\quad 21$

3.1 Visão computacional em interfaces homem-computador . . . . . . . . . . 22

3.2 Reconhecimento de gestos . . . . . . . . . . . . . . 23

3.3 Finite State Machines . . . . . . . . . . . . . . . . . . 25

3.4 Hidden Markov Models . . . . . . . . . . . . . . . . . 27

3.5 Realidade virtual . . . . . . . . . . . . . . . . . . . 29

3.6 Breve histórico . . . . . . . . . . . . . . . . . . . 29

3.7 Alguns sistemas comerciais . . . . . . . . . . . . . 31

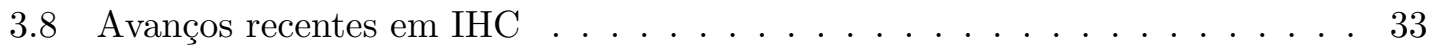


3.9 Avanços recentes em reconhecimento de gestos . . . . . . . . . . . . . 35

4 Introdução ao uso das GPUs $\quad 39$

4.1 Dificuldades no uso das GPUs . . . . . . . . . . . . . . . . . . . . . . . 42

4.2 Linguagens para programar GPU . . . . . . . . . . . . . . . . 45

4.2 .1 A linguagem GLSL . . . . . . . . . . . . . . . . . . 45

4.2 .2 A linguagem CUDA . . . . . . . . . . . . . . . . 47

4.3 Soluções existentes . . . . . . . . . . . . . . . . . . . . . . 48

5 Processamento de vídeo em tempo real usando GPU 51

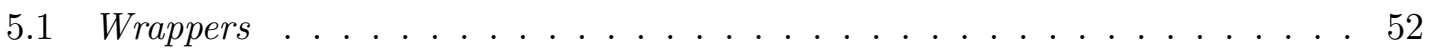

$5.1 .1 \quad$ Wrappers GLSL . . . . . . . . . . . . . . 53

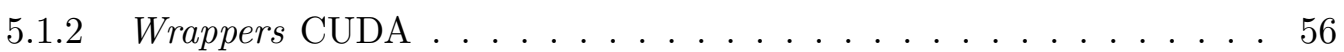

5.2 Resultados . . . . . . . . . . . . . . . . . . 58

6 Reconhecimento de gestos $\quad 61$

6.1 Pré-processamento . . . . . . . . . . . . . . . . . . 65

6.2 Subtração de background . . . . . . . . . . . . . . . 66

6.3 Correção de altura . . . . . . . . . . . . . . . . . . . 66

6.4 Cálculo do esqueleto . . . . . . . . . . . . . . . . . . . . . . . 69

6.5 Localização das extremidades . . . . . . . . . . . . . . . 70

6.6 Rotulação das extremidades . . . . . . . . . . . . . . . . . . 73

6.7 Classificação da pose . . . . . . . . . . . . . . . . . . 76

6.8 Classificação da pose: métrica entre grafos . . . . . . . . . . . . . . . . . 78

6.9 Classificação dos gestos . . . . . . . . . . . . . . . . . . . . 79

6.10 Discussão . . . . . . . . . . . . . . . . . . . . 81

$\begin{array}{lll}7 & \text { Experimento com gestos de goleiro } & 83\end{array}$

7.1 Captura do dataset experimental . . . . . . . . . . . . . . . . 83

7.1 .1 Motivação . . . . . . . . . . . . . . . . . 84 
$7.1 .2 \quad$ Hardware usado . . . . . . . . . . . . . . . . . . . 84

7.1.3 Definição do volume de captura . . . . . . . . . . . . . . . 85

7.1 .4 Área de captura . . . . . . . . . . . . . . . 86

7.2 Classificação estática . . . . . . . . . . . . . . . . . . 88

7.3 Conjunto de poses $\ldots \ldots \ldots \ldots \ldots$. . . . . . . . . . . . . . . . 94

7.4 Conjunto de gestos . . . . . . . . . . . . . . . . . 95

7.5 Cálculo do erro . . . . . . . . . . . . . . . . . . . . . 97

7.6 Erro usando a métrica entre grafos . . . . . . . . . . . . . . . . . . 104

7.7 Tempo de processamento f . . . . . . . . . . . . . . . 105

7.8 Discussão . . . . . . . . . . . . . . . . . . . 106

8 Conclusão $\quad 131$

A Biblioteca VisionGL $\quad 139$

A.1 src/vglImage.h File Reference . . . . . . . . . . . . . . . . . 139

A.1.1 Function Documentation . . . . . . . . . . . . . . 142

A.2 src/glsl2cpp_BG.h File Reference . . . . . . . . . . . . . . . 153

A.2.1 Function Documentation . . . . . . . . . . . . . . 154

A.3 src/glsl2cpp_shaders.h File Reference . . . . . . . . . . . . . 155

A.3.1 Function Documentation . . . . . . . . . . . . . 158

A.4 src/glsl2cpp_Stereo.h File Reference . . . . . . . . . . . . . . . 173

A.4.1 Function Documentation . . . . . . . . . . . . . . . . . 174 



\section{Lista de Figuras}

2.1 Modelo de câmera pinhole. . . . . . . . . . . . . . . 7

2.2 Imagem com distorção radial. . . . . . . . . . . . . . . . . . . . . 10

2.3 Imagem sem distorção radial. . . . . . . . . . . . . . . . . . . . 11

2.4 Par de imagens com paralaxe. . . . . . . . . . . . . . . . 12

2.5 Par de imagens sem paralaxe. . . . . . . . . . . . . . . . 13

2.6 A disparidade do ponto $M$ nesse sistema de câmeras é dada por $u_{1}-u_{2}$, que são vetores no sistema de coordenadas da imagem. . . . . . . . . . . . . 14

2.7 Geometria epipolar. . . . . . . . . . . . . . . . . 15

2.8 Linhas epipolares correspondentes. . . . . . . . . . . . . . . . . 16

2.9 Linhas epipolares após a retificação. . . . . . . . . . . . . . . . . 17

5.1 Para que a API OpenGL faça processamento genérico, é preciso mapear cada matriz de dados em uma textura ou pixelbuffer. . . . . . . . . . . . . . 54

5.2 A biblioteca proposta chama as funções do OpenGL, necessárias para transferir a imagem entre contextos, de forma transparente para o programador. $\quad 54$

6.1 Pipeline do sistema de reconhecimento de gestos proposto. . . . . . . . . . 62

6.2 Segmentação de background do frame 460 da sequência thiagopx0. . . . . . . 63

6.3 Segmentação de background do frame 850 da sequência felipe0. . . . . . . . . 64

6.4 Ângulos visuais ocupados pelo usuário a diferentes distâncias da câmera. . . 68

6.5 Frame 148 da sequência thiagopx0 depois da subtração de fundo. . . . . . . 69

6.6 Frame 132 da sequência thiagopx1 depois da subtração de fundo. . . . . . . 69 
6.7 Localização das extremidades no frame 348 da sequência thiagopx0. . . . . 71

6.8 Exemplo de extremidade em um ciclo no frame 730 da sequência thiagopx0. 73

6.9 Modelo simplificado do corpo humano, com catorze ossos. . . . . . . . . . . 74

7.1 Volume de captura visto de cima. . . . . . . . . . . . . . . . 87

7.2 Volume de captura visto de lado. . . . . . . . . . . . . . . . . 87

7.3 Keyframes, extraídos da sequência felipe-key, usados na classificação estática. 93

7.4 Keyframes extraídos da sequência felipe-key. . . . . . . . . . . . . . . . . . 109

7.5 Espera na sequência felipe0, a partir do frame 570 a cada 5 frames. . . . . . 110

7.6 Esqueletos da Figura 7.5 . . . . . . . . . . . . . . . . . . . . . 110

7.7 Espera na sequência rodrigo0, a partir do frame 580 a cada 5 frames. . . . . 111

7.8 Esqueletos da Figura $7.7 \ldots \ldots \ldots 111$

7.9 Pegada na sequência felipe0, a partir do frame 795 a cada 5 frames. . . . . 112

7.10 Esqueletos da Figura 7.9. . . . . . . . . . . . . . . . . . . . . . . . 112

7.11 Pegada na sequência rodrigo0, a partir do frame 780 a cada 3 frames. . . . 113

7.12 Esqueletos da Figura 7.11. . . . . . . . . . . . . . . . . . . . 113

7.13 Encaixe na sequência felipe0, a partir do frame 1195 a cada 5 frames. . . . 114

7.14 Esqueletos da Figura 7.13. . . . . . . . . . . . . . . . . . . . . . . . 114

7.15 Encaixe na sequência rodrigo0, a partir do frame 1205 a cada 5 frames. . . 115

7.16 Esqueletos da Figura 7.15 . . . . . . . . . . . . . . . . . . . 115

7.17 Entrada na sequência felipe0, a partir do frame 1330 a cada 5 frames. . . . 116

7.18 Esqueletos da Figura 7.17 . . . . . . . . . . . . . . . . . . . 116

7.19 Entrada na sequência rodrigo0, a partir do frame 1375 a cada 5 frames. . . 117

7.20 Esqueletos da Figura 7.19 . . . . . . . . . . . . . . . . . . . . 117

7.21 Salto na sequência felipe1, a partir do frame 1460 a cada 5 frames. . . . . . 118

7.22 Esqueletos da Figura 7.21. . . . . . . . . . . . . . . . . . 118

7.23 Salto na sequência rodrigo1, a partir do frame 1720 a cada 5 frames. . . . . 119

7.24 Esqueletos da Figura 7.23. . . . . . . . . . . . . . . . . . . . . . . 119 
7.25 Salto para a direita em felipe0, a partir do frame 1580 a cada 5 frames. . . 120

7.26 Esqueletos da Figura 7.25 . . . . . . . . . . . . . . . . . . . 120

7.27 Salto para a direita em rodrigo1, a partir do frame 1645 a cada 5 frames. . 121

7.28 Esqueletos da Figura 7.27 . . . . . . . . . . . . . . . . . . . . . 121

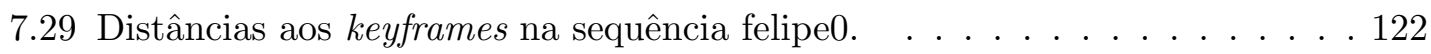

7.30 Distâncias aos keyframes com restrição de transição na sequência felipe0. 123

7.31 Distâncias aos keyframes na sequência felipe1. . . . . . . . . . . . . . . 124

7.32 Distâncias aos keyframes com restrição de transição na sequência felipe1. 125

7.33 Distâncias aos keyframes na sequência rodrigo0. . . . . . . . . . . . . 126

7.34 Distâncias aos keyframes com restrição de transição na sequência rodrigo0. 127

7.35 Distâncias aos keyframes na sequência rodrigo1. . . . . . . . . . . . . 128

7.36 Distâncias aos keyframes com restrição de transição na sequência rodrigo1. 129

8.1 Esquema da instalação. . . . . . . . . . . . . . . . . . . 135

8.2 Instalação e tela do ponto de vista do usuário. . . . . . . . . . . . . . . 136 


\section{Lista de Tabelas}

5.1 Tempo médio em milissegundos para processar uma imagem $1024 \times 1024$ pixels 59

6.1 Tamanho dos ossos considerando uma altura de 118 pixels. . . . . . . . . . 74

7.1 Características intrínsecas da câmera. . . . . . . . . . . . . . 85

7.2 Elementos do volume de captura. . . . . . . . . . . . . 86

7.4 Profundidade em função da disparidade. . . . . . . . . . . . . . . . . . . 89

7.5 Matriz de confusão do classificador por Momentos de Hu. . . . . . . . . . 90

7.6 Matriz de confusão do classificador por Correlação de Fase. . . . . . . . . . 90

7.7 Matriz de confusão do classificador por Coeficiente de Correlação. . . . . . . 90

7.8 Matriz de confusão do classificador por Correlação Cruzada. . . . . . . . . . 91

7.9 Matriz de confusão do classificador por Distância de Chamfer entre os esqueletos dos blobs. . . . . . . . . . . . . . . . . . 91

7.10 Matriz de confusão do classificador por Distância de Chamfer entre os contornos dos blobs. . . . . . . . . . . . . . . . 91

7.11 Matriz de confusão do classificador por menor distância ao keypoint (Voronoi). 92

7.12 Matriz de confusão do classificador por menor Distância entre Grafos. . . 92

7.13 Percentuais de acertos nas quatro sequências de vídeos. . . . . . . . . . 92

7.14 Keypoints. As coordenadas das cinco extremidades são relativas ao baricentro. O $y$ do baricentro é sua coordenada na imagem; $\mathrm{d} x$ e d $z$ são a variação de $x$ e $z$ em alguns quadros. Valores extraídos da sequência felipe-key. . . . 96

7.15 Matriz de transição. . . . . . . . . . . . . . . . . . . . 97

7.16 Resultado obtido com as sequências felipe 0 e felipe 1 . . . . . . . . . . 102 
7.17 Resultado obtido com as sequências rodrigo0 e rodrigo1 . . . . . . . . . . . 102

7.18 Resultado da métrica entre grafos nas sequências felipe0 e felipe1 . . . . . . 104

7.19 Resultado da métrica entre grafos nas sequências rodrigo0 e rodrigo1 . . . . 104

7.20 Tempos médios de processamento em milissegundos. . . . . . . . . . . . . . 105 


\section{Convenções}

Algumas convenções usadas no texto:

- Fonte typewriter é usada para denotar nomes de funções, variáveis, tipos de dados, palavras reservadas de alguma linguagem, comandos e listagens de arquivos.

- Fonte em itálico é usada quando algum termo importante está sendo introduzido, ou para palavras estrangeiras. Pixel e mouse, por exemplo, são algumas exceções por serem muito comuns.

- Pontos no plano ou espaço são denotados por letras em negrito: m, M, C.

- Escalares são denotados por letras em itálico: $k, r, f, X, u$.

- Retas e vetores: $\vec{l}$.

- Pontos e vetores também podem ser representados por suas coordenadas, que são escalares: $(X, Y, Z),(u, v)$.

- Matrizes: $[F]$.

- Planos: $\mathcal{R}, \mathcal{E}, \mathcal{F}$.

- Denotamos o conjunto dos números reais por $\mathbb{R}$, o dos naturais por $\mathbb{N}$ e o dos inteiros por $\mathbb{Z}$.

- Espaços: $\mathbb{R}^{3}, \mathbb{R}^{n}$ com $n$ inteiro. 



\section{Capítulo 1}

\section{Introdução}

O problema de reconhecimento de gestos tem sido bastante estudado nos últimos anos e é recorrente em diversas áreas, dentre as quais podemos citar a de interfaces homemcomputador, especialmente as baseadas em câmeras, e captura de movimento. Tais áreas são bastante ativas, havendo vários reviews sobre o assunto [1, 2, 45, 77, 78, 79, 15].

O reconhecimento dos gestos do usuário pode ser feito de duas maneiras diferentes: observando-se a configuração global de seu corpo, através de sua silhueta; ou observando-se a configuração de partes do seu corpo, como por exemplo, as mãos.

Para medir a posição de seus membros, pode-se usar dispositivos como acelerômetros, emissores de rádio ou de ultrassom. Existem também roupas especiais com sensores que medem os ângulos das articulações do usuário.

A detecção dos membros pode também ser feita através de câmeras. Normalmente os sistemas baseados em câmeras exigem que o usuário vista alguma roupa especial ou prenda marcadores em partes específicas do corpo.

O problema no uso desses equipamentos é que, além de não permitirem a total liberdade 
de movimentos do usuário, exigem uma cuidadosa preparação cada vez que um novo usuário precise usar o sistema. A preparação envolve prender os emissores ou marcadores na parte do corpo apropriada ou vestir a roupa especial. Dependendo do ambiente, isso pode tornar seu uso impraticável.

Para evitar esse passo demorado de preparação do usuário, o ideal é que o sistema não exija o uso de rastreadores eletrônicos e marcadores presos ao corpo do usuário. Por causa desses problemas, ultimamente se tem dado mais ênfase a sistemas baseados em câmeras, sem marcadores. Além disso, especialmente nas aplicações de interação homem computador, o reconhecimento de gestos deve ser feito em tempo real.

Existem sistemas baseados em câmeras bastante caras, ou que usam oito ou mais câmeras em diversos ângulos para compor um volume do usuário. A montagem e calibração de tais sistemas costumam ser complexas.

Quanto mais câmeras, mais complexa a montagem do ambiente de captura, porém, menos câmeras implicam em menos informação. No caso de uma câmera, a análise de silhueta do usuário dá bons resultados apenas quando não há ambiguidades ou autooclusão. Para contornar esses problemas usam-se, por exemplo, restrições físicas e modelos de cor.

O objetivo deste trabalho é criar um sistema que reconheça os gestos do usuário em tempo real, sem marcadores, roupas ou fundo especial. A fim de diminuir a complexidade da montagem e calibração do sistema, usamos apenas duas câmeras e um computador. O fundo deve ser estático, ou seja, não devem aparecer outras pessoas, ou plantas que podem se movimentar com o vento. Também deve ser de cor diferente de todas as partes do corpo e roupa do usuário. Tal contraste é importante para a etapa de subtração de fundo, que dá como resultado a silhueta do usuário. A ausência de marcadores dificulta a tarefa de segmentação e localização dos membros. 
Para conseguir processar vídeo em tempo real, é usado o poder de processamento das GPUs (Graphics Processing Units). Foi criada uma biblioteca que esconde do usuário as complexidades da programação das GPUs. A biblioteca proposta é fácil de usar e mais rápida do que outras existentes.

O reconhecimento de gestos começa com a detecção da região da imagem onde se encontra o usuário. Nessa região, são localizadas as regiões mais salientes como candidatas a extremidades do corpo, ou seja, mãos, pés e cabeça. As extremidades encontradas recebem um rótulo que indica que parte do corpo representam. Em seguida, um vetor com as coordenadas das extremidades é gerado.

Para identificar a pose do usuário, classifica-se o vetor com as coordenadas das extremidades de seu corpo. Finalmente, é feita a classificação temporal, ou seja, o reconhecimento do gesto, que usa uma FSM (Finite State Machine) bastante simples porém suficiente para classificar os gestos.

Como estudo de caso, foram selecionados alguns gestos de goleiro de futebol de campo e o sistema foi programado para reconhecê-los. No sistema proposto, tal programação é simples, exigindo apenas que se escolham alguns quadros do vídeo que representem bem as poses, e criar um grafo de transição entre as poses. No texto, os termos matriz de transição e grafo de transição são equivalentes.

Os resultados obtidos com os gestos de goleiro foram animadores, com uma alta taxa de acerto. Um trabalho futuro poderia incluir a implementação de um sistema completo de realidade virtual para treinamento esportivo, que é uma das principais motivações desta tese.

O ambiente de realidade virtual para treino de goleiros poderia corrigir o usuário quando cometesse erros, por exemplo, de posicionamento e de escolha da técnica de defesa. Tal sistema poderia ser adaptado para treinar qualquer atividade que envolva gestos ou 
movimentos do corpo. O usuário teria, projetada em um telão à sua frente, a visão do campo de um ponto de vista atrás do goleiro. Veria uma representação sua com transparência, para não ocultar a bola e os jogadores. Para aumentar a sensação de imersão no jogo, tal projeção poderia ser estereoscópica, com o uso de óculos polarizados.

Neste primeiro capítulo foram apresentados os objetivos do trabalho, assim como as motivações para a criação do sistema de reconhecimento de gestos. No Capítulo 2 são apresentados alguns fundamentos de visão computacional tridimensional. O modelo de câmeras pinhole é apresentado e os princípios por trás da visão estéreo são discutidos. Ainda neste capítulo, apresentamos o processo de calibração do sistema proposto. No Capítulo 3 é feita uma pequena revisão da área de reconhecimento de gestos e visão computacional em interfaces homem-computador. Um breve histórico e os avanços mais recentes nessas áreas são apresentados. No Capítulo 4 apresentamos uma pequena introdução ao uso das GPUs, em especial no processamento de imagens, descrevemos duas linguagens usadas para programá-las, e bibliotecas de processamento de imagens que usam seu poder de processamento.

A partir daqui, são apresentadas as contribuições desta tese. A biblioteca que propomos, que tira proveito da velocidade das GPUs para fazer procesamento de vídeo em tempo real é apresentada no Capítulo 5. No Capítulo 6 é apresentado em detalhes o pipeline de processamento de vídeo, classificação de poses e de gestos. No Capítulo 7 mostramos um estudo de caso, com gestos de goleiro, em que a solução proposta é bem sucedida. Também são descritos os procedimentos para captura dos dataset de imagens estéreo. Ainda nesse capítulo há imagens ilustrando exemplos dos gestos classificados. Discussões sobre as contribuições, comentários finais e próximos passos da pesquisa são apresentados no Capítulo 8 . 


\section{Capítulo 2}

\section{Fundamentos de Visão Computacional 3D}

O modelo de câmera pinhole é o modelo de câmera mais simples que existe, e será usado em toda a tese. Esse modelo explica as transformações do espaço tridimensional para o plano de imagem, bidimensional.

Esse modelo é idealizado, ou seja, uma câmera que siga exatamente esse modelo é impossível. Nesse modelo, toda a luz passa por um orifício pontual de área nula. Com isso, teoricamente, sempre teríamos imagens do mundo perfeitamente focadas qualquer que seja a distância entre a câmera e o objeto. Na prática, porém, um orifício de área nula não permitiria a passagem da luz, impossibilitando a detecção da imagem qualquer que seja o tipo de sensor usado.

Câmeras pinhole reais possuem orifícios com área maior que zero, porém, quanto maior a área do orifício, mais os objetos aparecem desfocados. Ao se usar câmeras pinhole, o tamanho do orifício deve balancear captação de luz e desfoque. Quanto menor o orifício, 


\section{CAPÍTULO 2. FUNDAMENTOS DE VISÃO COMPUTACIONAL 3D}

menor o desfoque e maior a necessidade de se iluminar a cena para se produzir imagens bem expostas.

Na prática, câmeras pinhole são raras e quase sempre se usam câmeras com lentes. As lentes permitem uma maior captação de luz e conseguem focalizar objetos a certas distâncias.

Um problema do modelo de câmera pinhole é que ele não explica a distorção radial, presente em câmeras com lentes. Usaremos esse modelo, e eliminaremos a distorção radial das imagens captadas usando câmeras com lentes, conforme explicado na Seção 2.2.

\subsection{O modelo de câmera pinhole}

Os elementos mais importantes da câmera descrita no modelo são um plano $\mathcal{R}$, chamado plano retinal, ou plano de imagem, e um ponto $\mathbf{C}$ fora de $\mathcal{R}$, o centro ótico. A Figura 2.1 mostra os principais elementos do modelo de câmera pinhole.

A projeção $\mathbf{m}$ de um ponto $\mathbf{M}$ do espaço tridimensional é a interseção do raio ótico (C, M) com o plano $\mathcal{R}$.

O eixo ótico é a linha, perpendicular ao plano retinal, que passa por $\mathbf{C}$.

O plano $\mathcal{F}$, que contém $\mathbf{C}$ e é paralelo a $\mathcal{R}$, é chamado plano focal. Podemos definir um sistema de coordenadas ortonormal com origem em $\mathbf{C}$, tendo um eixo paralelo ao eixo ótico e dois eixos no plano focal. Tal sistema é chamado sistema de coordenadas da câmera.

A distância entre o ponto $\mathbf{C}$ e o plano $\mathcal{R}$ é chamada distância focal. Muitas vezes é definida como sendo igual a 1 para facilitar as contas.

O sistema de coordenadas no plano $\mathcal{R}$ dado por $(u, v)$ é chamado sistema de coordena- 


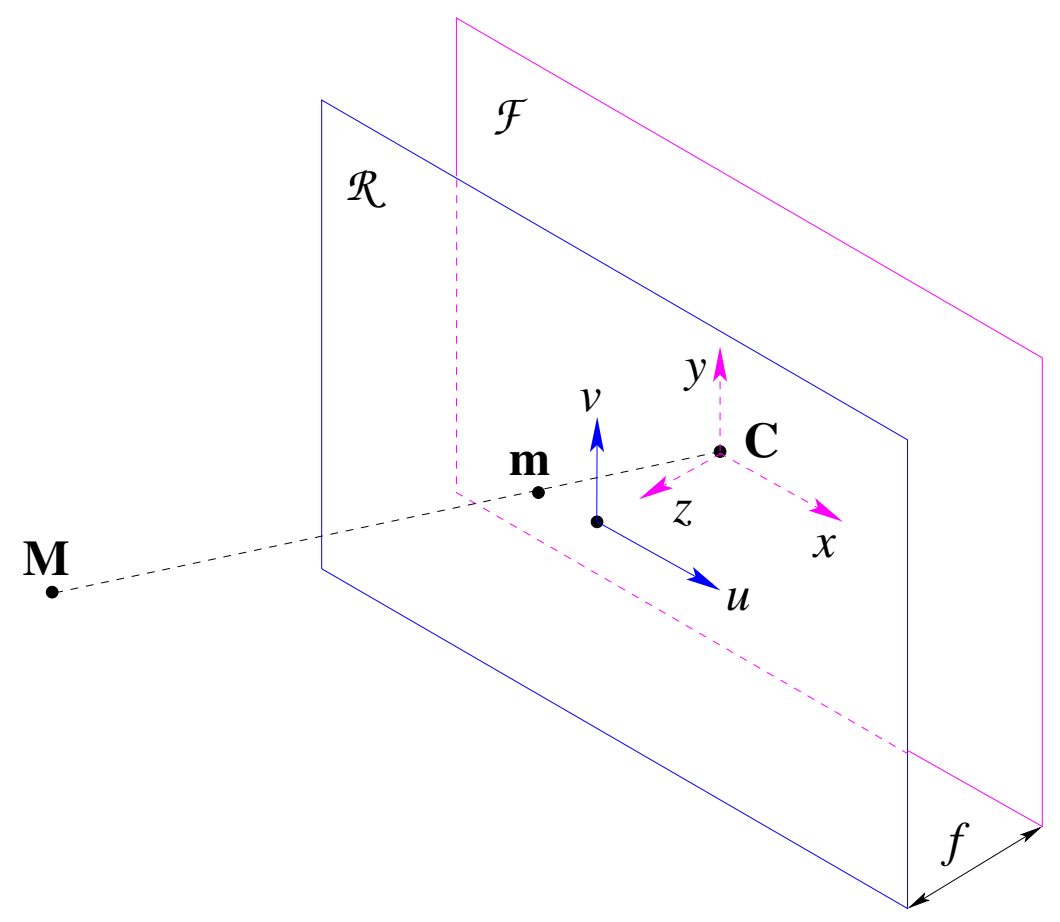

Figura 2.1: Modelo de câmera pinhole.

das da imagem. A principal operação que precisamos fazer é encontrar a projeção de um ponto $\mathbf{M}=(X, Y, Z)$, do sistema de coordenadas da câmera, para o ponto $\mathbf{m}=(u, v)$, do sistema de coordenadas da imagem.

Para isso assumimos que o $\mathbf{C}$ está na origem e a distância focal $f$ é igual a 1 . Sendo assim, a projeção de $\mathbf{M}$ é $\mathbf{m}=(u, v, 1)$ onde $u=X / Z$ e $v=Y / Z$. 


\section{CAPÍTULO 2. FUNDAMENTOS DE VISÃO COMPUTACIONAL 3D}

\subsection{Distorção radial}

Câmeras com lentes apresentam dois tipos principais de distorção radial. A distorção barrel amplia a parte central da imagem e a cena aparece como se sua imagem tivesse sido mapeada sobre uma superfície esférica. A distorção pincushion reduz a parte central da imagem e amplia as partes periféricas.

Com a distorção radial, linhas retas no espaço tridimensional são projetadas sobre curvas na imagem, não obedecendo ao modelo de câmera pinhole. Ao se eliminar a distorção radial, linhas retas no mundo são projetadas sobre retas na imagem

A distorção radial pode ser modelada pelas fórmulas abaixo [86]. Os valores $k_{1}$ e $k_{2}$ são chamados coeficientes de distorção radial.

$$
\begin{gathered}
u^{\prime}=u\left(1+k_{1} r^{2}+k_{2} r^{4}\right), \\
v^{\prime}=v\left(1+k_{1} r^{2}+k_{2} r^{4}\right), \\
\text { onde } r^{2}=u^{2}+v^{2} .
\end{gathered}
$$

Para obter os coeficientes de distorção radial, utilizamos algumas funções do OpenCV e um padrão xadrez, que é posicionado em frente à câmera.

As imagens capturadas pela câmera são processadas primeiro pela função que localiza os vértices do tabuleiro de xadrez, cvFindChessboardCornerGuesses. Em seguida, a função cvCalibrateCamera recebe os pontos e retorna os coeficientes de distorção radial. Para corrigir a distorção, usa-se a função cvUndistortOnce com os coeficientes de distorção radial como parâmetros. Caso a câmera possua comprimento focal fixo, os coeficientes podem e devem ser salvos para uso posterior, pois não mudam, evitando repetir o processo de calibração. 
A Figura 2.2 mostra a imagem original, com distorção radial. A Figura 2.3 mostra a imagem corrigida, sem distorção. Ambas com os pontos detectados sobrepostos pela função cvDrawChessboardCornerGuesses.

\subsection{Mapa de profundidade e disparidade}

É possível se obter um mapa de profundidade de uma cena a partir de um par de suas imagens obtidas simultaneamente de pontos de vista diferentes. Um mapa de profundidade é uma imagem em tons de cinza onde a intensidade do pixel é proporcional à sua distância da câmera.

É fundamental que as imagens sejam obtidas a partir de pontos de vista diferentes para que haja paralaxe. Há paralaxe em um par de imagens quando pontos de objetos distantes (background) e de objetos próximos (foreground) são projetados nas imagens com posição relativa diferente, como na Figura 2.4. A Figura 2.5 mostra um exemplo de par de imagens sem paralaxe e, portanto, inadequado para se extrair informação de profundidade.

Os algoritmos que geram mapas de profundidade buscam, no par de imagens, pontos chamados correspondentes. Pontos correspondentes são projeções de um mesmo ponto do espaço tridimensional. Vamos assumir por enquanto que os planos de imagem das duas câmeras estão perfeitamente alinhados. Nesse caso, projeções de pontos no infinito ocuparão a mesma posição em ambas as imagens

Devido ao efeito da paralaxe, quanto mais próximo estiver o objeto, mais distantes suas projeções estarão nas coordenadas da imagem. Essa distância é chamada disparidade e é a partir dela que calculamos a profundidade dos pontos. A Figura 2.6 ilustra o cálculo da disparidade. Se os planos retinais das duas câmeras forem paralelos, pontos no infinito possuem disparidade igual a zero. O ponto $M$ da figura possui disparidade $d=u_{1}-u_{2}$. 


\section{CAPÍTULO 2. FUNDAMENTOS DE VISÃO COMPUTACIONAL 3D}

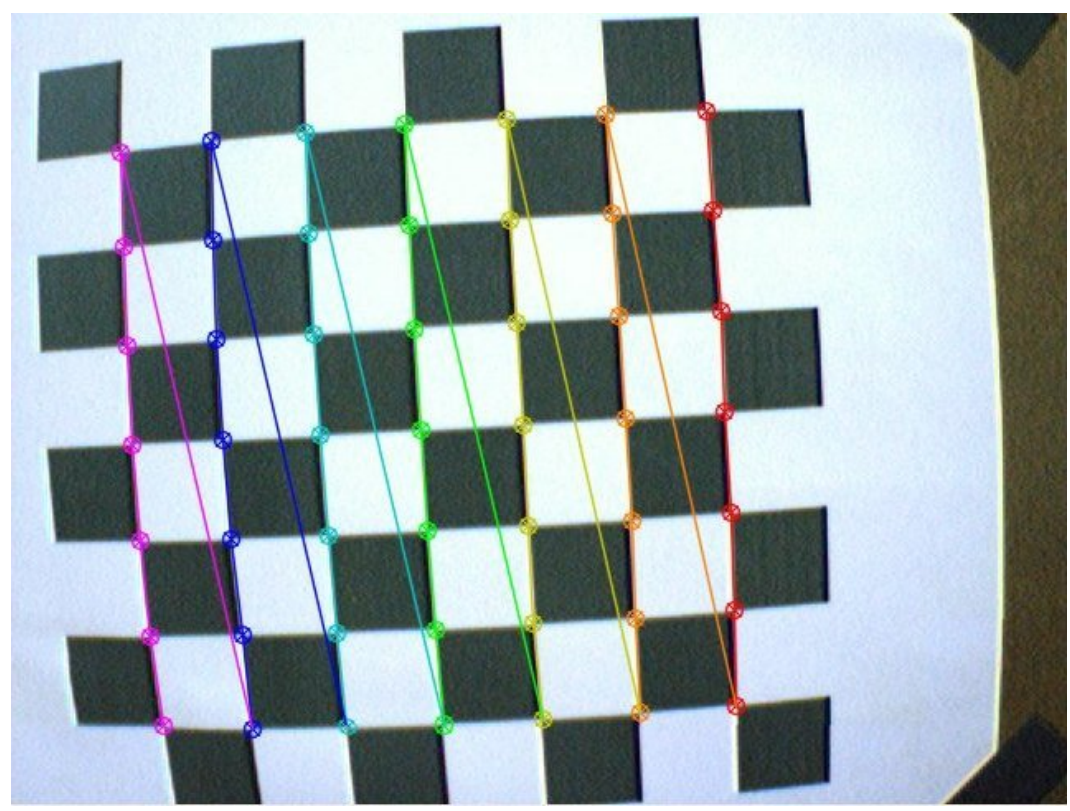

Figura 2.2: Imagem com distorção radial.

A distância entre os centros óticos é chamada baseline. Na Figura 2.6 é ilustrada por $b$. Uma vez que sabemos o valor do baseline, $b$, assumindo comprimento focal como unitário e tendo calculado o valor da disparidade, $d$, podemos calcular a distância $z$ ao ponto M. Por semelhança entre triângulos, temos que $z=b / d$. Na prática, o valor de $b$ é em, digamos, centímetros, e $d$ é em pixels. Para encontrar $z$ na unidade desejada é preciso multiplicá-lo por alguma constante.

Uma alternativa é utilizar o comprimento focal da câmera e o tamanho do pixel em centímetros também. Esses valores são encontrados nas especificações técnicas da câmera. O tamanho do pixel é igual ao tamanho do CCD dividido pelo número de pixels na direção do eixo $u$. 


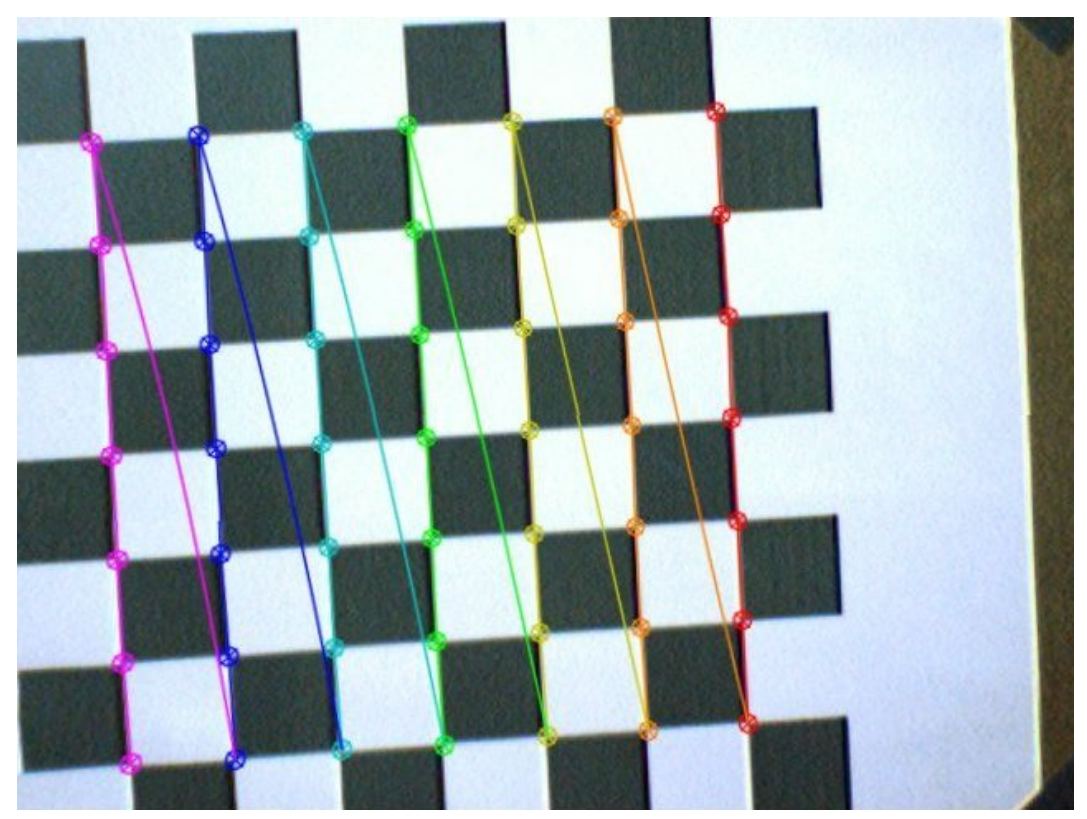

Figura 2.3: Imagem sem distorção radial.

\subsection{Restrição epipolar}

Buscar pontos correspondentes exaustivamente em um par de imagens é um problema extremamente demorado computacionalmente. Para se resolver esse problema eficientemente, é necessário se aplicar restrições ao conjunto de pontos que serão comparados.

Um tipo de restrição bastante usado ao se trabalhar com pares de câmeras é a restrição epipolar. Graças a ela, o espaço de busca por correspondências deixa de ser bidimensional para ser unidimensional. Em outras palavras, tendo um ponto $\mathbf{m}_{1}$ da imagem 1, não precisamos mais buscar seu ponto correspondente $\mathbf{m}_{2}$ na imagem 2 inteira, bastando procurar ao longo de uma linha.

A Figura 2.7 ilustra o princípio por trás da restrição epipolar. Cada plano que contiver a reta formada pelos centros óticos $\mathbf{C}_{1}$ e $\mathbf{C}_{2}$ é um plano epipolar. 


\section{CAPÍTULO 2. FUNDAMENTOS DE VISÃO COMPUTACIONAL 3D}
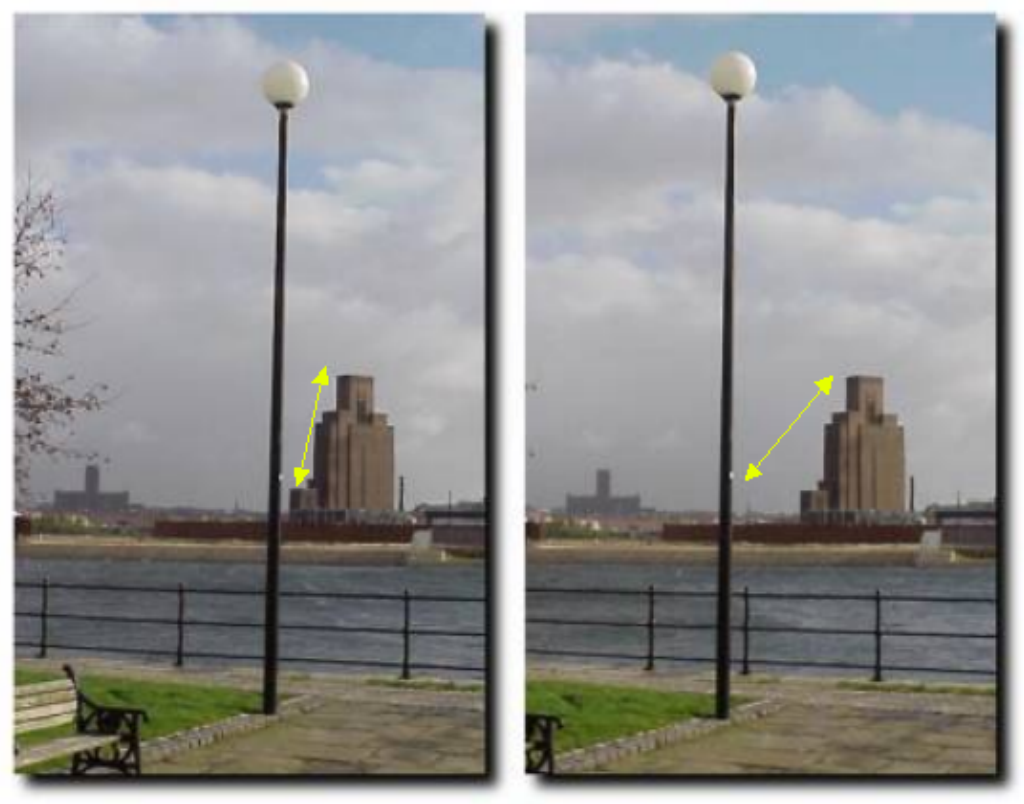

Figura 2.4: Par de imagens com paralaxe.

Seja $\mathcal{E}$ um plano epipolar, sua interseção com os planos de imagem $\mathcal{R}_{1}$ e $\mathcal{R}_{2}$ forma um par de linhas epipolares correspondentes $\vec{l}_{1}$ e $\vec{l}_{2}$. Qualquer ponto do espaço pertencente a $\mathcal{E}$ terá sua projeção em $\vec{l}_{1}$ e $\vec{l}_{2}$. Portanto, ao buscar o ponto $\mathbf{m}_{2}$, correspondente a $\mathbf{m}_{1}$, se $\mathbf{m}_{1}$ pertencer a $\vec{l}_{1}$ então $\mathbf{m}_{2}$ pertence a $\vec{l}_{2}$.

\subsection{Matriz fundamental}

O primeiro passo no processo de calibração, descrito na Seção 2.2 é a correção de distorção radial. O passo seguinte é encontrar o conjunto de linhas epipolares do par de imagens.

As linhas epipolares dependem da posição e ângulo relativo das câmeras. Caso estejam imóveis, podem ser salvas em arquivo e reutilizadas. As linhas epipolares são completamente definidas por uma matriz 3x3 chamada matriz fundamental . 


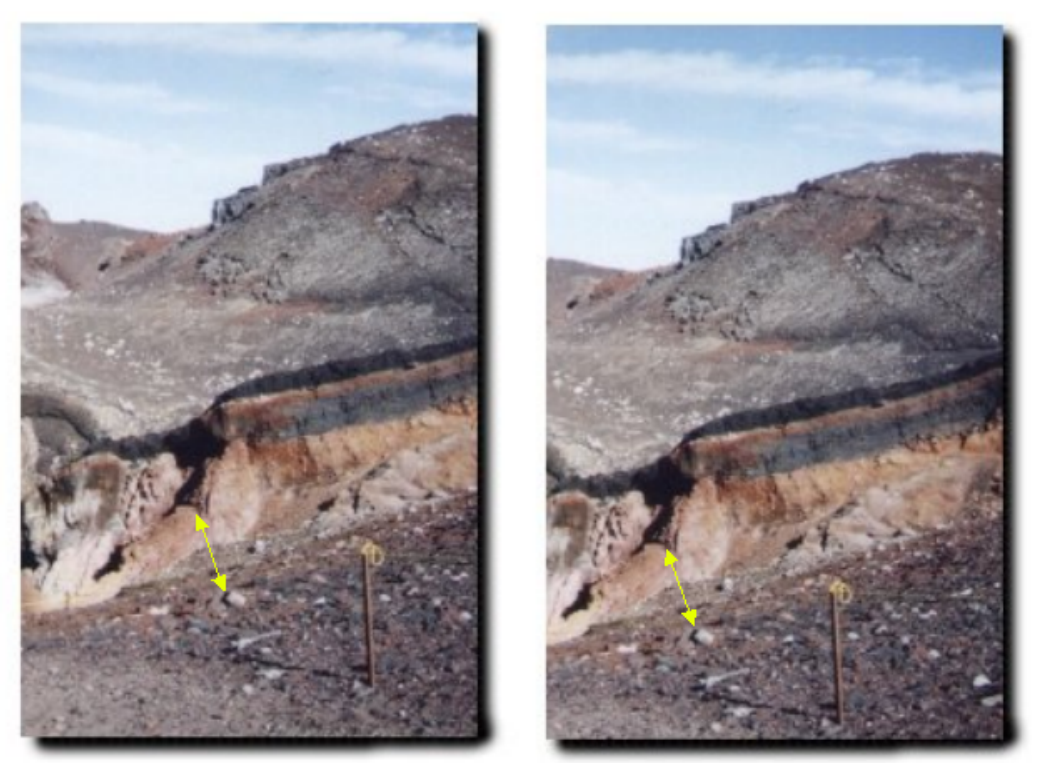

Figura 2.5: Par de imagens sem paralaxe.

É possível encontrar a matriz fundamental de um par de imagens numericamente, a partir de um conjunto de pares de pontos correspondentes, desde que esses pontos não estejam em uma configuração degenerada [49].

Um conjunto de correspondências é geometricamente degenerado se não definir unicamente a matriz fundamental $[F]$. Um exemplo de configuração degenerada é quando os pontos estão em um plano. Como estamos usando um padrão xadrez para encontrar pontos correspondentes e seus pontos se localizam em um plano, é preciso utilizar mais de um quadro, com o padrão xadrez em planos diferentes do espaço.

Para encontrar o conjunto de correspondências entre os pontos do padrão xadrez, usamos novamente a função cvFindChessboardCornerGuesses. São armazenados correspondências entre pontos de trinta quadros, e passados como parâmetro para a função cvFindFundamentalMatrix, que retorna a matriz fundamental. 


\section{CAPÍTULO 2. FUNDAMENTOS DE VISÃO COMPUTACIONAL 3D}

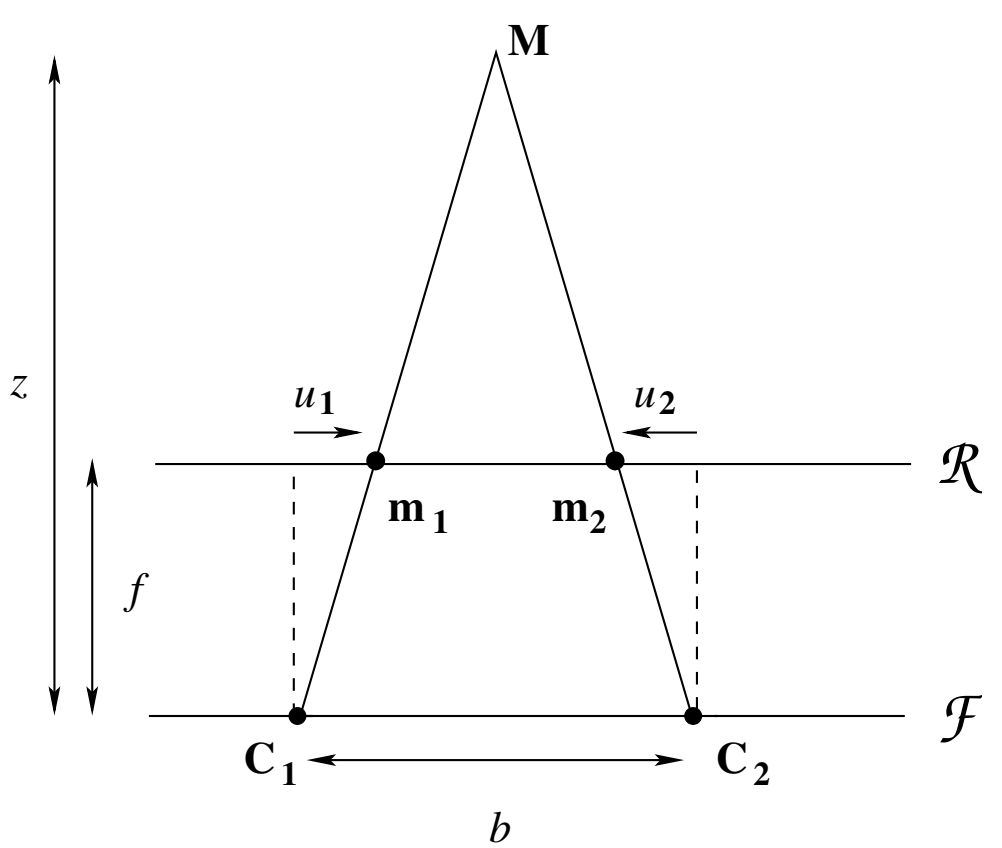

Figura 2.6: A disparidade do ponto $M$ nesse sistema de câmeras é dada por $u_{1}-u_{2}$, que são vetores no sistema de coordenadas da imagem.

Para encontrar a linha epipolar $\vec{l}_{2}$, na imagem 2 , correspondente a um ponto $\mathbf{m}_{1}$, da imagem 1, usamos a fórmula

$$
[F] \mathbf{m}_{1}=\vec{l}_{2}
$$

Para encontrar $\vec{l}_{1}$, correspondente a $\mathbf{m}_{2}$, usamos

$$
[F]^{T} \mathbf{m}_{2}=\vec{l}_{1}
$$

onde $\mathbf{m}_{1}$ e $\mathbf{m}_{2}$ são as pontos em questão expressos usando coordenadas homogêneas, ou seja, com o valor 1 na terceira dimensão. Os vetores $\vec{l}_{1}$ e $\overrightarrow{l_{2}}$ são os coeficientes de uma reta 


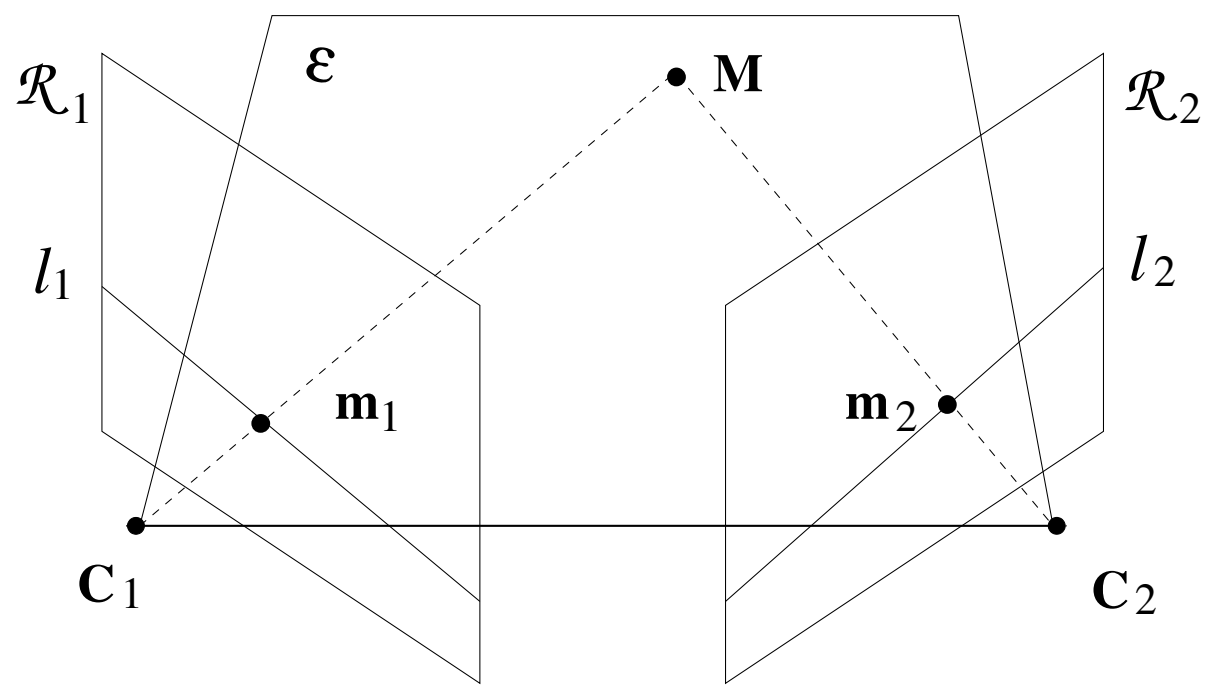

Figura 2.7: Geometria epipolar.

no plano da imagem, ou seja, se $\vec{l}=(a, b, c)$, então $a u+b v+c=0$, onde $(u, v)$ representa um ponto no sistema de coordenadas da imagem.

\subsection{Retificação}

Retificar uma imagem é fazer com que as linhas epipolares fiquem paralelas a suas linhas de varredura horizontais. Isso é importante tanto para aumentar a velocidade quanto para simplificar os algoritmos. Com a imagem retificada, podemos assumir que pares de pontos correspondentes sempre possuem o mesmo valor de coordenada $v$, ou seja, estão em linhas horizontais de mesmo índice.

Para retificar as imagens usamos uma transformação chamada homografia $[49,38]$. Para encontrá-la, escolhemos dois pares de linhas epipolares correspondentes, um será a borda superior da imagem, o outro será a borda inferior. Para cada linha, pegamos seus pontos extremos, direito e esquerdo. Tais pontos extremos serão mapeados para os cantos 


\section{CAPÍTULO 2. FUNDAMENTOS DE VISÃO COMPUTACIONAL 3D}

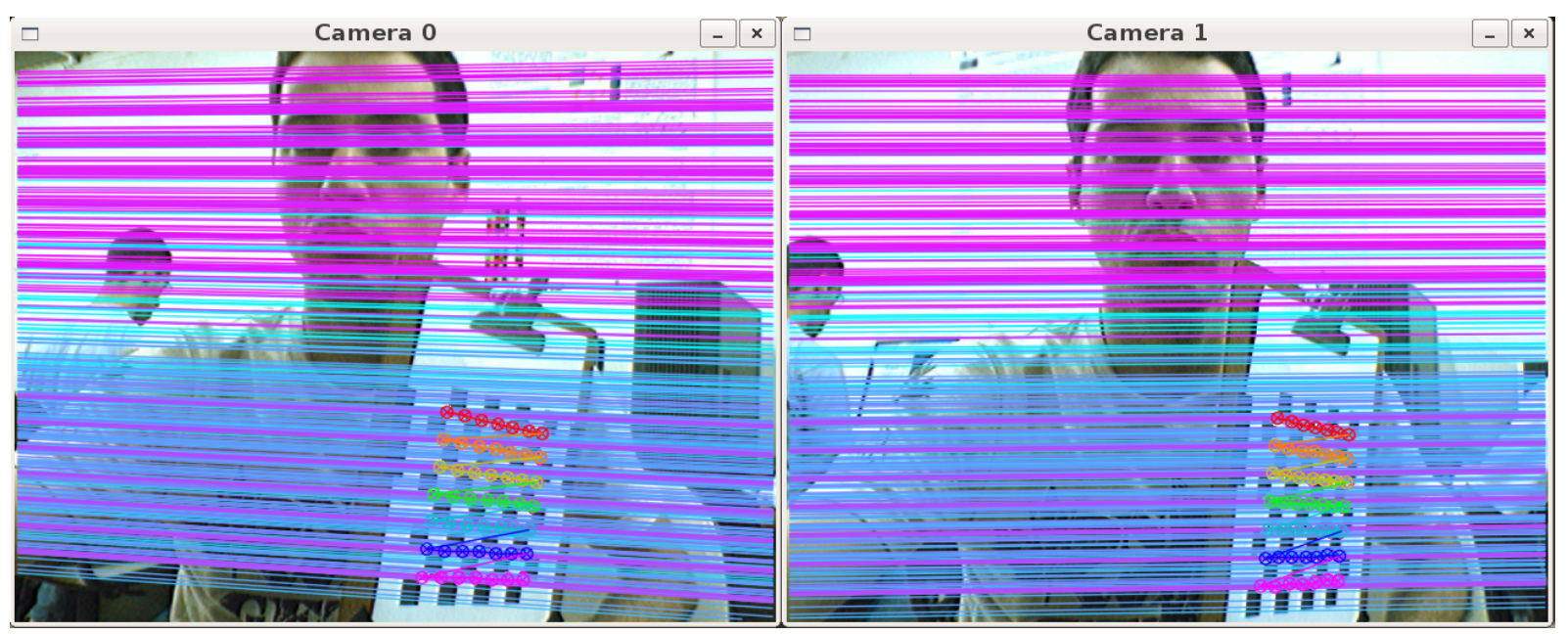

Figura 2.8: Linhas epipolares correspondentes.

da imagem retificada. Suponha que a imagem possua tamanho $(w, h)$, então os cantos são $(0,0),(0, w-1),(0, h-1)$ e $(w-1, h-1)$.

O resto do processo é feito separadamente para as imagens 1 e 2. Para cada imagem, passamos para a função do OpenCV [86] cvFindHomography os pontos extremos das suas linhas epipolares e os cantos da imagem retificada. A função devolve uma matriz $3 \times 3$ correspondente a uma transformação homográfica [49, 38]. Temos assim duas transformações homográficas, uma para cada imagem. Tais transformações podem ser salvas e reutilizadas desde que as câmeras não mudem seu ângulo e sua posição uma em relação à outra.

A Figura 2.9 mostra o resultado da retificação do par de imagens da Figura 2.8. Observe como as linhas epipolares estão paralelas às linhas de varredura. 

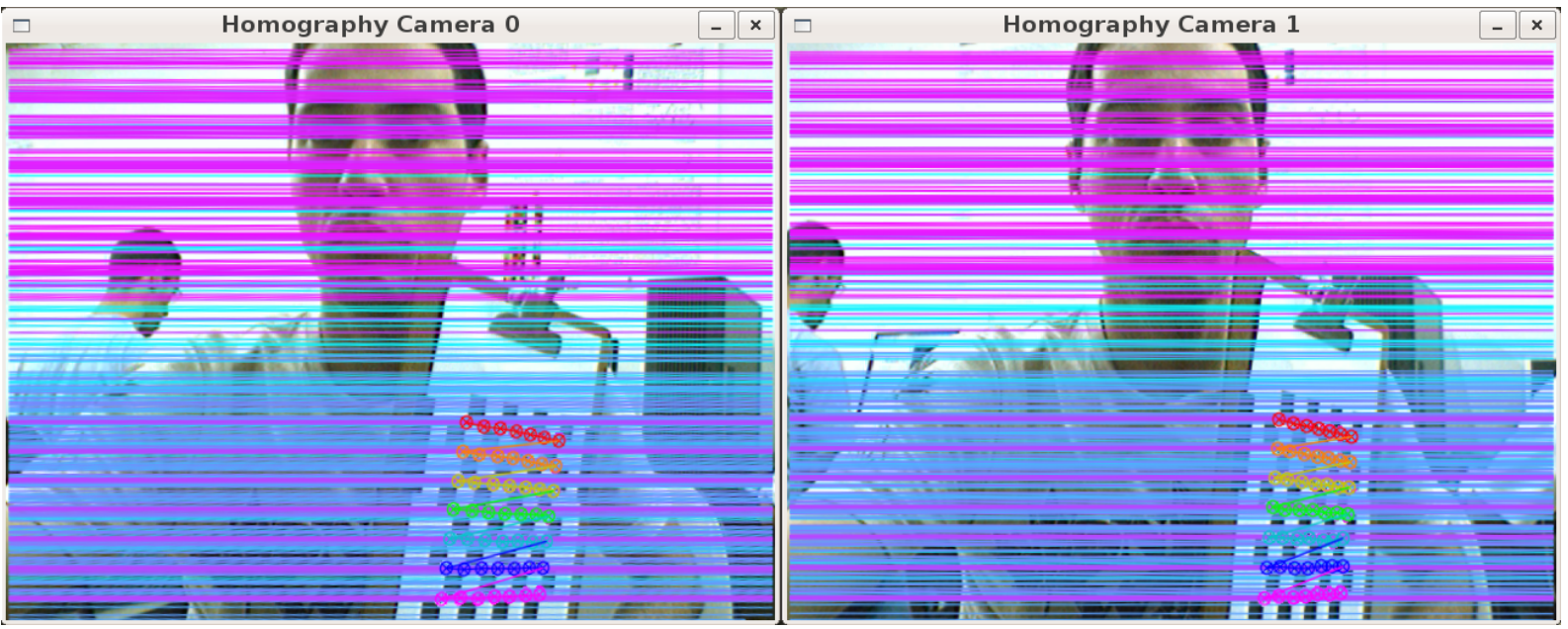

Figura 2.9: Linhas epipolares após a retificação.

\subsection{Visão estéreo}

A visão estéreo se baseia no uso de dois sensores, olhos, ou no nosso caso câmeras, para se obter informações de profundidade.

Para que se possa extrair a informação de profundidade da cena, os dois sensores não podem ter o mesmo centro ótico. A profundidade é obtida através do efeito paralaxe. Quanto mais próximo das câmeras estiver um ponto, mais deslocadas ficam suas projeções, uma em relação à outra, nas cordenadas das imagens.

Uma vez que temos um par de imagens retificado, garantimos que os pontos correspondentes estão na mesma linha de varredura. O algoritmo de visão estéreo deve então percorrer cada linha de varredura e, para cada pixel $\mathbf{m}_{1}$ na imagem 1 , encontrar seu correspondente $\mathbf{m}_{2}$ na mesma linha da imagem 2. Definimos como disparidade a diferença entre o índice das colunas de $\mathbf{m}_{1}$ e $\mathbf{m}_{2}$. Algoritmos de visão estéreo esparsa encontram a disparidade apenas para alguns pontos da imagem. 


\section{CAPÍTULO 2. FUNDAMENTOS DE VISÃO COMPUTACIONAL 3D}

Algoritmos de visão estéreo densa encontram a disparidade para todos os pontos da imagem. Precisam de muito mais tempo de processamento que os de visão estéreo esparsa. Uma técnica para encontrar a disparidade é buscar para $\mathbf{m}_{1} \mathbf{o} \mathbf{m}_{2}$ com maior correlação [37]. A correlação é calculada entre pequenas janelas centradas em $\mathbf{m}_{1}$ e $\mathbf{m}_{2}$.

Usa-se também no lugar da correlação a soma das diferenças entre os pixels das janelas, técnica conhecida como AD (Absolute Differences). Uma variação é o uso da soma dos quadrados das diferenças entre o valor dos pixels das janelas. Essa técnica é conhecida pela sigla SSD (Sum of Squared Differences). Em ambos os casos, o escolhido é o $\mathbf{m}_{2}$ com menor soma [96].

Para melhorar o resultado, Ruigang Yang [113] implementou uma técnica que usa janelas de vários tamanhos para uso em GPU. Chamou-a de MML (Multiple Mipmap Level).

\subsection{Processo de calibração}

Nesta seção descrevemos o procedimento que usamos na calibração do par de câmeras. O par de imagens passa por três transformações antes de entrar no pipeline de processamento propriamente dito. São os seguintes: correção de distorção radial, correção de perspectiva e retificação.

A correção de distorção radial depende apenas dos parâmetros intrínsecos da câmera. Uma vez encontrados, podem ser salvos em arquivo e reutilizados. Para calcular os parâmetros de cada câmera, como descrito na Seção 2.2, deve-se mover um padrão xadrez por todo seu campo visual.

Na montagem do sistema de captura, colocamos as câmeras próximas ao nível do solo. A vantagem desse posicionamento é que a parede em frente ao usuário fica livre para que 
se façam projeções. O problema disso é que a cabeça do usuário em pé, por causa da perspectiva, tenderá a ficar mais ao centro da imagem que seus pés. Quanto mais próximo das extremidades laterais da imagem, mais visível é esse efeito. Optamos então por realizar esse passo de correção de perspectiva.

Antes de iniciar a gravação, o operador do sistema deve definir na imagem de cada câmera três retas. Uma horizontal que define a linha do horizonte, e duas verticais próximas às extremidades da imagem, que definem o ponto de fuga no infinito. A partir destas três retas, uma matriz de homografia, de tamanho $3 \times 3$, é calculada e salva em arquivo. Tal passo é opcional; caso o sistema não encontre o par de arquivos de correção de perspectiva, a matriz identidade, $3 \times 3$, é usada.

O terceiro passo de calibração define a retificação do par de imagens. O operador do sistema deve mover um padrão de calibração xadrez de modo que seja visível por ambas as câmeras simultaneamente. O sistema calcula a homografia, como descrito na Seção 2.6 e mostra o par de imagens retificado na tela. Quando satisfeito, o operador interrompe o processo e o sistema salva as homografias em um par de arquivos. 
20 CAPÍTULO 2. FUNDAMENTOS DE VISÃO COMPUTACIONAL 3D 


\section{Capítulo 3}

\section{Trabalhos relacionados}

Como foi descrito anteriormente, nosso objetivo é criar um sistema que reconheça gestos em tempo real, através de câmeras, sem o uso de marcadores. Pode-se dizer que esse problema se encaixa na área de visão computacional em interfaces homem-computador.

O trabalho é motivado pela criação de um simulador realista de goleiro de futebol. O realismo se refere tanto à entrada, ou seja, na forma como o usuário controla o jogo, quanto à saída, ou seja, na visualização dos resultados. Para obter tal realismo, propomos usar como entrada as imagens do usuário detectadas por câmeras, e como saída, imagens tridimensionais projetadas em uma tela. Tal proposta pode ser considerada um sistema de realidade virtual.

A seguir descrevemos brevemente as duas áreas, dando atenção especial ao foco desta tese, que aborda o problema de identificação de gestos. 


\subsection{Visão computacional em interfaces homem-computador}

A área de visão computacional estuda métodos para se analisar imagens e extrair delas alguma informação. Sistemas que usam visão computacional em suas interfaces captam imagens do usuário ou de alguma parte de seu corpo, como rosto ou mãos, através de câmeras e as interpretam, para em seguida responder de acordo com o esperado.

Para que seja usada em interfaces homem-computador, o ideal é que a análise das imagens seja feita em tempo real. Em outras palavras, o sistema com o qual o usuário interage deve responder às suas ações com um atraso imperceptível pelo usuário. Mais objetivamente, segundo Card [18, 19], tal atraso deve ser menor que 0,1 s, "para manter a ilusão de animação no mundo".

No livro de Kisakanin [62] usa-se a sigla RTV4HCI (Real-Time Vision for HumanComputer Interaction) para se referir ao uso de técnicas de visão computacional em tempo real para interação homem-computador. A sigla VBI (Vision Based Interfaces) também é normalmente usada.

Segundo Turk [104], o objetivo da área é desenvolver algoritmos e sistemas que percebem seres humanos e suas atividades, permitindo a criação de interfaces mais naturais, poderosas e efetivas. Em um contexto mais amplo, envolve o que se chama interfaces perceptuais [105], interfaces multimodais [55], ou ainda interfaces pós-WIMP (Window, Icon, Menu, Pointing device) [55].

Turk $[105,103]$ também lista os aspectos mais importantes das interfaces baseadas em visão:

Presença e localização: o usuário está presente ou não, e qual sua posição (detecção e rastreamento do rosto e do corpo).

Identidade: quem está presente (reconhecimento de face). 
Expressão facial: o usuário está sorrindo, falando, bocejando (modelagem e análise de expressões faciais).

Foco de atenção: o que o usuário está olhando (rastreamento da face, gaze tracking).

Postura e movimento do corpo: qual a pose e como a pessoa se move (modelagem e rastreamento do corpo).

Gestos: saber se a movimentação das mãos, corpo ou cabeça possui alguma semântica (reconhecimento de gestos, rastreamento das mãos).

Atividade: o que a pessoa faz (análise dos movimentos do corpo).

\subsection{Reconhecimento de gestos}

O termo reconhecimento de gestos se refere a reconhecer o significado de expressões de movimento das mãos, pés, cabeça, face ou corpo [77]. Formalmente, podemos definir um gesto como uma sequência de poses [35]. Uma pose é uma configuração do corpo em um dado instante.

Para tal, é necessário detectar a posição das diversas partes do corpo e ângulos das articulações. Isso pode ser feito através de dispositivos eletrônicos conectados ao corpo, como acelerômetros, sensores magnéticos, emissores ultrassônicos ou roupas com sensores. Outro método é através de câmeras, que têm a vantagem de não atrapalhar os movimentos do usuário, e evitar a necessidade de conectar diversos dispositivos ao corpo. A desvantagem é que é necessário lidar com o problema da oclusão entre partes do corpo.

Técnicas baseadas em câmeras também variam entre si em fatores como número de câmeras, taxa de aquisição de dados, necessidade do uso de marcadores ou roupas especiais, necessidade do uso de background especial, como no chromakey, características de baixo 
nível usadas, como contorno, esqueleto, histogramas ou momentos.

Quando não se usam marcadores, o problema de localizar os membros do usuário se torna bem mais difícil. Muitos autores tentam contornar esse problema com o uso de várias câmeras [70, 21, 76, 23, 24, 54]. Quanto mais câmeras, há mais informação que pode ser usada para se recuperar a posição dos membros do usuário. Porém, isso aumenta o tempo de processamento e a complexidade do sistema.

Com menos câmeras há menos informação e, no caso de uma câmera, a análise de silhueta do usuário dá bons resultados apenas quando não há ambiguidades ou autooclusão [20]. Para contornar esses problemas usam-se modelos de cor [74], restrições físicas [20], superfícies de convolução [101]. Okada criou um banco de dados de silhuetas em árvore, e o percorre para identificar a pose do usuário [85].

Há ainda técnicas que funcionam bem em vários tipos de imagem, mas que exigem muito tempo de computação e não são adequadas para sistemas de interação em tempo real. A técnica de Davison [33], que usa annealed particle filtering, funciona tanto para uma quanto para várias câmeras, porém requer trinta segundos de processamento por quadro. Lee [68] localiza a face e os contornos, em imagens estáticas, para estimar a pose acima da cintura, mas cada quadro requer alguns minutos para ser processado.

Kohler [64] divide as tarefas de reconhecimento de gestos em processamento de imagens de baixo nível e de alto nível. Dentre as tarefas de alto nível estão o reconhecimento de gestos estáticos e dinâmicos.

O reconhecimento de gestos estáticos, ou poses, pode ser feito por template matching, redes neurais, árvores de decisão, momentos de $\mathrm{Hu}$ [53] e outras técnicas tradicionais de reconhecimento de padrões. O reconhecimento de gestos dinâmicos é mais complicado e requer técnicas que levem em consideração o tempo ou a ordem em que as poses são feitas, sendo um caso especial do problema de classificação temporal. 
Seja uma sequência um conjunto de dados em que uma das dimensões é o tempo. Kadous [58] divide em três tipos os problemas de classificação temporal.

Classificação fraca: quando uma sequência deve receber um único rótulo.

Classificação forte: quando uma sequência corresponde não a um único rótulo mas a uma sequência de rótulos.

Classificação pré-segmentada: quando temos uma função capaz de dividir nossa sequência de entrada em sequências menores, recaindo assim em um problema de classificação fraca.

Para se resolver problemas de classificação temporal, em particular reconhecimento de gestos, normalmente se usam HMMs (Hidden Markov Models) [90, 112, 98, 4], DTW (Dynamic Time Warping) [82, 59, 11], RNN (Recurrent Neural Network) [6, 81, 57], PCA (Principal Component Analysis) [61, 29], FSMs (Finite State Machines) [52, 32, 51] e Condensation [13]. Davis [30, 31] usa uma motion-energy image (MEI) associada a uma motion-history image (MHI) para identificar gestos. Pode funcionar em qualquer ângulo se o treinamento usar múltiplas câmeras.

Na próxima seção descreveremos formalmente as FSM.

\subsection{Finite State Machines}

Uma Finite State Machine (FSM) é uma maneira de representar um sistema, suas entradas e suas saídas. O sistema pode ser visto como uma caixa preta, em cujo interior ficam armazenadas as variáveis de estado. Um problema de engenharia reversa ou de análise consiste em modelar o interior da caixa preta.

Formalmente, uma Finite State Machine (FSM) é uma 5 -tupla $M=\left\{S, X, Z, f_{s}, f_{z}\right\}$, 
com um conjunto de estados finito $S=\left\{\sigma_{1}, \ldots, \sigma_{n}\right\}$, um alfabeto de entrada finito $X=$ $\left\{\chi_{1}, \ldots, \chi_{q}\right\}$, um alfabeto de saída finito $Z=\left\{\zeta_{1}, \ldots, \zeta_{p}\right\}$, uma função de transição $f_{s}$ e uma função de saída $f_{z}$ dadas por

$$
\begin{aligned}
z_{t} & =f_{z}\left(x_{t}, s_{t}\right) \\
s_{t+1} & =f_{s}\left(x_{t}, s_{t}\right)
\end{aligned}
$$

onde $x_{t}$ é o símbolo de entrada. $y_{t}$ é o símbolo de saída. e $s_{t}$ é o estado de $M$ no tempo discreto $i_{t}, t \in \mathbb{N}[46,8]$. A seguir descrevemos alguns dos trabalhos que usam FSM para reconhecer gestos.

Davis [32] reconhece um pequeno subconjunto de gestos da American Sign Language executados por um usuário usando luvas com marcadores nas pontas dos dedos. Impõe uma restrição de similaridade de três frames, ou seja, exige que três frames consecutivos tenham as mesmas propriedades antes de avançar para o próximo estado. Ainda segundo Davis, uma vantagem da máquina usada é evitar a necessidade de time warping. Os gestos são reconhecidos em função da característica binária, de movimento ou não, de cada dedo.

Bobick [14] propõe uma técnica de representação de estados de configuração que pode ser usada para reconhecer gestos feitos movimentando o ponteiro de um mouse ou a mão. A representação do gesto é feita por uma "curva protótipo", uma aproximação da sua trajetória média no espaço. A curva é particionada em estados nebulosos definidos pela clusterização das coordenadas dos pontos do conjunto de treinamento. O reconhecimento usa um algoritmo de programação dinâmica.

Hong $[52,51]$ modela gestos com gaussianas multidimensionais, cujas dimensões são as coordenadas das mãos e cabeça na imagem. Um gesto é reconhecido quando todos os seus estados são percorridos.

Verma [107] clusteriza pontos da trajetória da mão do usuário. Define os estados como 
sendo cada um desses clusters, e a trajetória da mão define as transições entre estados.

Recentemente, Zhi [71], usou uma FSM para reconhecer cinco tipos diferentes de trajetórias de mãos em vídeos de mapas de profundidade.

\subsection{Hidden Markov Models}

Um HMM é um modelo probabilístico que descreve uma cadeia de Markov cujos estados não são diretamente obseráveis. Os parâmetros necessários para modelar uma cadeia de Markov são as probabilidades de transição entre seus estados. A cadeia de Markov define uma sequência de estados com índice de tempo $t$ discreto. Denotamos o estado no instante $t$ por $\omega(t)$.

Seja $n$ o número de estados possíveis, o conjunto de estados é $\left\{\omega_{1}, \ldots, \omega_{n}\right\}$. A cadeia de Markov é definida pelas probabilidades de transição do estado $\omega_{i}$ para $\omega_{j}$, onde $i$ e $j$ pertencem a $\{1, \ldots, n\}$. Denotamos as probabilidades de transição do estado $i$ para o estado $j$ por $P\left(\omega_{j}(t+1) \mid \omega_{i}(t)\right)=a_{i j}$. Tais valores costumam ser dispostos em uma matriz de probabilidades de transição, de tamanho $n \times n$, onde a soma de cada linha deve ser igual a 1 .

Em um HMM, o estado não é diretamente observável, apenas dados de saída dependentes do estado. A cadeia emite a cada instante $t$ um valor $v(t)$ que pode ser discreto, como um inteiro ou um rótulo de um conjunto finito, ou contínuo, como uma tupla de $\mathbb{R}^{r}, r$ inteiro. Tal saída depende de alguma distribuição de probabilidade, portanto, para definir o HMM, além da matriz de probabilidades de transição, é preciso definir as probabilidades dos valores de saída em função do estado.

No caso discreto, denotamos a probabilidade de emissão de $v_{k}$ no tempo $t$ pelo estado $j$ por $P\left(v_{k}(t) \mid \omega_{j}(t)\right)=b_{j k}$. No caso contínuo, podemos dar como exemplo o chamado 
Normal Hidden Markov Model, que é um HMM em que a distribuição de $v(t)$ dado $\omega(t)$ é gaussiana. Nesse caso, dado que $\omega(t)=j$, dizemos que $v(t) \sim N\left(\mu_{j}, \sigma_{j}^{2}\right)$, que denota uma distribuição normal com média $\mu_{j}$ e variância $\sigma_{j}^{2}$. Nesse modelo, então, existem $n$ distribuições normais, uma para cada um dos $n$ estados ocultos.

Dois problemas importantes no escopo dos HMM são:

Decodificação: dada uma sequência de $T$ valores observados $(v(1), \ldots, v(T))$, determinar a sequência de estados ocultos mais provável, $(\omega(1), \ldots, \omega(T))$ que gerou a sequência observada. Normalmente é feita com o algoritmo de Viterbi.

Aprendizado: dada a estrutura do HMM, como número de estados ocultos, estimar as probabilidades de transição $a_{i j}$. Caso a saída seja discreta, estimar as probabilidades $b_{j k}$. Caso a saída seja contínua, estimar os parâmetros de cada uma das $n$ distribuições. Normalmente é feita com o algoritmo forward-backward.

Para fazer a decodificação para o caso discreto é necessário encontrar o estado $j$ mais provável a partir da informação de que foi emitido o símbolo $v_{k}$ no tempo $t$. Para isso, o algoritmo de Viterbi calcula, para cada $j, \alpha_{j}(t)=b_{j k} \sum_{i=1}^{n} \alpha_{i}(t-1) a_{i j}$. O estado escolhido é o $j$ que tem o maior valor de $\alpha_{j}(t)$. O estado em $t=0$ é o estado inicial do modelo; o valor de $\alpha$ para o estado inicial é igual a um, e zero para os demais estados.

No escopo de reconhecimento de gestos, os valores emitidos a cada instante $t$ correspondem ao vetor de características extraídos de uma, ou mais imagens no caso de múltiplas câmeras, naquele instante. A pose corresponde ao estado atual do HMM, que é oculto, ou seja, desconhecido, e é o que queremos descobrir através do processo de decodificação. Os gestos são dados pela sequência de poses.

Mais detalhes sobre HMM podem ser encontrados nos livros de Duda [34] e Cappé [17]. 


\subsection{Realidade virtual}

Myron Krueger [65] usa o termo realidade artificial para indicar interfaces que mostram ambientes artificiais sem algo similar no mundo real. Esse termo inclui a tecnologia dos HMD (Head Mounted Displays) [99] que, segundo ele, eram caminhos diferentes para o mesmo objetivo, de interagir usando o corpo inteiro com eventos sintetizados por computador, mas que eventualmente se tornariam tão convincentes que seriam aceitos como uma experiência real.

Realidade virtual é essa versão realista da realidade artificial de Krueger. Segundo Burdea e Coiffet [16], realidade virtual é uma interface homem-computador sofisticada que envolve simulações em tempo real e interação através de vários sentidos. Tais sentidos são a visão, audição, tato, olfato e paladar.

Os mesmos autores dão uma definição alternativa, $I^{3}$ de Imersão-Interação-Imaginação. A interação envolve canais multisensoriais, e a imaginação se refere à capacidade do usuário de perceber objetos inexistentes. Esses dois fatores contribuem para a sensação do usuário de imersão em um mundo virtual.

\subsection{Breve histórico}

Uma das primeiras aplicações usando visão computacional para implementar uma interface homem-computador é o Videoplace, de Myron Krueger [65], proposto em 1974 e implementado na década de 1980. É uma instalação artística onde o usuário tem sua sombra projetada sobre um anteparo, a sombra é captada por uma câmera analógica e assim se obtém um contorno bem definido com facilidade. Tal imagem é digitalizada e processada por uma série de circuitos especializados. A saída, alterada de diversas maneiras, é então projetada em tempo real à frente do usuário. 
O usuário interage com o sistema usando o próprio corpo. Foram implementadas diversas aplicações, nas quais o usuário pode desenhar na tela, ver uma série de seus contornos sobrepostos com cores diferentes, interagir com um inseto animado, dentre outras.

Em 1987, Krueger criou outra instalação, a Videodesk Videoplace Teleconference. Consistia em uma mesa onde o contorno das mãos de um usuário era capturado. Em uma tela o usuário via o contorno de sua mão justaposto à imagem do contorno do corpo de outra pessoa. Assim, dois usuários interagiam e se comunicavam.

Para conseguir processar as imagens de uma câmera em 10 ms ou menos, Freeman, por volta de 1996 [42, 40, 41], criou uma câmera com um tipo de hardware especializado, chamada artificial retina.

A câmera de Freeman é semelhante a câmeras digitais comuns. A diferença está no fato de ser capaz de realizar processamento de imagem de baixo nível. É capaz de calcular os momentos da imagem ou histogramas de orientação [42], economizando ciclos da CPU.

Com sua câmera especial, detecta as coordenadas $x$ e $y$, e a orientação da mão, e usa esses valores para controlar um carrinho de brinquedo. Em outro experimento, usa os histogramas de orientação para identificar gestos e jogar "pedra, papel e tesoura" contra o computador. Usa a mesma técnica para detectar a posição dos braços do usuário e com isso controlar um simulador de voo.

Em 1998, Freeman implementa um algoritmo de fluxo ótico rápido, baseado na diferença simétrica entre duas imagens capturadas em momentos diferentes [40]. Com isso detecta se o usuário está se movendo, e usa essa informação em um jogo que simula uma corrida de obstáculos. Demonstra ainda o uso de correlação para detectar a mão do usuário em uma cena e, com isso, controlar o volume, mudar o canal e desligar uma televisão.

O sistema ALIVE [73] implementa uma metáfora chamada espelho mágico. O usuário vê sua imagem na tela rodeada por criaturas tridimensionais sintéticas. As criaturas 
são agentes autônomos que reagem às ações do usuário. O sistema detecta tais ações interpretando os pontos mais salientes do contorno bidimensional do usuário.

O sistema Pfinder [110] é derivado do ALIVE, mas é mais sofisticado e mais geral. Usa um modelo estatístico de forma e cor para obter as posições mais prováveis das partes do corpo na imagem.

Uma instalação artística popular inspirada no Videoplace é a Full Body Games de Warren [108], com os jogos Duck and Jump, Collider, Color Match, Two Touch e Color Shooter. O visual é minimalista, o usuário vê apenas seu contorno sobre um fundo negro. O foco desse trabalho é explorar os diferentes tipos de interação, jogabilidade, esforço físico

e tipo de ação que jogos "full body" podem proporcionar. Essa instalação esteve disponível para uso do público que visitou o FILE (Festival Internacional de Linguagem Eletrônica) São Paulo 2008.

\subsection{Alguns sistemas comerciais}

Na década de 1990 apareceram alguns sistemas comerciais. Um dos primeiros foi o Mandala Gesture Xtreme (GX) System, de 1996. O pacote incluía computador, câmera, placas de vídeo e captura, instalações opcionais de anteparos para chromakey, e licença de software. Dentre os jogos, havia o Sharkbait, Volleyball, Snowboarding e um jogo de basquete chamado Full Court Slam.

Usava um algoritmo de subtração de fundo para separar a imagem do usuário da cena, e a mostrava com um fundo sintético. Em Sharkbait o usuário deve desviar de tubarões e pegar peixes se movendo por uma cena representando o fundo do oceano; para se mover para cima e para os lados, deve apontar com o braço estendido para a direção desejada, ou se abaixar para descer. Snowboarding é uma corrida para dois a quatro jogadores; a 
prancha é controlada pela inclinação do corpo. Em Volleyball o usuário deve evitar que uma bola virtual caia no chão; a direção da bola depende do ângulo de contato com o contorno do jogador. Full Court Slam é o mais complexo, reconhecendo gestos como drible, bloqueio, lance à cesta e roubo de bola.

O Me2Cam Virtual Game System da Intel, comercializado entre 1999 e 2002, era um pacote com câmera e jogos para PC. Nesses jogos, a imagem do usuário era separada da cena, por um algoritmo de subtração de fundo, e mostrada com um fundo sintético na tela. Em Snow Surfin o usuário controla um snowboard inclinando o corpo para os lados. Em Bubble Mania deve-se desviar ou tocar bolhas que caem da parte superior da tela, dependendo de sua cor.

O GameCam da Reality Fusion, lançado em 1999, é similar aos outros dois sistemas. Dentre os títulos disponíveis estão Basketball, Karate e Volleyball.

Existem exemplos mais recentes de jogos que usam câmeras em consoles de video game. Para XBOX 360, há o jogo TotemBall, lançado em 2006, que requer a câmera XBOX Live Vision ${ }^{1}$. A câmera do Playstation 2 é a EyeToy. No jogo Antigrav o usuário controla um hoverboard $^{2}$. O usuário vê um personagem sintético, e não sua imagem, como nos outros jogos. Na tela há um elemento interessante de feedback, a posição das mãos e da cabeça do usuário conforme o jogo interpreta, e o quanto se deve movê-los para obter algum efeito ${ }^{3}$.

A empresa Gesture $T e k^{4}$ detém diversas patentes. Dentre os produtos que usam as patentes licenciadas dessa empresa estão o EyeToy da Sony e o ION Educational Game System da Hasbro.

A empresa 3DV Systems ${ }^{5}$, comprada pela Microsoft em 2009, está projetando uma

\footnotetext{
${ }^{1}$ http://www.xbox.com/en-US/games/t/totemballxboxlivearcade/

${ }^{2}$ Prancha flutuante, como a que aparece no filme Back to the Future Part II.

${ }^{3}$ http://www.gamespot.com/ps2/sports/eyetoyantigrav/review.html

${ }^{4}$ http://www.gesturetek.com

${ }^{5}$ http://www. 3dvsystems.com
} 
versão de sua câmera $Z C a m^{\mathrm{TM}}$ voltada para uso doméstico. É uma câmera monocular que detecta profundidade lançando um pulso de luz infravermelha e calculando o tempo que a luz demora para refletir nos objetos da cena e retornar, técnica conhecida como Time Difference Of Arrival (TDOA). Na página web da empresa há um demo de jogo de boxe que usa o mapa de profundidade da cena como entrada,

\subsection{Avanços recentes em IHC}

Em 2002, Savelsbergh [95] estudou as decisões de goleiros ante chutes de atacantes. Os goleiros assistiam a um vídeo de um atacante batendo um pênalti, tentavam descobrir a direção do chute e registravam sua decisão através de um joystick.

Em 2003, Mueller [80] implementa o protótipo de um jogo esportivo, para dois jogadores interagirem a distância, chamado Breakout for Two. Cada jogador olha para uma tela, inicialmente preenchida com imagens de tijolos semi-transparentes e, com uma bola de futebol ou de tênis, deve atingir os tijolos até revelar a imagem do oponente, capturada em tempo real durante o jogo. A sensação é de que os jogadores se vêem e conversam de lados opostos de uma parede de vidro.

Em 2004, Bideau [12] analisou a reação de goleiros de handebol com realidade virtual. A animação de um atacante lançando a bola em direção ao gol era mostrada em um HMD, e a reação do goleiro era gravada com um sistema de captura de movimento. A animação do atacante foi sintetizada a partir de dados de captura de movimento de atacantes reais.

Em 2005, Hämäläinen [48] implementou o jogo de artes marciais Kick Ass Kung-Fu. É uma instalação de realidade artificial onde o usuário vê em uma tela sua imagem de perfil e inimigos artificiais. Deve golpeá-los e esquivar de seus ataques. A interface é bidimensional, ignorando os movimentos laterais. Usa subtração de fundo para localizar 
o usuário, e fluxo ótico para estimar a velocidade dos golpes. O mapeamento da posição do usuário para a tela nem sempre é direto, havendo a possibilidade de amplificar os movimentos horizontais e verticais, além de haver ocasiões em que o usuário se vê em câmera lenta.

Em 2006, Hong [50] descreve uma interface tridimensional que divide o espaço ao redor do usuário em caixas. O sistema detecta, a cada instante, se alguma parte do corpo do usuário se encontra em alguma caixa, e a sequência em que as caixas são tocadas para comandos mais complexos. Além disso, um método de subtração de background, que compara as cores RGB normalizado com RGB para eliminar sombras, é proposto nesse artigo.

Em 2007, Chu [25] usa câmeras infravermelhas para localizar quatro contornos de diferentes ângulos do usuário. A partir dos contornos, gera um poliedro mínimo que aproxima o volume do usuário. Em seguida ajusta elipsoides para obter a posição das partes do corpo do usuário. Para rastrear os movimentos do usuário, usa um filtro de partículas [5].

Em 2008, um protótipo de controle chamado HandsFree $3 D^{6}$, baseado em uma câmera tridimensional, foi desenvolvido pela empresa Kapor Enterprises ${ }^{7}$ para o jogo online Second Life. O objetivo deste controle é substituir o mouse e alguns comandos de teclado. O avatar $^{8}$ se locomove quando o usuário inclina o corpo para a frente, para trás ou para os lados. Além disso, alguns gestos foram mapeados para comandos do mouse. A posição da mão direita controla a posição do mouse na tela, e a posição da mão esquerda controla cliques dos botões do mouse. A câmera usada é a ZCam, fabricada pela empresa 3DV Systems.

\footnotetext{
${ }^{6}$ http: //www.handsfree3d.com

${ }^{7}$ http://www.kei.com

${ }^{8}$ Personagem digital que representa o usuário na tela.
} 


\subsection{Avanços recentes em reconhecimento de gestos}

Tradicionalmente, existem duas principais formas de abordar o problema de reconhecimento de gestos através de câmeras. A abordagem top-down, ou reconhecimento por reconstrução, primeiro reconstrói um modelo completo do usuário, como em captura de movimento, e a partir desse dado reconhece o gesto. A abordagem bottom-up, ou reconhecimento direto, parte de características de baixo nível da imagem ou da região que o usuário ocupa. Nesse último caso, é necessário segmentar o usuário por meio de técnicas de subtração de background.

O reconhecimento por reconstrução envolve ajustar modelos do corpo humano à imagem para, em seguida, deconhecer os gestos ou ações. Tipicamente usam-se stick figures [47, 114] ou modelos geométricos [94] para representar os membros. Mais informações sobre reconhecimento por reconstrução podem ser encontradas nas revisões de Moes-

lund [79, 78] e Aggarwal [3]. A seguir, discutiremos avanços no reconhecimento direto de gestos.

Uma das primeiras evidências de que a abordagem bottom-up pode ser usada em reconhecimento de gestos é dada por Johansson [56]. Em seu experimento, fixa doze pequenas lâmpadas em pessoas e grava vídeos de ações, como dança ou caminhada, onde apenas os pontos de luz são visíveis. Ao mostrar tais vídeos para uma audiência, verifica que seres humanos conseguem reconhecer as ações com facilidade, em poucos instantes.

Um tipo de abordagem bottom-up que tem sido bastante usada recentemente, conhecida como analysis by synthesis, envolve sintetizar silhuetas e compará-las com as obtidas através de câmeras. Assume-se que, se a pose obtida pela câmera é parecida com a sintetizada, significa que o usuário estava em uma pose semelhante à obtida por captura de movimento.

Okada, Fengjun Lv e Kilner abordam o problema através da geração de um banco 
de dados com centenas ou milhares de poses obtidas com equipamentos de captura de movimento. Okada [85] agrupa as poses semelhantes por hierarchical pair-wise clustering gerando uma árvore. A árvore é usada para se encontrar a pose mais próxima de cada quadro a ser analisado. Usa-se uma distância XOR ponderada entre a silhueta obtida por subtração de background e as silhuetas armazenadas na árvore. Nos níveis próximos à raiz, as poses são aproximações grosseiras e a comparação usa uma versão subamostrada da silhueta. Nas folhas as aproximações são melhores e a resolução usada na comparação é mais alta. Consegue processar cerca de 10 quados por segundo usando o processador Cell.

Fengjun Lv [72], por sua vez, não tenta obter a pose tridimensional do usuário a cada quadro. Seu banco de dados possui quinze ações com cerca de quatro keyframes por ação, e armazena versões de tais poses de diversos ângulos, para que o reconhecimento seja independente do ponto de vista. Também propõe uma forma de escolha automática de keyframes. Define uma função de energia que depende da movimentação das articulações entre quadros consecutivos. Os escolhidos são os que quadros com máxima ou mínima energia dentro de uma janela temporal.

Kilner [60] usa múltiplas câmeras para montar cascos convexos de jogadores em um jogo de rúgbi profissional. Esses cascos convexos são comparados com volumes sintetizados a partir de dados de captura de movimento. A comparação é feita usando-se histogramas volumétricos com coordenadas polares esféricas.

Em 2007, Tresadern [102] avalia e compara descritores de formas para reconhecimento de poses, como DCT (Discrete Cosine Transform), distância de Chamfer e HoSC (Histogram of Shape Contexts). Em 2008, Weinland [109] usa uma representação estática formada por key poses, ignorando qualquer informação temporal, como duração ou ordem em que as poses podem aparecer. Consegue obter bons resultados, mas reconhece limitações, como diferenciar o ato de sentar do de levantar de uma cadeira, por exemplo. 
Para escolher as key poses, usa uma técnica de forward feature selection [63].

Em 2010, Lee [66] compara o desempenho de diferentes métodos e conclui que, apesar de ser possível obter bons resultados com com classificação puramente estática, melhores resultados são obtidos através de métodos que levam em conta a informação temporal, como HMM ou com time-window. Este último usa uma janela temporal terminada no quadro a ser classificado, e o classifica como a pose que mais ocorre na janela. Para classificar as poses, usa métodos baseados na aparência do foreground, HOG (Histogram of Gradients) e fluxo ótico.

Nosso objetivo é classificar os gestos do usuário sem necessariamente reconstruir sua configuração tridimensional completa. Como o reconhecimento dos gestos visa o uso em interação homem-computador, podemos assumir que o ambiente é controlado, ou seja, podemos assumir background estático e câmeras fixas. Também podemos assumir que o usuário sempre olha para a câmera, o que simplifica a tarefa de reconhecimento.

Devemos usar uma abordagem baseada em keyframes. Usaremos ainda filtragem por time-window, porém, com uma janela curta, de modo que gestos curtos possam ser reconhecidos em tempo real. Usaremos ainda informação a priori de como os gestos se concatenam no tempo, o que deve melhorar os resultados. Propomos duas técnicas para comparação com keyframes capazes de distinguir poses muito parecidas. 


\section{Capítulo 4}

\section{Introdução ao uso das GPUs}

Neste capítulo apresentamos uma introdução à arquitetura e a algumas linguagens usadas na programação das Unidades de Processamento Gráfico, mais conhecidas pela sigla GPU, do inglês Graphis Processing Units. Apresentamos também algumas bibliotecas que usam seus recursos no processamento de vídeo em tempo real.

As GPUs foram criadas para fazer processamento gráfico muito mais rapidamente que as CPUs, em outras palavras, para sintetizar imagens de uma cena ou objeto do ponto de vista de uma câmera em taxa de vídeo, ou seja, 24 quadros por segundo ou mais. Tal objetivo tem implicações importantes em sua arquitetura. Se cada pixel na tela é gerado

pelo mesmo algoritmo, e a cada instante milhares de pixels precisam ser calculados, é possível transferir tal processamento para um chip especializado capaz de executar esse algoritmo para vários pixels paralelamente.

A cena ou objeto é representado por um modelo composto por polígonos, que são definidos por seus vértices. Para sintetizar a cena corretamente, é necessário conhecer as fontes de luz, propriedades de cada polígono, como refletividade, cor e tantas mais quanto mais detalhes se deseja na imagem final. Quanto mais detalhada, mais polígonos a cena 
deve conter, e mais propriedades cada polígono deve possuir, portanto, mais computação é necessária. Esse processo de síntese de imagens costuma ser chamado renderização.

O processo de renderização exige que sejam feitos cálculos sobre grandes conjuntos de dados, mais especificamente vértices e fragmentos. Os vértices são os elementos fundamentais dos poliedros que compõem a cena. Fragmentos equivalem a pixels da imagem final porém, com profundidades variadas. Na renderização, as cores dos fragmentos são combinadas ou o fragmento mais próximo da câmera é escolhido para compor a imagem final.

Com o progresso da computação gráfica, não só a resolução das telas e imagens aumentou, mas também o nível de detalhes das cenas. Além disso, a adição de novos efeitos exigiam implementações de novos circuitos especializados em hardware. Com tais demandas, não só o número de pixels processados simultaneamente aumentou, mas também a complexidade das GPUs. Para evitar a complexidade crescente, uma saída natural foi tornar as GPUs programáveis. Hoje, as GPUs são providas de múltiplas ALUs (Arithmetic and Logic Units), ou núcleos, que trabalham em paralelo, e barramentos de dados extremamente rápidos.

As GPUs modernas podem ser descritas como um conjunto de núcleos com arquitetura SIMD (Single Instruction Multiple Data). Da mesma maneira que as CPUs convencionais, GPUs são capazes de executar operações aritméticas, lógicas e de ponto flutuante. Uma diferença importante é que a GPU é capaz de rodar diversas threads simultaneamente, uma em cada ALU. São capazes de fazer controle de fluxo, porém, pouca área no chip é dedicada a esta função, pois são otimizadas para processar threads que seguem o mesmo caminho de execução. Quando as threads seguem caminhos diferentes definidos pelo controle de fluxo, o desempenho cai significativamente. 
Para se ter uma ideia, a placa GeForce ${ }^{\circledR}$ GTX $280^{1}$ da NVIDIA ${ }^{\circledR}$, possui duzentos e quarenta núcleos. Seu barramento de memória possui 512 bits e largura de banda de mais de 140 Gbytes/s [83]. A comunicação com a memória RAM (Random Access Memory) é feita através do barramento PCI express 2.0 x16, cuja largura de banda é de 8 Gbytes/s. O pico teórico de processamento é de quase um TFlop ${ }^{2}$, dez vezes maior que o de um processador Intel ${ }^{\circledR}$ Xeon $^{\circledR}$ Quad-Core $3,2 \mathrm{MHz}$, de cerca de 100GFlops ${ }^{3}$.

É natural tentar usar esse poder de processamento para acelerar cálculos paralelizáveis, como simulações baseadas em equações diferenciais, operações em matrizes, processamento de imagens e de sinais [88]. Porém, o uso das GPUs em cálculos para os quais não foram projetadas oferece algumas dificuldades que serão descritas na Seção 4.1.

Gradualmente, as GPUs começaram a ser projetadas com recursos destinados a computação genérica, e não apenas computação gráfica. Um desses recursos é por exemplo o suporte a operações de ponto flutuante com 32 bits.

Como existem diversas GPUs no mercado, cada uma com recursos próprios, uma maneira de se criar programas que suportem todas elas simultaneamente é através de uma API (Application Programming Interface). OpenGL é uma API de computação gráfica, provavelmente a mais usada em todo o mundo. Permite a criação de jogos, programas de visualização científica ou qualquer aplicação que precise renderizar cenas ou objetos tridimensionais. Aplicações escritas em OpenGL podem rodar em qualquer GPU, de modo que o programador não precisa aprender a linguagem de cada uma delas. Versões antigas do OpenGL permitiam a renderização de objetos sempre da mesma maneira, ou seja, através de seu conhecido pipeline fixo, o que refletia os recursos do hardware disponível na época. Esse pipeline recebia como entrada um conjunto de vértices, texturas e matrizes de transformação, e retornava uma imagem renderizada na tela.

\footnotetext{
${ }^{1}$ Lançada em setembro de 2008

${ }^{2}$ CUDA Programming Guide e http://techreport.com/articles.x/14934/5

${ }^{3}$ CUDA Programming Guide e http://theinquirer.net/default.aspx?article $=42423$
} 
Versões mais recentes de OpenGL, para acompanhar o desenvolvimento das GPUs, se tornaram mais flexíveis, e permitem a inserção de programas escritos em linguagem GLSL(OpenGL Shading Language) no pipeline. Programas que rodam na GPU são normalmente chamados shaders. Porém, o uso do OpenGL em uma aplicação para a qual não foi projetado acaba sendo pouco natural e complexo. Todos os dados de entrada devem ser adaptados para formatos que o OpenGL aceite, como texturas e polígonos. Os dados de saída por sua vez, devem ser extraídos da imagem renderizada a partir dos dados de entrada. Mesmo com o mais recente pipeline programável, aproveitar o poder de processamento das GPU para aplicações diferentes de renderizar uma cena envolvem bastante engenhosidade.

Para facilitar o uso das GPUs em processamento genérico, a NVIDIA lançou a linguagem CUDA ${ }^{4}$ (Compute Unified Device Architecture), que oference várias facilidades em relação ao OpenGL. Neste capítulo descreveremos duas linguagens usadas para programação de shaders, GLSL e CUDA ${ }^{\mathrm{TM}}$. Ambas as linguagens possuem suas vantagens, e ambas seriam úteis em uma biblioteca de processamento de vídeo.

Pesquisadores da área de visão computacional têm criado bibliotecas de shaders com o objetivo de acelerar os cálculos, como as bibliotecas GPUCV e OpenVidia [36, 43]. Tais bibliotecas serão descritas na Seção 4.3 .

\subsection{Dificuldades no uso das GPUs}

Talvez o maior problema no uso das GPUs é a necessidade de adaptar os algoritmos de modo que possam utilizar alguma API gráfica. Tal adaptação costuma ser pouco natural, visto que tais API não foram feitas para resolver problemas genéricos, como as CPU.

Outro problema é o atraso na hora de enviar os dados da RAM (Random Access

\footnotetext{
${ }^{4} \mathrm{~A}$ versão 0.8 .2 foi lançada em 2007
} 
Memory) para a memória da GPU. As GPUs não têm acesso direto à memória RAM nem aos registradores da CPU. Todos os dados necessários para o processamento da GPU devem ser explicitamente transferidos da RAM para a memória da GPU. Ao final do processamento, se os dados forem apenas ser exibidos na tela, a visualização é quase instantânea. Porém, se houver necessidade de gravá-los ou de qualquer outro uso pela CPU, devem ser transferidos de volta para a RAM. Tais transferências são um gargalo importante, e o atraso causado não é desprezivel.

Os shaders mais comuns são os vertex shaders e os fragment shaders. Os vertex shaders são os programas que rodam sobre os vértices de uma cena. Podem ser usados por exemplo para animar ondas no oceano a partir de um modelo senoidal.

Os fragment shaders rodam sobre fragmentos. Pode-se dizer que um fragmento é um pixel antes de ser desenhado na imagem final. Em uma mesma coordenada de um pixel da imagem podem haver vários fragmentos, mas, em uma renderização sem transparência, o que estiver mais próximo da câmera deve aparecer. Os fragment shaders podem ser usados para mapear texturas sobre polígonos da cena. Tais texturas podem ser imagens pré-armazenadas ou sintetizadas por algum shader.

Existem diversas linguagens feitas para programar as GPUs. Muitas são inspiradas na linguagem $\mathrm{C}$, com a qual muitos programadores já estão acostumados, para que a transição entre programar CPU para GPU seja feita com mais facilidade. Dentre elas podemos citar a GLSL, que é parte da especificação OpenGL ${ }^{\circledR}$ [87], a linguagem $\mathrm{Cg}$, ou $C$ for graphics [39], e a linguagem HLSL. A linguagem Cg foi criada pela NVIDIA para uso com OpenGL, e a HLSL foi criada pela Microsoft ${ }^{\circledR}$ para uso com Direct3D ${ }^{\circledR}$. As três possuem as mesmas características básicas, portanto, escolhemos falar sobre a GLSL, por ser parte da especificação do OpenGL e compatível com todas as GPUs e sistemas operacionais. 
Ainda assim, tais linguagens são mapeamentos de alto nível dos recursos da GPU e, portanto, terão as mesmas limitações que o hardware. Algumas GPUs, por exemplo, não suportam números de ponto flutuante de 64 bits.

Existem dois exemplos que ilustram bem as limitação do modelo de programação em GPU, referentes à capacidade de fazer operações de gather e scatter. Uma operação de gather é pegar dados de várias posições da memória, e uma operação de scatter é gravar dados em várias posições da memória. Os vertex shaders podem fazer operações de scatter, mas só têm acesso de leitura aos dados de um único vértice. Os fragment shaders podem fazer operações de gather, mas só podem gravar a saída referente a um único fragmento. Outra limitação importante é a impossibilidade de controlar a ordem em que os vértices e fragmentos são processados.

Existem novas tecnologias sendo criadas para eliminar essas limitações, como a linguagem CUDA, feita para as últimas placas NVIDIA GeForce. Em CUDA é possível criar shaders que processam vértices e fragmentos na ordem que o programador quiser, o que permite a implementação, por exemplo, de algoritmos otimizados que usam resultados ou dados de fragmentos vizinhos.

Um exemplo é o filtro de média com janela de tamanho arbitrário. Esse algoritmo pode rodar em tempo linear no tamanho da imagem, independente do tamanho da janela. Isso é possível pois o filtro é separável (ou seja, igual ao resultado da filtragem por uma linha horizontal seguido da filtragem por uma linha vertical com mesmas dimensões da janela) e, porque a média de um pixel, no sentido vertical e no horizontal, é igual a do pixel vizinho mais uma diferença que depende de apenas dois pixels, o primeiro da janela do anterior e o último da janela atual ${ }^{5}$.

\footnotetext{
${ }^{5}$ Ver exemplo boxFilter do CUDA SDK
} 


\subsection{Linguagens para programar GPU}

Aqui apresentamos duas linguagens usadas para programar GPU. Escolhemos a GLSL por fazer parte da especificação OpenGL e por ser muito semelhante a outras linguagens populares como Cg (C for graphics) e HLSL (High Level Shading Language). Escolhemos também a linguagem CUDA, por possuir recursos poderosos e ausentes na GLSL.

\subsubsection{A linguagem GLSL}

A linguagem GLSL é de alto nível, independente de hardware, que faz parte da especificação OpenGL. Foi projetada seguindo uma série de objetivos e diretivas descritos resumidamente abaixo [93].

A linguagem deveria funcionar bem com OpenGL, provendo uma alternativa ao seu antigo pipeline fixo. Deve expor funcionalidades otimizadas no hardware, como tipos de dados e instruções ausentes na CPU. A especificação OpenGL muda rapidamente para acompanhar os desenvolvimentos tecnológicos na área, portanto, GLSL deve ser genérica o suficiente para expor funcionalidades do hardware que ainda não foram inventadas.

A linguagem GLSL foi criada para ser de fácil uso e demorar a se tornar obsoleta. Por isso foi feita com a mesma sintaxe do C, uma linguagem bem sucedida e popular há vários anos, com a qual muitos dos que trabalham com computação gráfica já estão acostumados.

Os tipos de dados suportados são o inteiro, ponto flutuante e valor booleano. A linguagem também suporta nativamente operações com vetores de até quatro posições e matrizes quadradas. Tais tipos de dados são o vec2, vec3 e vec4, para vetores de ponto flutuante com duas a quatro posições, e mat2, mat3 e mat4, para matrizes quadradas de ponto flutuante com duas a quatro posições por linha e coluna.

Para acessar a memória de textura, deve-se usar os tipos de dados sampler1D, sampler2D 
e sampler3D, para texturas com uma, duas ou três dimensões. Funções escritas em GLSL podem receber parâmetros de entrada, mas retornam valores apenas através de variáveis embutidas. Variáveis embutidas são variáveis que começam com gl_ e podem ser usadas como dados de entrada ou para retornar resultados.

Nos vertex shaders, por exemplo, algumas das variáveis embutidas visíveis são g1_Vertex gl_ModelViewMatrix e gl_FrontColor. A primeira contém as coordenadas do vértice no espaço, a segunda é uma matriz de transformação do OpenGL, ambas são variáveis de entrada. Já gl_FrontColor é usado como saída e contém a cor associada ao vértice. Nos fragment shaders são visíveis, por exemplo, gl_TexCoord e gl_FragColor. A primeira, uma variável de entrada, contém as coordenadas da textura referente ao fragmento, e a segunda, variável de saída, contém a cor que o fragmento deve ter. Uma operação comum nos fragment shaders é consultar a cor de uma variável de tipo sampler na posição dada por gl_TexCoord e armazená-la em gl_FragColor, operação chamada de mapeamento de textura.

A linguagem GLSL pode ser usada para se implementar filtros para processamento de imagens, apesar de não ter sido criada para isso. Cada filtro pode ser implementado como um fragment shader, e a imagem de entrada deve ser gravada em uma textura.

Para se gerar uma cena com OpenGL, o programador deve definir uma câmera virtual, com localização no espaço, ângulo de abertura e a direção para onde aponta. No nosso caso, queremos processar imagens por uma série de operadores, e é fundamental que cada operador grave os pixels de saída na exata posição onde devem estar, para que os resultados não apareçam distorcidos.

Isso é possível se criarmos um retângulo que ocupe exatamente o campo visual da câmera, e em seguida mapearmos a textura, contendo a imagem de entrada, sobre o retângulo utilizando o fragment shader desejado. Esse shader pode pegar o valor da 
textura na posição correspondente à saída e alterá-lo de várias formas. Também pode ler valores da textura em uma pequena janela e combiná-los antes de gravar a saída. Assim é possível implementar operadores como dilatação, erosão, gradiente, mediana e vários outros.

O fragment shader pode também combinar valores de várias texturas, assim, é possível implementar operações como mínimo, máximo, soma e diferença absoluta entre imagens. O ideal é gravar a saída em um framebuffer que não será mostrado e copiar o resultado para uma textura, assim é possível montar um pipeline onde as operações usam texturas como entrada e saída. Framebuffer é o nome dado à memória onde a saída dos shaders é armazenada.

\subsubsection{A linguagem CUDA}

A sigla CUDA significa Compute Unified Device Architecture. É uma nova arquitetura de hardware e software para se usar as GPUs como um co-processador paralelo sem ter que mapear as instruções e dados para uma API gráfica [83]. Pode ser usada a partir das placas GeForce 8 Series.

Também é inspirada na linguagem C para facilitar seu aprendizado, porém, código escrito em CUDAdeve ser compilado usando o compilador nvcc, presente no CUDASDK (Software Development Kit).

Existem dois tipos de funções que rodam na GPU, e ambas devem ser precedidas pelo qualificador adequado. Funções que são chamadas pelo código que roda na CPU devem ser precedidas por _-_global_--, e as que são chamadas pelo código que roda na GPU devem ser precedidas por _-_device__.

Nas GPUs compatíveis, existem vários multiprocessadores, cada um com quatro núcleos. O programador deve dividir os dados em blocos, e os blocos em threads, sendo que cada 
bloco rodará em um único multiprocessador. Isso é feito definindo uma configuração de execução ao se chamar uma função _-global_.. Uma configuração de execução contém o número de blocos e o número de threads em cada bloco.

Existem quatro constantes embutidas visíveis em todas as funções _-global__: gridDim contém o número de blocos; blockIdx contém o índice do bloco; blockDim contém o número de threads do bloco; e threadIdx contém o índice da thread. Lembrando que a linguagem foi criada para se operar sobre grande volume de dados em formato de vetor ou matriz, o programador deve usar essas constantes para definir qual índice da imagem ou do vetor cada bloco e respetiva thread deve utilizar.

Esse ponto é uma diferença importante entre essa linguagem e GLSL e afins. A linguagem CUDA, por exigir que o programador controle em baixo nível que dado será utilizado a partir das constantes embutidas, código escrito em CUDAcostuma ser bem mais longo, sujeito a mais erros e mais depuração que código escrito em GLSL. O programador deve calcular o índice do pixel a ser processado a partir das constantes embutidas, calculadas em função da configuração de execução escolhida. Porém é justamente isso que permite que sejam feitos códigos mais otimizados em CUDA, já que o programador tem controle sobre a ordem em que os dados são processados dentro de uma thread.

\subsection{Soluções existentes}

Podemos citar pelo menos três bibliotecas que podem ser usadas para processamento de vídeo: OpenCV, OpenVidia e GPUCV.

OpenCV é uma biblioteca bastante popular, é bem completa, com diversas funções para segmentação, reconhecimento de objetos, análise de formas, detecção e rastreamento de características, e reconstrução tridimensional [86]. Aproveita as instruções MMX/SSE 
da arquitetura Intel para paralelizar operações, porém, a paralelização é muito menor que a alcançável usando GPU.

As bibliotecas GPUCV e OpenVidia foram implementadas usando a API (Application Programming Interface) gráfica OpenGL. OpenVidia é uma biblioteca de funções de processamento de imagens com menos funções que a OpenCV, mas que aproveita o poder de processamento das GPUs [43]. Possui funções implementadas em CUDA e Cg. Possui filtros como detecção de bordas Canny, registro de pares de imagens, mapa de profundidade de imagens estéreo, rastreamento de características, transformadas Radon e Hough. Porém, apesar de fornecer uma série de shaders prontos para usar, a OpenVidia não esconde do programador as complexidades do OpenGL. Seu uso exige que o programador carregue e compile os arquivos com os códigos fonte dos shaders, carregue as imagens em texturas, ou seja, uma série de tarefas mecânicas e sujeitas a erro, e não relacionadas diretamente ao problema que precisa ser resolvido.

O objetivo da GPUCV é permitir o uso da GPU no processamento de imagens minimizando o esforço do programador [36]. Possui um subconjunto das funções da OpenCV portadas para rodar em GPU. Na prática, para usar a GPUCV, o programador precisa apenas substituir as chamadas a funções da OpenCV pelas funções da GPUCV. Isso se constitui em uma enorme vantagem sobre a OpenVidia. Não é necessário, portanto, saber OpenGL, mas a criação de novas funções está limitada por um pequeno conjunto de templates, e, apesar de fornecer algumas macros para facilitar o trabalho, o programador que deve criar o código wrapper.

No Capítulo 5 propomos uma solução alternativa, capaz de gerar o código wrapper automaticamente, sem as limitações apresentadas pela OpenVidia e GPUCV. 


\section{Capítulo 5}

\section{Processamento de vídeo em tempo real usando GPU}

Neste capítulo, descreveremos uma maneira de encadear código de vários shaders com facilidade, permitindo a criação de um pipeline de processamento de vídeo de alto desempenho. O encadeamento é possível através do uso de código wrapper, ou seja, uma função em $\mathrm{C}++$ que envia as imagens e outros parâmetros de entrada à GPU sem que o programador precise fazer chamadas à API OpenGL. Trazer os dados da GPU para a RAM toma bastante tempo. A biblioteca só faz essa operação quando necessário ou explicitamente solicitado pelo programador.

O código wrapper é gerado automaticamente a partir do código fonte dos shaders. Existe uma correspondência de um para um entre os parâmetros de entrada do wrapper e do shader. O programador precisa apenas definir essa correspondência e a lista de parâmetros de entrada da função wrapper.

Descreveremos um gerador de código que oculta do programador detalhes de pro- 


\section{CAPÍTULO 5. PROCESSAMENTO DE VÍDEO EM TEMPO REAL}

gramação que podem ser automatizados. Na criação de funções de processamento de

imagens e vídeo, tais complexidades são desnecessárias, introduzem erros, dificultam a implementação e manutenção do código. Assim o programador não precisa se preocupar em aprender OpenGL, nem em como passar os dados do contexto da linguagem $\mathrm{C}++$ para o contexto das linguagens GLSL e CUDA, podendo se concentrar na criação de seus operadores e filtros de imagens.

\section{$5.1 \quad$ Wrappers}

No contexto da linguagem $\mathrm{C}++$, ou seja, na RAM, a imagem é armazenada em uma estrutura IplImage compatível com OpenCV. Quando uma imagem é carregada de um arquivo ou capturada de uma câmera, é armazenada nessa estrutura.

Para usar os recursos de processamento do dispositivo que contém a GPU, é necessário que a imagem seja armazenada na memória de vídeo em um espaço lógico pertencente ao contexto do OpenGL. Esse contexto é responsável pelo armazenamento das imagens no dispositivo, pela execução dos shaders e pela exibição na tela. Para salvar o resultado, deve-se copiá-lo explicitamente da memória de vídeo para a RAM.

A linguagem CUDA roda em um contexto separado do OpenGL. Para usarmos um operador escrito em CUDA, devemos copiar a imagem para seu contexto. Para exibir o resultado, devemos retorná-lo para o contexto do OpenGL. A Figura 5.1 ilustra as operações envolvidas. Na biblioteca proposta, isso é transparente para o programador, que transfere as imagens entre contextos com uma única chamada de função.

A biblioteca proposta oculta do programador as diversas operações feitas com OpenGL necessárias para que a imagem percorra o pipeline de shaders corretamente. No dispositivo, cada imagem é armazenada em uma textura. A saída de um shader é gravada sempre em 
um framebuffer. Para armazenar a saída em uma ou mais texturas, é preciso associá-las ao framebuffer usando glBindFramebufferEXT(), como mostra a Figura 5.1. Com isso, a saída do shader vai direto para a textura de destino sem haver necessidade de cópias de grandes regiões da memória.

Também é necessário que a textura seja mapeada em um retângulo que ocupe exatamente o campo visual da câmera do OpenGL. Como matriz modelview usamos a identidade, e as texturas são mapeadas sobre um retângulo com extremos em $(-1,-1)$ e $(1,1)$.

Cada imagem criada possui uma textura e um FBO (framebuffer object) associado. Quando a imagem é dado de entrada, usa-se a textura, e quando é de saída, grava-se no FBO, que redireciona a saída para a textura. Com isso, é possível montar um pipeline onde a entrada e a saída de cada shader é feita através de texturas. O tipo de shader apropriado para esse tipo de operação é o fragment shader.

\subsubsection{Wrappers GLSL}

Para gerar os wrappers de GLSL em linguagem $\mathrm{C}++$, usamos um gerador de código, escrito em linguagem Perl, que processa cada shader e grava dois arquivos de saída: o arquivo h, de headers, e o arquivo cpp, com o código fonte. Cada shader é armazenado em um arquivo com extensão frag, e deve conter uma função main.

Os arquivos com os shaders processados não são alterados, e devem estar presentes em tempo de execução. O gerador de código espera três argumentos: o prefixo dos arquivos de saída, o diretório que contém os shaders, e o caminho relativo dos shaders para que o programa os encontre em tempo de execução.

Na primeira vez que um shader é chamado pela aplicação, o texto do arquivo frag deve ser carregado e compilado com glCompileShader. Em caso de sucesso, o identificador do shader é armazenado em uma variável estática, tipo GLuint, dentro da respectiva 
CAPÍTULO 5. PROCESSAMENTO DE VÍDEO EM TEMPO REAL

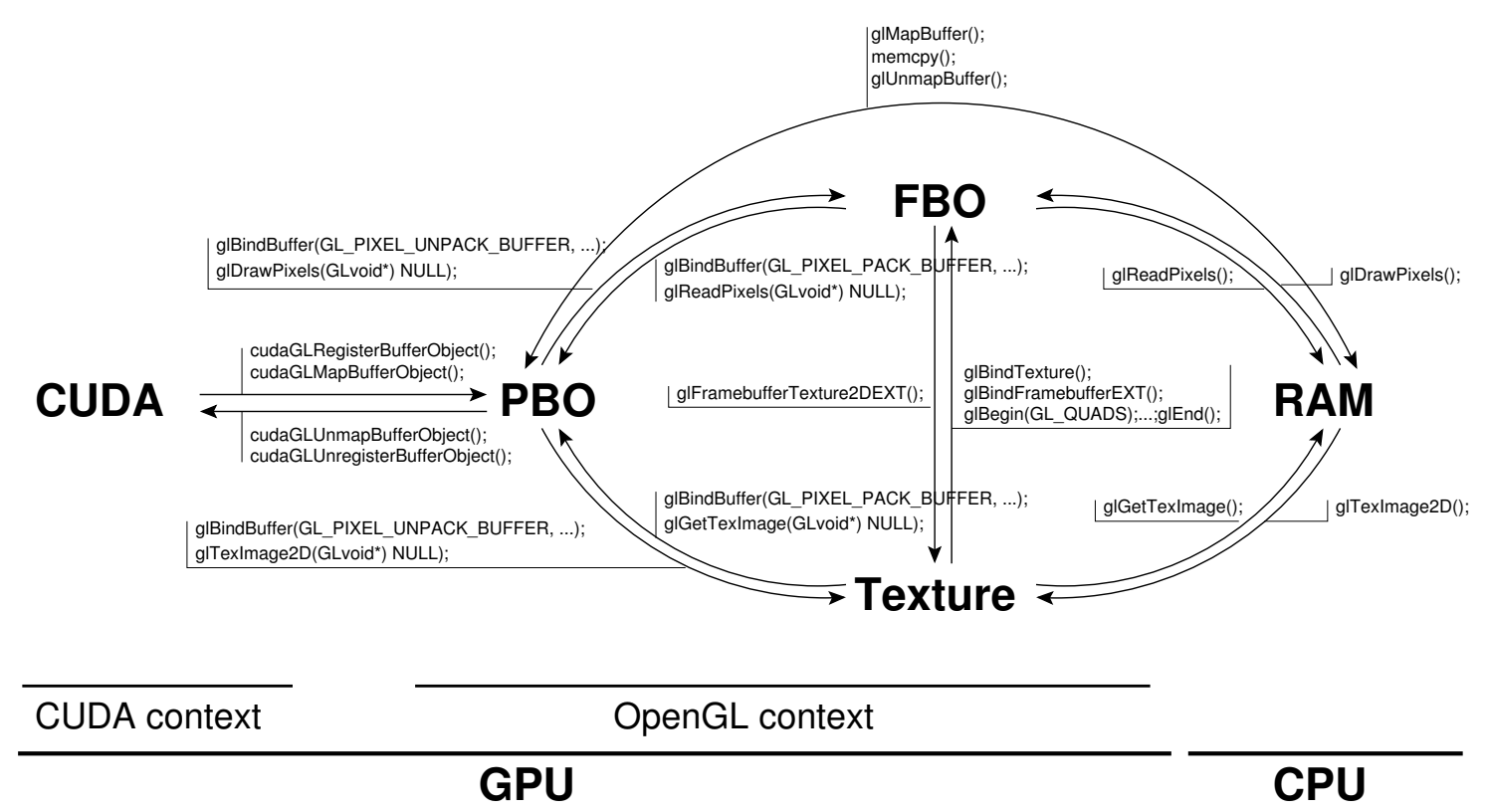

Figura 5.1: Para que a API OpenGL faça processamento genérico, é preciso mapear cada matriz de dados em uma textura ou pixelbuffer.
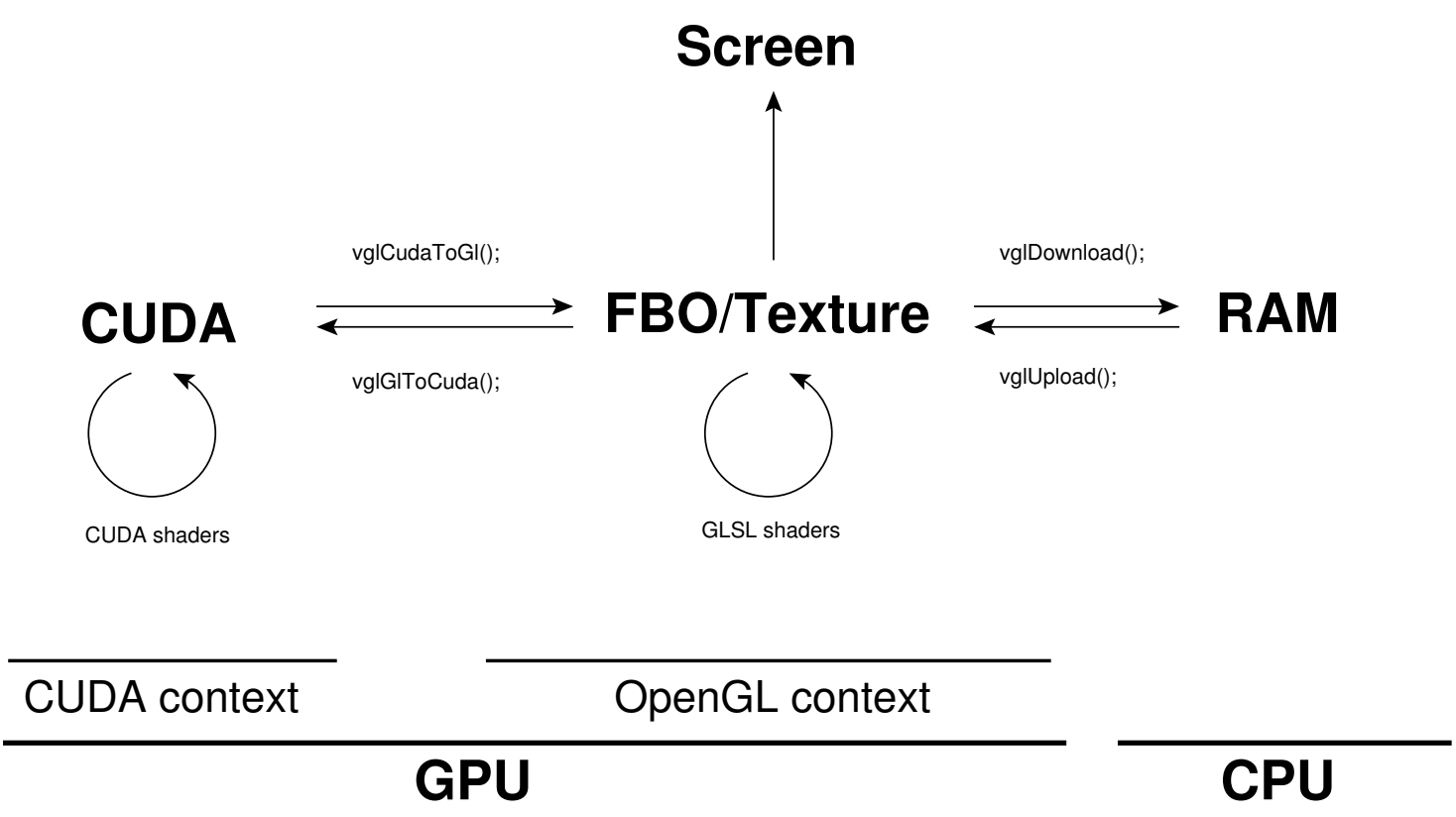

Figura 5.2: A biblioteca proposta chama as funções do OpenGL, necessárias para transferir a imagem entre contextos, de forma transparente para o programador. 
função wrapper em $\mathrm{C}++$, para que não seja necessário recarregá-lo e recompilá-lo. Os detalhes sobre o processo de compilação de shaders GLSL podem ser consultados no livro de Wright [111].

O arquivo vglMipMap.frag possui, inseridos no código em GLSL compilável, três tipos de comentários que são interpretados pelo gerador de código para criar a função wrapper, cujo nome é definido pelo nome do arquivo.

O primeiro, comentário de documentação, de múltiplas linhas entre as linhas 1 e 3, é copiado para os dois arquivos de saída, h e cpp. O objetivo dessa cópia é permitir o uso do doxygen para geração de documentação.

Na linha 4 está o primeiro comentário de única linha que ocupa uma linha inteira, o comentário de declaração. O conteúdo desse comentário define os parâmetros de entrada da função vglMipMap, em C++. É uma lista, entre parênteses, de pares < tipo de dado, nome de variável>, separados por vírgula, como em $\mathrm{C}++$. Os tipos aceitos são, float, int e VglImage. Este último é usado para passar imagens de entrada e saída, e deve ser precedido por uma das três palavras ligação semântica: IN_TEX, OUT_FBO ou IN_OUT, indicando que a imagem é dado de entrada, saída ou ambos, respectivamente.

O terceiro tipo, o comentário de atribuição, é o de única linha presente depois de uma definição de variável tipo uniform, como na linha 6. Define que valor o código $\mathrm{C}++$ deve atribuir à variável uniform do GLSL. Nesse exemplo, o código da linha 6 gera a seguinte linha no wrapper: glUniform1f(glGetUniformLocation(f, "level"), lod);

Para cada variável uniform tipo sampler deve haver um VglImage com semântica de entrada, e são associadas uma à outra na ordem em que aparecem no código. Neste caso os comentários de definição de valor são ignorados.

No caso de múltiplas imagens de saída, grava-se apenas no primeiro FBO. As demais texturas de saída são associadas cada uma a um diferente GL_COLOR_ATTACHMENT desse 


\section{CAPÍTULO 5. PROCESSAMENTO DE VÍDEO EM TEMPO REAL 56 USANDO GPU}

FBO. É possível assim criar funções que suportam múltiplas imagens, tanto de entrada quanto de saída.

listagem de vglMipMap.frag

1. /** vglMipmap

2. Get specified level of detail

3. $* 1$

4. // (IN_TEX: VglImage* src, OUT_FBO: VglImage* dst, float lod)

5. uniform sampler2D sampler0;

6. uniform float level; // lod

7. void main(void) \{

8. gl_FragColor $=$ texture2DLod (sampler0, gl_TexCoord[0].xy, level);

9. $\}$

\subsubsection{Wrappers CUDA}

Para gerar os wrappers de CUDA em $\mathrm{C}++$, também usamos um gerador de código escrito em linguagem Perl. O gerador de código analisa uma lista de arquivos com extensão kernel e gera três arquivos de saída: gera um arquivo com extensão cu contendo todos os wrappers dos operadores CUDA, um arquivo $\mathrm{h}$ com os protótipos de todas as funções wrapper, e um arquivo kernel com as funções em CUDA.

O arquivo kernel gerado nada mais é do que a concatenação de todos os arquivos kernel processados pelo gerador de código. É incluído no arquivo cu por uma diretiva \#include do $\mathrm{C}++$. 
O gerador de código espera dois argumentos: o prefixo dos arquivos de saída, e o diretório que contém os shaders, ou operadores.

Como se pode observar na listagem de vglCudaInvert.kernel, existem três tipos de comentários como nos operadores em GLSL. O nome da função é definido pelo nome do arquivo, portanto, a função wrapper será chamada vglCudaInvert.

listagem de vglCudaInvert.kernel

1. /** vglCudaInvert

2. Inverts image in CUDA context.

3. $* /$

4. // $<<<$ in->h, 384 $>>>$ (IO_PBO: VglImage* In, IO_PBO: VglImage* Out)

5. // (In->cudaPtr, Out->cudaPtr, In->w, In->h, In->nChan)

6. template<typename $\mathrm{T}>$

7. _-global_- void global_Invert $(\mathrm{T} *$ in, $\mathrm{T} *$ out, int $\mathrm{w}$, int $\mathrm{h}$, int $\mathrm{nChan})\{$

9. $\mathrm{T} *$ arr $\mathrm{in}=\mathrm{in}+\mathrm{blockIdx} . \mathrm{x} * \mathrm{nChan} * \mathrm{w}$;

10. $\mathrm{T} *$ arr_out $=$ out + blockIdx.x $*$ nChan $* \mathrm{w}$;

11. int $\operatorname{minj}=$ threadIdx. $x$;

12. int $\max j=\mathrm{nChan} * \mathrm{w}$;

13. int $d j=$ blockDim.x;

14. for $($ int $j=\operatorname{minj} ; j<\max j ; j+=d j)\{$

15. $\operatorname{arr} \_o u t ~[j]=-\operatorname{arr} \_i n[j] ;$

16. $\}$

17. $\}$ 


\section{CAPÍTULO 5. PROCESSAMENTO DE VÍDEO EM TEMPO REAL 58 USANDO GPU}

O primeiro, comentário de documentação, de múltiplas linhas entre as linhas 1 e 3, é copiado para os dois arquivos de saída, h e cpp. O objetivo dessa cópia é permitir o uso do doxygen para geração de documentação.

Na linha 4 está o comentário de declaração. O conteúdo desse comentário define os parâmetros de entrada da função vglCudaInvert, em $\mathrm{C}++$. O primeiro item nesse comentário, entre os símbolos " $<<<$ " e " $>>>$ ", é uma configuração de execução, necessária nas chamadas a funções em CUDA. O shader definido na listagem será chamado com essa configuração. O segundo item é uma lista, entre parênteses, de pares <tipo de dado, nome de variável>, separados por vírgula, como em $\mathrm{C}++$. Os tipos aceitos são, float, int e VglImage. Este último é usado para passar imagens de entrada ou saída, e deve ser precedido pela palavra ligação semântica: IO_PBO, indicando que a imagem é dado de entrada ou saída, e que será armazenada em um Pixel Buffer Object. Em implementações futuras podemos permitir o uso de texturas e, para isso, outras semânticas devem ser criadas.

O terceiro tipo, o comentário de atribuição, na linha 5, define os valores que a função wrapper deve usar para chamar o shader. É uma lista entre parênteses com valores separados por vírgulas. Esses valores serão usados na chamada do shader, e o número de elementos dessa lista deve ser o mesmo que o número de parâmetros que o shader requer.

\subsection{Resultados}

Comparamos as funções da biblioteca proposta, que chamaremos VGL (de VisionGL), com funções equivalentes da OpenCV e da GPUCV. Usamos o comando runbench do aplicativo GPUCVConsole, fornecido com a biblioteca GPUCV. Para testar nosso código, adicionamos a esse aplicativo chamadas às nossas funções. 
Os testes foram feitos em um Athlon X2 com 2 Gbytes de RAM e em uma GPU GeForce 8800 GTS. Cada operador foi testado cinquenta vezes em cada biblioteca. As células da Tabela 5.1 contém o tempo médio em milissegundos.

A biblioteca VGL obteve resultados próximos aos da GPUCV, alguns mais rápidos e um, como é o caso da erosão $5 \times 5$, mais lento, como mostra a Tabela 5.1 , onde apresentamos os mesmos operadores de Farrugia [36] para efeito de comparação. Os tempos não incluem compilação dos shaders e transferências entre a memória RAM e a GPU.

Todos os shaders testados são escritos em GLSL, tanto na GPUCV quanto na nossa biblioteca. As pequenas diferenças na implementação dos shaders não são suficientes para explicar as diferenças de tempo, e mesmo shaders idênticos apresentaram tempos diferentes, como é o caso do threshold. Atribuímos as diferenças de tempo às diferenças nos códigos wrapper, que precedem as chamadas aos códigos que rodam na GPU.

Outra vantagem da biblioteca proposta é que concentra toda a programação em um único arquivo, facilitando a prototipação, implementação e manutenção de novos operadores. O programador cria o código, seja em GLSL ou em CUDA, e a partir de pequenos comentários inseridos no código, uma função em $\mathrm{C}++$ é gerada automaticamente.

\begin{tabular}{c|ccc}
\hline \hline & OpenCV & GPUCV & VGL \\
\hline Erosão $3 \times 3$ & 38.0 & 1.0 & 0.9 \\
Erosão $5 \times 5$ & 63.2 & 1.8 & 2.2 \\
RGB para XYZ & 11.6 & 0.9 & 0.2 \\
RGB para HSV & 20.6 & 0.9 & 0.3 \\
Threshold & 2.2 & 1.0 & 0.2 \\
\hline
\end{tabular}

Tabela 5.1: Tempo médio em milissegundos para processar uma imagem 1024×1024 pixels 
CAPÍTULO 5. PROCESSAMENTO DE VÍDEO EM TEMPO REAL 


\section{Capítulo 6}

\section{Reconhecimento de gestos}

Na literatura existem trabalhos que usam a cor da pele para localizar as mãos e o rosto do usuário. Hong [52, 51], por exemplo, exige que o usuário vista roupas com mangas compridas para localizar corretamente as mãos. No nosso método, não há essa exigência. O usuário pode vestir qualquer roupa e até mesmo estar de luvas, bastando que as cores sejam diferentes do background.

Na solução que propomos, o importante é a configuração do contorno do usuário. Não são localizadas as mãos exatamente, mas as extremidades mais salientes. Para identificar os gestos de que necessitamos na aplicação, esta abordagem se mostrou satisfatória.

O pipeline de processamento é dividido em diversas etapas, que serão descritas nas seções deste capítulo. A Figura 6.1 ilustra as etapas do pipeline. A primeira etapa é um pré-processamento, em que são aplicadas as transformações encontradas pelo processo de calibração. É feita a correção de distorção radial, opcionalmente uma correção de perspectiva, e a retificação. Em seguida, é feita a subtração do background, da qual obtemos um par de imagens, cada uma com uma região que indica onde está o corpo do usuário. 


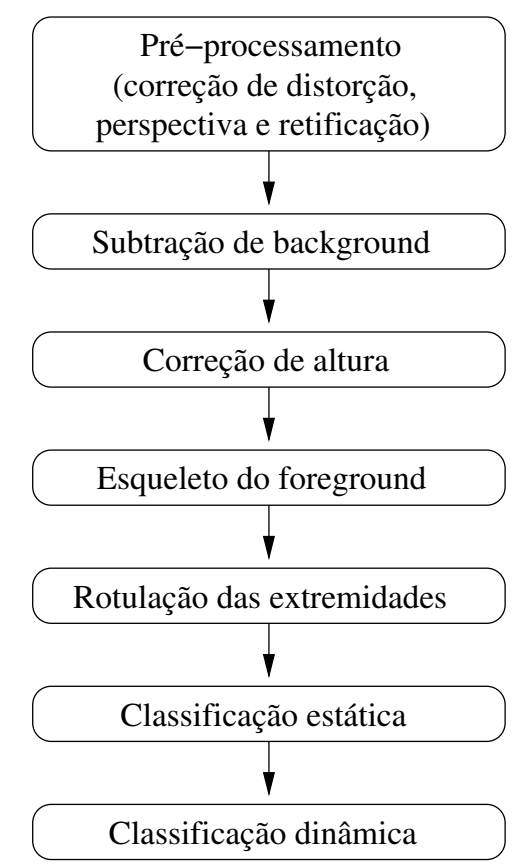

Figura 6.1: Pipeline do sistema de reconhecimento de gestos proposto.

Da disparidade entre os baricentros deste par de regiões, obtemos a distância do usuário às câmeras. Dessa distância, calculamos um fator de correção das dimensões do usuário, para que o usuário em pé com os braços abertos tenha sempre a mesma altura e largura, independente de sua distância à câmera.

A partir deste ponto a segunda imagem do par de câmeras é ignorada. Para o reconhecimento de gestos, a segunda imagem só é importante para se encontrar a distância aproximada do usuário à câmera.

Em seguida, calculamos um esqueleto com a mesma topologia do foreground de uma das imagens. Desse esqueleto, extraímos um vetor de pixels candidatos às cinco extremidades do corpo que são as mãos, os pés e a cabeça. 


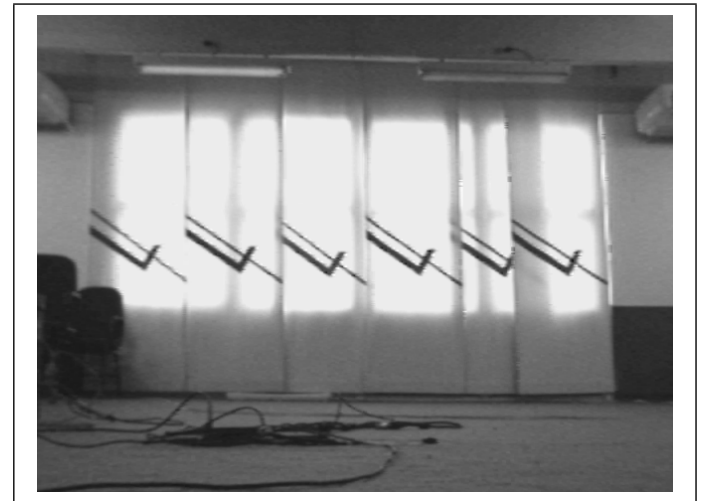

(a) Câmera esquerda: background.

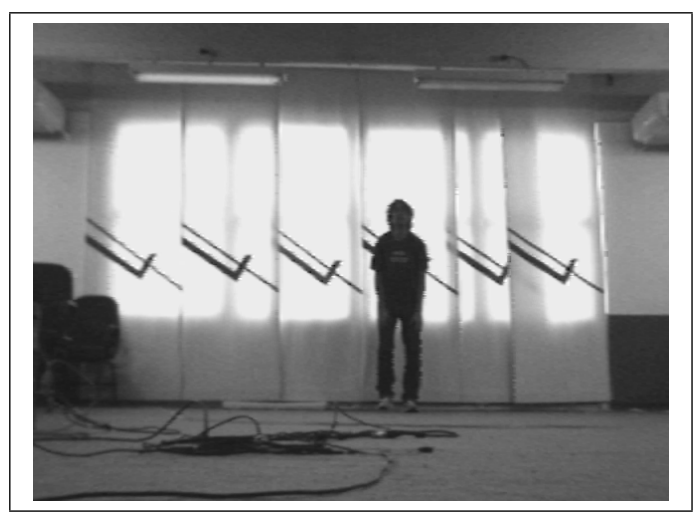

(c) Câmera esquerda.

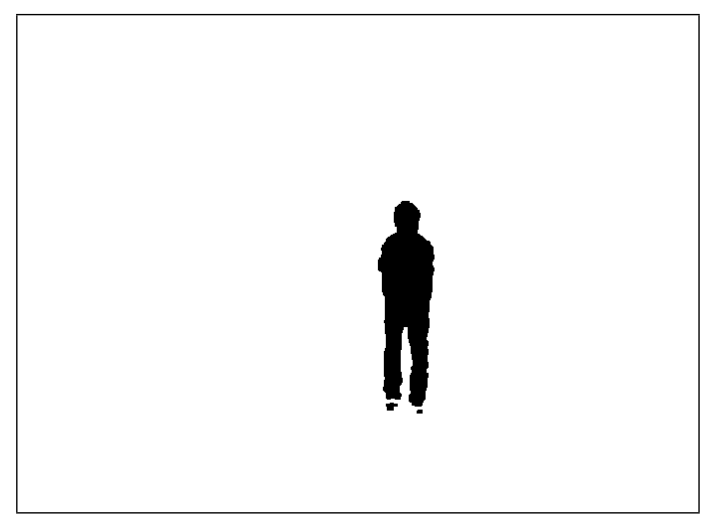

(e) Câmera esquerda: segmentação.

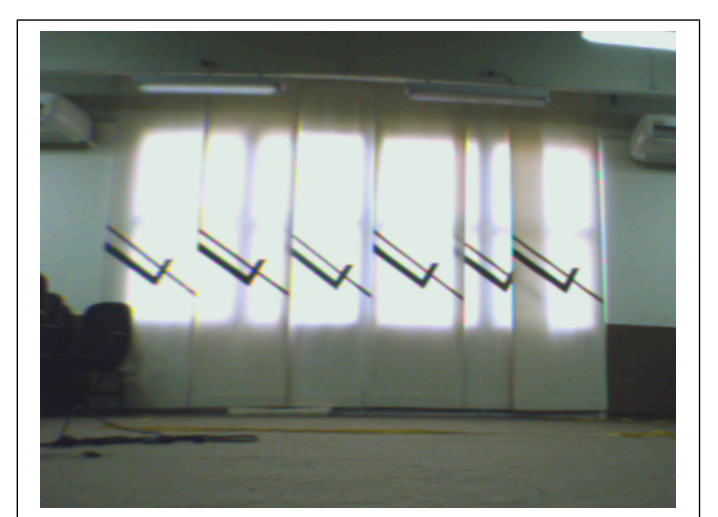

(b) Câmera direita: background.

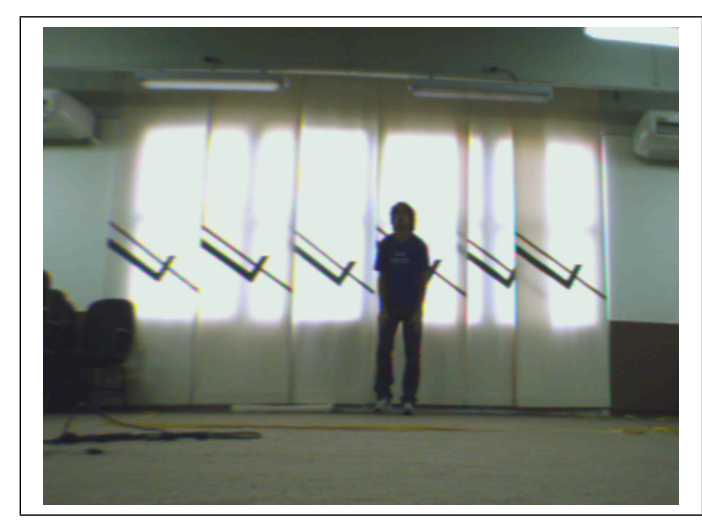

(d) Câmera direita.

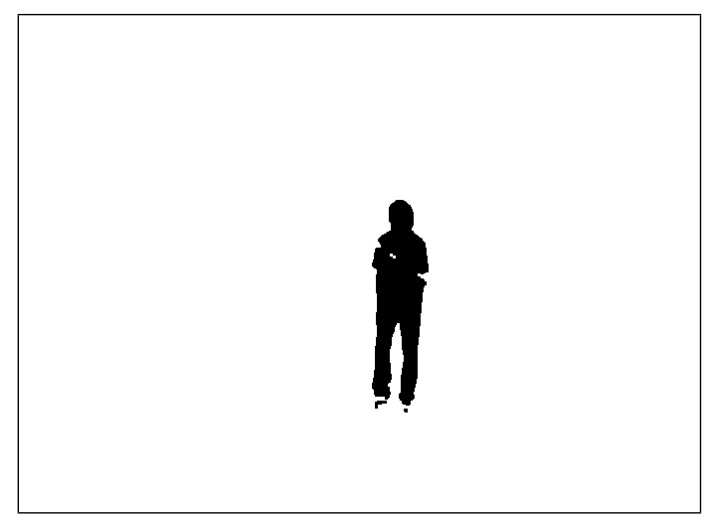

(f) Câmera direita: segmentação.

Figura 6.2: Segmentação de background do frame 460 da sequência thiagopx0. 


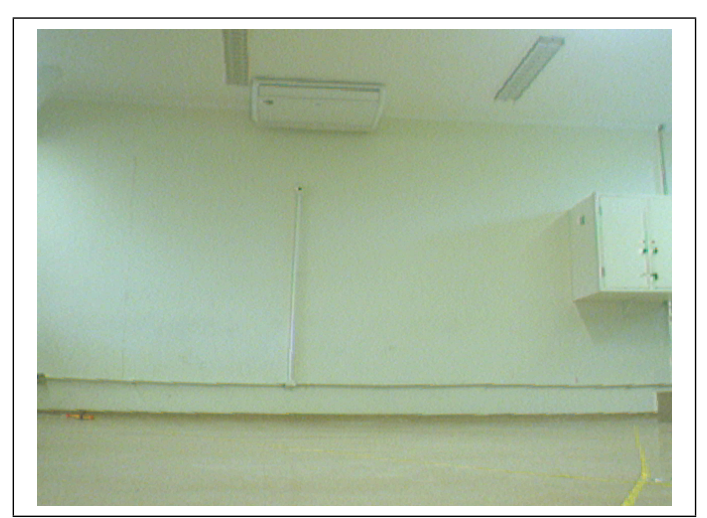

(a) Câmera esquerda: background.

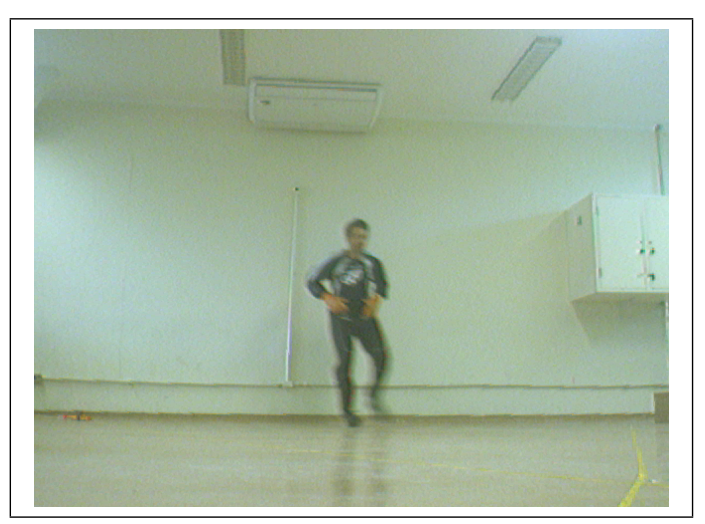

(c) Câmera esquerda.

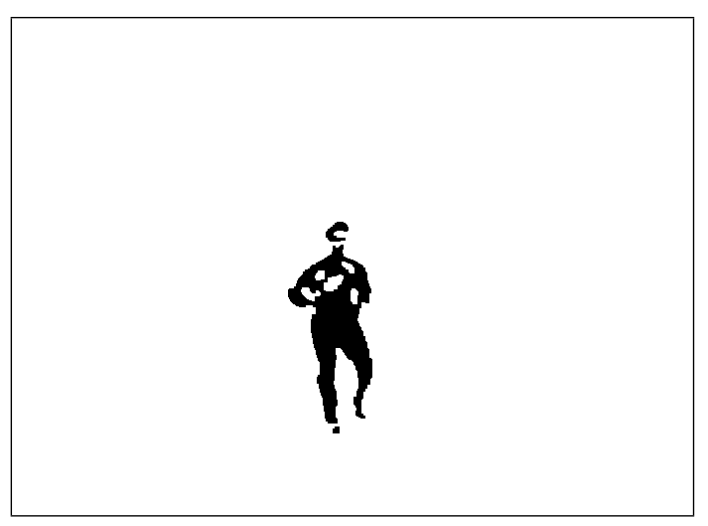

(e) Câmera esquerda: segmentação.

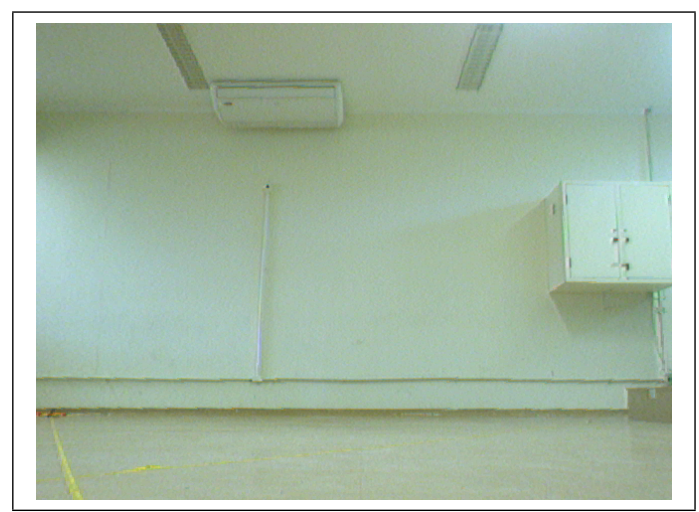

(b) Câmera direita: background.

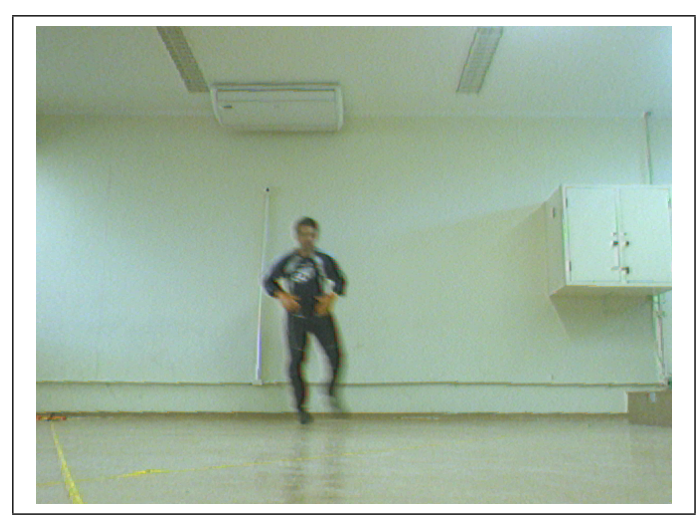

(d) Câmera direita.

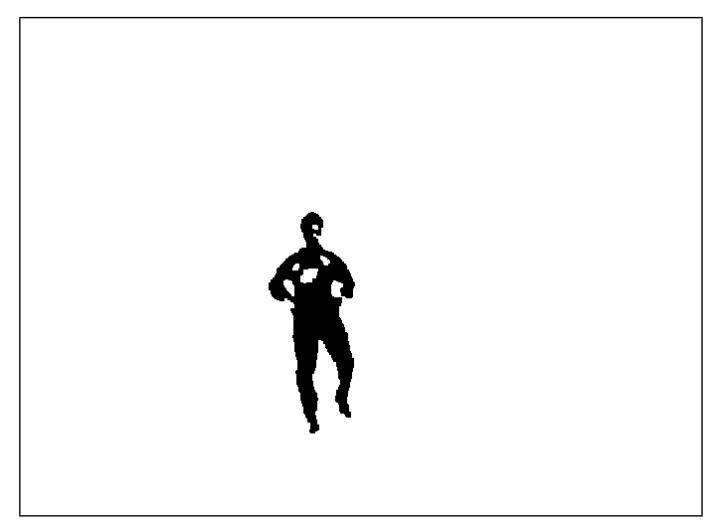

(f) Câmera direita: segmentação.

Figura 6.3: Segmentação de background do frame 850 da sequência felipe0. 
A abordagem usada foi inspirada nos artigos de Pedro Correa [27, 26, 44]. Como Correa, usamos os pontos mais proeminentes da região definida pelo corpo do usuário. A forma de cálculo dos pontos, porém, foi modificada para acelerar o cálculo.

Cada uma das cinco extremidades do corpo equivale a um rótulo, e todos devem ser associados a alguma extremidade do esqueleto. O esqueleto, porém, pode ter menos e até mais de cinco extremidades, assim, pode haver extremidades do esqueleto com nenhum, um ou mais de um rótulo. Formalmente, sendo $A$ o conjunto de cinco extremidades do corpo, ou rótulos, e $B$, o conjunto de extremidades do esqueleto, deve haver uma relação binária total de $A$ em $B$, ou seja, todo elemento de $A$ se relaciona com algum elemento de $B$. O conjunto de extremidades do esqueleto deve conter pelo menos duas extremidades.

Os últimos passos são a classificação estática, da pose, e dinâmica, dos gestos. Nas próximas seções, são descritas todas as etapas do pipeline com mais detalhes.

\subsection{Pré-processamento}

A primeira etapa visa corrigir as dirtorções da imagem causadas pelas lentes e projeção perspectiva. Em primeiro lugar, é feita uma correção de distorção radial, para eliminar a distorção barrel causada pela lente da câmera

Em seguida é feita uma correção de perspectiva, de modo que linhas verticais no mundo fiquem paralelas às colunas de pixels da imagem, e a linha do horizonte fique paralela às linhas de pixels da imagem. Finalmente é feita a retificação, que faz com que linhas epipolares tenham a mesma coordenada vertical no par de imagens. A Seção 2.8 descreve o processo de calibração, que gera os parâmetros usados no pré-processamento. 


\subsection{Subtração de background}

O segundo passo do pipeline é a subtração de background. Para isso, devem ser gravados alguns frames sem o usuário e um modelo de fundo deve ser gerado. O fundo é modelado por gaussianas, uma para cada canal, vermelho, verde e azul, de cada pixel. Os melhores resultados foram obtidos quando definimos como foreground os pixels cuja cor é mais distante da média do que 2,5 desvios-padrão, e quando o modelo de fundo não muda depois de inicializado. Com cinquenta frames para modelar o fundo, conseguimos obter estimativas das médias e desvios-padrão dos pixels que deram boas segmentações.

As Figuras 6.2 e 6.3 mostram exemplos de segmentação de fundo. Observe que as Figuras 6.3(c) e 6.3(d) apresentam motion blur e reflexos que não atrapalham a segmentação, mostrada nas Figuras 6.3(e) e 6.3(f). Porém as partes de cor clara da roupa são confundidas com o background. Isso é corrigido no próximo passo por uma dilatação seguida de uma erosão condicional [7].

\subsection{Correção de altura}

Para nos referir à região definida pelo foreground, usamos o termo blob (binary large object). O passo seguinte do processamento é encontrar o baricentro de cada blob no sistema de coordenadas da imagem, ou seja, a coordenada do pixel do baricentro $(u, v)$. No cálculo do baricentro, todos os pixels do foreground têm o mesmo peso.

Estamos usando um par de câmeras, câmera 1 e câmera 2, e calcularemos o baricentro das imagens de cada uma das câmeras $\left(u_{1}, v_{1}\right)$ e $\left(u_{2}, v_{2}\right)$, respectivamente. A diferença entre os valores $u_{1}$ e $u_{2}$ nos dá a disparidade aproximada de nosso usuário posicionado no interior do volume de captura. A partir de tal disparidade podemos encontrar sua distância até as câmeras e consequentemente o fator de normalização de altura. 
Quanto maior a distância do usuário à câmera, menor o ângulo visual que seu corpo ocupa. Isso pode ser corrigido, de modo que as dimensões da imagem de seu corpo sejam sempre as mesmas, independente de sua distância à câmera.

Seja $D$ a distância das câmeras ao plano de fundo em centímetros. Neste plano o usuário tem a menor altura possível. É possível redimensionar a imagem de modo que o usuário em pé sempre tenha esta altura, mesmo estando próximo à câmera. Para isso, devemos multiplicar as dimensões da imagem, tanto $u$, horizontal, quando $v$, vertical, pelo que chamaremos de fator de correção de altura $\lambda$.

Supondo que os planos retinais das câmeras sejam paralelos, pontos no infinito terão disparidade zero. Como descrito na Seção 2.3, a relação entre disparidade e distância é dada pela fórmula $z=f b / d$, onde $z$ é a distância do objeto à câmera em centímetros, $f$ é o comprimento focal da câmera em pixels, b é o baseline em centímetros, e $d$ é a disparidade em pixels.

Queremos que a imagem do usuário sempre tenha a mesma altura que sua imagem quando ele se encontra à distância $D$ das câmeras. Portanto o fator de correção $\lambda$ na disparidade correspondente a $D$ deve ser 1,0. Seja $a$ a altura do usuário, e $z$ sua distância à câmera, posicionada no chão. A razão $a / D$ dá a tangente do ângulo que queremos que a altura $a$ ocupe sempre. A razão $a / z$ dá a tangente do ângulo que o usuário ocupa quanto não está em $D$. Queremos encontrar um fator de correção $\lambda$ tal que, se multiplicado por $a / z$ nos dá $a / D$. Então $\lambda=z / D$.

Depois de encontrar o fator de correção $\lambda$, fazemos uma mudança de escala das duas imagens dos blobs. Na mudança de escala da largura, o centro da imagem é fixo, e na da altura, o nível do solo é fixo, dado pela linha do horizonte do passo de correção de perspectiva nas coordenadas da imagem. Em outras palavras, o pixel na linha do solo e no centro da imagem não tem suas coordenadas alteradas. Mesmo que não seja feita a 


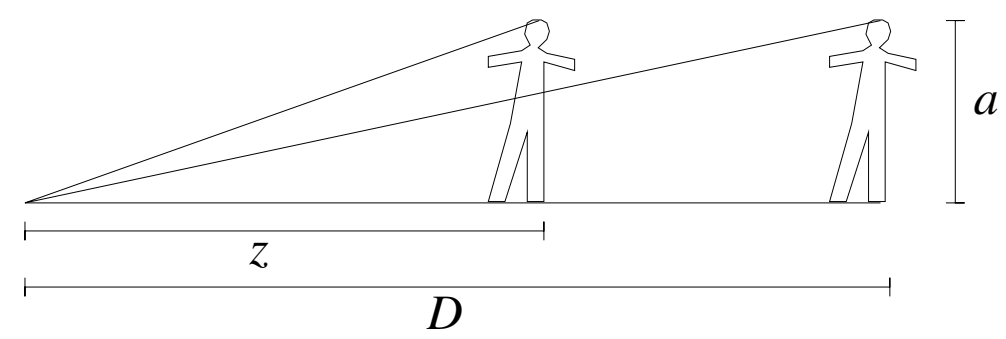

Figura 6.4: Ângulos visuais ocupados pelo usuário a diferentes distâncias da câmera.

correção de perspectiva no pré-processamento, a informação sobre a linha do horizonte é importante para a correção de altura.

Nenhuma informação das imagens originais, de antes da subtração do background, são usadas a partir daqui. Os demais passos do pipeline são feitos sobre uma das duas imagens escalonadas dos blobs, e a imagem da outra câmera é ignorada. Da imagem escalonada do blob é obtida a informação necessária para o resto do pipeline, que são as coordenadas das extremidades e do baricentro do blob.

Após a correção de escala, é feito um fechamento morfológico por um quadrado de lado igual a 5 pixels. Isso é importante pois partes mais estreitas do corpo podem ser confundidas com o background e fazer com que o foreground não tenha uma única componente conexa. Esse tamanho de elemento estruturante se mostrou adequado. Valores muito grandes devem ser evitados pois tendem a eliminar partes importantes do contorno.

Como foi mostrado na Figura 6.3, o blob que contém a segmentação do foreground pode ter alguns buracos, que devem ser fechados. Um fechamento morfológico por um elemento estruturante grande fecharia os buracos, mas poderia modificar o contorno do $b l o b$, por exemplo quando as mãos estão próximas ao corpo. Dilatamos o blob cinco vezes por uma cruz elementar e fazemos uma erosão condicional [7]. Dessa forma o contorno é mantido. O número de dilatações foi obtido empiricamente, e imagens em escala maior 
podem precisar de mais dilatações.

\subsection{Cálculo do esqueleto}

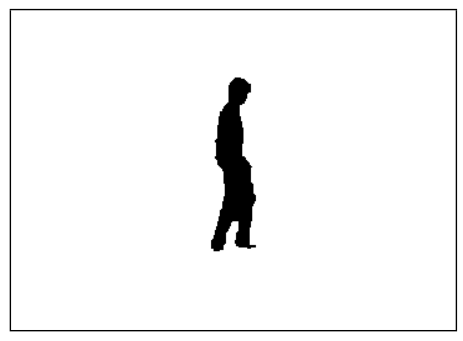

(a) Blob.

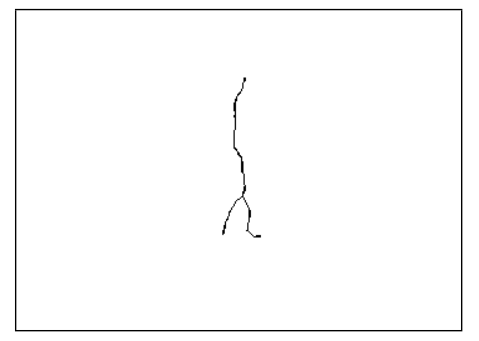

(b) Afinamento de Bernard.

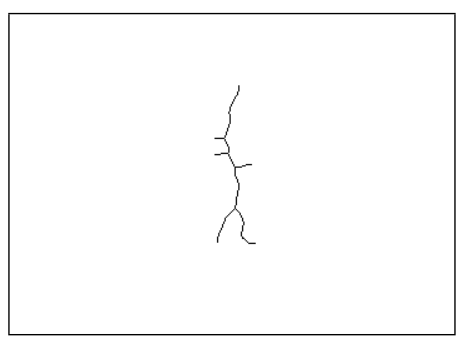

(c) Afinamento de Chin.

Figura 6.5: Frame 148 da sequência thiagopx0 depois da subtração de fundo.

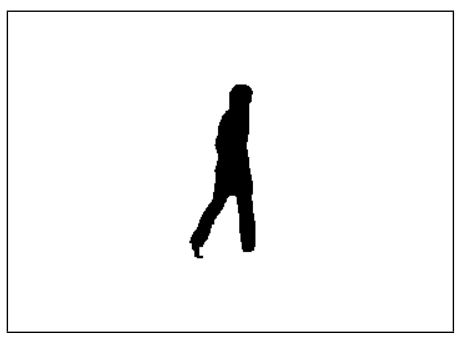

(a) Blob.

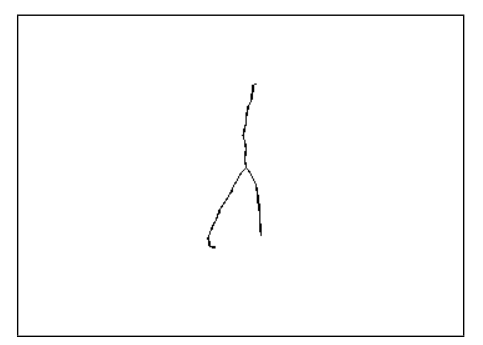

(b) Afinamento de Bernard.

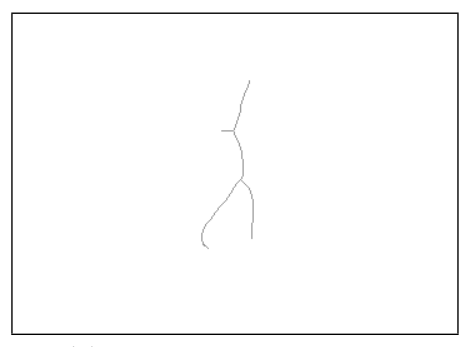

(c) Afinamento de Chin.

Figura 6.6: Frame 132 da sequência thiagopx1 depois da subtração de fundo.

Para gerar o esqueleto a partir do blob, escolhemos o algoritmo de Bernard e Manzanera [9] analisado por Couprie [28] e Bertrand [10] quanto à preservação da topologia. Comparamos esse algoritmo com o de Chin [22], que também preserva a topologia, mas este apresentou resultados visualmente piores. O algoritmo de Chin tem a tendência de deixar no esqueleto grandes linhas, ou "ossos", se formarem a partir de pequenos ruídos no contorno do blob. As Figuras 6.5 e 6.6 mostram dois exemplos típicos de blob. 


\subsection{Localização das extremidades}

Esta etapa do pipeline parte do esqueleto da região definida pelo foreground, gera um sinal unidimensional com a distância geodésica ao baricentro, e desse sinal encontra as extremidades e as rotula como mãos, pés e cabeça. A seguir, especificaremos o processo em detalhes.

A partir da imagem contendo o esqueleto, é gerado um sinal unidimensional no qual o eixo das abscissas representa os pixels da borda do esqueleto, e o eixo das ordenadas mostra a distância geodésica ao baricentro. Desse sinal são escolhidos os picos, que são correspondentes às partes mais salientes do esqueleto, como candidatas a mãos, pés e cabeça. Chamaremos tais partes de extremidades.

Dentre os pontos do esqueleto, aquele mais próximo ao baricentro é escolhido. Chamaremos tal ponto de pixel raiz, apesar de nosso esqueleto poder ter ciclos, como em um grafo. O pixel raiz recebe 1 como valor da distância geodésica para diferenciá-lo do background, que possui valor 0. A partir do pixel raiz é feita uma busca em largura nos pixels da imagem de modo que, a cada passo, um novo pixel é rotulado com a menor distância geodésica dos seus vizinhos já visitados mais 1 . Uma nova imagem é gerada contendo apenas os pixels visitados nesta busca, ou seja, que estão na mesma componente conexa do pixel raiz. É uma imagem em tons de cinza, 16 bits ou mais, pois apenas 8 bits (256 tons de cinza) normalmente não são suficientes para representar as distâncias.

A partir do pixel raiz, varremos uma linha horizontal da imagem para um dos lados, direito ou esquerdo, em busca do pixel mais distante. Esse pixel mais distante, denotado por $p_{0}$, será a origem do nosso sinal unidimensional. O valor do sinal é a distância geodésica ao baricentro, armazenada como o tom de cinza do pixel.

A partir do pixel $p_{0}$, varremos a borda do esqueleto em um sentido, anti-horário ou horário, para construir nosso sinal. Não basta varrer a borda até encontrar $p_{0}$ novamente, 


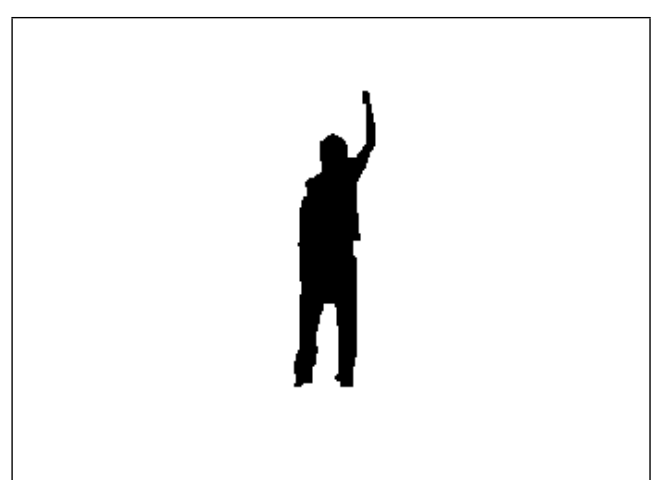

(a) Blob.

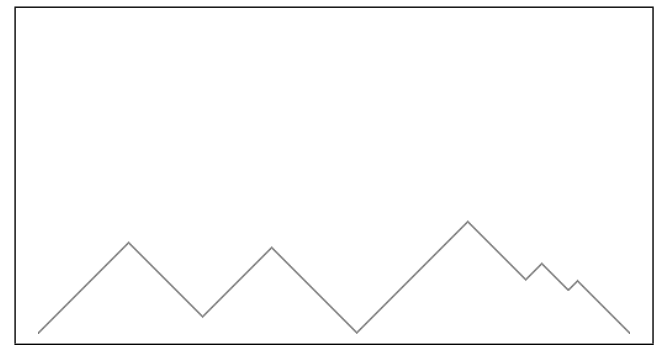

(c) Sinal da distância geodésica.

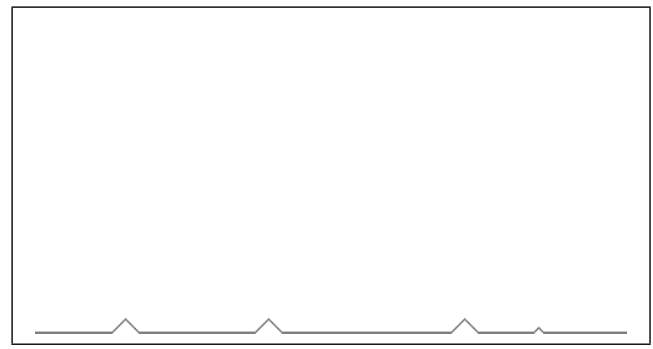

(e) Após tophat por linha de 23 pixels.

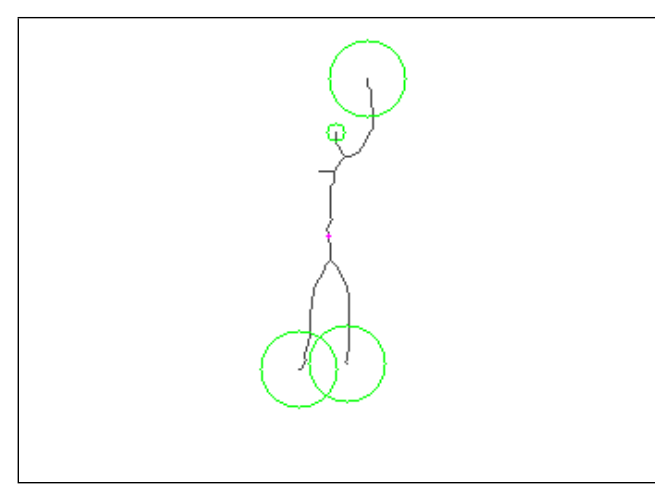

(b) Extremidades destacadas por círculos.

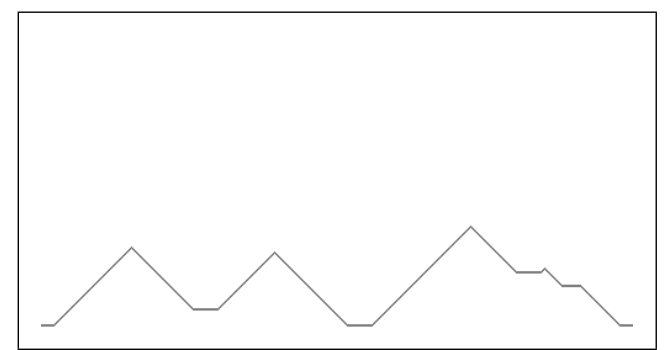

(d) Após fechamento morfológico por linha de 21 pixels.

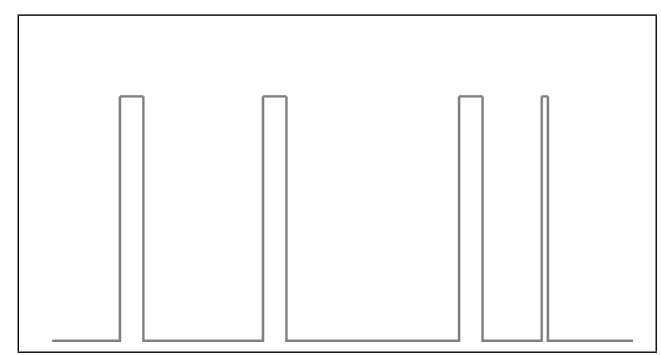

(f) Após thresholding.

Figura 6.7: Localização das extremidades no frame 348 da sequência thiagopx0.

pois se nesse ponto o esqueleto tiver largura de um pixel, esse mesmo pixel será visitado mais de uma vez. No início da varredura, o pixel seguinte a $p_{0}$ é o $p_{1}$. É preciso varrer a borda até encontrar novamente $p_{0}$ seguido de $p_{1}$. 
A Figura 6.7(a) mostra o blob antes do cálculo do esqueleto. A Figura 6.7(b) mostra o esqueleto e destaca a localização das extremidades por círculos. A Figura 6.7(c) mostra o sinal com as distâncias geodésicas a partir do pixel origem. O sinal dá uma volta completa no esqueleto e se pode observar cinco picos nesse sinal. Os dois primeiros correspondem às pernas, o terceiro corresponde ao braço levantado, o quarto à cabeça e o quinto é um ruído que acaba sendo eliminado.

O sinal é filtrado para eliminar picos espúrios, provenientes de pequenas protuberâncias no esqueleto. O filtro é um fechamento morfológico por uma linha, com 21 pixels de largura. Equivale a eliminar ossos 10 pixels ou menos de comprimento. A Figura 6.7(d) mostra o sinal após a filtragem. Para localizar os picos após a filtragem, é usado um operador top hat por um elemento estruturante com dois pixels a mais que o do filtro. $\mathrm{O}$ elemento estruturante do top hat deve ser maior que o do filtro. Se não for, dois picos vizinhos de mesma altura e com distância igual ao tamanho do elemento estruturante serão eliminados. A Figura 6.7(e) mostra o sinal após o top hat.

O passo final é fazer um thresholding, que identifica a localização aproximada de todos os picos. A localização exata é dada pelo pixel com maior distância geodésica contido na região indicada pelo thresholding. A Figura 6.7(e) mostra o resultado do thresholding. A Figura 6.7(b) destaca as extremidades por meio de círculos de tamanho proporcional à largura dos picos dados pelo thresholding.

Cada extremidade é armazenada em um vetor com as três seguintes informações: coordenadas em pixels de cada extremidade, a distância geodésica ao pixel raiz, e uma flag que diz se a extremidade se encontra ou não em um ciclo.

Para saber se a extremidade se encontra ou não em um ciclo, é feito o teste descrito a seguir. Os pixels da borda do esqueleto ficam armazenados em um vetor. Seja $i$ o índice da extremidade em questão. Calcula-se a distância euclidiana entre os pixels em $(i+c)$ e 
$(i-c)$. Se o pixel em $i$ estiver em um ciclo, a distância entre os outros dois pixels tenderá a ser próxima de $2 c$, o que indica que os três pixels estão alinhados. Se não estiver em um ciclo, os pixels em $(i+c)$ e $(i-c)$ devem estar próximos entre si e distância tenderá a ser próxima de zero. Consideramos que o pixel está em um ciclo se tal distância for maior que $c$, que equivale ao caso em que os três pixels formam um triângulo equilátero. $\mathrm{O}$ valor de $c$ não pode ser muito grande de modo que $(i+c)$ e $(i-c)$ estejam fora do ciclo. O valor de $c$ usado foi 3 .

A Figura 6.8 mostra um caso de extremidade encontrada em um ciclo.

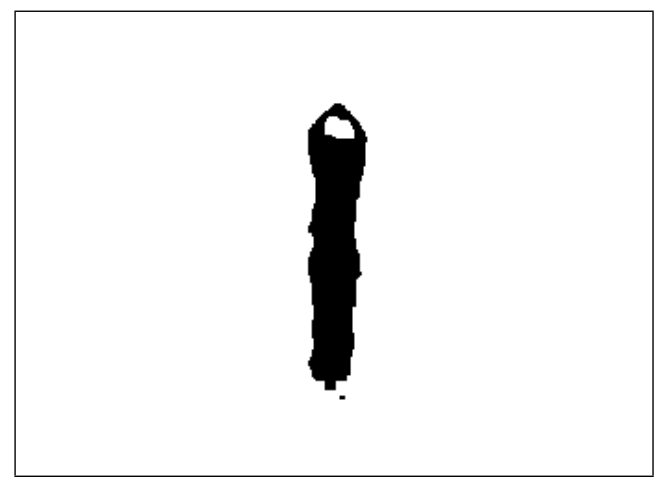

(a) Segmentação do foreground

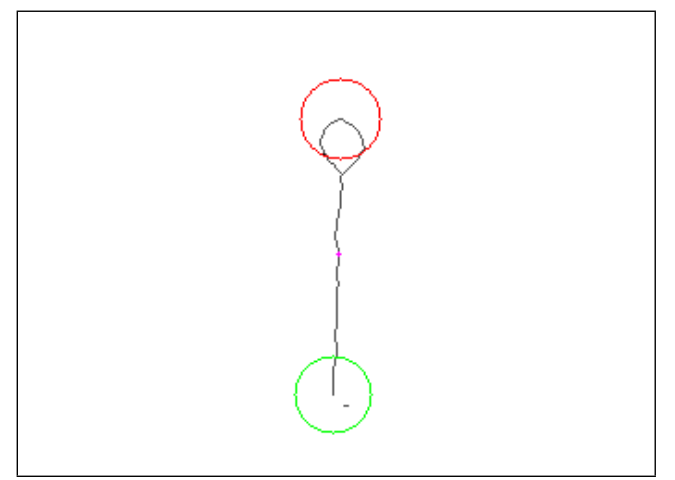

(b) A extremidade superior se encontra em um ciclo.

Figura 6.8: Exemplo de extremidade em um ciclo no frame 730 da sequência thiagopx0.

\subsection{Rotulação das extremidades}

O procedimento de rotulação usa uma heurística baseada na hipótese de que a cabeça deve estar acima dos pés. A rotulação depende das dimensões de um modelo de corpo humano em pixels. Tal medida é obtida manualmente pelo operador do sistema. As dimensões de cada osso dependem da altura do usuário em pixels, e são frações desse valor. O 
tamanho dos ossos é mostrado na Tabela 6.1. Na tabela é mostrado o tamanho dos ossos considerando que o usuário aparece na imagem com altura de 118 pixels.

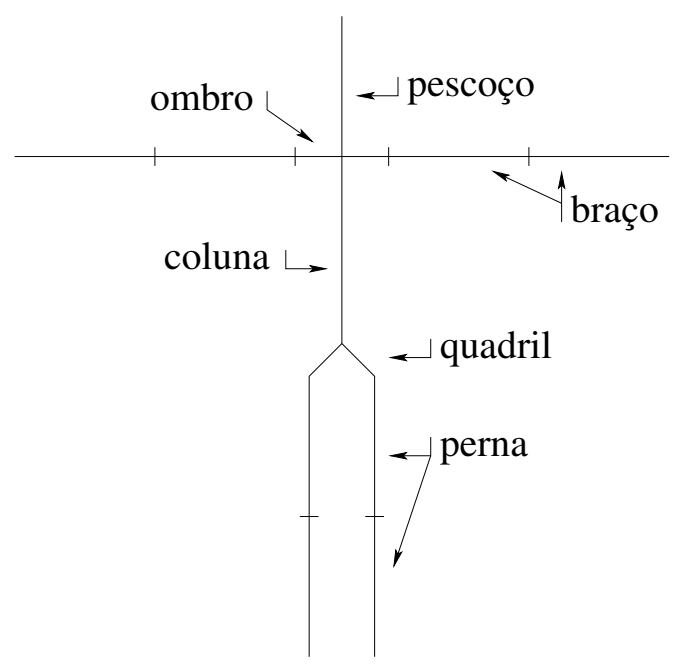

Figura 6.9: Modelo simplificado do corpo humano, com catorze ossos.

Foi considerado um modelo simples, composto por catorze ossos. A Figura 6.9 mostra o modelo do corpo humano usado. Cada uma das cinco extremidades do corpo, cabeça, mão direita e esquerda, e pé direito e esquerdo, equivale a um rótulo, e todos devem ser associados a alguma extremidade do esqueleto.

O esqueleto, porém, raramente possui cinco extremidades, apenas quando o usuário se encontra com os braços e pernas afastados, de frente para a câmera. Mesmo nesse caso, partes da roupa podem formar extremidades espúrias, e podemos obter mais de

\begin{tabular}{r|cc}
\hline \hline Parte do corpo & Razão em relação à altura & Tamanho em pixels \\
\hline Braço, perna e pescoço & $3 / 14$ & 25 \\
Quadril e ombro & $1 / 14$ & 8 \\
Coluna & $4 / 14$ & 34 \\
\hline
\end{tabular}

Tabela 6.1: Tamanho dos ossos considerando uma altura de 118 pixels. 
cinco extremidades. Muitas vezes o esqueleto possui entre duas e quatro extremidades, como quando os braços estão junto ao corpo. As pernas juntas aparecem como uma única extremidade. Devido a esses fatores, há extremidades do esqueleto que podem receber tanto nenhum como mais de um rótulo.

Esta etapa usa, como dado de entrada, a saída devolvida pela etapa anterior, que é o vetor com as informações sobre as extremidades encontradas.

Considere que as coordenadas em pixels $(u, v)$ da imagem têm como origem o pixel superior esquerdo, e que crescem na direção do pixel inferior direito. O ponto mais próximo ao baricentro, denominado pixel raiz, é por convenção o primeiro pixel do vetor.

A cabeça é a extremidade mais alta na imagem, ou seja, com menor valor de $v$ na imagem, cuja distância geodésica ao centro é menor que duas vezes o tamanho da coluna em pixels, e que não está em um ciclo.

O primeiro pé é a extremidade mais baixa na imagem, ou seja, com maior valor de $v$ na imagem. O segundo pé é a segunda extremidade mais baixa na imagem, e deve estar mais abaixo que a coordenada $v$ do baricentro mais duas vezes o tamanho do quadril. Se nenhuma extremidade for encontrada com essas características, a mesma extremidade do primeiro pé é usada.

Os candidatos a mãos são as extremidades ainda não rotuladas, ou seja, que não são cabeça nem pés. A mão direita (esquerda) é a extremidade mais à direita (esquerda) na imagem, ou seja, com maior (menor) valor de $u$ na imagem que não está em um ciclo. Se a mesma extremidade for rotulada como as duas mãos, testamos sua posição em relação ao baricentro; se estiver à esquerda, rotulamos o baricentro como mão direita, e vice-versa.

Neste ponto, ou ambas ou nenhuma das mãos já rotularam extremidades. No segundo caso, buscamos a extremidade mais alta na imagem que esteja em um ciclo para rotular como ambas as mãos. Se não houver tal extremidade, rotulamos o baricentro como ambas 
as mãos, assumindo que o usuário está com as mãos junto ao corpo.

Se nenhuma extremidade tiver sido rotulada como cabeça, rotulamos a extremidade mais alta como tal. Nesse ponto, cada um dos cinco rótulos correspondentes às extremidades do corpo está associado a uma extremidade do esqueleto. A saída deste passo é um vetor de características com as coordenadas $(u, v)$ em pixels das cinco extremidades, as coordenadas do baricentro, e a disparidade em pixels.

Outra dimensão incluída no vetor de características é a distância do usuário à câmera em pixels. A fórmula $z=f b / d$, apresentada na Seção 6.3, nos dá a profundidade em centímetros. Para obter a profundidade em pixels, devemos dividir este valor por $\mu$, um fator de conversão de centímetros para pixels. O cálculo de $\mu$ é mostrado na Tabela 7.2.

\subsection{Classificação da pose}

Esta etapa consiste em associar a cada quadro do vídeo uma pose. Como discutido na seção anterior, de cada quadro extraímos um vetor com treze características, que são as posições $(u, v)$ das cinco extremidades e do baricentro, mais a profundidade do baricentro em pixels.

Antes da classificação, um pré-processamento é necessário. As coordenadas das extremidades do corpo devem ser relativas ao baricentro. A posição horizontal do baricentro não deve influenciar na classificação, apenas sua variação no tempo. A coordenada vertical, correspondente ao eixo $y$, é mantida inalterada, mas as duas coordenadas, correspondentes ao deslocamento no plano $(x, z)$, são modificadas. Recebem a diferença entre o valor do quadro atual, no tempo $t$, e o do quadro correspontende a $t-3$, onde $t$ é o índice do quadro. Observe que esses valores podem ter uma ordem de grandeza bem diferente das demais colunas do vetor. Para que todas as colunas sejam consideradas adequadamente, é 
provável que seja necessário multiplicar tais colunas por algum fator de correção de escala, de modo que todas as colunas tenham a mesma ordem de grandeza.

Gostaríamos que a definição das classes fosse uma operação simples. Optamos por definir as classes através de keyframes. Destes quadros extraímos o vetor de características, que definem pontos no $\mathbb{R}^{13}$. Tais pontos são chamados keypoints. A divisão do espaço é feita pelo diagrama de Voronoi definido por esses pontos. Uma mesma classe pode ser definida por mais de um quadro, bastando atribuir o mesmo nome a mais de um keyframe.

O operador do sistema deve escolher como keyframes quadros tão próximos quanto possível do que ele considera a pose correta. Se na maior parte do tempo o usuário fica em alguma pose próxima à considerada correta, saindo dela apenas nos momentos de transição, espera-se que o método funcione bem. Se a dita pose correta permite muitas variações, é provável que a técnica do keyframe não seja a mais adequada, pois exegiria muitos keyframes para representar alguma pose, e casos não previstos na escolha provavelmente seriam confundidos com poses semelhantes mas incorretas.

A classificação é simples, bastando calcular qual keypoint é o mais próximo ao vetor de características do quadro em questão, e atribuir ao quadro a pose do keypoint mais próximo. Tal abordagem, apesar de simples, mostrou resultados satisfatórios, com a vantagem da simplicidade na definição das classes.

Uma maneira alternativa de se definir os keypoints seria através da média de um conjunto de quadros, consecutivos ou não, escolhidos pelo operador do sistema para representar aquela pose. Outra opção seria, a partir desses quadros, calcular a média e desvio padrão de uma gaussiana para cada pose. O passo de classificação poderia usar uma abordagem bayesiana, escolhendo melhor resposta a correspondente à gaussiana com maior probabilidade no ponto a ser classificado, como se faz nos algoritmos de decodificação dos HMM. 


\subsection{Classificação da pose: métrica entre grafos}

Um método alternativo desenvolvido gera, a partir do esqueleto do usuário, um pequeno grafo em que cada vértice é definido por um feature point do esqueleto. Feature points são as extremidades e bifurcações presentes no esqueleto. Outro feature point é o chamado pixel raiz (ver Seção 6.5) e o vértice definido por ele será a raiz do grafo em questão. Apesar da denominação, o grafo pode não ser uma árvore e conter ciclos. Chamaremos esse grafo de feature graph.

Para cada keyframe, é gerado um feature graph. A classificação de um quadro é feita encontrando o feature graph mais próximo, usando a métrica entre grafos descrita a seguir.

Sejam $G_{1}$ e $G_{2}$ os dois grafos que queremos comparar. Ambos os grafos estão dispostos no plano da imagem. As coordenadas de cada vértice são as mesmas dos feature points que os definiram menos as coordenadas da raiz, ou seja, são transladados de modo que a raiz tenha as coordenadas $(0,0)$.

É calculada a distância euclidiana entre cada um dos vértices de $G^{1}$ e $G^{2}$. Denotamos por $|G|$ o número de vértices de $G$. Temos então uma tabela com $\left|G^{1}\right| \times\left|G^{2}\right|$ distâncias. Dizemos que um vértice $v_{i}^{1}$, pertencente a $G^{1}$, corresponde ao vértice $v_{j}^{2}$, pertencente a $G^{2}$, se $v_{j}^{2}$ é o vértice mais próximo de $v_{i}^{1}$ e vice versa. Chamamos de distância $V$ de $v_{i}^{1}$ a $G^{2}$ a distâncias entre $v_{i}^{1}$ e seu vértice correspondente em $G^{2}$.

As arestas dos grafos definem segmentos de reta no plano. Para todos os demais vértices $v_{k}^{1}$ de $G^{1}$, que não têm correspondentes em $G^{2}$, são calculadas as distâncias a todos os segmentos de reta definidos pelas arestas de $G^{2}$. Chamamos de distância $E$ de $v_{k}^{1}$ a $G^{2}$ a menor distância encontrada desta maneira.

Ao final do processo, teremos o mesmo número de distâncias $V$ quanto pares de vértices correspondentes, e o mesmo número de distâncias $E$ quanto vértices sem correspondentes 
em $G^{1}$ e $G^{2}$. Definimos a métrica entre os grafos como a soma de todas as distâncias $V$ e $E$ encontradas, e a denotamos por $m\left(G^{1}, G^{2}\right)$.

A métrica que foi definida é relaxada, não possuindo todas as propriedades de uma função de distância. Essa métrica tem as propriedades abaixo:

Positivamente definida: $m\left(G^{1}, G^{2}\right) \geq 0$

Simétrica: $m\left(G^{1}, G^{2}\right)=m\left(G^{2}, G^{1}\right)$

Nula para pontos coincidentes: $G^{1}=G^{2} \rightarrow m\left(G^{2}, G^{1}\right)=0$

Não possui duas propriedades necessárias para ser uma distância, citadas a seguir:

Desigualdade triangular: $m\left(G^{1}, G^{2}\right)+m\left(G^{2}, G^{3}\right) \geq m\left(G^{1}, G^{3}\right)$

Nula apenas para pontos coincidentes: $G^{1}=G^{2} \leftrightarrow m\left(G^{2}, G^{1}\right)=0$

\subsection{Classificação dos gestos}

Como foi visto na Seção 3.3, um FSM é uma técnica para modelar sistemas com número finito de entradas e saídas. A entrada do FSM equivale às poses observadas, e a saída equivale à pose considerada correta. Definimos gestos como subsequências de poses de saída da FSM [35]. Uma matriz de transição binária nos indica a possibilidade ou não de uma pose $j$ suceder a uma pose $i$.

De cada quadro extraímos informações, como por exemplo um vetor de características. A partir desse vetor, precisamos descobrir qual é o gesto que o usuário está fazendo. O método de classificação de poses recebe como entrada as características extraídas do frame, e seleciona o rótulo correspondente à pose mais provável. O resultado, ou seja, o rótulo, é 
enviado à FSM, que por sua vez, em função do estado e da entrada atual, define o próximo estado e a pose sendo feito pelo usuário.

No escopo de reconhecimento de gestos, podemos assumir que um ser humano é incapaz de trocar muito rapidamente de pose, ou seja, ao entrar em um novo estado, nele deve permanecer ao menos por alguns instantes. Por isso, a FSM filtra mudanças muito rápidas, impondo uma restrição quanto ao número mínimo de frames necessários para que se considere que foi feita uma nova pose. Da mesma maneira, podemos assumir que existem poses entre as quais uma transição imediata é impossível, por exemplo, de abaixado para saltando sem passar por uma pose intermediária. Tal conhecimento a priori pode ser informado ao sistema pelo operador através da matriz de transição binária.

A FSM começa com a pose de saída correspondente à pose do primeiro quadro classificado. Para classificar o quadro seguinte, ou seja, definir sua pose, o algoritmo considera apenas as poses para as quais a transição é permitidas pela matriz de transição, portanto, poses não permitidas são ignoradas. Além disso, há um filtro temporal, que permite a mudança de pose de saída apenas quando três quadros consecutivos são classificados com o mesmo nome. O nome da pose funciona como uma classe de equivalência para a filtragem temporal, portanto, pode acontecer de quadros consecutivos corresponderem a poses diferentes, mas, por terem o mesmo nome, a transição imediata é permitida.

A classificação dos quadros é feita por um classificador de distância mínima, usando o vetor com as coordenadas das extremidades do corpo como explicado na Seção 6.7 ou pela distância entre grafos como explicado na Seção 6.8. Observe que em nenhum dos dois métodos é especificada a função de distribuição dos dados de saída, portanto não é possível usar técnicas bayesianas de classificação. 


\subsection{Discussão}

A princípio tentamos uma abordagem bastante simples, na qual o estado atual é dado pela classificação do quadro atual. Cada quadro era classificado independentemente dos anteriores, e os gestos eram reconhecidos a partir da sequência de poses. Essa abordagem se mostrou inadequada devido ao ruído. Era comum que quadros isolados fossem classificados incorretamente, levando a uma classificação incorreta dos gestos.

Para diminuir a quantidade de ruído, adicionamos um filtro temporal, que só muda a pose de saída depois que três quadros recebem o mesmo nome. Os melhores resultados foram obtidos quando inserimos a informação de quais transições entre poses são permitidas, através de uma matriz de transição na qual cada posição $(i, j)$, quando não nula, indica que a transição da pose $i$ para $j$ é possível.

A matriz de transição armazena a informação a priori que temos sobre os gestos, ou seja, em que ordem as poses podem aparecer. Se sabemos que uma certa pose " $b$ " só pode aparecer depois da pose " $a$ ", inserimos tal informação na matriz. Isso evita que alguma pose semelhante a " $b$ ", que apareça depois de poses diferentes de " $a$ ", seja classificada como " $b$ " incorretamente. 


\section{Capítulo 7}

\section{Experimento com gestos de goleiro}

Começamos este capítulo descrevendo as motivações para se capturar um dataset experimental e os passos para se realizar a captura. Em seguida, apresentamos uma aplicação do classificador de gestos desenvolvido. A aplicação identifica gestos de goleiro.

\subsection{Captura do dataset experimental}

A montagem do experimento de captura pode demorar horas e, sem um planejamento adequado, diversos atrasos podem ocorrer. Uma das primeiras coisas a se fazer é definir o volume de captura, que depende do ângulo de visão das câmeras, também conhecido como FOV, do inglês field of view. Esta decisão influi na escolha do local de captura. Abaixo apresentamos em detalhes os cálculos realizados. 


\subsubsection{Motivação}

A principal motivação para se capturar um dataset de sequências de imagens experimental é possuir imagens nas condições em que o sistema, quando pronto, deve ser usado. São várias as condições necessárias para se obter imagens úteis, e tais condições, durante a implementação do sistema, podem ser impossíveis de serem atingidas.

O sistema deve capturar movimentos de um usuário em pé e distante vários metros das câmeras. Isso requer uma montagem em um ambiente espaçoso, o que nem sempre é possível. Para se obter um mapa de profundidade abrangente, a distância entre as câmeras, ou baseline, deve ser maior que um metro. A iluminação deve ser adequada e a cena não deve possuir superfícies espelhadas.

Outras motivações são possuir dados sempre iguais para facilitar a depuração, evitar o processo de calibração das câmeras a cada teste, e possuir dados de exemplo para ilustrar o processo, seja com figuras ou com vídeo.

\subsubsection{Hardware usado}

Foram usadas câmeras Firewire, também conhecidas como IEEE 1394, por capturarem simultaneamente pares de imagens e por permitirem o uso de DMA (Direct Memory Access). Com DMA, as imagens das câmeras são enviadas para a memória RAM (Random Access Memory) sem consumir ciclos da CPU (Central Processing Unit).

Tais câmeras são capazes de capturar vídeo VGA $(640 \times 480$ pixels $)$ a 30 quadros por segundo. Temos um par de câmeras, totalizando 60 quadros por segundo. Uma imagem VGA possui 307.200 pixels. Multiplicado por 60 são 18.432 .000 pixels por segundo. Se as imagens forem em tons de cinza, cada pixel ocupa um byte; se forem RGB (24 bits), cada pixel ocupa três bytes, totalizando 55.296 .000 bytes por segundo. 
A largura de banda necessária para gravar o dataset composto por sessenta imagens coloridas por segundo é de 55 Mbytes por segundo. Para conseguir gravar tais imagens com essa velocidade usamos um disco rígido SATA II, com um cache de 32 Mbytes, 7200 RPM. Criamos uma partição que continha os primeiros setores do disco, ou seja, sua área mais externa. Nos discos modernos, tal área possui mais setores por cilindro que na área interna, o que proporciona uma maior largura de banda.

\subsubsection{Definição do volume de captura}

Definimos o volume de captura a partir de características intrínsecas das câmeras, em função do tamanho $b$ do baseline e da menor altura $h$ que o volume deve possuir. Definimos $h$ como $250 \mathrm{~cm}$, que é a altura de um gol de futebol de campo.

As características intrínsecas das câmeras que usamos são descritas na Tabela 7.1.

\begin{tabular}{lll}
\hline Símbolo & Valor & Descrição \\
\hline$f$ & 738 pix & distância focal \\
$V_{\text {fov }}$ & $36^{\circ}$ & ângulo visual vertical (vertical field of view) \\
$H_{\text {fov }}$ & $48^{\circ}$ & ângulo visual horizontal (horizontal field of view) \\
\hline
\end{tabular}

Tabela 7.1: Características intrínsecas da câmera.

Alguns elementos do volume de captura que podemos calcular estão descritos na Tabela 7.2. Os valores de $l$ e $L$ são a menor distância necessária para que um objeto de altura $h$ esteja completamente contido na câmera. O volume de captura útil, portanto, começa a essa distância das câmeras.

A Figura 7.1 mostra o significado de $l$ e $w$ em relação ao volume de captura $\mathcal{V}$. Observe que o ângulo de abertura da câmera é o $H_{\text {fov }}$. Os pontos $\mathbf{C}_{1}$ e $\mathbf{C}_{2}$ representam as câmeras.

A Figura 7.2 mostra o significado de $l, L$ e $h$ em relação ao volume de captura $\mathcal{V}$. Observe que o ângulo de abertura da câmera é o $V_{\text {fov }}$. O ponto $\mathbf{C}$ representa a posição do 
centro ótico das câmeras. Na prática, o centro ótico não estará exatamente no chão.

O valor $L$ aparece apenas para ilustrar o uso da lei dos senos, e não será usado. Pela lei dos senos, $h / \sin \left(V_{\text {fov }}\right)=2 r$, onde $r$ é o raio do círculo onde o triângulo está inscrito.

A profundidade da sala nesta montagem é de $700 \mathrm{~cm}$. O plano perpendicular ao eixo ótico nesta profundidade é o plano de fundo. Cada pixel neste plano é um quadrado de lado $0,84 \mathrm{~cm}$.

\subsection{4 Área de captura}

A área de captura é o triângulo no chão contido no campo visual de ambas as câmeras. Se os planos retinais das câmeras estiverem alinhados, o ponto de disparidade nula está no infinito. A área de captura útil, porém, bem menor, é o trapézio com base maior $k$ e base menor $w$. Na Figura 7.1 apenas $w$ é mostrado.

A relação entre disparidade em pixels, $d$, e profundidade em centímetros, $z$, é dada por $z=f b / d$, onde $f$ é o comprimento focal em pixels, e $b$ é o baseline em centímetros.

\begin{tabular}{|c|c|c|c|}
\hline Símbolo & Valor & Fórmula & Descrição \\
\hline$h$ & $250 \mathrm{~cm}$ & & Altura mínima do volume de captura \\
\hline$b$ & 90 a $150 \mathrm{~cm}$ & $\left|C_{1}-C_{2}\right|$ & Baseline \\
\hline$n$ & 101 a $169 \mathrm{~cm}$ & $\frac{b}{2 \tan \left(H_{\text {fov }} / 2\right)}$ & Ponto teórico mais próximo \\
\hline$l$ & $344,1 \mathrm{~cm}$ & $h \cot \left(V_{\text {fov }}\right)$ & $\begin{array}{l}\text { Distância mínima entre a câmera no } \\
\text { chão e o volume de captura }\end{array}$ \\
\hline$L$ & $384,7 \mathrm{~cm}$ & $\frac{h}{2} \cot \left(V_{\text {fov }} / 2\right)$ & $\begin{array}{l}\text { Distância mínima entre a câmera em } \\
h / 2 \text { e o volume de captura }\end{array}$ \\
\hline$w$ & $342,6 \mathrm{~cm}-b$ & $2 l \tan \left(H_{\text {fov }} / 2\right)-b$ & $\begin{array}{l}\text { Largura do volume de captura na } \\
\text { extremidade de } l\end{array}$ \\
\hline$D$ & $700 \mathrm{~cm}$ & & Profundidade da sala \\
\hline$\mu$ & $0,97 \mathrm{~cm} / \mathrm{pix}$ & $2 D \tan \left(H_{\text {fov }} / 2\right) / 640$ & $\begin{array}{l}\text { Tamanho teórico do pixel em } \\
\text { uma imagem de } 640 \times 480 \text { pixels }\end{array}$ \\
\hline
\end{tabular}

Tabela 7.2: Elementos do volume de captura. 


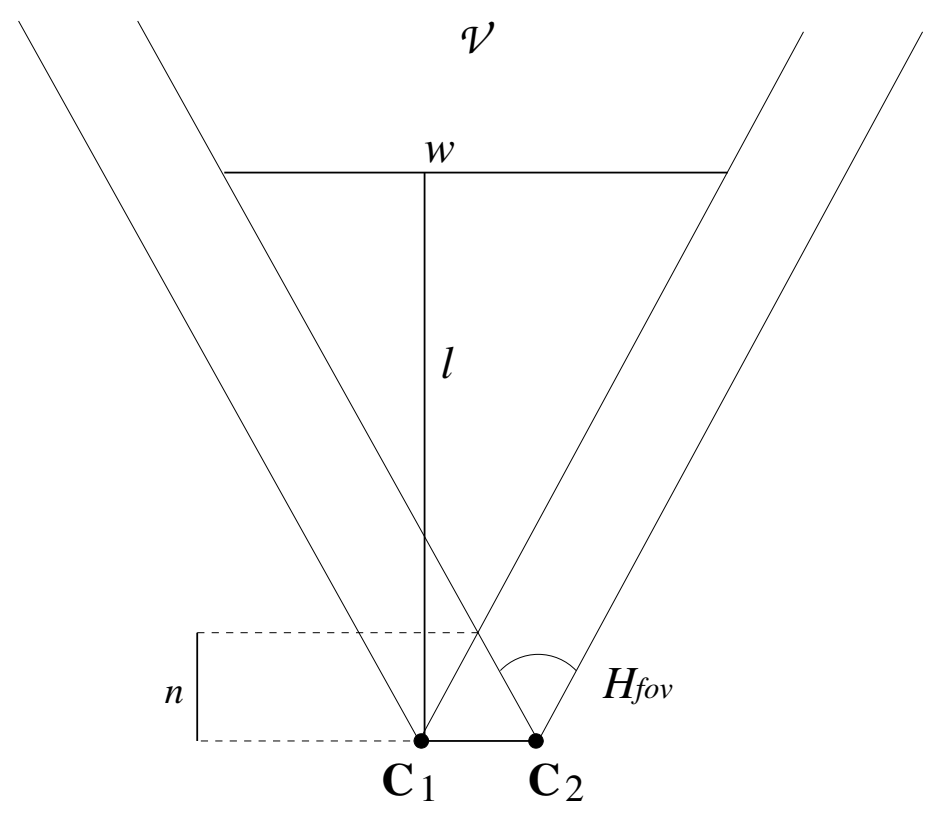

Figura 7.1: Volume de captura visto de cima.

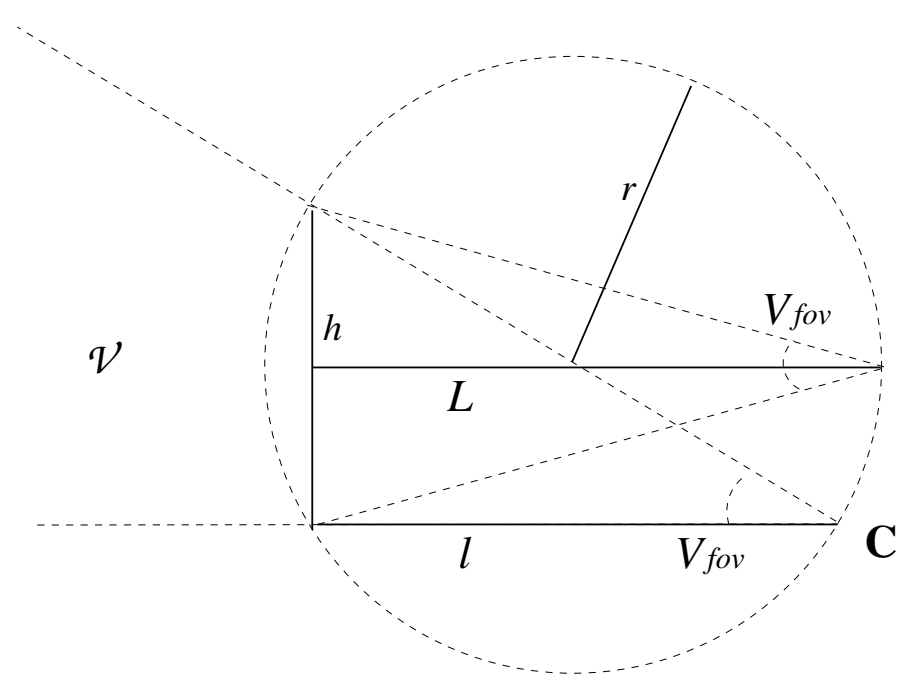

Figura 7.2: Volume de captura visto de lado. 
Com isso podemos fazer uma tabela mostrando a profundidade em função da disparidade e do baseline. A Tabela 7.4 mostra as profundidades em função da disparidade. Como nossa câmera estará no chão, vamos considerar apenas as profundidades maiores que $l$, mostradas em negrito nas colunas $z$. Nas colunas $d z$ estão a variação de profundidade equivalente a uma variação de um pixel de disparidade. Quanto menor esse valor, melhor nossa resolução do espaço. Marcamos em negrito valores de $d z$ menores que $6 \mathrm{~cm}$, um valor arbitrário, que se mostrou suficiente para modelar bem a movimentação do usuário.

O dataset foi capturado em uma sala com sete metros de profundidade. O baseline que usamos foi de $120 \mathrm{~cm}$, nos dando o intervalo de disparidades de 130 a 250 pixels, entre os sete metros da profundidade da sala e os $344 \mathrm{~cm}$, que é o valor de $l$.

\subsection{Classificação estática}

Nesta seção apresentamos uma comparação entre os diversos métodos testados para a classificação estática. Neste estudo, ao contrário da etapa de classificação dinâmica, é usada apenas a informação de um único frame, sendo ignoradas as informações de frames anteriores. Portanto, também não é usada nenhuma informação de direção de movimento ou velocidade.

São consideradas as seguintes oito poses diferentes: aberto, espera, pegada, encaixe, entrada, salto-c, salto-d e salto-e. Cada pose é representada por um keyframe. A Figura 7.3 mostra os keyframes usados no experimento de classificação estática. Foram testados classificadores baseados em momentos de $\mathrm{Hu}$ [67, 92, 91], correlação de fase [84], coeficiente de correlação [115], correlação cruzada, distância de Chamfer entre os esqueletos dos blobs, distância de Chamfer entre as bordas dos blobs [71, 102], distância euclidiana aos vetores de extremidades dos keypoints, e distância entre grafos, sendo estes dois últimos descritos no Capítulo 6. 


\begin{tabular}{|c|c|c|c|c|c|c|c|c|c|c|}
\hline \multirow{2}{*}{$\begin{array}{c}\text { Baseline } \\
\text { Disp. }\end{array}$} & \multicolumn{2}{|r|}{90} & \multicolumn{2}{|r|}{105} & \multicolumn{2}{|r|}{120} & \multicolumn{2}{|r|}{135} & \multicolumn{2}{|r|}{150} \\
\hline & $z$ & $d z$ & $z$ & $d z$ & $z$ & $d z$ & $z$ & $d z$ & $z$ & $d z$ \\
\hline 0 & $\infty$ & & $\infty$ & & $\infty$ & & $\infty$ & & $\infty$ & \\
\hline 1 & 66420,0 & 33210,0 & 77490,0 & 38745,0 & 88560,0 & 44280,0 & 99630,0 & 49815,0 & 110700,0 & 55350,0 \\
\hline 2 & 33210,0 & 1070,0 & 38745,0 & 12915,0 & 44280,0 & 14760,0 & 49815,0 & 16605,0 & 55350,0 & 18450,0 \\
\hline 3 & 22140,0 & 5535,0 & 25830,0 & 6457,5 & 29520,0 & 7380,0 & 33210,0 & 8302,5 & 36900,0 & 9225,0 \\
\hline 4 & 16605,0 & 3321,0 & 19372,5 & 3874,5 & 22140,0 & 4428,0 & 24907,5 & 4981,5 & 27675,0 & 5535,0 \\
\hline 5 & 13284,0 & 2214,0 & 15498,0 & 2583,0 & 17712,0 & 2952,0 & 19926, 0 & 3321,0 & 22140,0 & 3690,0 \\
\hline 10 & 6642,0 & 603,8 & 7749,0 & 704,5 & 8856,0 & 805,1 & 9963,0 & 905,7 & 11070,0 & 1006,4 \\
\hline 20 & 3321,0 & 158,1 & 3874,5 & 184,5 & 4428,0 & 210,9 & 4981,5 & 237,2 & 5535,0 & 263,6 \\
\hline 30 & 2214,0 & 71,4 & 2583,0 & 83,3 & 2952, 0 & 95,2 & 3321,0 & 107,1 & 3690,0 & 119,0 \\
\hline 40 & 1660,5 & 40,5 & 1937,3 & 47,3 & 2214,0 & 54,0 & 2490,8 & 60,8 & 2767,5 & 67,5 \\
\hline 50 & 1328,4 & 26,0 & 1549,8 & 30,4 & 1771,2 & 34,7 & 1992,6 & 39,1 & 2214,0 & 43,4 \\
\hline 60 & 1107,0 & 18,1 & 1291,5 & 21,2 & 1476,0 & 24,2 & 1660,5 & 27,2 & 1845,0 & 30,2 \\
\hline 70 & 948,9 & 13,4 & 1107,0 & 15,6 & 1265,1 & 17,8 & 1423,3 & 20,0 & 1581,4 & 22,3 \\
\hline 80 & 830,3 & 10,3 & 968,6 & 12,0 & 1107,0 & 13,7 & 1245,4 & 15,4 & 1383,8 & 17,1 \\
\hline 90 & 738,0 & 8,1 & 861,0 & 9,5 & 984,0 & 10,8 & 1107,0 & 12,2 & 1230,0 & 13,5 \\
\hline 100 & 664,2 & 6,6 & 774,9 & 7,7 & 885,6 & 8,8 & 996, 3 & 9,9 & 1107,0 & 11,0 \\
\hline 110 & 603,8 & 5,4 & 704,5 & 6,3 & 805,1 & 7,3 & 905,7 & 8,2 & 1006,4 & 9,1 \\
\hline 120 & 553,5 & 4,6 & 645,8 & 5,3 & 738,0 & 6,1 & 830,3 & 6,9 & 922,5 & 7,6 \\
\hline 130 & 510,9 & 3,9 & 596,1 & 4,6 & 681,2 & 5,2 & 766,4 & 5,9 & 851,5 & 6,5 \\
\hline 140 & 474,4 & 3,4 & 553,5 & 3,9 & 632,6 & 4,5 & 711,6 & 5,0 & 790,7 & 5,6 \\
\hline 150 & 442,8 & 2,9 & 516,6 & 3,4 & 590,4 & 3,9 & 664,2 & 4,4 & 738,0 & 4,9 \\
\hline 160 & 415,1 & 2,6 & 484,3 & 3,0 & 553,5 & 3,4 & 622,7 & $\mathbf{3}, \mathbf{9}$ & 691,9 & 4,3 \\
\hline 170 & 390,7 & 2,3 & 455,8 & 2,7 & 520,9 & 3,0 & 586, 1 & 3,4 & 651,2 & 3,8 \\
\hline 180 & 369,0 & 2,0 & 430,5 & 2,4 & 492,0 & 2,7 & 553,5 & $\mathbf{3}, \mathbf{1}$ & 615,0 & 3,4 \\
\hline 190 & 349,6 & 1,8 & 407,8 & 2,1 & 466,1 & 2,4 & 524,4 & 2,7 & 582,6 & 3,1 \\
\hline 200 & 332,1 & 1,7 & 387,5 & $\mathbf{1}, \mathbf{9}$ & 442,8 & 2,2 & 498,2 & 2,5 & 553,5 & 2,8 \\
\hline 210 & 316,3 & 1,5 & 369,0 & $\mathbf{1}, \mathbf{7}$ & 421,7 & 2,0 & 474,4 & 2,2 & 527,1 & 2,5 \\
\hline 220 & 301,9 & 1,4 & 352,2 & 1,6 & 402,5 & 1,8 & 452,9 & 2,0 & 503,2 & 2,3 \\
\hline 230 & 288,8 & $\mathbf{1}, \mathbf{3}$ & 336,9 & $\mathbf{1}, \mathbf{5}$ & 385,0 & $\mathbf{1}, \mathbf{7}$ & 433,2 & $\mathbf{1}, \mathbf{9}$ & 481,3 & 2,1 \\
\hline 240 & 276,8 & $\mathbf{1}, \mathbf{1}$ & 322,9 & $\mathbf{1}, \mathbf{3}$ & 369,0 & $\mathbf{1}, \mathbf{5}$ & 415,1 & $\mathbf{1}, \mathbf{7}$ & 461,3 & $\mathbf{1}, \mathbf{9}$ \\
\hline 250 & 265,7 & 1,1 & 310,0 & 1,2 & 354,2 & $\mathbf{1}, \mathbf{4}$ & 398,5 & 1,6 & 442,8 & 1,8 \\
\hline 260 & 255,5 & 1,0 & 298,0 & 1,1 & 340,6 & $\mathbf{1}, \mathbf{3}$ & 383,2 & 1,5 & 425,8 & 1,6 \\
\hline 270 & 246,0 & 0,9 & 287,0 & 1,1 & 328,0 & 1,2 & 369,0 & 1,4 & 410,0 & $\mathbf{1}, \mathbf{5}$ \\
\hline 280 & 237,2 & 0,8 & 276,8 & 1,0 & 316,3 & $\mathbf{1}, \mathbf{1}$ & 355,8 & 1,3 & 395,4 & 1,4 \\
\hline
\end{tabular}

Tabela 7.4: Profundidade em função da disparidade. 


\begin{tabular}{|l|rrrrrrrr|r|r|}
\hline aberto & $\mathbf{5 3 2}$ & 11 & 0 & 63 & 0 & 0 & 0 & 0 & 606 \\
espera & 6 & $\mathbf{2 2 9 8}$ & 34 & 1814 & 6 & 22 & 74 & 146 & 4400 \\
pegada & 0 & 178 & $\mathbf{2 8}$ & 18 & 0 & 1 & 0 & 0 & 225 \\
encaix & 0 & 21 & 0 & $\mathbf{2 4 3}$ & 13 & 0 & 0 & 0 & 277 \\
entrad & 0 & 1 & 0 & 105 & $\mathbf{2 2 7}$ & 0 & 0 & 0 & 333 \\
salto-c & 0 & 18 & 1 & 1 & 0 & $\mathbf{8}$ & 31 & 10 & 69 \\
salto-r & 0 & 30 & 2 & 0 & 0 & 0 & $\mathbf{1 1}$ & 27 & 70 \\
salto-1 & 0 & 9 & 0 & 9 & 0 & 2 & 39 & $\mathbf{1 2}$ & 71 \\
\hline
\end{tabular}

Tabela 7.5: Matriz de confusão do classificador por Momentos de Hu.

\begin{tabular}{|l|rrrrrrrr|r|r|}
\hline aberto & $\mathbf{4 3 7}$ & 105 & 5 & 13 & 37 & 4 & 1 & 4 & 606 \\
espera & 291 & $\mathbf{2 1 2 4}$ & 351 & 317 & 1089 & 69 & 77 & 82 & 4400 \\
pegada & 30 & 105 & $\mathbf{3 9}$ & 6 & 32 & 9 & 2 & 2 & 225 \\
encaix & 22 & 45 & 14 & $\mathbf{9 2}$ & 89 & 3 & 6 & 6 & 277 \\
entrad & 18 & 32 & 9 & 80 & $\mathbf{1 7 3}$ & 3 & 10 & 8 & 333 \\
salto-c & 4 & 19 & 0 & 3 & 16 & $\mathbf{1 7}$ & 2 & 8 & 69 \\
salto-r & 0 & 9 & 3 & 9 & 25 & 3 & $\mathbf{1 6}$ & 5 & 70 \\
salto-1 & 6 & 8 & 10 & 6 & 7 & 5 & 5 & $\mathbf{2 4}$ & 71 \\
\hline
\end{tabular}

Tabela 7.6: Matriz de confusão do classificador por Correlação de Fase.

\begin{tabular}{|l|rrrrrrrr|r|}
\hline aberto & $\mathbf{5 7 0}$ & 36 & 0 & 0 & 0 & 0 & 0 & 0 & 606 \\
espera & 0 & $\mathbf{3 0 7 5}$ & 959 & 64 & 119 & 8 & 148 & 27 & 4400 \\
pegada & 0 & 152 & $\mathbf{6 3}$ & 0 & 0 & 10 & 0 & 0 & 225 \\
encaix & 0 & 52 & 34 & $\mathbf{1 1 1}$ & 79 & 0 & 1 & 0 & 277 \\
entrad & 0 & 18 & 10 & 58 & $\mathbf{2 4 7}$ & 0 & 0 & 0 & 333 \\
salto-c & 0 & 9 & 0 & 0 & 0 & $\mathbf{3 9}$ & 0 & 21 & 69 \\
salto-r & 0 & 4 & 2 & 0 & 0 & 2 & $\mathbf{6 2}$ & 0 & 70 \\
salto-l & 0 & 5 & 0 & 0 & 0 & 10 & 0 & $\mathbf{5 6}$ & 71 \\
\hline
\end{tabular}

Tabela 7.7: Matriz de confusão do classificador por Coeficiente de Correlação. 


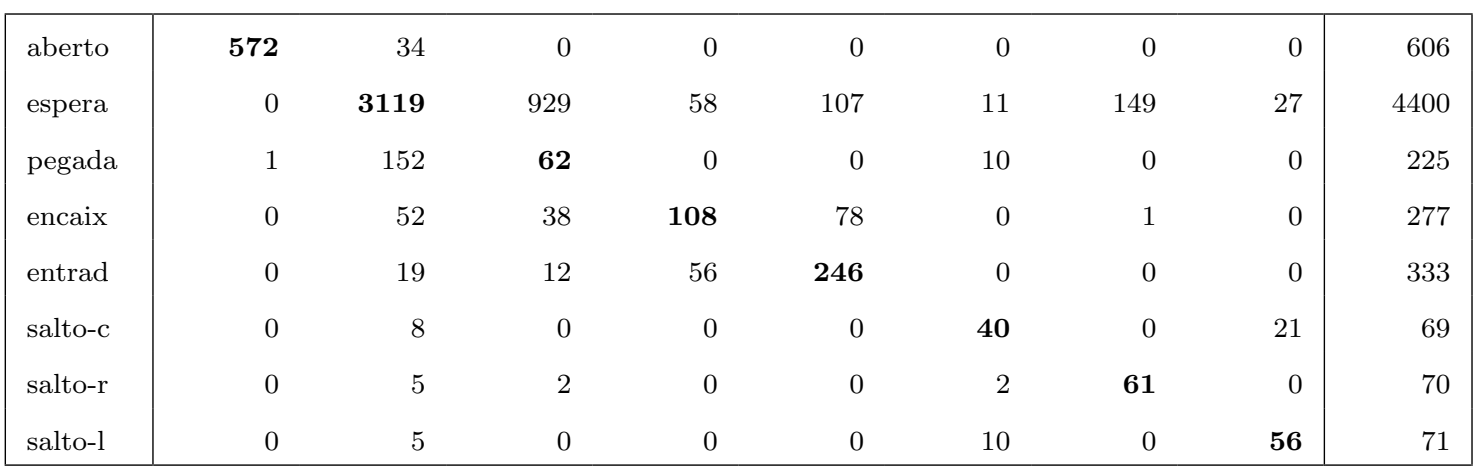

Tabela 7.8: Matriz de confusão do classificador por Correlação Cruzada.

\begin{tabular}{|l|rrrrrrrr|r|}
\hline aberto & $\mathbf{5 9 8}$ & 6 & 0 & 0 & 0 & 1 & 1 & 0 & 606 \\
espera & 2 & $\mathbf{2 6 3 2}$ & 781 & 337 & 23 & 64 & 553 & 8 & 4400 \\
pegada & 0 & 99 & $\mathbf{9 3}$ & 5 & 0 & 10 & 18 & 0 & 225 \\
encaix & 0 & 45 & 64 & $\mathbf{1 2 8}$ & 30 & 0 & 10 & 0 & 277 \\
entrad & 0 & 18 & 51 & 105 & $\mathbf{1 5 8}$ & 0 & 1 & 0 & 333 \\
salto-c & 0 & 20 & 1 & 0 & 0 & $\mathbf{3 4}$ & 2 & 12 & 69 \\
salto-r & 0 & 3 & 0 & 0 & 0 & 3 & $\mathbf{6 4}$ & 0 & 70 \\
salto-l & 1 & 8 & 4 & 0 & 0 & 4 & 1 & $\mathbf{5 3}$ & 71 \\
\hline
\end{tabular}

Tabela 7.9: Matriz de confusão do classificador por Distância de Chamfer entre os esqueletos dos blobs.

\begin{tabular}{|l|rrrrrrrr|r|}
\hline aberto & $\mathbf{5 8 3}$ & 23 & 0 & 0 & 0 & 0 & 0 & 0 & 606 \\
espera & 0 & $\mathbf{2 9 8 6}$ & 1154 & 91 & 2 & 2 & 154 & 11 & 4400 \\
pegada & 0 & 138 & $\mathbf{6 5}$ & 0 & 0 & 22 & 0 & 0 & 225 \\
encaix & 0 & 9 & 36 & $\mathbf{2 0 7}$ & 24 & 0 & 1 & 0 & 277 \\
entrad & 0 & 1 & 9 & 176 & $\mathbf{1 4 7}$ & 0 & 0 & 0 & 333 \\
salto-c & 0 & 7 & 0 & 0 & 0 & $\mathbf{4 2}$ & 1 & 19 & 69 \\
salto-r & 0 & 0 & 0 & 0 & 0 & 0 & $\mathbf{6 7}$ & 3 & 70 \\
salto-l & 0 & 10 & 0 & 0 & 0 & 16 & 0 & $\mathbf{4 5}$ & 71 \\
\hline
\end{tabular}

Tabela 7.10: Matriz de confusão do classificador por Distância de Chamfer entre os contornos dos blobs. 


\begin{tabular}{|l|rrrrrrrr|r|r|}
\hline aberto & $\mathbf{5 8 9}$ & 0 & 17 & 0 & 0 & 0 & 0 & 0 & 606 \\
espera & 1 & $\mathbf{3 5 3 8}$ & 484 & 341 & 2 & 0 & 30 & 4 & 4400 \\
pegada & 0 & 44 & $\mathbf{1 7 8}$ & 0 & 0 & 0 & 3 & 0 & 225 \\
encaix & 0 & 10 & 4 & $\mathbf{2 5 6}$ & 5 & 0 & 2 & 0 & 277 \\
entrad & 0 & 0 & 0 & 171 & $\mathbf{1 6 2}$ & 0 & 0 & 0 & 333 \\
salto-c & 0 & 4 & 22 & 0 & 0 & $\mathbf{1 6}$ & 8 & 19 & 69 \\
salto-r & 0 & 17 & 6 & 0 & 0 & 6 & $\mathbf{4 1}$ & 0 & 70 \\
salto-l & 0 & 13 & 18 & 0 & 0 & 11 & 4 & $\mathbf{2 5}$ & 71 \\
\hline
\end{tabular}

Tabela 7.11: Matriz de confusão do classificador por menor distância ao keypoint (Voronoi).

\begin{tabular}{|l|rrrrrrrr|r|r|}
\hline aberto & $\mathbf{5 9 6}$ & 10 & 0 & 0 & 0 & 0 & 0 & 0 & 606 \\
espera & 1 & $\mathbf{3 7 0 1}$ & 253 & 371 & 6 & 0 & 68 & 0 & 4400 \\
pegada & 0 & 102 & $\mathbf{1 2 3}$ & 0 & 0 & 0 & 0 & 0 & 225 \\
encaix & 0 & 10 & 0 & $\mathbf{2 6 0}$ & 5 & 0 & 2 & 0 & 277 \\
entrad & 0 & 0 & 0 & 160 & $\mathbf{1 7 3}$ & 0 & 0 & 0 & 333 \\
salto-c & 0 & 43 & 0 & 4 & 0 & $\mathbf{1 4}$ & 5 & 3 & 69 \\
salto-r & 0 & 19 & 0 & 0 & 0 & 2 & $\mathbf{4 9}$ & 0 & 70 \\
salto-1 & 0 & 50 & 1 & 0 & 0 & 0 & 0 & $\mathbf{2 0}$ & 71 \\
\hline
\end{tabular}

Tabela 7.12: Matriz de confusão do classificador por menor Distância entre Grafos.

\begin{tabular}{l|rrrr|r}
\hline \hline & felipe0 & felipe1 & rodrigo0 & rodrigo1 & Total \\
\hline Momentos de Hu & $57.33 \%$ & $51.18 \%$ & $54.03 \%$ & $58.81 \%$ & $55.51 \%$ \\
Correlação de fase & $51.26 \%$ & $47.01 \%$ & $47.27 \%$ & $47.67 \%$ & $48.29 \%$ \\
Coef. de correlação & $63.94 \%$ & $66.94 \%$ & $73.48 \%$ & $73.65 \%$ & $69.79 \%$ \\
Correlação cruzada & $64.69 \%$ & $67.78 \%$ & $73.92 \%$ & $74.38 \%$ & $70.47 \%$ \\
Dist. Chamfer esqueleto & $64.62 \%$ & $66.11 \%$ & $59.17 \%$ & $59.66 \%$ & $62.14 \%$ \\
Dist. Chamfer bordas & $63.94 \%$ & $66.64 \%$ & $69.52 \%$ & $72.86 \%$ & $68.45 \%$ \\
Voronoi & $80.23 \%$ & $82.79 \%$ & $76.15 \%$ & $79.16 \%$ & $79.41 \%$ \\
Dist. entre grafos & $81.66 \%$ & $83.78 \%$ & $79.74 \%$ & $81.53 \%$ & $81.57 \%$ \\
\hline
\end{tabular}

Tabela 7.13: Percentuais de acertos nas quatro sequências de vídeos. 


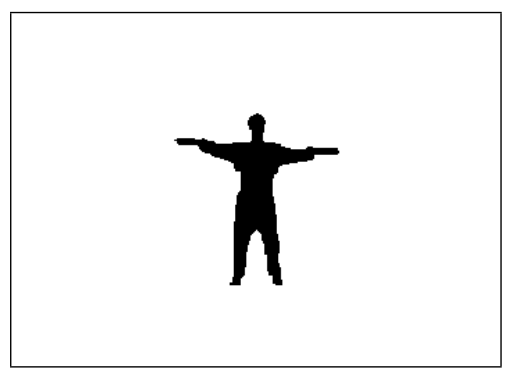

(a) Aberto.

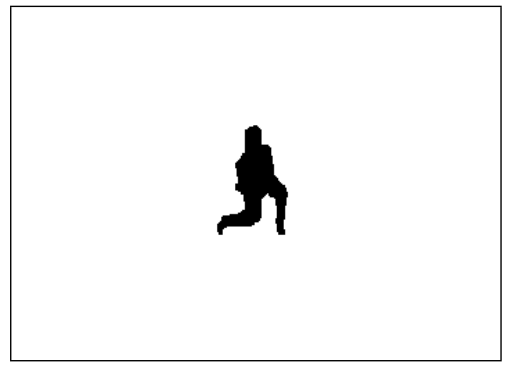

(c) Encaixe.

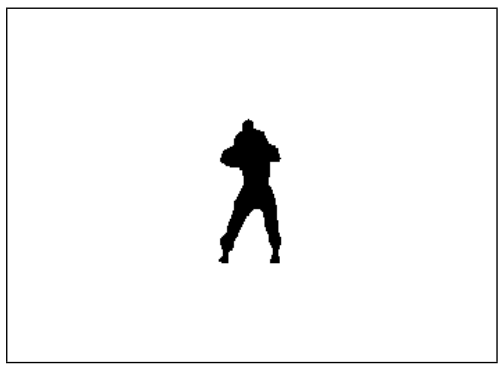

(e) Pegada.

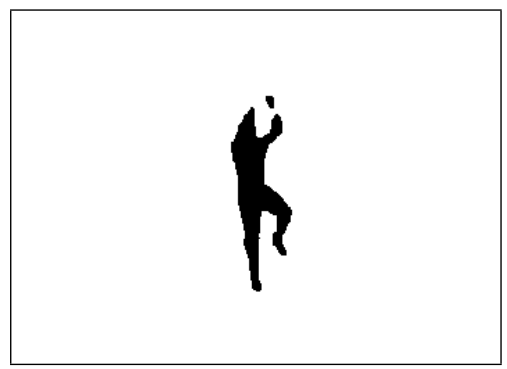

(g) Salto-d.

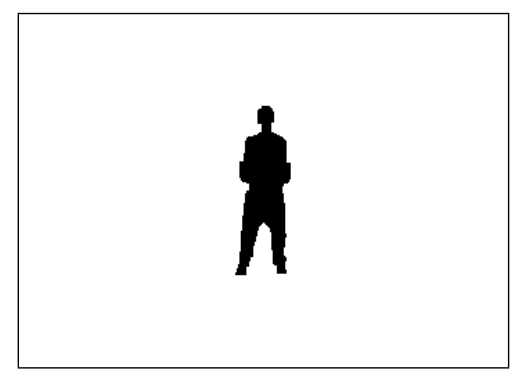

(b) Espera.

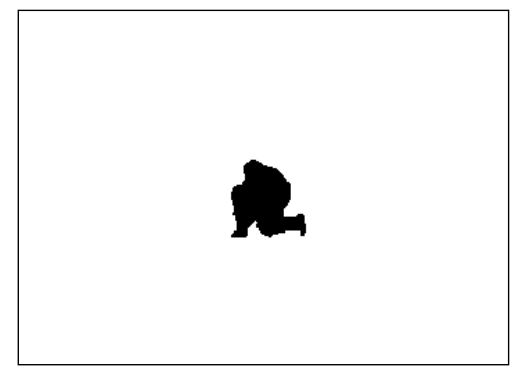

(d) Entrada.

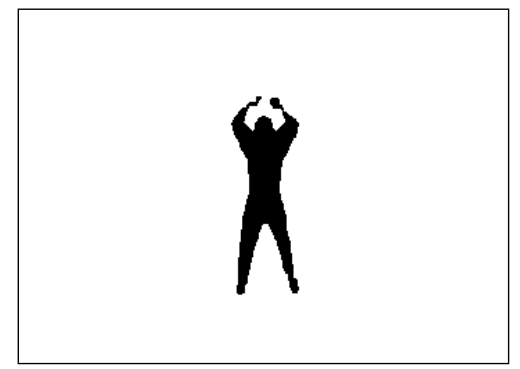

(f) Salto-c.

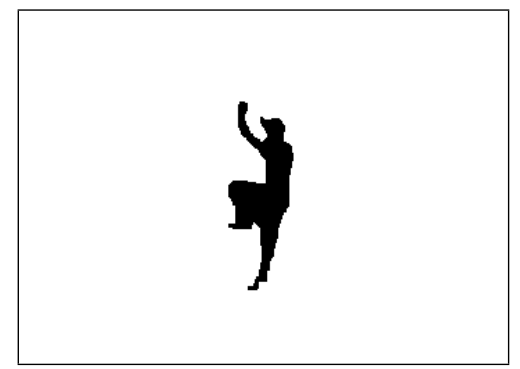

(h) Salto-e.

Figura 7.3: Keyframes, extraídos da sequência felipe-key, usados na classificação estática. 
As Tabelas 7.5 a 7.12 mostram as matrizes de confusão de cada um dos classificadores testados. A diagonal principal indica os acertos e a última coluna indica o total de frames de cada classe. O total de acertos de cada classificador, portanto, é dado pela somatória da diagonal principal. O total de frames, pela somatória da última coluna, igual a 6051 frames para todos os classificadores.

A Tabela 7.13 mostra os percentuais de acertos obtidos por todos os classificadores. Para cada classificador, o total de frames é dado pela soma da última coluna das Tabelas 7.5 a 7.12. O total de acertos por sua vez é dado pela soma da diagonal principal.

Pode-se observar que os melhores resultados foram os obtidos pelos classificadores propostos nesta tese, denominados Voronoi e Distância entre Grafos, iguais a 79,41\% e $81,57 \%$ respectivamente. O terceiro melhor resultado, que ficou relativamente distante do segundo, foi obtido pela Correlação Cruzada, com percentual de acerto de 70,47\%.

\subsection{Conjunto de poses}

No total, são definidas doze poses, que são as seguintes: aberto, espera, espera-d, espera-e, espera-f, espera-t, pegada, encaixe, entrada, salto, salto- $d$ e salto-e. Os nomes de algumas das poses têm um sufixo seguido de uma letra. A letra indica a direção do movimento, " $d$ " para direita, " $e$ " para esquerda, " $f$ ' para frente e " $t$ " para trás. Cada uma dessas poses é representada por um keypoint diferente no $\mathbb{R}^{13}$.

Todas as colunas têm o valor em pixels. As colunas $d x$ e $d z$, porém, foram multiplicadas por 10 para que passassem a ter aproximadamente a mesma ordem de grandeza das demais dimensões do vetor de características. O valor de deslocamento de cinco pixels em três frames foi obtido se observando a saída de tal valor e o vídeo simultaneamente. Quando o usuário estava parado, o valor do deslocamento ficava bem abaixo de cinco, e quando 
começava a se locomover, ultrapassava esse valor com facilidade.

A Figura 7.4 mostra os keyframes usados, e a Tabela 7.14 mostra os vetores de características dos keypoints. Na tabela 7.14, as cinco poses de espera e as três poses de salto têm nomes diferentes. Porém, os melhores resultados foram obtidos quando todas as poses de espera recebem o mesmo nome, idem para as poses de salto. Os resultados mostrados foram obtidos dessa maneira. O nome é usado pelo filtro temporal, que só permite uma mudança de estado depois que três quadros recebem o mesmo nome.

O método de classificação de poses deve conseguir classificar bem quadros cujo vetor de características reflete adequadamente a pose. Temos um problema, porém quando poses

diferentes possuem o mesmo vetor de características. Duas poses que o algoritmo é incapaz de diferenciar são a pose de espera com o corpo levemente abaixado, e a pose do encaixe. No encaixe, os braços estão dobrados e as mãos juntas, próximas ao peito. Na pose de espera, as mãos estão abaixadas, mas, se estiverem junto ao corpo, o algoritmo não as detecta. Formalmente, diz-se que as duas poses diferentes são mapeadas para vetores de características semelhantes.

\subsection{Conjunto de gestos}

Os gestos a serem detectados são cinco, e correspondem às poses citadas na seção anterior sem o sufixo, exceto espera, ou seja: aberto, pegada, encaixe, entrada e salto.

Todos os gestos são compostos por uma sequência de poses espera, seguida por uma sequência de poses com o mesmo nome do próprio gesto. O gesto termina quando o usuário retorna a uma pose espera. Além disso, o gesto aberto pode começar com uma sequência de poses pegada, e o gesto entrada pode começar com uma sequência de poses encaixe. Isso é indicado colocando-se o valor 1 na matriz de transição, nas posições (pegada, aberto) 


\begin{tabular}{c|ccc|cc|cc|cc|cc|cc|c}
\hline \hline Nome & \multicolumn{3}{|c|}{ baricentro } & \multicolumn{2}{|c|}{ cabeça } & \multicolumn{2}{|c|}{ pé esq. } & \multicolumn{2}{|c|}{ pé dir. } & \multicolumn{2}{|c|}{ mão esq. } & \multicolumn{2}{c}{ mão dir. } & \\
da pose & $\mathrm{d} x$ & $y$ & $\mathrm{~d} z$ & $x$ & $y$ & $x$ & $y$ & $x$ & $y$ & $x$ & $y$ & $x$ & $y$ & frame \\
\hline aberto & 0 & 326 & 0 & 0 & -49 & -19 & 68 & 15 & 65 & -59 & -36 & 57 & -28 & 486 \\
espera & 0 & 334 & 0 & 0 & -56 & -20 & 59 & 13 & 57 & 0 & 0 & 0 & 0 & 647 \\
espera-d & 50 & 334 & 0 & 0 & -56 & -20 & 59 & 13 & 57 & 0 & 0 & 0 & 0 & 647 \\
espera-e & -50 & 334 & 0 & 0 & -56 & -20 & 59 & 13 & 57 & 0 & 0 & 0 & 0 & 647 \\
espera-f & 0 & 334 & 50 & 0 & -56 & -20 & 59 & 13 & 57 & 0 & 0 & 0 & 0 & 647 \\
espera-t & 0 & 334 & -50 & 0 & -56 & -20 & 59 & 13 & 57 & 0 & 0 & 0 & 0 & 647 \\
pegada & 0 & 336 & 0 & -5 & -45 & -24 & 53 & 13 & 53 & -20 & -20 & 16 & -20 & 1066 \\
encaixe & 0 & 356 & 0 & -2 & -37 & -26 & 35 & 17 & 34 & 0 & 0 & 0 & 0 & 1228 \\
entrada & 0 & 370 & 0 & -6 & -22 & -22 & 24 & 28 & 23 & 0 & 0 & 0 & 0 & 1642 \\
salto & 0 & 311 & 0 & 0 & -45 & -17 & 75 & 22 & 74 & -3 & -64 & 8 & -61 & 2075 \\
salto-d & 0 & 306 & 0 & 0 & -56 & 3 & 72 & 21 & 47 & 0 & 0 & 18 & -50 & 2003 \\
salto-e & 0 & 321 & 0 & -9 & -50 & -32 & 27 & -18 & 72 & -23 & -59 & 0 & 0 & 1933 \\
\hline
\end{tabular}

Tabela 7.14: Keypoints. As coordenadas das cinco extremidades são relativas ao baricentro. O y do baricentro é sua coordenada na imagem; $\mathrm{d} x$ e dz são a variação de $x$ e $z$ em alguns quadros. Valores extraídos da sequência felipe-key.

e (encaixe, entrada), onde o primeiro valor do par indica a linha, e o segundo, a coluna.

Dessa forma, armazenamos informação a priori que temos do problema na matriz de transição, o que nos ajuda a obter melhores resultados. Outra informação a priori que inserimos na matriz é o fato de que os gestos aberto, pegada, entrada e encaixe são feitos pelo usuário parado. Por isso, não há transições para esses estados a partir dos estados com movimentação horizontal espera-d, espera-e, espera-f e espera-t.

A Tabela 7.15 mostra a matriz com as transições permitidas. A diagonal principal inteira contém o valor 1 pois toda pose pode ser seguida dela mesma. Tanto a linha quanto a coluna espera contêm o valor 1 pois todos os gestos começam e terminam nesta pose. Como já foi explicado, também são permitidas as transições (pegada, aberto) e (encaixe, entrada), Ainda são permitidas as transições de estados de espera em movimento para qualquer um dos três tipos de salto, já que estas poses podem começar com o usuário correndo. Finalmente são permitidas todas as transições entre os três tipos de salto, já 


\begin{tabular}{c|c|ccccc|ccc|ccc}
\hline \hline aberto & 1 & 1 & 0 & 0 & 0 & 0 & 0 & 0 & 0 & 0 & 0 & 0 \\
\hline espera & 1 & 1 & 1 & 1 & 1 & 1 & 1 & 1 & 1 & 1 & 1 & 1 \\
espera-d & 0 & 1 & 1 & 0 & 0 & 0 & 0 & 0 & 0 & 1 & 1 & 1 \\
espera-e & 0 & 1 & 0 & 1 & 0 & 0 & 0 & 0 & 0 & 1 & 1 & 1 \\
espera-f & 0 & 1 & 0 & 0 & 1 & 0 & 0 & 0 & 0 & 1 & 1 & 1 \\
espera-t & 0 & 1 & 0 & 0 & 0 & 1 & 0 & 0 & 0 & 1 & 1 & 1 \\
\hline pegada & 1 & 1 & 0 & 0 & 0 & 0 & 1 & 0 & 0 & 0 & 0 & 0 \\
encaixe & 0 & 1 & 0 & 0 & 0 & 0 & 0 & 1 & 1 & 0 & 0 & 0 \\
entrada & 0 & 1 & 0 & 0 & 0 & 0 & 0 & 0 & 1 & 0 & 0 & 0 \\
\hline salto & 0 & 1 & 0 & 0 & 0 & 0 & 0 & 0 & 0 & 1 & 1 & 1 \\
salto-d & 0 & 1 & 0 & 0 & 0 & 0 & 0 & 0 & 0 & 1 & 1 & 1 \\
salto-e & 0 & 1 & 0 & 0 & 0 & 0 & 0 & 0 & 0 & 1 & 1 & 1 \\
\hline
\end{tabular}

Tabela 7.15: Matriz de transição.

que a diferença entre estas poses está basicamente no fato de uma ou outra perna estar levantada, e estas mudanças são possíveis dentro de um mesmo salto.

\subsection{Cálculo do erro}

Para medir o erro do método, agrupamos poses equivalentes, dentre as doze poses descritas anteriormente, e as rotulamos. Apenas seis nomes são considerados, que são os nomes das poses sem o sufixo: aberto, espera, pegada, encaixe, entrada e salto. Para efeito de cálculo do erro, salto, salto-d e salto-e, por exemplo, são equivalentes.

Para cada uma das quatro sequências analisadas, foi criado um arquivo com o groundtruth. É um arquivo CSV (Comma Separated Values) que contém em cada linha o índice do quadro onde cada pose começa. Em seguida temos um trecho de um arquivo de groundtruth como exemplo. 
Trecho de listagem de arquivo groundtruth

00000 ; espera

00280 ; aberto

00463 ; espera

00802 ; pegada

00825 ; espera

A princípio, teríamos um acerto quando um quadro é classificado como tendo a pose gravada no arquivo de groundtruth, e um erro no caso contrário. Porém o arquivo de groundtruth é definido subjetivamente por um operador humano. Muitas vezes, mesmo para o operador, na transição entre poses é difícil dizer onde exatamente termina uma pose e começa a outra. Zhi [71], para contabilizar o erro de seu classificador, simplesmente desconsidera os frames que nem um humano consegue distinguir. Neste trabalho optamos por, ao contrário de Zhi, manter os frames de transição. Quando classificados corretamente, são considerados como acerto, mas quando errados, são contabilizados separadamente.

Seja $i$ o índice do quadro definido pelo arquivo groundtruth onde começa a pose " $b$ ", então, a pose anterior, digamos " $a$ ", vai até o quadro $i-1$. O trecho de transição vai de $i-9$ a $i+9$.

Assim, se um quadro, cujo groundtruth é " $a$ ", for classificado como "a", temos um match verde. Se um quadro "a" for classificado como " $b$ ", ou vice-versa, dentro do trecho de transição, temos um match amarelo. Os demais casos são erros, ou mismatch vermelho.

Dessa forma, pode-se fazer três tipos diferentes de análise. Uma análise mais rígida pode considerar os matches amarelos como erros; uma análise mais flexível pode considerálos como acertos; e uma terceira alternativa é desconsiderá-los, como propõe Zhi. O grande problema de se fazer a análise rígida é que, em vídeos com muitas regiões de transição, o índice de erro pode crescer muito, quando na verdade o algoritmo está apenas confundindo poses que ocorrem em sequência, confusão esta que não atrapalha o reconhecimento dos 
gestos.

Formalmente, podemos dizer que o erro é dado pela fórmula [106]

$$
E=\frac{1}{T} \sum_{t=1}^{T} L(\omega(t), \hat{\omega}(t))
$$

onde T é o número de quadros, $\omega(t)$ é o estado correto no instante $t$, ou seja, definido pelo groundtruth, $\hat{\omega}(t)$ é o estado identificado pelo algoritmo em $t$, e $L$ é a função de perda. Uma função de perda muito usada é a a chamada simétrica, ou zero-um, definida por

$$
L(a, b)= \begin{cases}0 & a=b \\ 1 & a \neq b\end{cases}
$$

No experimento proposto porém, a nossa função de perda verifica se $a$ possui o mesmo nome que $b$, ou seja, se $a \equiv b$. Usando a função de perda com equivalência no lugar de igualdade, obtemos os percentuais de match verde. Se a função de perda retorna um, temos o mismatch vermelho. Quanto aos matches amarelos, se quisermos fazer uma análise estrita e considerá-los erros, ela retorna um. Caso seja possível uma análise mais flexível e considerá-los acertos, ela deve retornar zero para ambos os estados adjacentes ao instante de transição.

O erro de classificação dos gestos pode ser obtido através do cálculo de distância entre strings. Tal medida pode ser obtida através da distância de Levenshtein [69]. Tal distância nos dá o número de diferenças entre duas strings, e tais diferenças podem ser de três tipos:

Substituição: quando temos um caracter que é diferente nas duas strings, como no segundo caracter de baaa e bbaa.

Inserção: quando um caracter está na segunda mas não está na primeira string, como no 
segundo caracter de baa e bbaa.

Deleção: quando um caracter não está na segunda mas está na primeira string, como no segundo caracter de bbaa e baa.

Se compararmos as diferenças entre as strings de classes de equivalência do groundtruth com as obtidas pelo algoritmo, obteremos como distância exatamente o total de matches amarelos e mismatches vermelhos. Se considerarmos porém que um match amarelo não é uma diferença ou um erro, teremos como distância o total de mismatches vermelhos.

Outra forma de calcular o erro de classificação dos gestos seria comparando as strings resultantes de um pós-processamento. Em primeiro lugar, eliminamos estados repetidos, por exemplo, $\left(\omega_{1}, \omega_{1}, \omega_{1}, \omega_{2}, \omega_{2}\right)$ sem repetições se tornaria $\left(\omega_{1}, \omega_{2}\right)$. Em seguida, detectamos os gestos compostos por mais de um tipo de pose e trocamos pelo nome do gesto, ou seja, subsequências (pegada, aberto) se tornam apenas (aberto), e subsequências (encaixe, entrada) se tornam apenas (entrada). Finalmente, eliminamos todas as ocorrências de (espera), já que todos os gestos começam e terminam por tal pose, assim a string resultante contém apenas os gestos que realmente interessam para a análise do erro. Comparamos a string resultante com a string do groundtruth, e o erro da classificação dos gestos é a distância de Levenshtein obtida.

Na sequência felipe0 temos como groundtruth uma string composta por um gesto aberto, seguido de três pegada, quatro encaixe, quatro entrada, e três salto, ou seja, quinze gestos. A string resultante possui três gestos a mais, ou seja, três inserções. Duas delas são devidas ao fato de que, o usuário, durante sua movimentação no estado de espera, acabou fazendo poses semelhantes a pegada e encaixe. A terceira se deve ao fato de que, após fazer um salto, colocou os braços numa posição semelhante à da pegada. Ver Figura 7.30.

Na sequência felipe1 temos como groundtruth uma string composta por um gesto aberto, seguido de quatro pegada, quatro encaixe, quatro entrada, e três salto, ou seja, dezesseis 
gestos. Nessa sequência, aparencem três pegada a mais após aberto, um encaixe não foi reconhecido e uma entrada foi reconhecida como encaixe, ou seja, cinco diferenças. Ver Figura 7.32 .

Na sequência rodrigo0, o groundtruth é o mesmo de felipe1. Aqui aparecem duas pegada após aberto, e uma pegada após o último salto. Ver Figura 7.34.

Na sequência rodrigo1, o groundtruth é o mesmo de felipe1. Apesar de a sequência obtida ter a distância de Levenshtein ao groundtruth igual a zero, pode-se observar na Figura 7.36 que a primeira pegada reconhecida é durante a espera, e a última pegada não foi reconhecida. Neste caso, a distância de Levenshtein não é uma boa medida. Uma medida mais adequada deveria considerar os instantes em que os gestos foram detectados e compará-los com os instantes dos gestos do groundtruth, encontrando assim uma inserção e uma deleção, ou seja, duas diferenças.

Boa parte dos erros é devida a reconhecer pegada e encaixe quando o usuário está apenas no estado de espera. No caso da pegada, as extremidades formadas pelos cotovelos são rotuladas como mãos. Porém, as mãos do usuário estão próximas à sua cabeça. Durante a espera, quando o usuário está com os cotovelos afastados mas mãos estão na altura do tórax, tal pose pode ser confundida com a pegada. De maneira semelhante, no encaixe, os braços estão juntos ao corpo mas as mãos estão próximas à cabeça. Durante a espera, quando o usuário está com os braços juntos ao corpo, mas com o tronco inclinado para a frente, tal pose pode ser confundida com o encaixe.

Outro erro encontrado foi reconhecer uma entrada como encaixe, devido ao fato de os dois gestos serem bastante semelhantes, diferindo apenas pela altura da cabeça e do baricentro do usário. Na verdade, na entrada, as mãos do usuário chegam próximas ao chão, enquanto que na encaixe, ficam próximas à cabeça. Devido a esses fatores, acreditamos que melhores resultados poderiam ser obtidos se pudéssemos localizar exatamente a 
posição das mãos. Para uso em interfaces de jogo, porém, é provável que tais erros sejam toleráveis, já que ocorrem em uma fração pequena do tempo, menor que três por cento, (na sequência rodrigo0, Tabela 7.17), considerando as sequências com filtro, e a confusão é apenas entre gestos muito semelhantes.

Testes de usabilidade devem ser feitos para se descobrir o quanto esses erros atrapalham a experiência do usuário e se o custo de se localizar as mãos compensa ou não.

\begin{tabular}{|c|c|c|c|c|c|c|c|c|}
\hline & \multicolumn{4}{|l|}{ felipe0 } & \multicolumn{4}{|l|}{ felipe1 } \\
\hline & \multicolumn{2}{|l|}{$\mathrm{s} /$ filtro } & \multicolumn{2}{|l|}{ c/ filtro } & \multicolumn{2}{|l|}{ s/ filtro } & \multicolumn{2}{|l|}{ c/ filtro } \\
\hline & quadros & $\%$ & quadros & $\%$ & quadros & $\%$ & quadros & $\%$ \\
\hline match verde & 1330 & $90.7 \%$ & 1289 & $87.9 \%$ & 1183 & $89.8 \%$ & 1132 & $85.8 \%$ \\
\hline match amarelo & 93 & $6.3 \%$ & 152 & $10.4 \%$ & 99 & $7.4 \%$ & 159 & $12.1 \%$ \\
\hline match subtotal & 1423 & $97.0 \%$ & 1441 & $98.2 \%$ & 1281 & $97.2 \%$ & 1291 & $97.9 \%$ \\
\hline mismatch & 44 & $3.0 \%$ & 26 & $1.8 \%$ & 37 & $2.8 \%$ & 28 & $2.1 \%$ \\
\hline total & 1467 & $100.0 \%$ & 1467 & $100.0 \%$ & 1319 & $100.0 \%$ & 1319 & $100.0 \%$ \\
\hline
\end{tabular}

Tabela 7.16: Resultado obtido com as sequências felipe0 e felipe1

\begin{tabular}{|c|c|c|c|c|c|c|c|c|}
\hline & \multicolumn{4}{|l|}{ rodrigo0 } & \multicolumn{4}{|l|}{ rodrigo1 } \\
\hline & \multicolumn{2}{|l|}{ s/ filtro } & \multicolumn{2}{|l|}{ c/ filtro } & \multicolumn{2}{|l|}{ s/ filtro } & \multicolumn{2}{|l|}{ c/ filtro } \\
\hline & quadros & $\%$ & quadros & $\%$ & quadros & $\%$ & quadros & $\%$ \\
\hline match verde & 1459 & $90.4 \%$ & 1426 & $88.4 \%$ & 1494 & $90.5 \%$ & 1491 & $90.3 \%$ \\
\hline match amarelo & 101 & $6.3 \%$ & 140 & $8.7 \%$ & 118 & $7.1 \%$ & 132 & $8.0 \%$ \\
\hline match subtotal & 1560 & $96.7 \%$ & 1566 & $97.0 \%$ & 1612 & $97.6 \%$ & 1623 & $98.3 \%$ \\
\hline mismatch & 54 & $3.3 \%$ & 48 & $3.0 \%$ & 39 & $2.4 \%$ & 28 & $1.7 \%$ \\
\hline total & 1614 & $100.0 \%$ & 1614 & $100.0 \%$ & 1651 & $100.0 \%$ & 1651 & $100.0 \%$ \\
\hline
\end{tabular}

Tabela 7.17: Resultado obtido com as sequências rodrigo0 e rodrigo1 
A Tabela 7.16 mostra os resultados obtidos nas sequências felipe0 e felipe1. São sequências com o mesmo usuário dos keyframes, onde obtivemos erros de 1,8\% e 2,1\%.

A Tabela 7.17 mostra os resultados obtidos nas sequências rodrigo0 e rodrigo1. Nesse caso, o usuário da sequência e o dos keyframes são diferentes, mesmo assim o percentual de erros foi baixo, ficando em $3,0 \%$ e 1,7\%. O erro total nas quatro sequências, considerandose os testes com filtro temporal, foi de $2,1 \%$.

As Figuras 7.5 a 7.28 mostram exemplos de sequências de gestos. Para cada quadro mostrado há uma imagem menor, que mostra em cinza a região do foreground, e em preto o esqueleto. Os círculos indicam as extremidades detectadas em cada esqueleto.

As Figuras 7.29 a 7.36 mostram os gráficos das distâncias de cada frame aos keyframes. Abaixo de cada gráfico há três barras coloridas. A barra superior indica qual a classe atribuída pelo sistema a cada frame. A barra inferior indica a classe definida pelo operador do sistema como groundtruth. A barra entre as outras duas indica o tipo de match. Se a classificação for igual ao groundtruth, temos um match verde, se for igual à classe seguinte ou anterior no intervalo te transição, temos um match amarelo, e se for diferente, temos um mismatch vermelho.

As Figuras 7.29, 7.31, 7.33 e 7.35 mostram as distâncias obtidas sem as restrições dadas pela matriz de transição.

As Figuras 7.30, 7.32, 7.34 e 7.36 mostram as distâncias obtidas usando a matriz de transição. Foram os melhores resultados obtidos, que são mostrados nas tabelas 7.16 e 7.17 . 


\subsection{Erro usando a métrica entre grafos}

Foram feitos testes com a técnica de classificação de poses usando distância entre grafos. Os resultados foram semelhantes, mas o erro ficou um pouco maior. Primeiro foi feito um teste com apenas os oito estados que não envolvem deslocamento, ou seja, os mesmo doze estados do teste anterior menos espera-d, espera-e, espera-f e espera-t.

\begin{tabular}{|l|r|r|r|r|r|r|r|r|}
\cline { 2 - 10 } \multicolumn{1}{c|}{} & \multicolumn{9}{l}{ felipe0 } & \multicolumn{2}{l|}{ felipe1 } \\
\cline { 2 - 10 } & \multicolumn{2}{l|}{ s/ filtro / filtro } & \multicolumn{2}{l|}{ s/ filtro } & \multicolumn{2}{l|}{ c/ filtro } \\
\cline { 2 - 10 } & quadros & $\%$ & quadros & $\%$ & quadros & $\%$ & quadros & $\%$ \\
\hline match verde & 1299 & $88.5 \%$ & 1269 & $86.5 \%$ & 1169 & $88.6 \%$ & 1139 & $86.4 \%$ \\
match amarelo & 114 & $7.8 \%$ & 160 & $10.9 \%$ & 118 & $8.9 \%$ & 161 & $12.2 \%$ \\
match subtotal & 1413 & $96.3 \%$ & 1429 & $97.4 \%$ & 1287 & $97.6 \%$ & 1300 & $98.6 \%$ \\
\hline mismatch & 54 & $3.7 \%$ & 38 & $2.6 \%$ & 32 & $2.4 \%$ & 19 & $1.4 \%$ \\
total & 1467 & $100.0 \%$ & 1467 & $100.0 \%$ & 1319 & $100.0 \%$ & 1319 & $100.0 \%$ \\
\hline
\end{tabular}

Tabela 7.18: Resultado da métrica entre grafos nas sequências felipe0 e felipe1

\begin{tabular}{|c|c|c|c|c|c|c|c|c|}
\hline & \multicolumn{4}{|l|}{ rodrigo0 } & \multicolumn{4}{|l|}{ rodrigo1 } \\
\hline & \multicolumn{2}{|l|}{$\mathrm{s} /$ filtro } & \multicolumn{2}{|l|}{ c/ filtro } & \multicolumn{2}{|l|}{$\mathrm{s} /$ filtro } & \multicolumn{2}{|l|}{ c/ filtro } \\
\hline & quadros & $\%$ & quadros & $\%$ & quadros & $\%$ & quadros & $\%$ \\
\hline match verde & 1393 & $86.3 \%$ & 1341 & $83.0 \%$ & 1476 & $89.4 \%$ & 1471 & $89.0 \%$ \\
\hline match amarelo & 134 & $8.3 \%$ & 181 & $11.2 \%$ & 131 & $7.9 \%$ & 146 & $8.8 \%$ \\
\hline match subtotal & 1527 & $94.6 \%$ & 1522 & $94.3 \%$ & 1607 & $97.3 \%$ & 1617 & $97.9 \%$ \\
\hline mismatch & 87 & $5.4 \%$ & 92 & $5.7 \%$ & 44 & $2.7 \%$ & 34 & $2.1 \%$ \\
\hline total & 1614 & $100.0 \%$ & 1614 & $100.0 \%$ & 1651 & $100.0 \%$ & 1651 & $100.0 \%$ \\
\hline
\end{tabular}

Tabela 7.19: Resultado da métrica entre grafos nas sequências rodrigo0 e rodrigo1 
Os melhores resultados, porém, foram obtidos com os mesmos doze estados do teste anterior. Para inserir a informação de deslocamento, usamos os mesmos valores de $d x$ e $d z$ do teste anterior, ou seja, cinco pixels de deslocamento em três quadros. Tal valor foi multiplicado por dez para que tivesse a mesma ordem de grandeza das distâncias entre grafos. Dessa maneira, o keypoint ficou com apenas duas colunas, $d x$ e $d z$, com exatamente os mesmos valores que no teste anterior.

A distância total entre o quadro atual e o keyframe foi calculada somando-se a distância entre grafos, como definida na Seção 6.5, com a distância aos keypoints com o deslocamento. A Tabela 7.18 mostra os resultados obtidos nas sequências felipe0 e felipe1, e a Tabela 7.19 mostra os resultados obtidos nas sequências rodrigo0 e rodrigo1. O erro total nas quatro sequências, considerando-se os testes com filtro temporal, foi de 3,0\%.

\subsection{Tempo de processamento}

O tempo médio de processamento dos quadros com foreground não vazio foi de $47,0 \mathrm{~ms}$ (milissegundos), com 1,0 ms de desvio padrão. Para processar vinte quadros por segundo são necessários 50 ms por quadro, portanto, podemos dizer que o sistema é capaz de rodar a vinte quadros por segundo. Os testes foram feitos em um Athlon X2 com 2 Gbytes de RAM e em uma GPU GeForce 8800 GTS.

\begin{tabular}{c|c|c}
\hline \hline Etapa & Tempo médio & Desvio-padrão \\
\hline Subtração de fundo & 9,7 & 0,4 \\
Correção de altura & 11,9 & 0,4 \\
Cálculo do esqueleto & 30,7 & 0,6 \\
Localização das extremidades & 39,7 & 0,9 \\
Classificação & 47,0 & 1,0 \\
\hline
\end{tabular}

Tabela 7.20: Tempos médios de processamento em milissegundos.

Os tempos médios do início do processamento até o término das etapas do pipeline são 
mostrados na Tabela 7.20. O tempo da etapa de classificação inclui tarefas como liberação de memória usada para armazenar imagens.

As etapas iniciais do pipeline são quase totalmente processadas pela GPU, desde as transformações realizadas no pré-processamento, subtração do background, cálculo do baricentro, correção de altura, até o cálculo do esqueleto são realizadas na GPU. As etapas finais, de localização, rotulação das extremidades, classificação de poses e gestos são processadas pela CPU.

\subsection{Discussão}

Durante o desenvolvimento da solução proposta, descrita no Capítulo 6 foram testados diversos algoritmos. Um dos primeiros algoritmos testados envolveu a classificação das poses com momentos de $\mathrm{Hu}[67,92,91]$. Os resultados porém mostraram muita confusão entre as poses espera, pegada e encaixe. Foram tentados métodos de template matching, como coeficiente de correlação, correlação cruzada, diferença quadrática e correlação de fase, mas tampouco foram bem sucedidos.

Em seguida foi desenvolvido o método para extrair as extremidades do esqueleto e rotulá-las. O método é semelhante ao de Correa [27], com algumas adaptações. Ao invés de gerar um esqueleto morfológico, que costuma ser bastante ruidoso, usamos o método de Bernard [9], que também tem a vantagem de preservar a topologia. Foram testados também diversos esqueletos condicionais por afinamento [7]. Aplicar o operador top hat na transformada da distância do blob também dá como resultado um esqueleto, mas tais esqueletos não preservam a topologia.

Os resultados foram melhores, que os anteriores mas ainda longe do resultado final. Os resultados melhoraram significativamente quando foi introduzida a restrição de transição 
entre estados. Houve melhora ainda quando foi implementado o filtro temporal, que exige que um novo estado seja reconhecido algumas vezes antes de se mudar para ele, de maneira semelhante à usada por Davis [32]

Finalmente foi introduzida a informação de movimentação. Sabendo que as poses aberto, pegada, encaixe e entrada são sempre feitas com o usuário parado, foram adicionados quatro estados em que há deslocamento do usuário, que são espera-d, espera-e, espera-f e espera-t. A transição direta destes estados para os quatro estados citados não é permitida pela matriz de transição. Primeiro o usuário deve entrar no estado espera, onde o usuário está parado.

O primeiro classificador, por menor distância ao keypoint com filtro temporal e restrições de transição, na análise mais flexível deu um erro bem pequeno, de 2,1\% do total de frames. Como explicado na Seção 7.5 a análise flexível considera acerto classificar um frame da região de transição como sendo da pose adjacente no vídeo. Na análise rígida, o erro aumenta para $11.8 \%$, porém a maior parte desse erro é devido às transições, e não atrapalha a classificação dos gestos. O segundo classificador, por menor distância entre grafos, com filtro temporal e restrições de transição, na análise flexível deu um erro de 3,0\% do total de frames. Na análise rígida, o erro aumenta para 13,7\%.

$\mathrm{Na}$ análise do erro, é interessante levar em conta não somente o número de frames classificados incorretamente, mas também o número de transições do vídeo. Quanto maior o número de transições, maior o número de frames difíceis de classificar, e mais difícil obter um erro próximo de zero. Nos quatro vídeos analisados, existem 6051 frames e 126 transições. Os quadros de transição ficam na fronteira entre poses e são difíceis de classificar mesmo por pessoas. O número de frames exatamente nas transições, 126, representa $2,1 \%$ do total de frames. Se considerarmos que o tempo de transição dura 9 frames, o que a 30 fps equivale a $0,3 \mathrm{~s}$, podemos dizer que temos 1134 frames difíceis de classificar, o que equivale a $18,7 \%$ do total. 


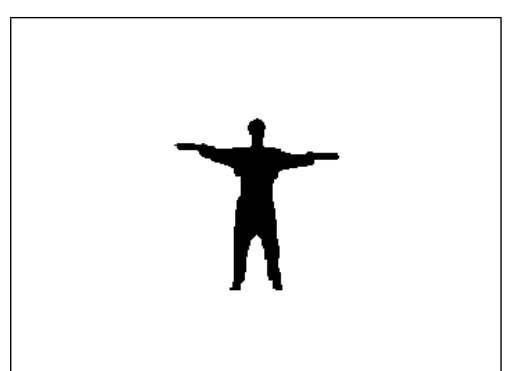

(a) Aberto.

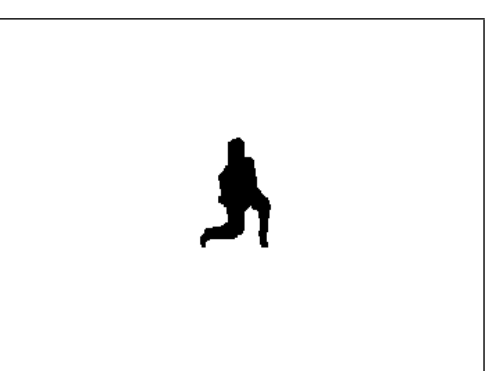

(c) Encaixe.

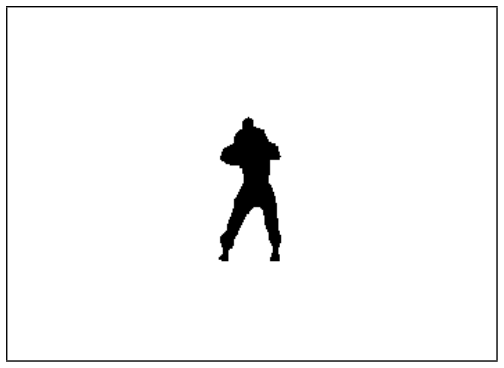

(e) Pegada.

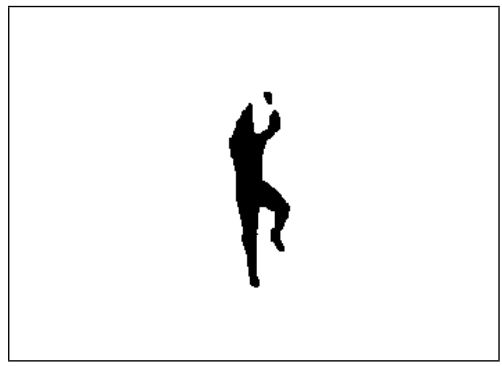

(g) Salto-d.

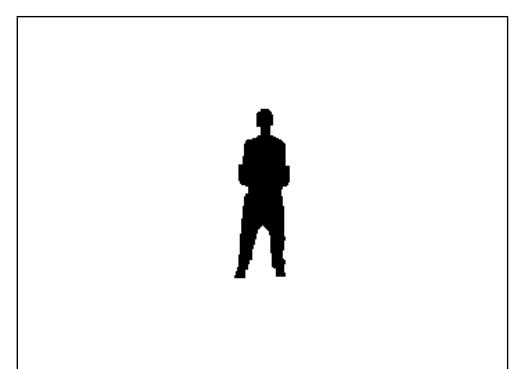

(b) Espera. O mesmo keyframe é usado nos cinco estados de espera, a diferença está no deslocamento horizontal.

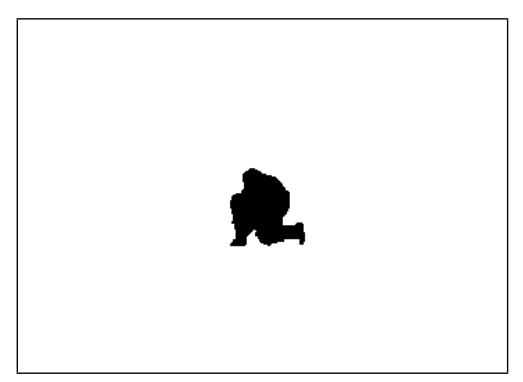

(d) Entrada.

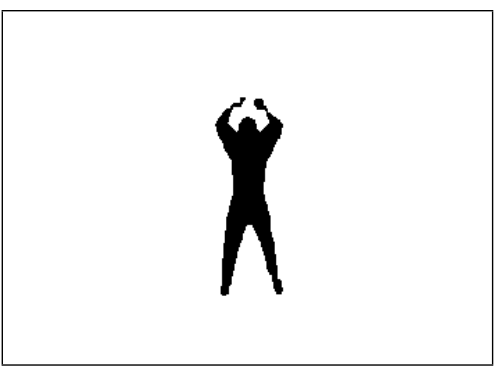

(f) Salto

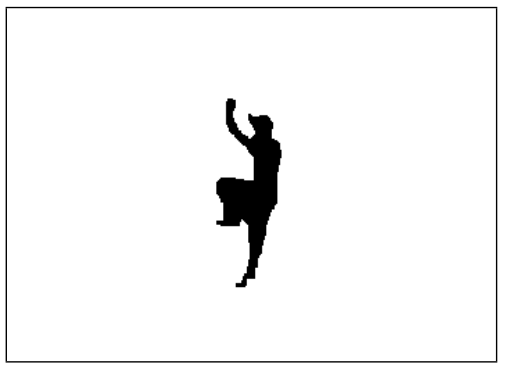

(h) Salto-e.

Figura 7.4: Keyframes extraídos da sequência felipe-key. 


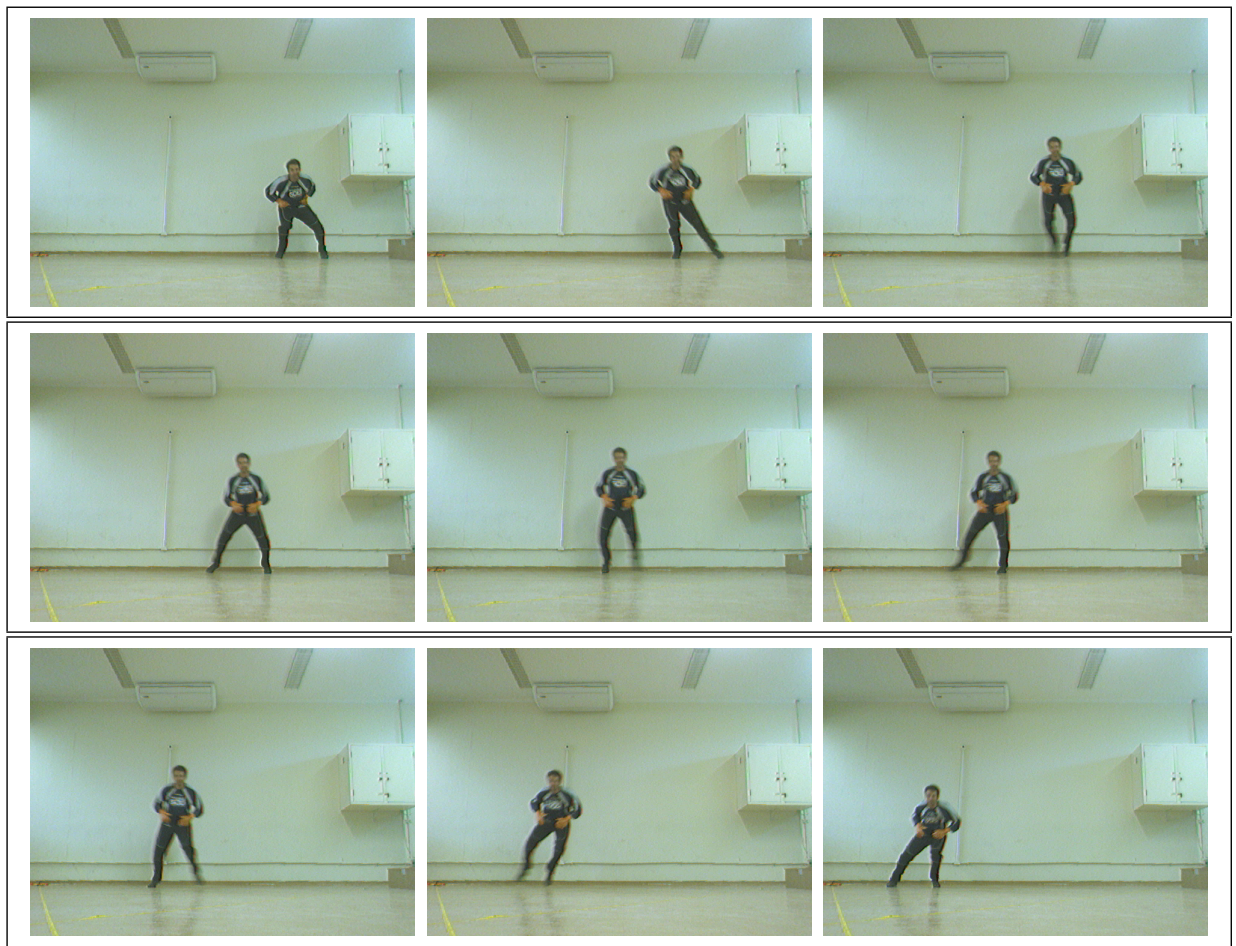

Figura 7.5: Espera na sequência felipe0, a partir do frame 570 a cada 5 frames.

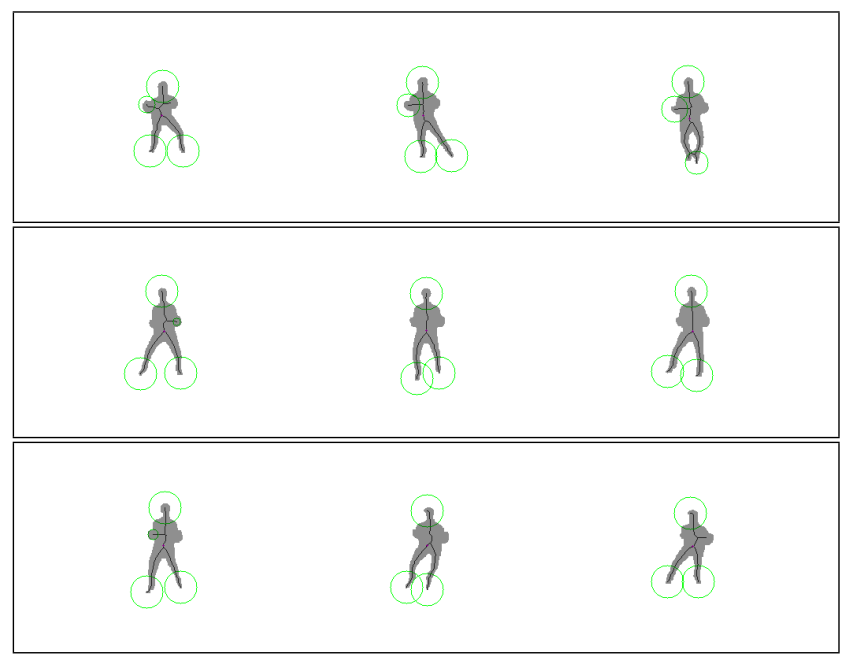

Figura 7.6: Esqueletos da Figura 7.5. 


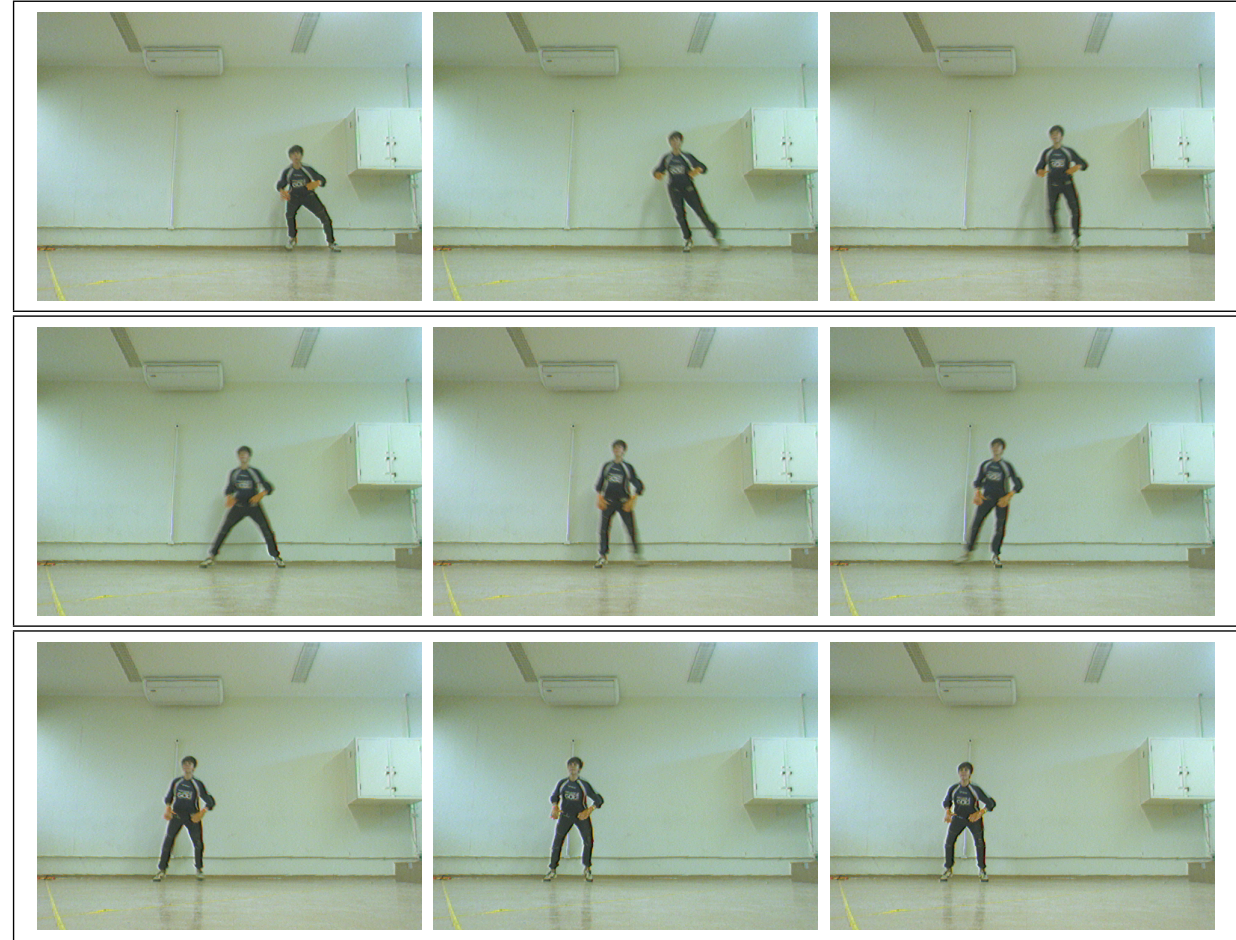

Figura 7.7: Espera na sequência rodrigo0, a partir do frame 580 a cada 5 frames.

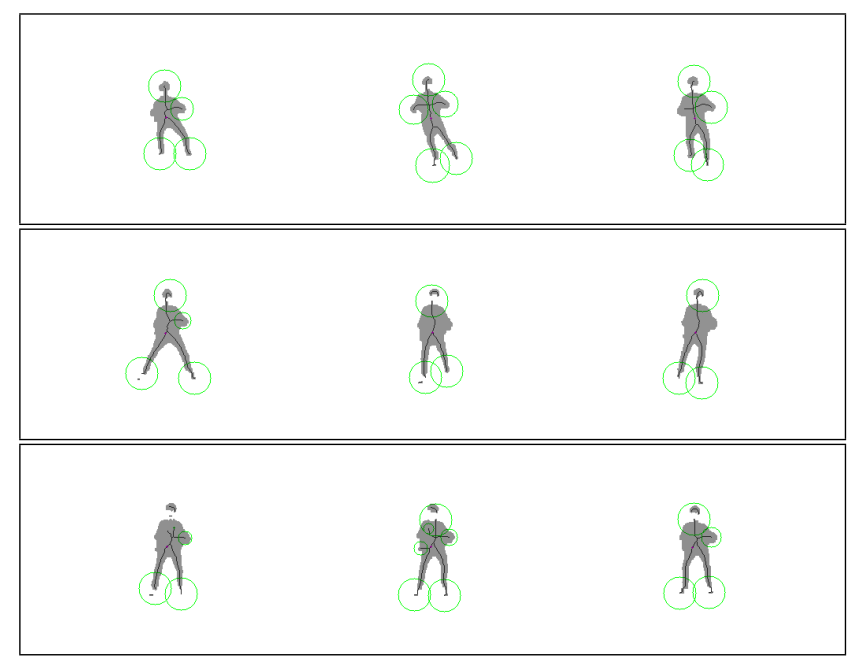

Figura 7.8: Esqueletos da Figura 7.7. 


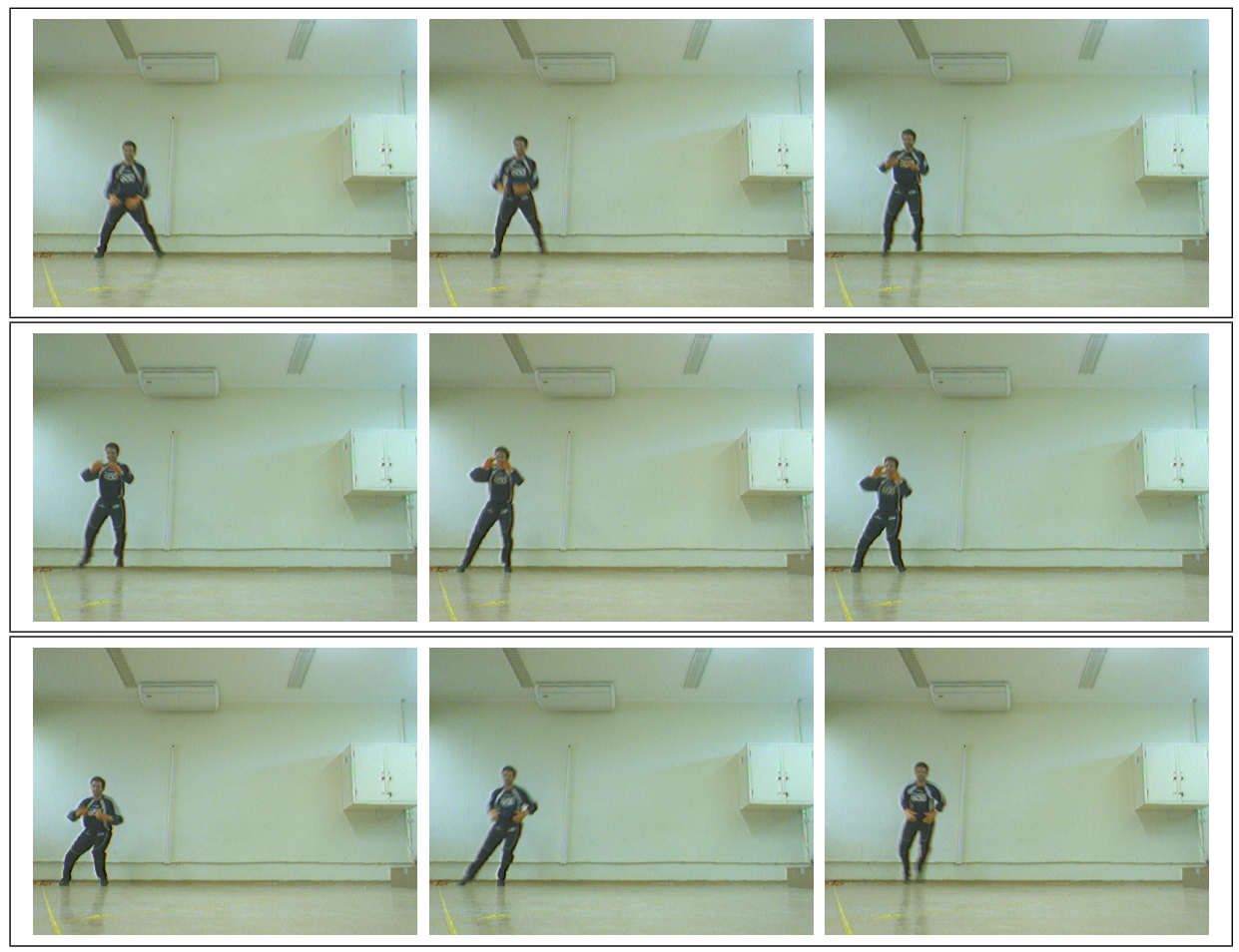

Figura 7.9: Pegada na sequência felipe0, a partir do frame 795 a cada 5 frames.

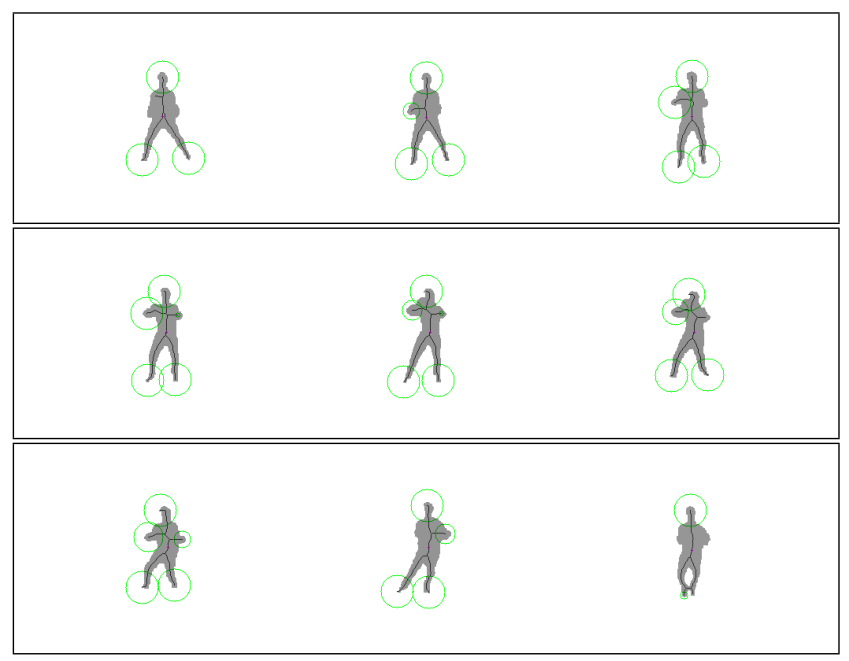

Figura 7.10: Esqueletos da Figura 7.9. 

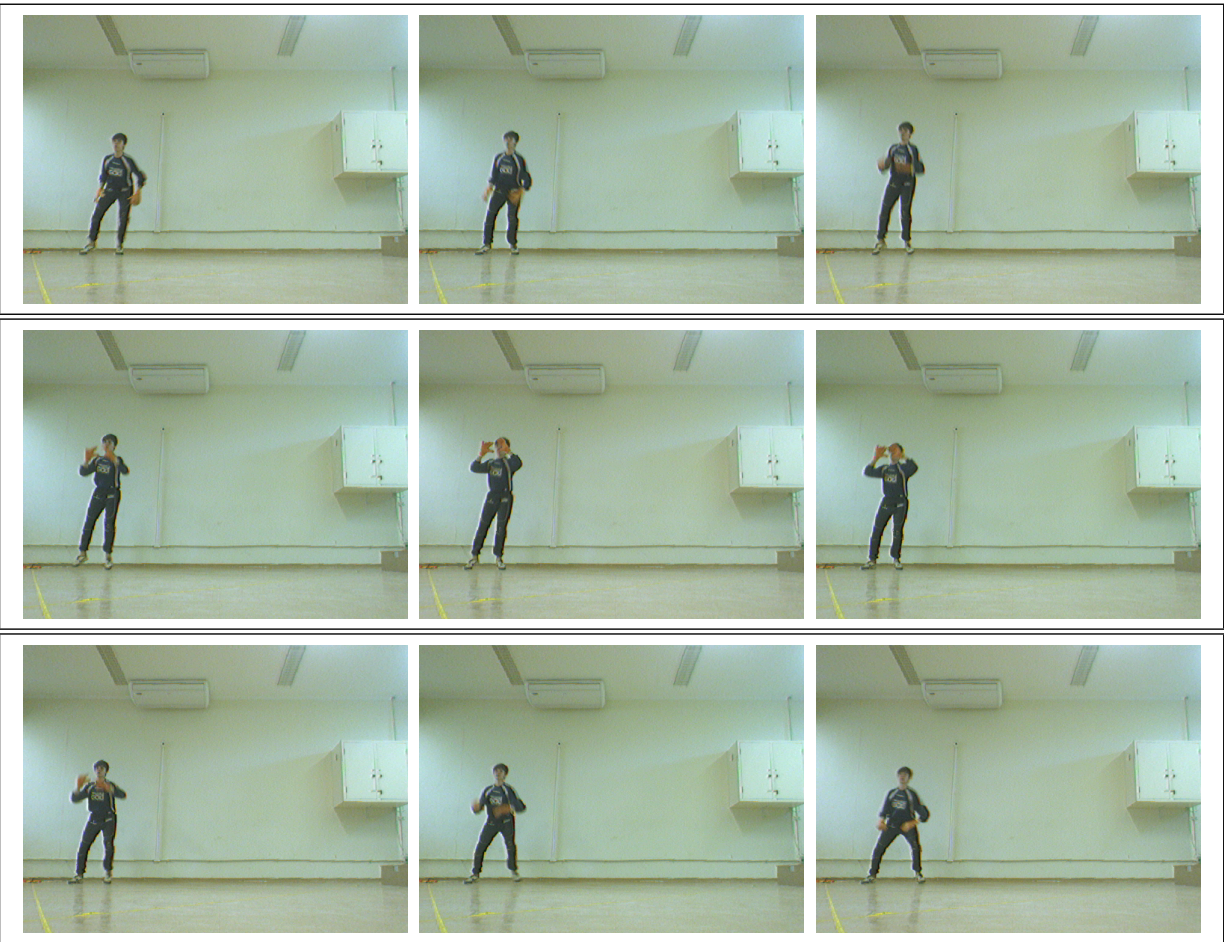

Figura 7.11: Pegada na sequência rodrigo0, a partir do frame 780 a cada 3 frames.

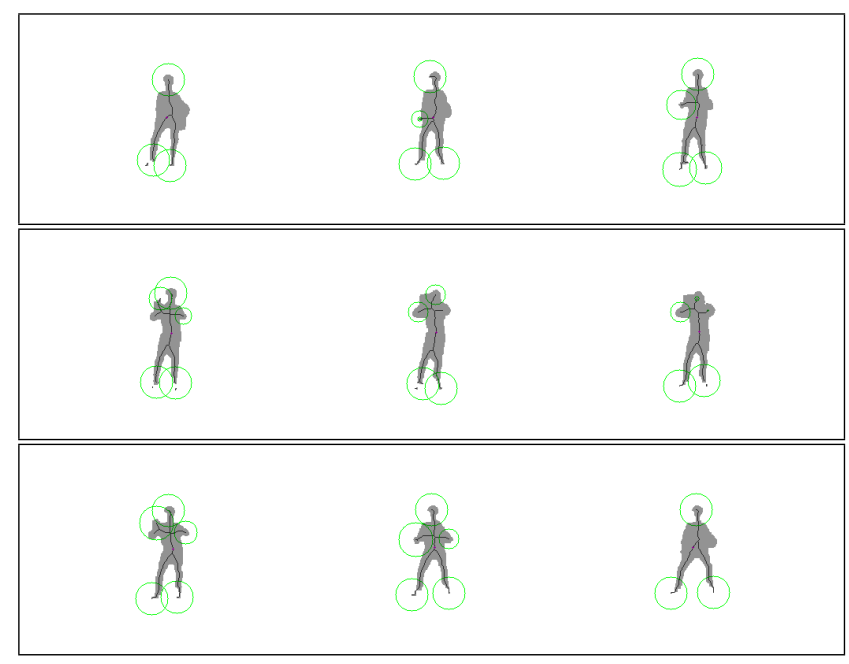

Figura 7.12: Esqueletos da Figura 7.11. 


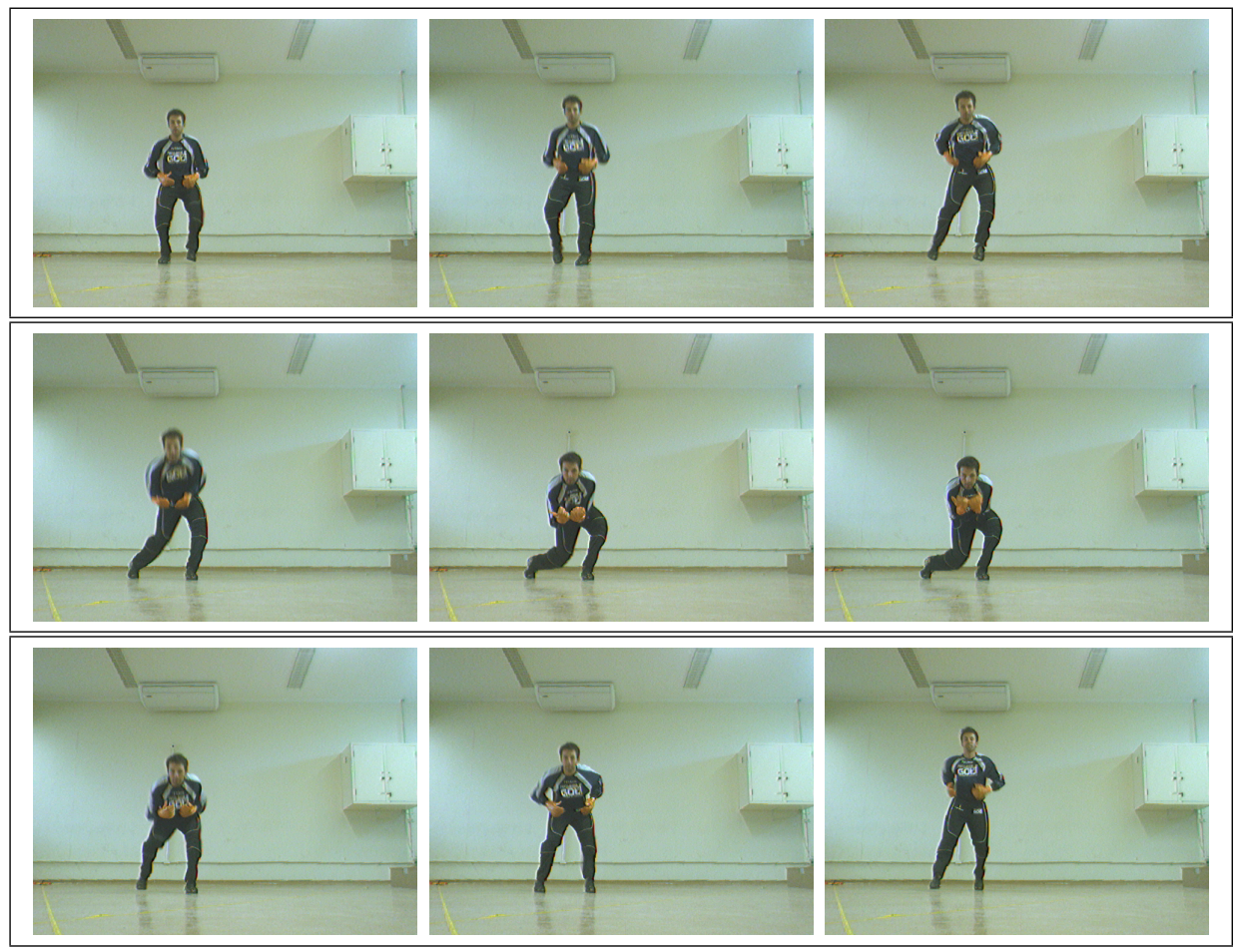

Figura 7.13: Encaixe na sequência felipe0, a partir do frame 1195 a cada 5 frames.

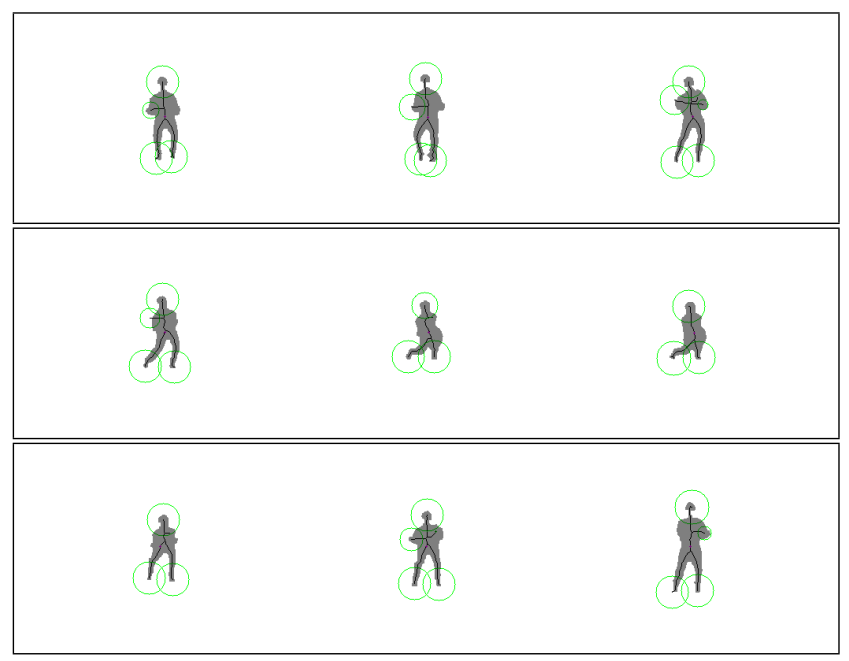

Figura 7.14: Esqueletos da Figura 7.13. 

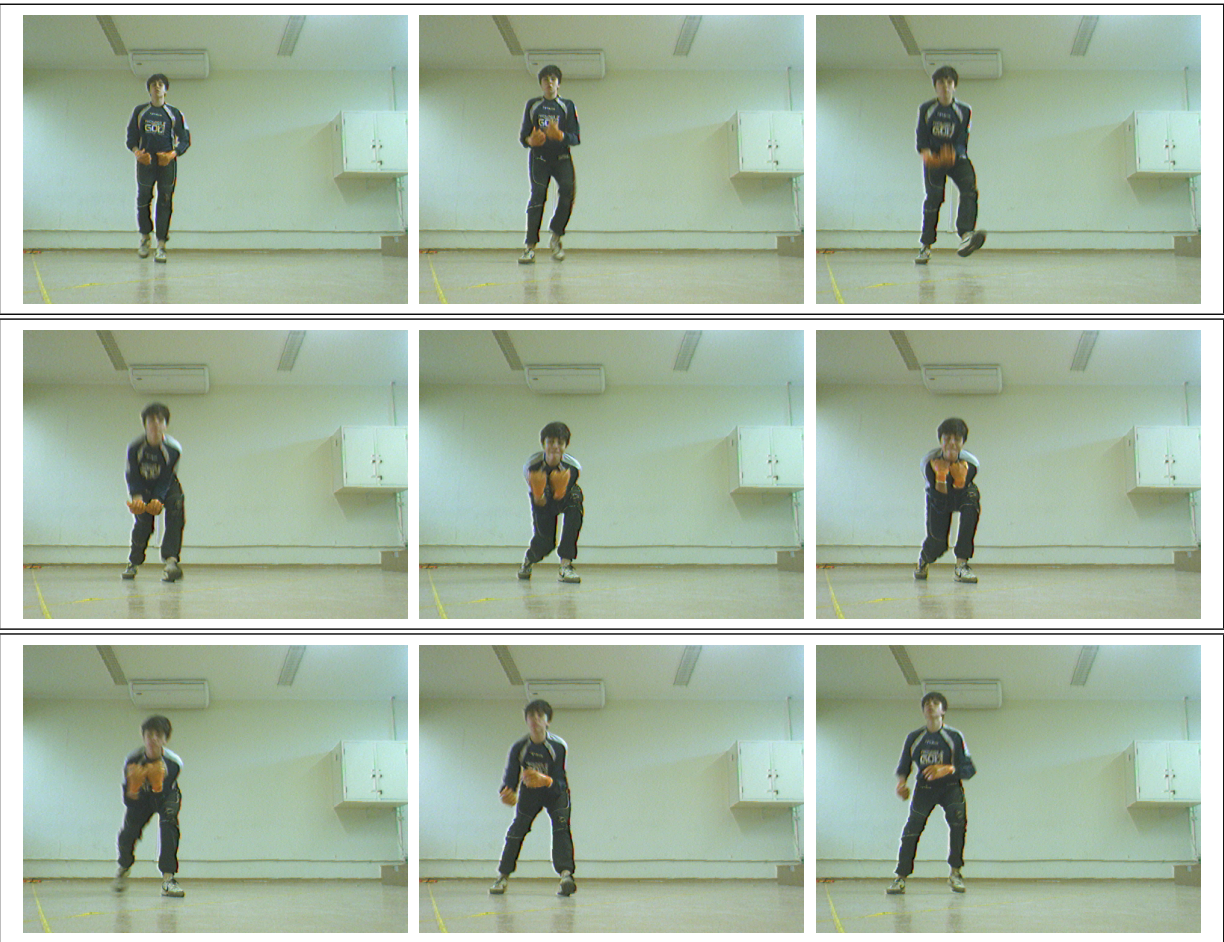

Figura 7.15: Encaixe na sequência rodrigo0, a partir do frame 1205 a cada 5 frames.

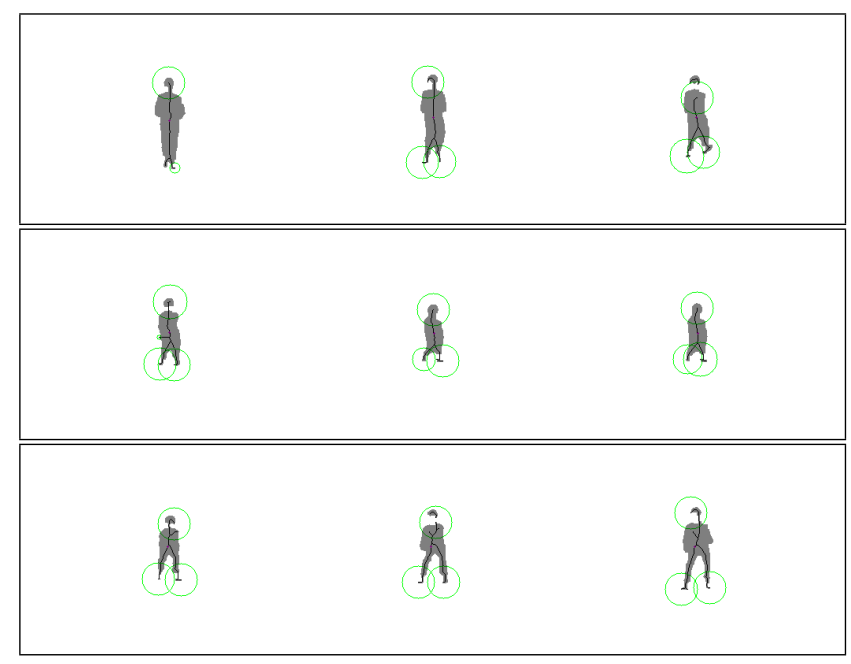

Figura 7.16: Esqueletos da Figura 7.15. 


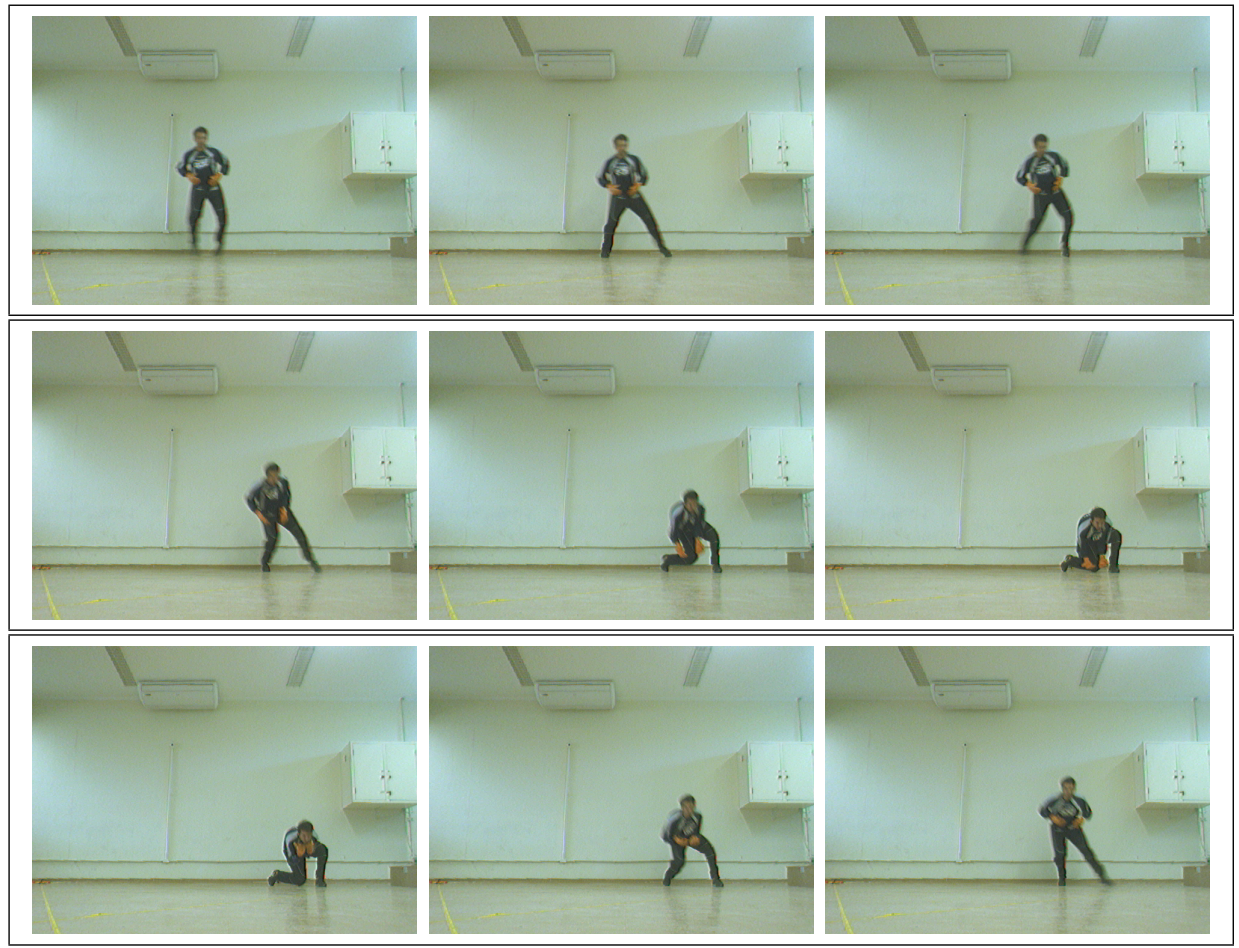

Figura 7.17: Entrada na sequência felipe0, a partir do frame 1330 a cada 5 frames.

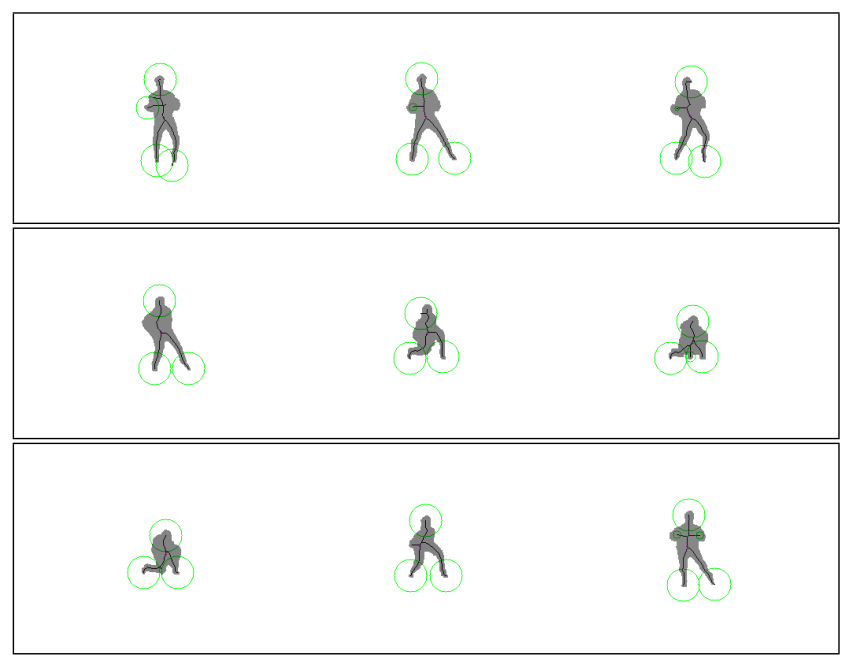

Figura 7.18: Esqueletos da Figura 7.17. 


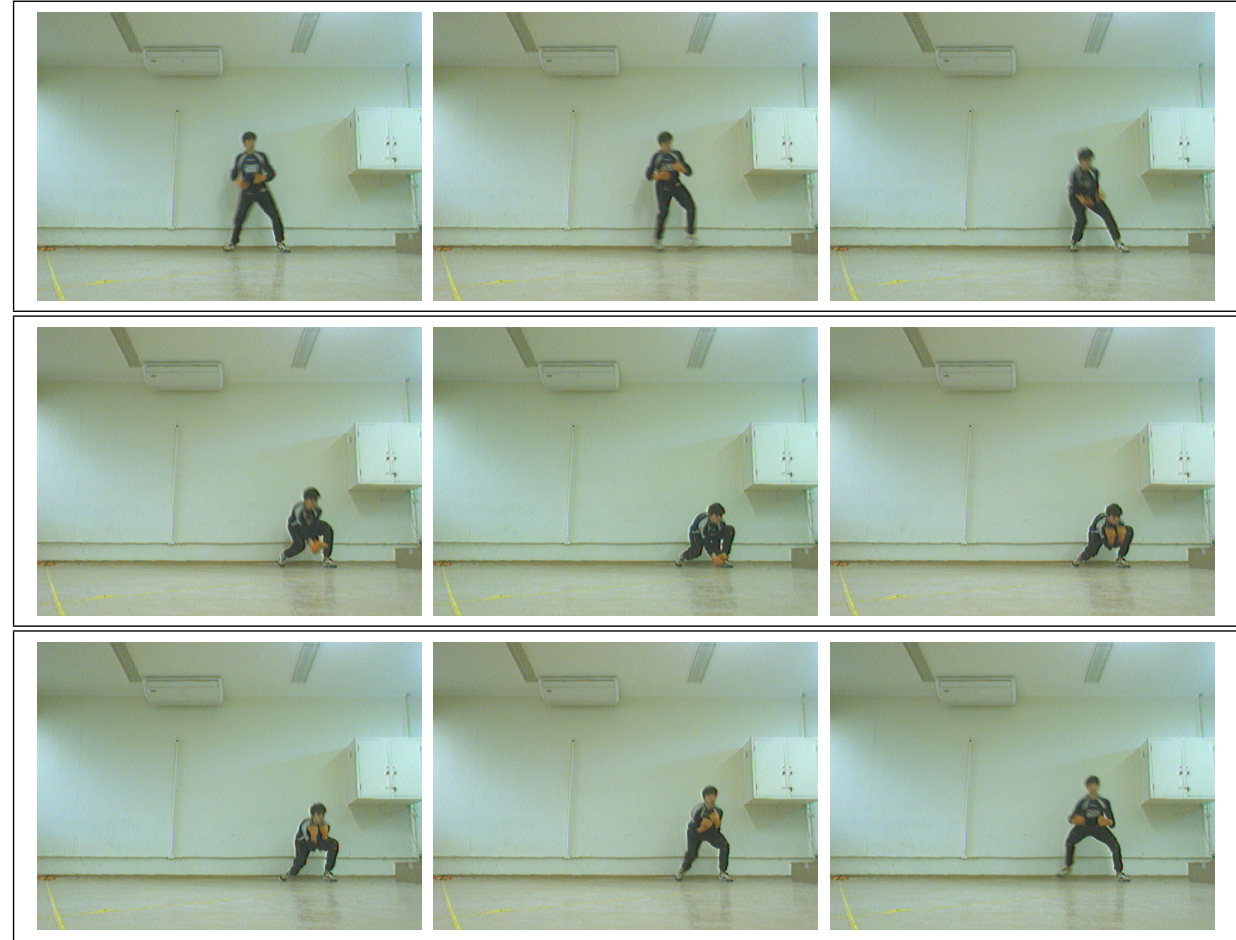

Figura 7.19: Entrada na sequência rodrigo0, a partir do frame 1375 a cada 5 frames.

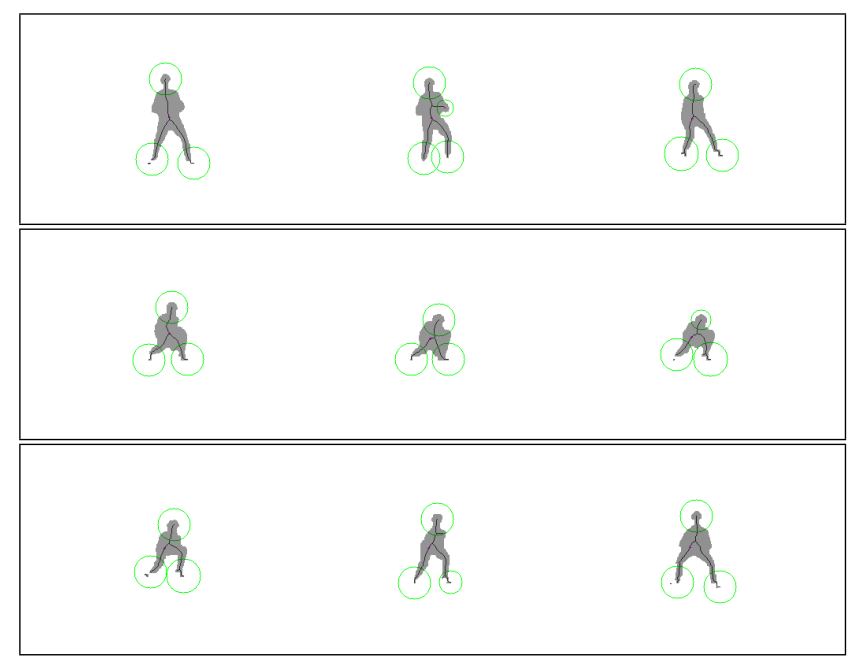

Figura 7.20: Esqueletos da Figura 7.19. 


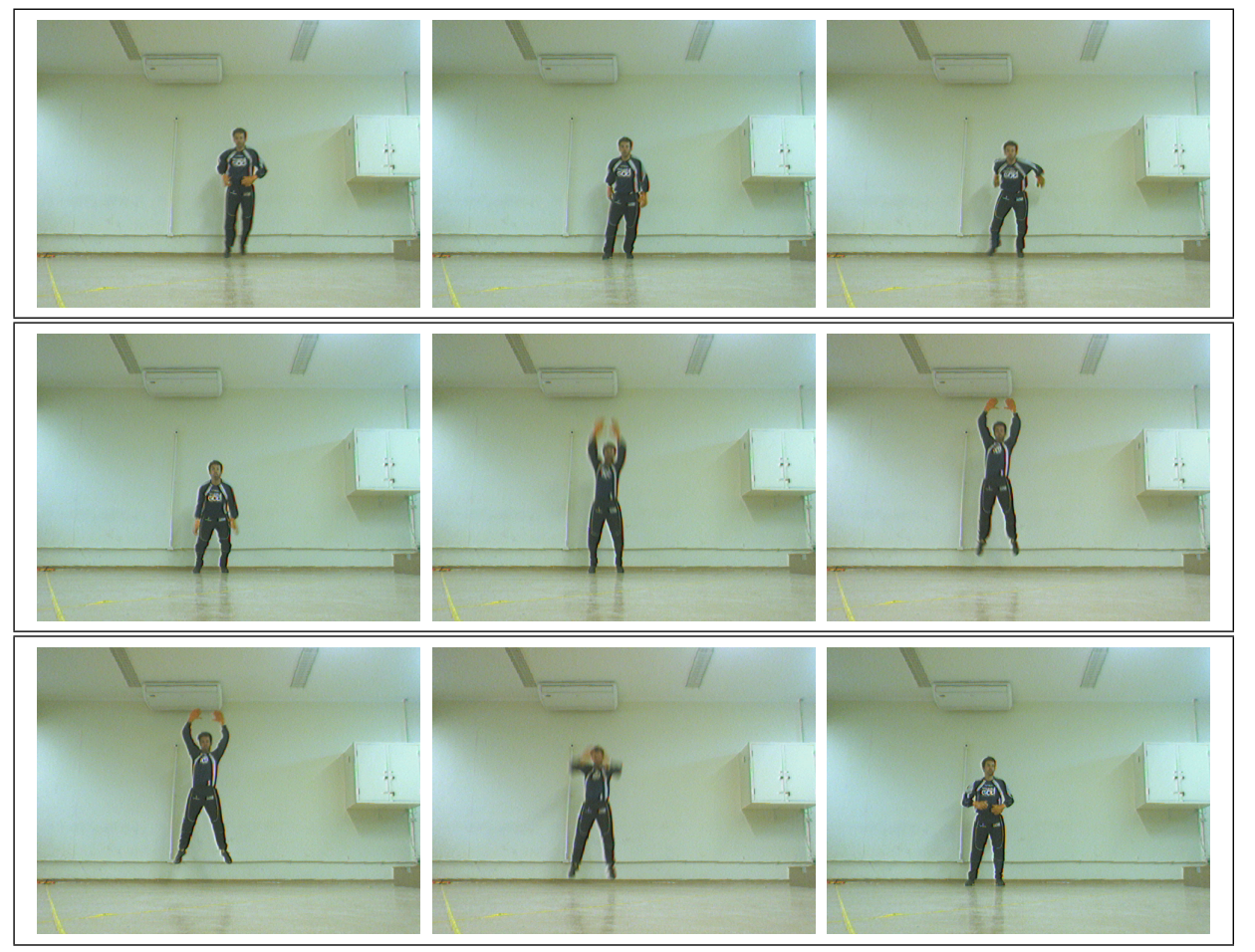

Figura 7.21: Salto na sequência felipe1, a partir do frame 1460 a cada 5 frames.

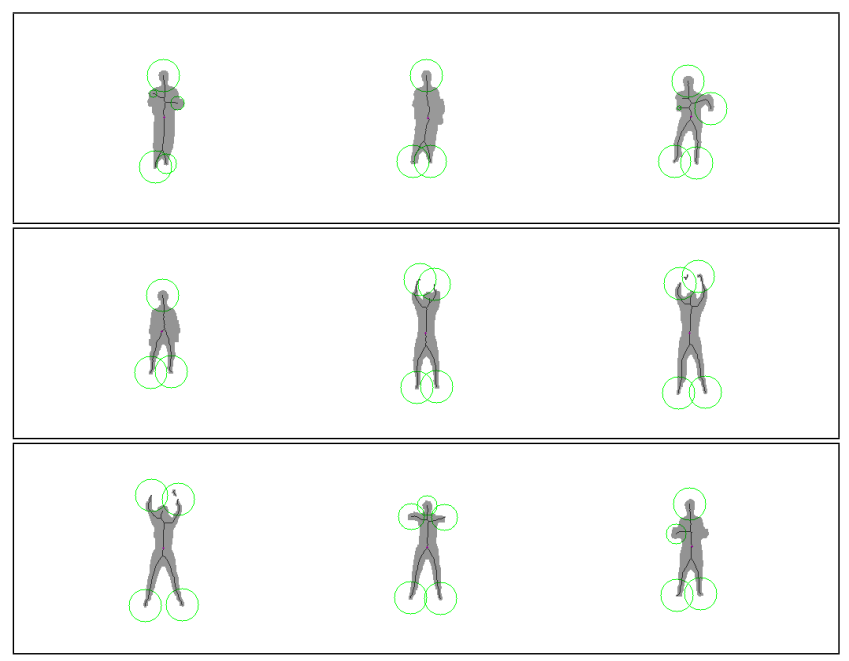

Figura 7.22: Esqueletos da Figura 7.21. 


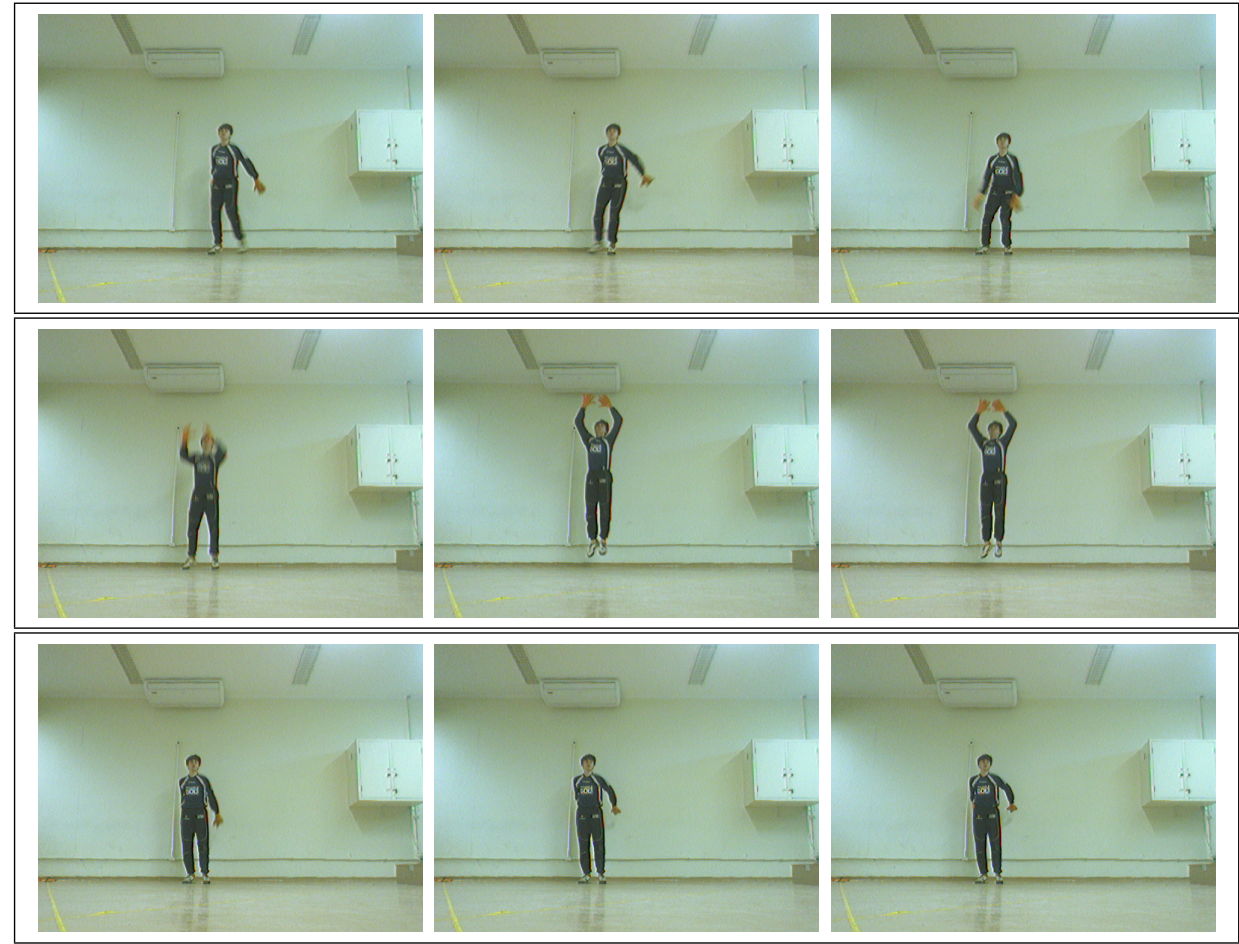

Figura 7.23: Salto na sequência rodrigo1, a partir do frame 1720 a cada 5 frames.

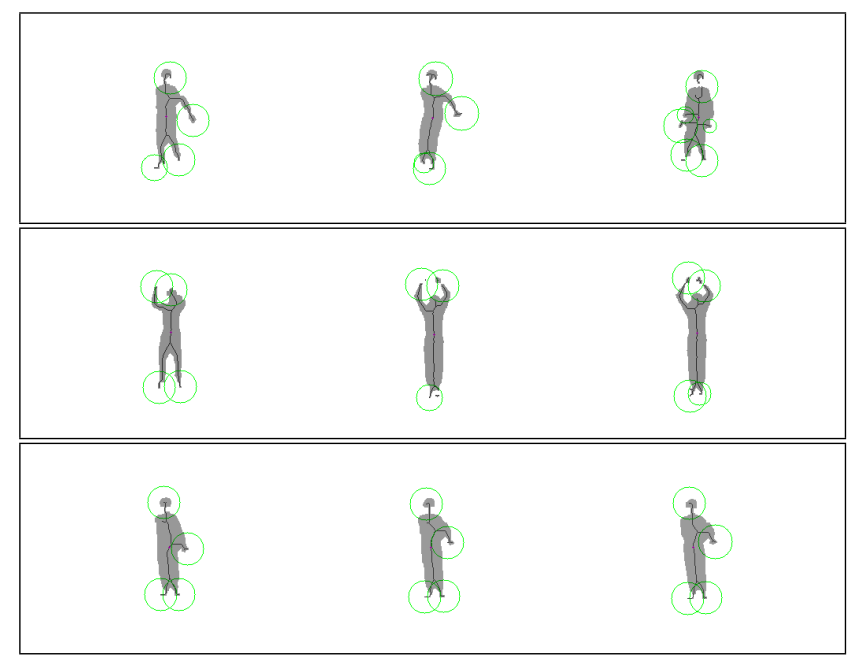

Figura 7.24: Esqueletos da Figura 7.23. 


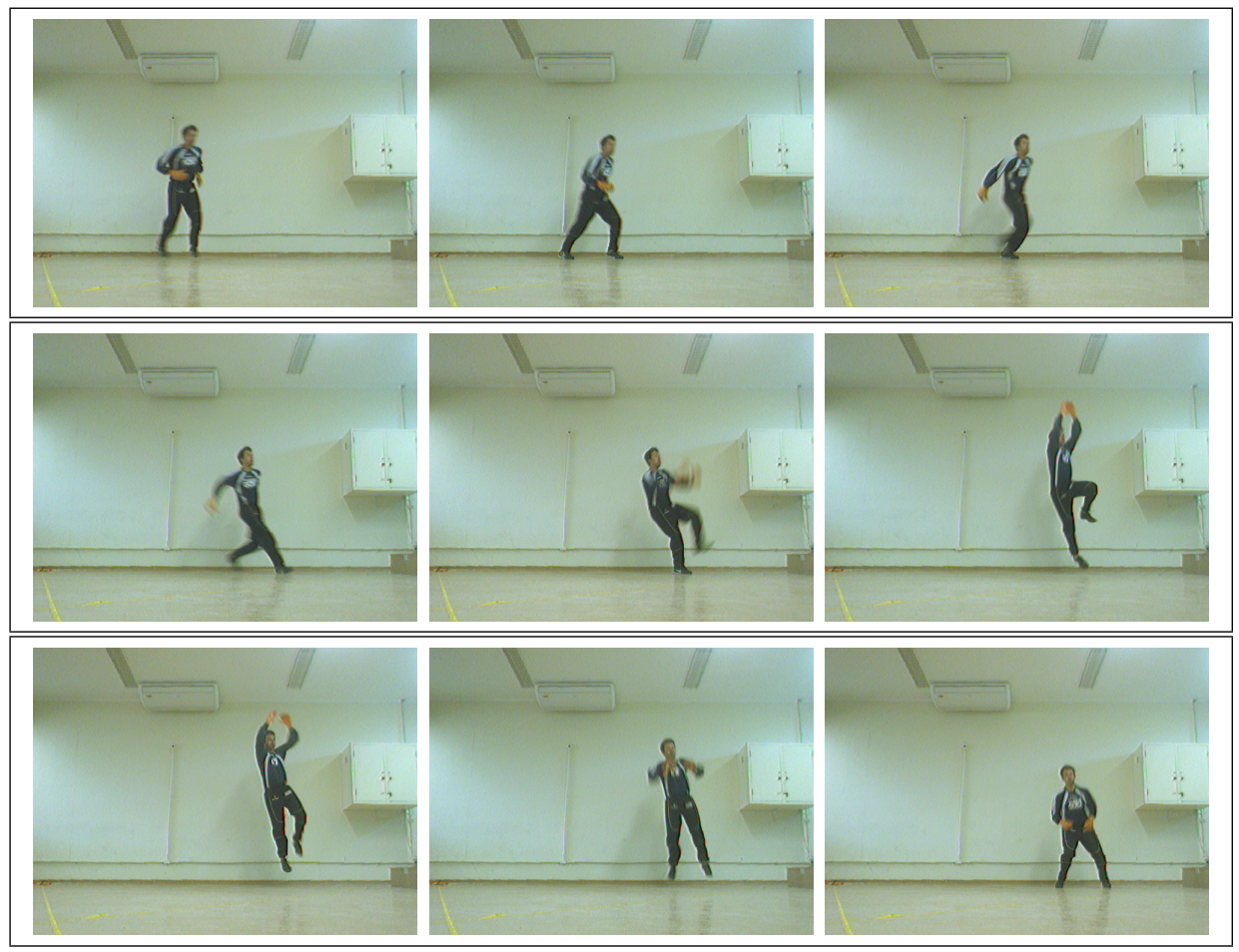

Figura 7.25: Salto para a direita em felipe0, a partir do frame 1580 a cada 5 frames.

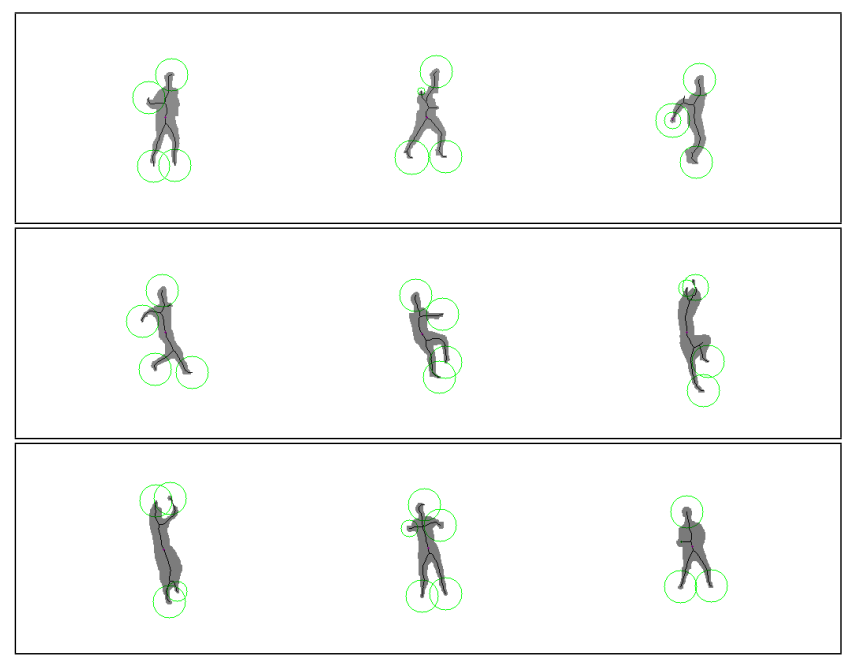

Figura 7.26: Esqueletos da Figura 7.25. 


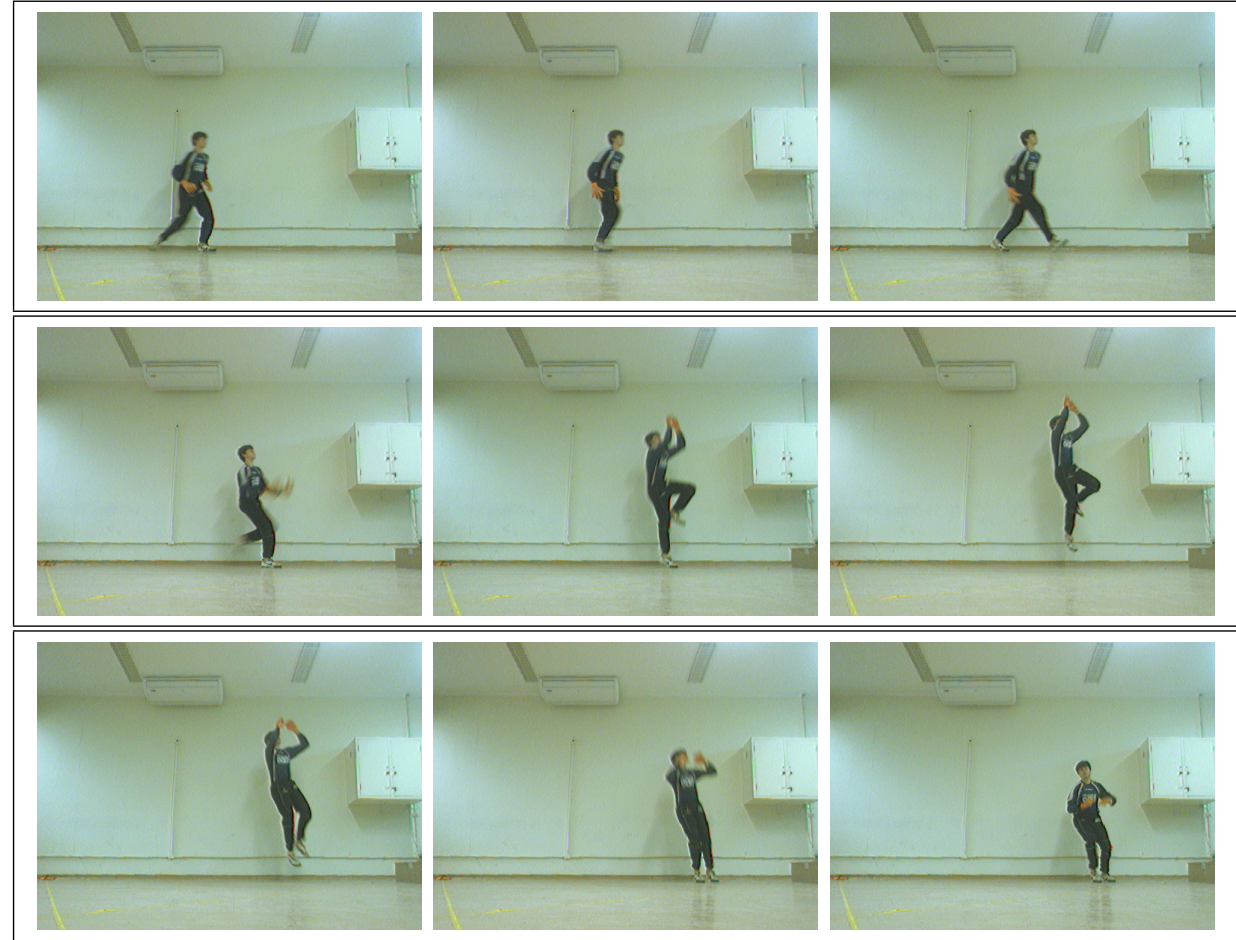

Figura 7.27: Salto para a direita em rodrigo1, a partir do frame 1645 a cada 5 frames.

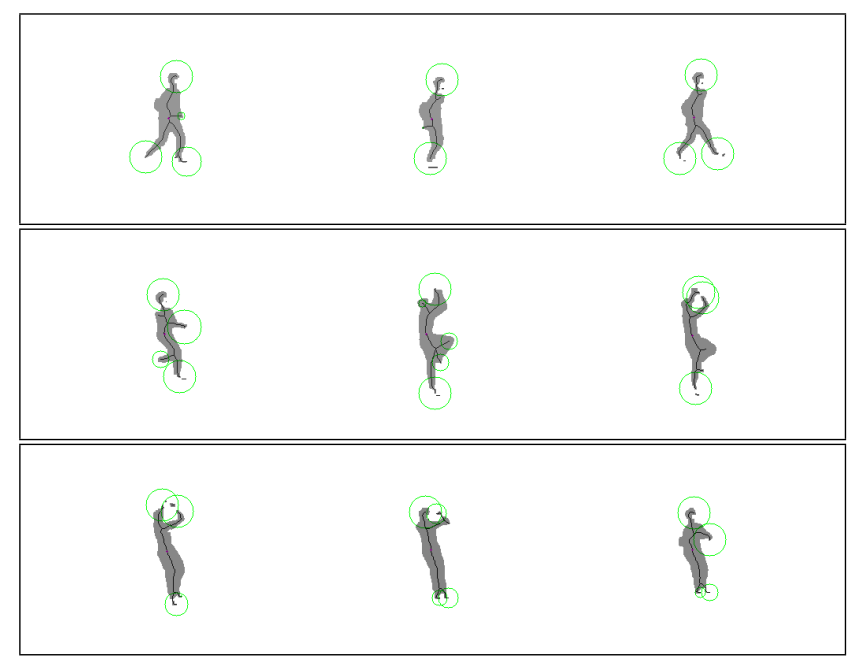

Figura 7.28: Esqueletos da Figura 7.27. 


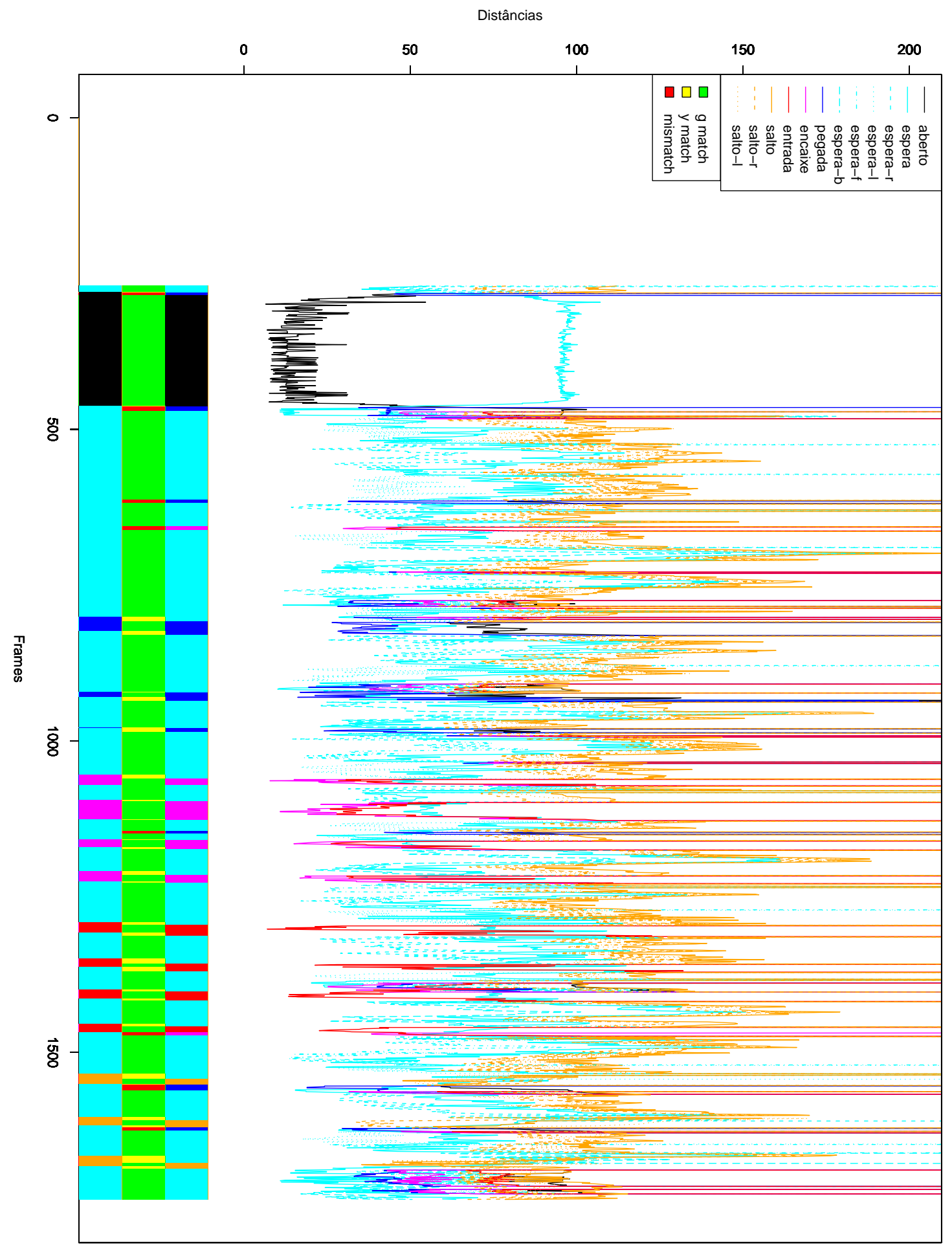

Figura 7.29: Distâncias aos keyframes na sequência felipe0. 


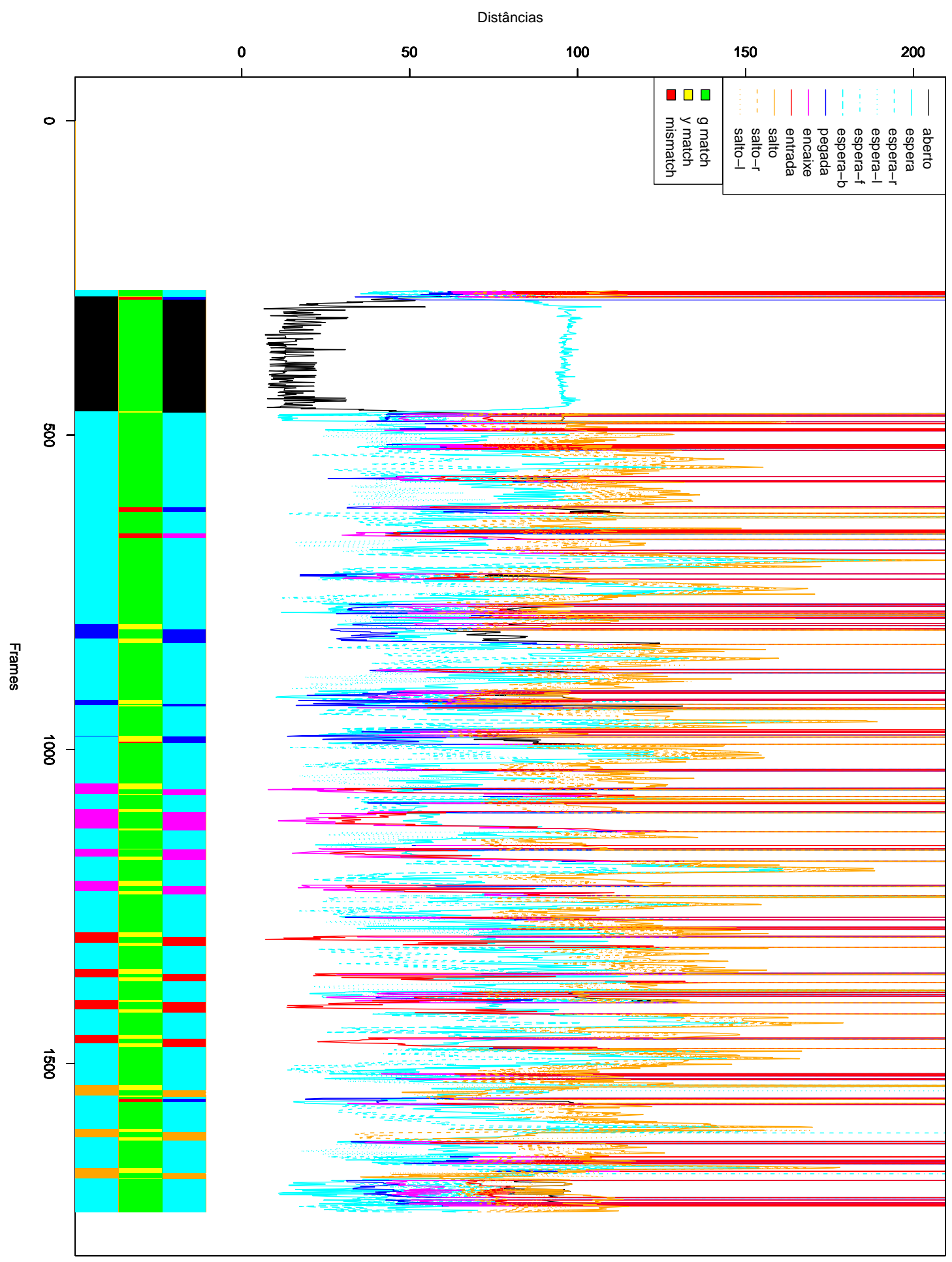

Figura 7.30: Distâncias aos keyframes com restrição de transição na sequência felipe0. 


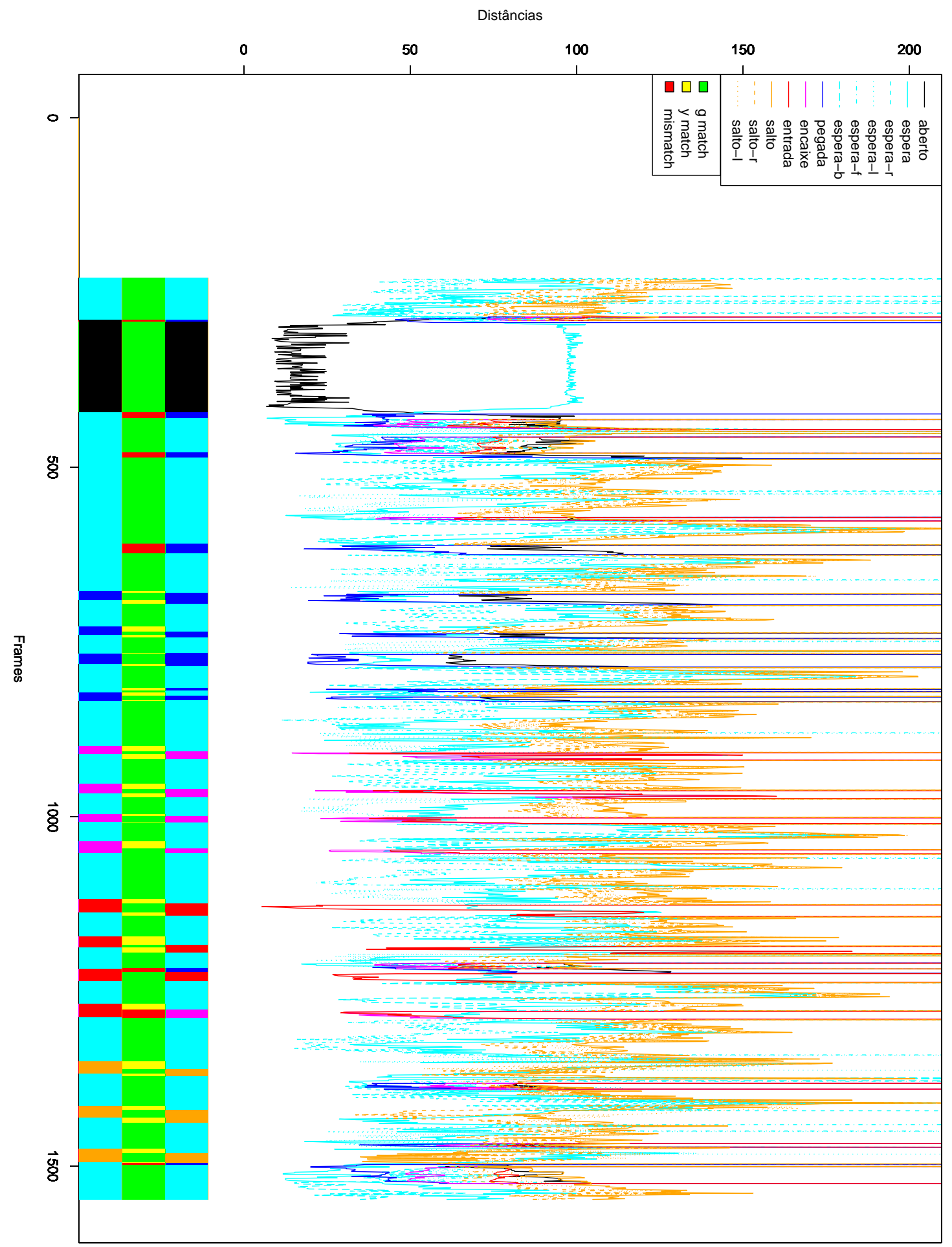

Figura 7.31: Distâncias aos keyframes na sequência felipe1. 


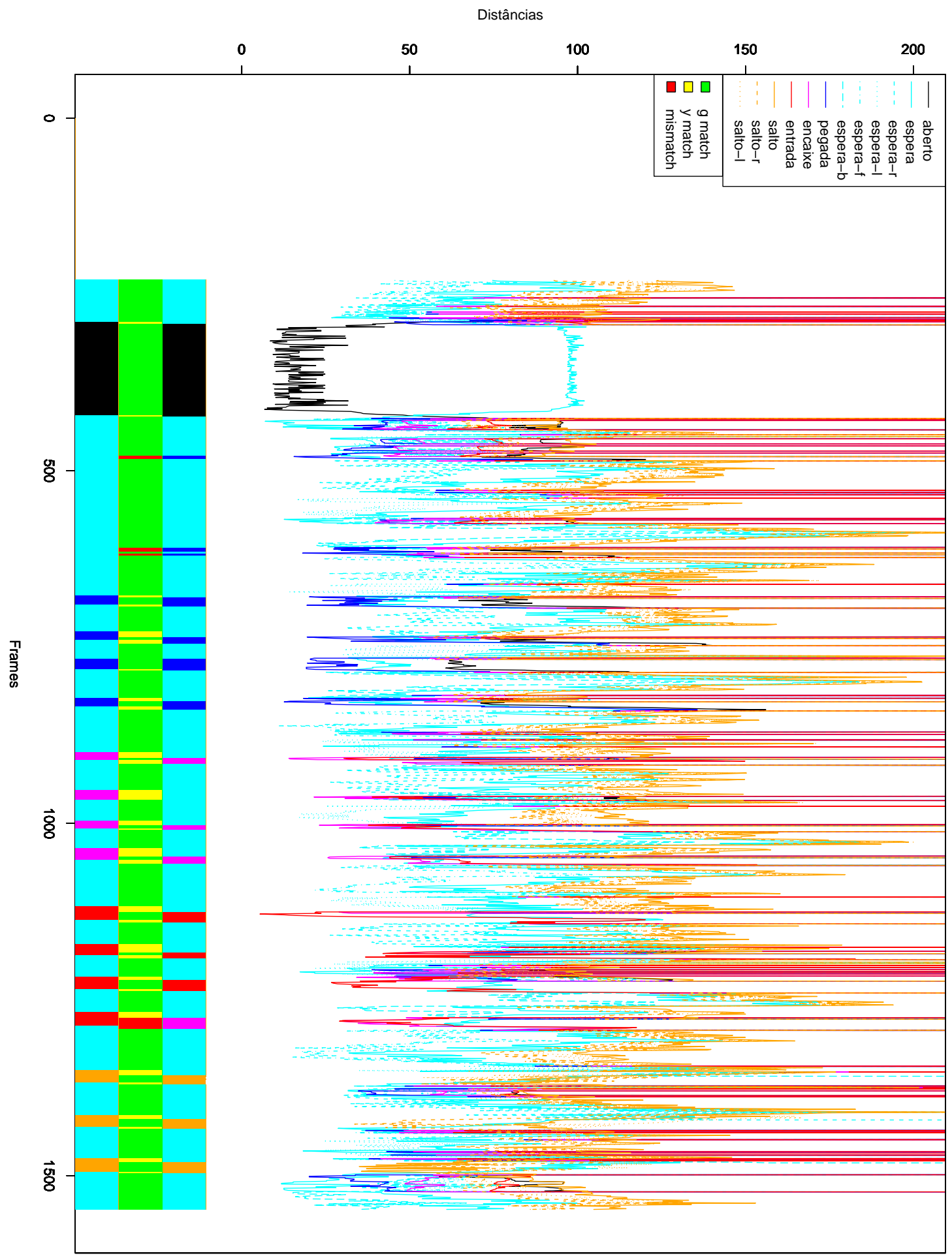

Figura 7.32: Distâncias aos keyframes com restrição de transição na sequência felipe1. 


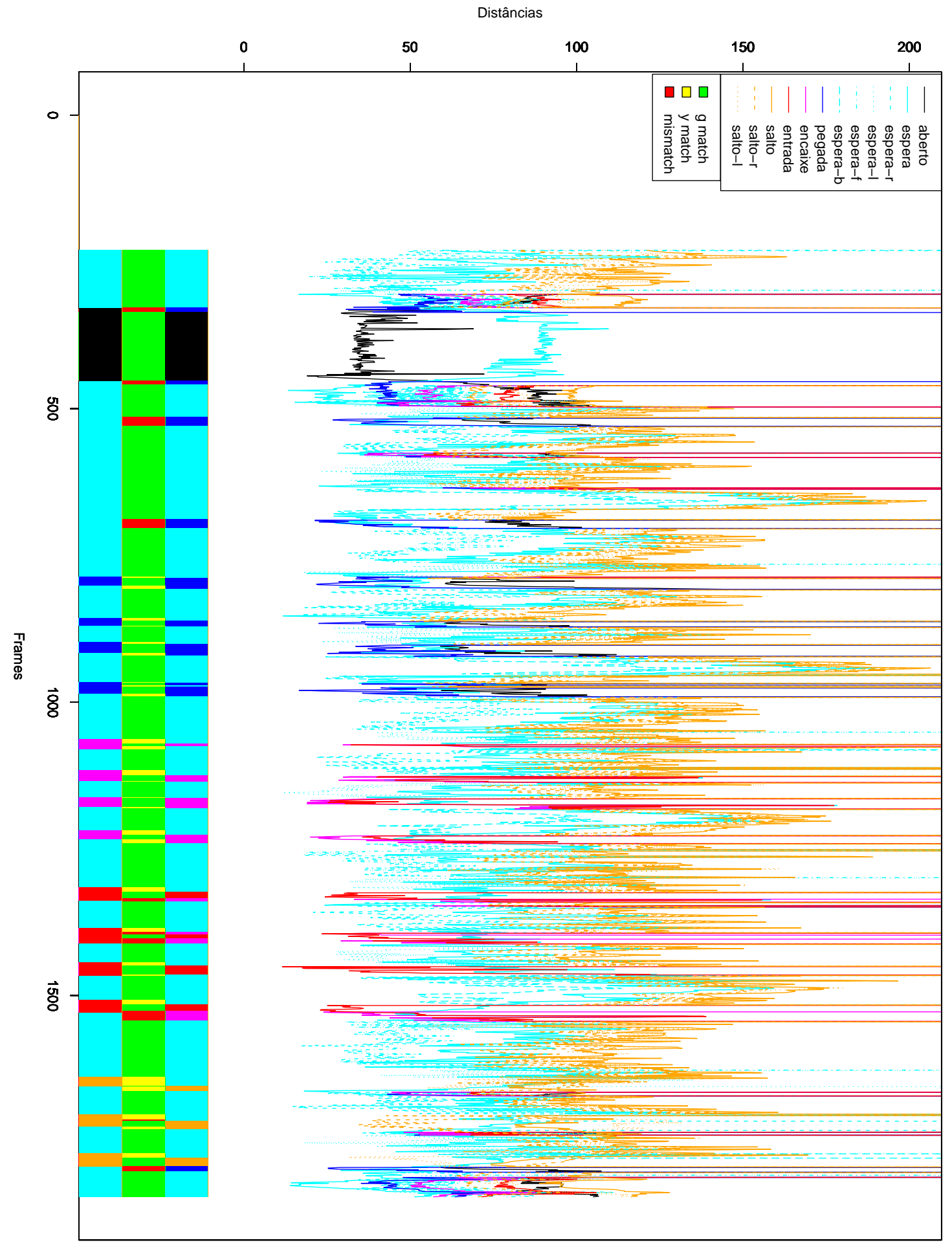

Figura 7.33: Distâncias aos keyframes na sequência rodrigo0. 


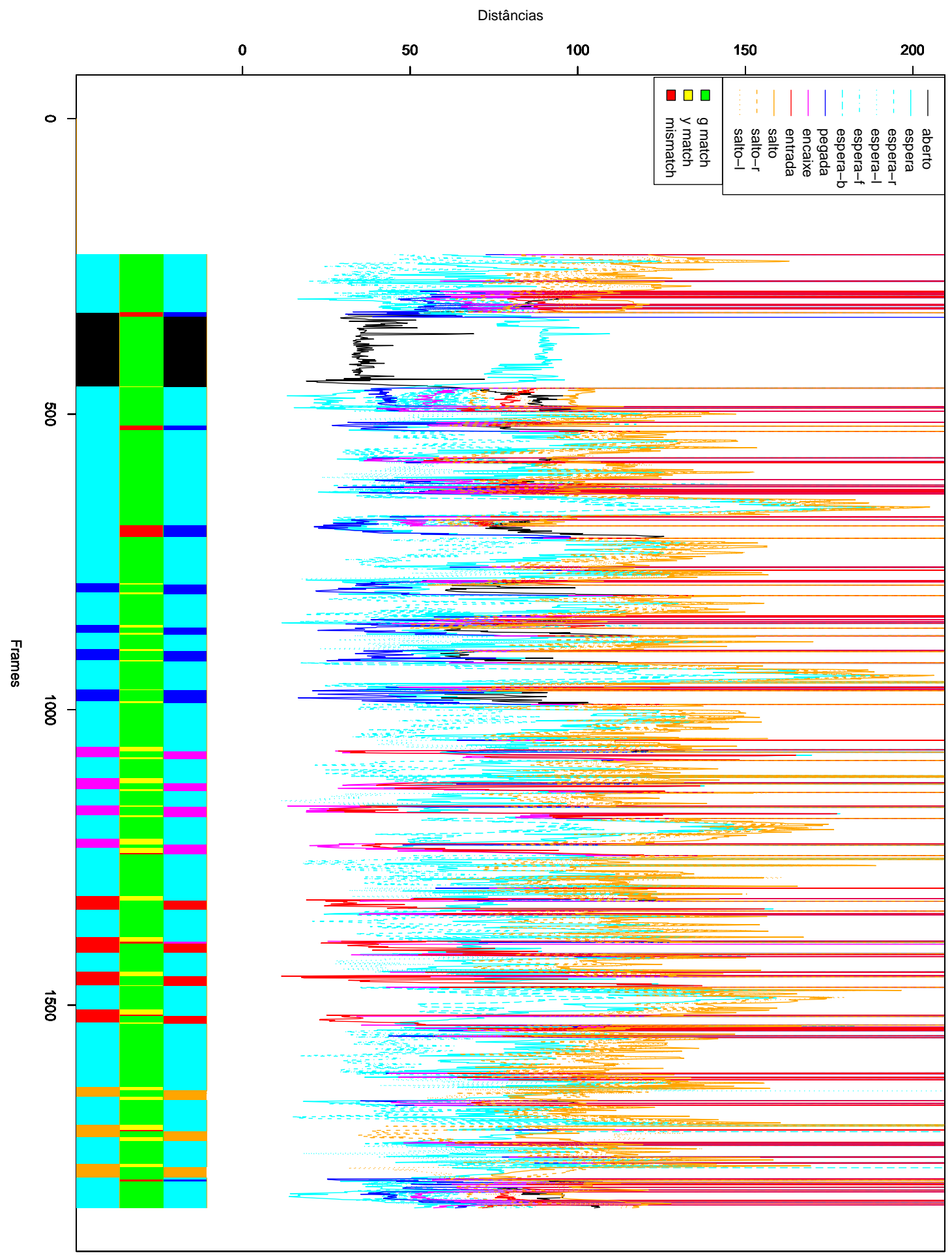

Figura 7.34: Distâncias aos keyframes com restrição de transição na sequência rodrigo0. 


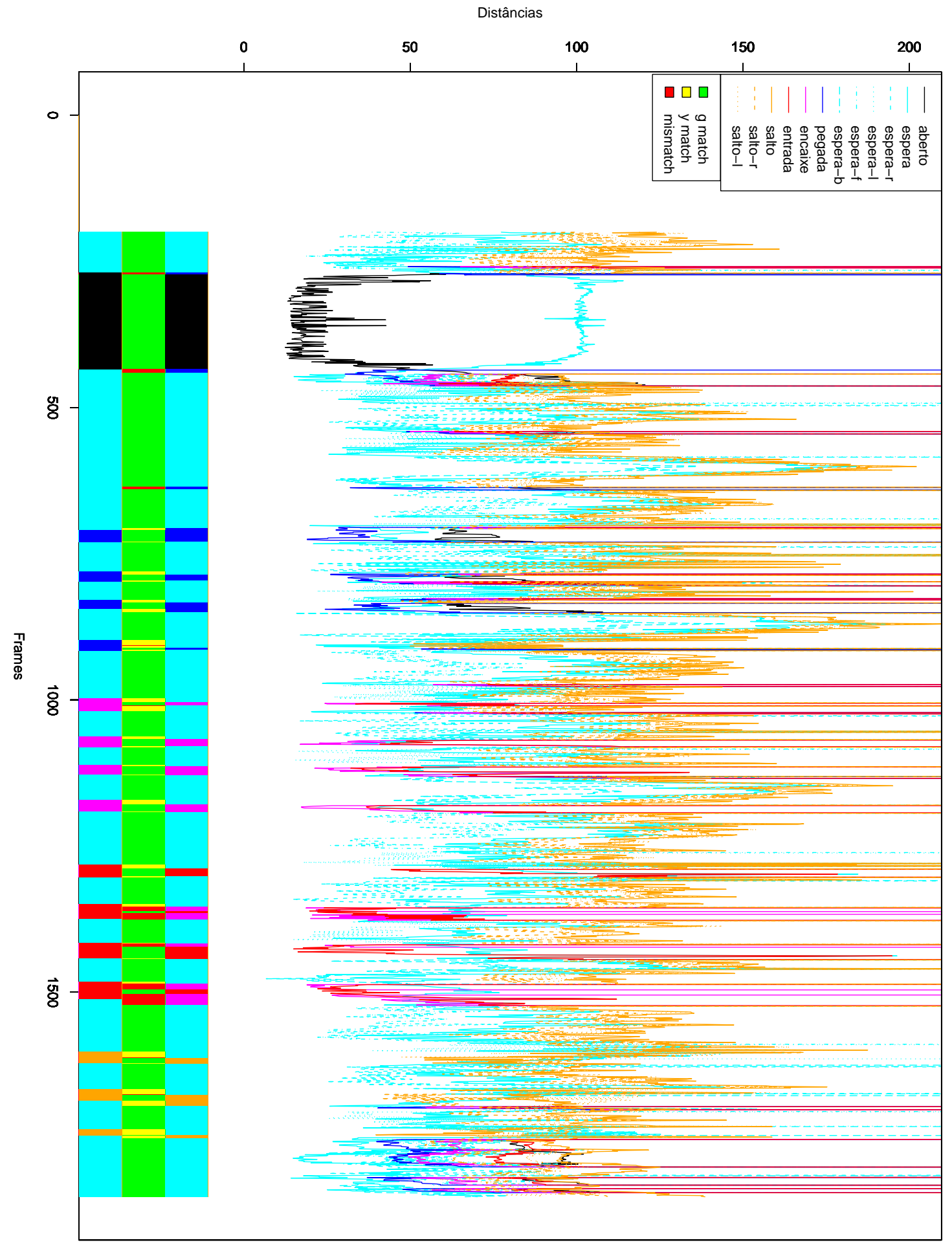

Figura 7.35: Distâncias aos keyframes na sequência rodrigo1. 


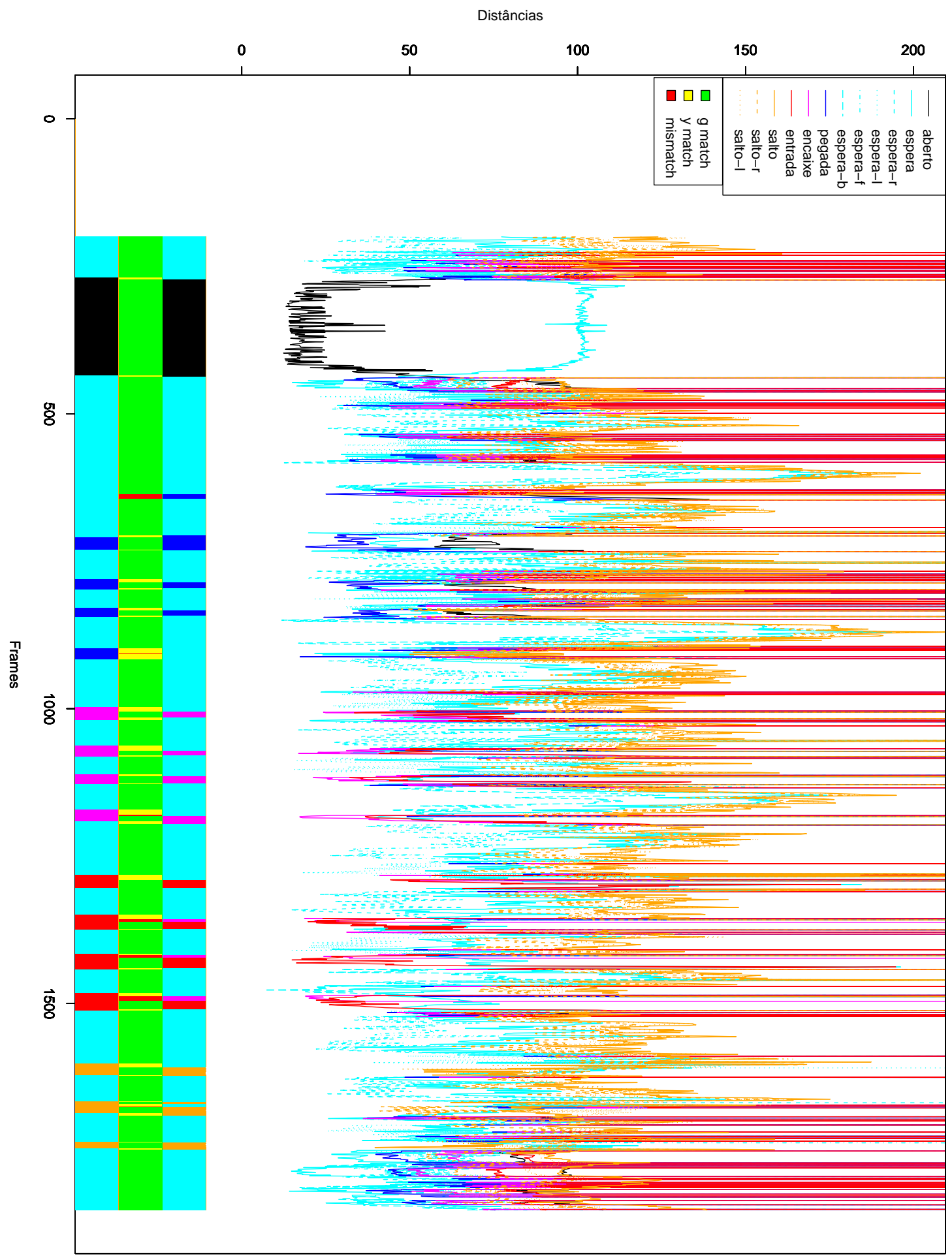

Figura 7.36: Distâncias aos keyframes com restrição de transição na sequência rodrigo1. 


\section{Capítulo 8}

\section{Conclusão}

Nesse trabalho, propomos o uso de uma FSM e novos métodos de classificação de poses com taxa de erro inferior a outros métodos tradicionalmente usados. Para definir o FSM, basta selecionar os keyframes e uma matriz de transição. Mudanças nos keyframes e na matriz de transição levam a flutuações pequenas no erro. O modelo foi definido com gestos de um usuário, e, mesmo aplicados a um vídeo de outro usuário, os erros obtidos foram praticamente os mesmos, o que indica que o método é robusto.

Todos os parâmetros do modelo, que são os keypoints e a matriz de transição, são definidos pelo operador do sistema a partir de informação a priori. Os keypoints poderiam ser definidos, porém, a partir da média dos keypoints com mesmo rótulo, contidos em um conjunto de treinamento. Se uma mesma pose tiver mais de uma maneira correta de ser feita, basta incluir no modelo os diferentes keyframes com o mesmo nome.

Normalmente os HMMs exigem grandes conjuntos de dados de treinamento e conhecimento dos algoritmos usados na modelagem, o que dificulta seu uso. O método proposto pode ser aplicado a qualquer conjunto de gestos, desde que não haja oclusão de partes do corpo importantes para definir as poses. Gestos que envolvem movimentar o braço 
esticado para a frente do tronco, como por exemplo um soco na direção da câmera, não seriam detectados, pois o contorno do usuário quase não muda.

Propomos duas maneiras de fazer a classificação da pose. A primeira é semelhante ao método de Correa [27], mas adaptada para suportar a correção de escala e para evitar o demorado cálculo da distância geodésica na região definida pelo corpo do usuário. A segunda usa uma distância entre grafos definidos pelo esqueleto da silhueta do usuário. Além dos dois métodos propostos, foram testados seis outros métodos de classificação estática. No experimento, cada frame foi analisado isoladamente, ou seja, foram ignorados os resultados e informações de frames anteriores e posteriores. Os métodos propostos tiveram percentual de acerto de 79,41\% e 81,57\% respectivamente. Todos os demais métodos testados tiveram percentual de acerto igual ou inferior a $70,47 \%$.

O reconhecimento de gestos foi feito a partir do reconhecimento de poses frame a frame. Para melhorar o percentual de acerto, foram usados um filtro temporal e uma matriz de transição, que restringe as possíveis transições entre poses. Com as melhorias, e ignorando as confusões entre poses sucessivas na classificação dos frames próximos ao instante de transição, o percentual de acerto dos dois métodos propostos chegou próximo a 100\%. O classificador por menor distância ao keypoint chegou a 97,9\%, e o de menor distância entre grafos chegou a 97,0\% dos frames classificados corretamente. Ignoramos as confusões próximas à transição pois elas não atrapalham a classificação dos gestos. Considerando tais confusões como erros, o percentual de acerto dos dois métodos diminui, chegando respectivamente a $88,2 \%$ e $86,3 \%$ dos frames classificados corretamente.

É proposta ainda uma nova biblioteca para processamento de vídeo em tempo real com vantagens sobre as outras atualmente disponíveis. A biblioteca proposta é mais rápida que a GpuCV na maioria dos operadores analisados. É mais fácil de usar que a OpenVidia, por esconder do programador as chamadas ao OpenGL, e é mais flexível que a GpuCV por permitir qualquer número de imagens de saída. Permite a criação de novos operadores 
com facilidade em GLSL e em CUDA, cujos códigos wrapper são gerados automaticamente. Evita a duplicação de código, pois cada operador é completamente definido em um único arquivo, facilitando a implementação e manutenção do código.

Quanto à continuação do trabalho, gostaríamos de adicionar uma etapa de medição automática da altura do usuário, para, em função deste valor, calcular o tamanho dos ossos automaticamente. A medida dos ossos seria útil em uma eventual etapa de captura de movimento para controle do avatar.

Outra possível melhoria seria incluir um modelo de aparência, ou seja, localizar as partes do corpo do usuário pela cor, de forma semelhante à feita por Nicolas Thome [100]. Para criar o modelo, o sistema pediria para o usuário ficar em pé com os braços estendidos para os lados, ou seja, fazer a chamada pose $T$.

Um trabalho futuro poderia envolver a comparação entre os percentuais de acerto usando a FSM definida nesta tese com um HMM, fazendo o treinamento com o algoritmo forward-backward e a decodificação, com o algoritmo de Viterbi.

Outra possibilidade é implementar a parte de realidade virtual do projeto, fazendo a integração com um jogo de futebol, com projeção estéreo das cenas do jogo em um telão.

Acreditamos que tal método simplificado pode contribuir com a popularização de interfaces baseadas em câmeras, por ser o processo de definição das poses e gestos uma tarefa simples. Tais interfaces são atualmente restritas a protótipos, como o projeto Natal da Microsoft, alguns poucos produtos comerciais, como o EyeToy do Playstation.

Acreditamos que interfaces baseadas em câmeras para reconhecimento de gestos têm um potencial enorme e inexplorado em diversas áreas, como no treinamento de gestos em esportes, na promoção de produtos comerciais em quiosques, e mesmo em videogames.

Um objetivo ambicioso para continuação deste trabalho seria a implementação de um 
simulador realista de goleiro de futebol, em que o usuário controlaria seu avatar $^{1}$ com o próprio corpo, e com a impressão de estar imerso em um jogo real.

Para criar a ilusão de imersão em um jogo, pode ser projetada a visão do campo de futebol a partir do ponto de vista do goleiro, ou de um ponto um pouco atrás dele. Pode ser usado um par de projetores, cada um com um filtro de polarização, e projetando a imagem referente a um dos olhos do usuário. Este, por sua vez, usando óculos com lentes polarizadas tem a ilusão de ver uma cena tridimensional.

Neste tipo de projeção, os objetos da cena aparecem imóveis em relação à tela. Para aumentar o realismo e a sensação de imersão, os objetos deveriam ter sua posição modificada conforme muda a posição da cabeça do usuário. Tal conceito é conhecido como virtual window, e exige o rastreamento da cabeça do usuário em tempo real [89, 75].

A princípio, se o usuário se locomove $x$ metros em qualquer direção dentro da área útil, a mesma distância é percorrida na área virtual do campo de futebol. Se a área útil for considerada muito pequena para que o usuário se movimente adequadamente, além da opção óbvia de aumentar a área, pode-se também usar como distância virtual a distância percorrida multiplicada por um fator maior que um.

Mesmo com uma área útil razoavelmente grande ou com a distância percorrida aumentada por algum percentual, é provável que isso não seja suficiente para o goleiro caminhar por todas as regiões necessárias do campo. Uma alternativa é reservar faixas nos limites da área útil onde, se o usuário as ocupar, o avatar continua caminhando mesmo estando o usuário parado.

Além da locomoção, o usuário deve poder comandar qualquer ação que um goleiro real faça. Listamos como ações de um goleiro pegar a bola no ar ou no chão, carregar a bola, lançar a bola com as mãos, chutá-la para longe, dominá-la com os pés, bater tiro de meta

\footnotetext{
${ }^{1}$ Personagem digital que representa o usuário na tela.
} 


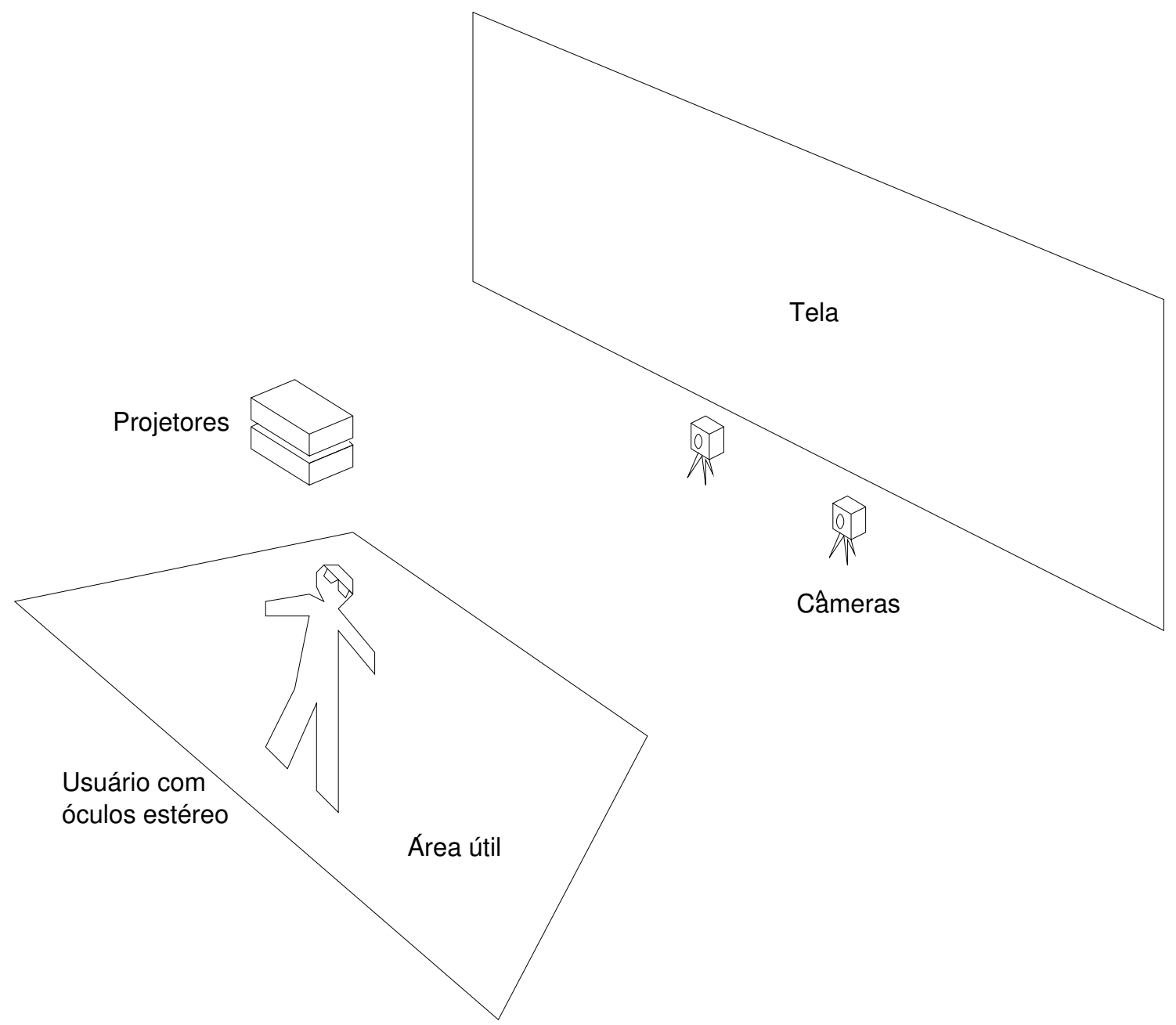

Figura 8.1: Esquema da instalação. 


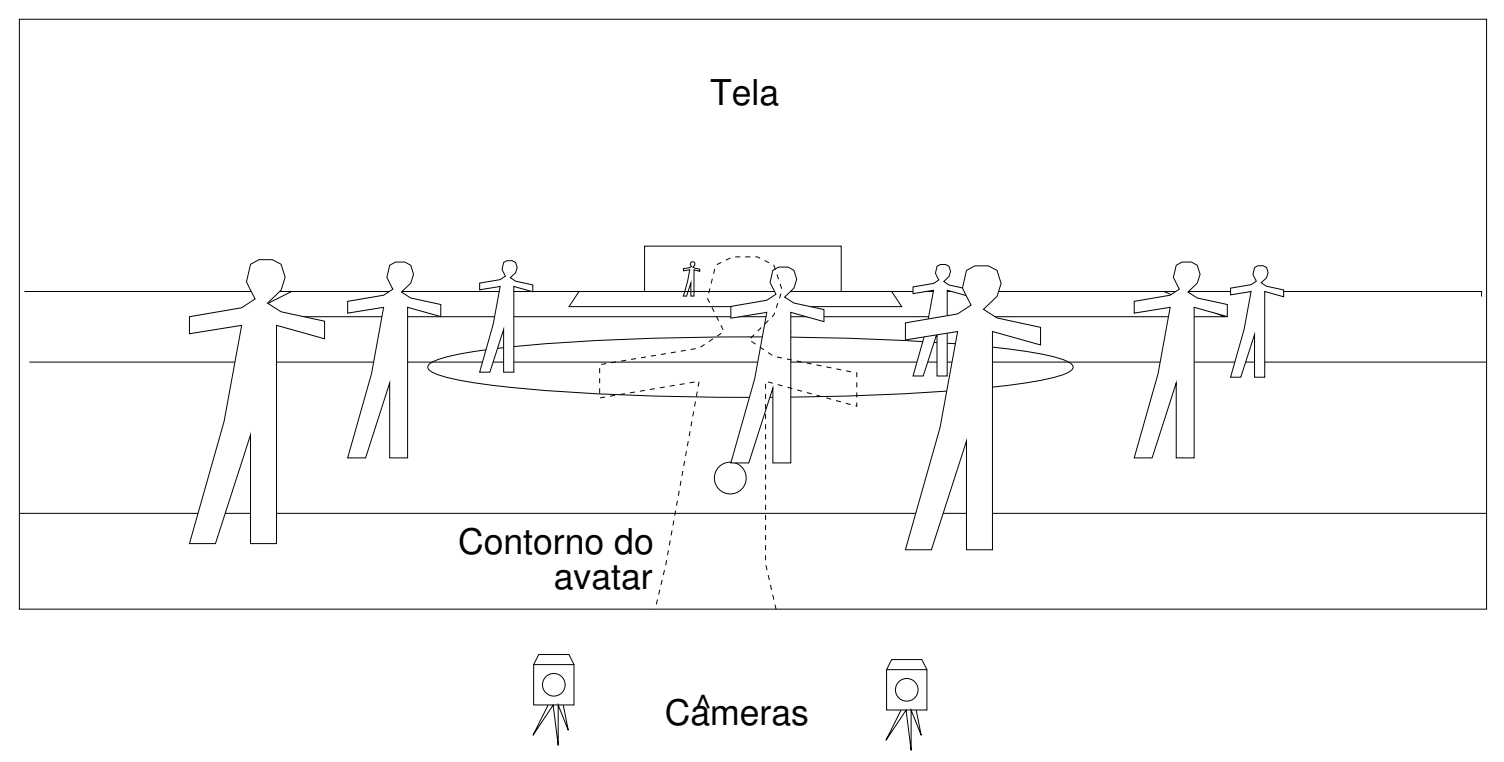

Figura 8.2: Instalação e tela do ponto de vista do usuário.

e pular. O ideal é mapear movimentos do usuário para essas ações da forma mais natural possível, evitando ao máximo gestos ou sinais que o usuário tenha que aprender.

Enquanto joga, o goleiro vê seu avatar pelas costas, como ilustra a Figura 8.2. Deve ser renderizado com transparência para evitar a oclusão da bola e de lances importantes. É muito importante que o avatar apareça na tela por um princípio de desenho de interfaces. Segundo uma das regras de ouro de Shneiderman [97], "para toda ação do usuário deve haver retorno do sistema. Para ações menores e frequentes, o retorno pode ser modesto, enquanto para ações maiores e pouco frequentes, o retorno pode ser mais substancial". Entendemos que a melhor forma de retorno é mostrar a ação resultante do avatar.

Idealmente, a tela deve ser projetada à frente do usuário, e grande o suficiente para que o usuário veja a ação do jogo mesmo estando ao fundo do quadrilátero útil. A Figura 8.1 mostra um esquema de como deve ser feita a instalação.

A Figura 8.2 ilustra como deve aparecer a tela para o usuário. Observe que os jogadores 
são opacos, as linhas do campo e outros jogadores ficam ocultos atrás do jogador mais próximo. Já o goleiro deve ser renderizado com transparência, para que seja possível ver a bola e outros jogadores em situações de ataque ou batida de pênalti. 


\title{
Apêndice A
}

\section{Biblioteca VisionGL}

\author{
A.1 src/vglImage.h File Reference \\ \#include <iostream> \\ \#include <GL/freeglut_std.h> \\ \#include <GL/freeglut_ext.h> \\ \#include <highgui.h> \\ \#include <cvaux.h> \\ \#include "vglContext.h" \\ \#include "vglImage.h" \\ \#include "vglLoadShader.h" \\ \#include "glsl2cpp_shaders.h"
}

\section{Functions}

- int vglInit () 
- int vglInit (int w, int h)

- void vglUpload (VglImage $*$ image, int swapRGB)

- VglImage $*$ vglCopyCreateImage (VglImage $*$ img_in)

- VglImage $*$ vglCopyCreateImage (IplImage $*$ img_in, int dim3, int has_mipmap)

- VglImage $*$ vglCreateImage (VglImage $*$ img_in)

- VglImage $*$ vglCreateImage (IplImage $*$ img_in, int dim3, int has_mipmap)

- VglImage $*$ vglCreateImage (CvSize size, int depth, int nChannels, int dim3, int has_mipmap)

- void vglReleaseImage (VglImage $* *$ p_image)

- void vglReplaceIpl (VglImage $*$ image, IplImage $*$ new_ipl)

- void vglDownloadFaster (VglImage $*$ image)

- void vglDownload (VglImage $*$ image)

- void vglDownloadFBO (VglImage $*$ image)

- void vglDownloadPPM (VglImage $*$ image)

- void vglDownloadPGM (VglImage $*$ image)

- VglImage $*$ vglLoadImage (char $*$ filename, int iscolor, int has_mipmap)

- void vglPrintImageInfo (VglImage $*$ image)

- void vglCopyImageTex (VglImage $*$ src, VglImage $*$ dst)

- void vglCopyImageTexFS (VglImage $*$ src, VglImage $*$ dst)

- void vglCopyImageTexVFS (VglImage $*$ src, VglImage $*$ dst)

- void vglVerticalFlip2 (VglImage $*$ src, VglImage $*$ dst)

- void vglHorizontalFlip2 (VglImage $*$ src, VglImage $*$ dst)

- void vglClear (VglImage $*$ image, float $r$, float g, float b, float a)

- void vglOpenSq3 (VglImage $*$ src, VglImage $*$ dst, VglImage $*$ buf, int times)

- void vglCloseSq3 (VglImage $*$ src, VglImage $*$ dst, VglImage $*$ buf, int times)

- void vglErodeSq3Sep (VglImage $*$ src, VglImage $*$ dst, VglImage $*$ buf, int times)

- void vglErodeSq5Sep (VglImage $*$ src, VglImage $*$ dst, VglImage $*$ buf, int times) 
- void vglCErodeCross3 (VglImage $*$ src, VglImage $*$ mask, VglImage $*$ dst, VglImage $*$ buf, int times)

- int SavePPM (char $*$ filename, int $\mathrm{w}$, int $\mathrm{h}$, void $*$ savebuf $)$

- int vglSavePPM (Vgllmage $*$ img, char $*$ filename)

- int SavePGM (char $*$ filename, int $\mathrm{w}$, int h, void $*$ savebuf)

- int vglSavePGM (VglImage $*$ img, char $*$ filename)

- IplImage $*$ LoadPGM (char $*$ filename)

- VglImage $*$ vglLoadPGM (char $*$ filename)

- int SaveYUV411 (char $*$ filename, int $\mathrm{w}$, int h, void $*$ savebuf)

- void vglDistTransformCross3 (VglImage $*$ src, VglImage $*$ dst, VglImage $*$ buf, VglImage $*$ buf2, int times)

- void vglDistTransformSq3 (VglImage $*$ src, VglImage $*$ dst, VglImage $*$ buf, VglImage $*$ buf2, int times)

- void vglDistTransform5 (VglImage $*$ src, VglImage $*$ dst, VglImage $*$ buf, VglImage *buf2, int times)

- void vglGetLevelDistTransform5 (VglImage $*$ src, VglImage $*$ dst, VglImage $*$ buf, VglImage $*$ buf2, int times)

- void vglThinBernard (VglImage $*$ src, VglImage $*$ dst, VglImage $*$ buf, int times)

- void vglThinChin (VglImage $*$ src, VglImage $*$ dst, VglImage $*$ buf, int times)

- void vglBaricenterVga (VglImage $*$ src, double $* x \_a v g$, double $* y \_a v g$, double *pix_count)

- void vglMultiOutput_model (VglImage $*$ src, VglImage $*$ dst, VglImage $*$ dst1)

- void vglInOut_model (VglImage $*$ dst, VglImage $*$ dst1)

- void vglMultiInput_model (VglImage $* \operatorname{src0}$, VglImage $* \operatorname{src1}$, VglImage $*$ dst) 


\section{A.1.1 Function Documentation}

\section{A.1.1.1 IplImage $*$ LoadPGM (char $*$ filename)}

Load image data from PGM file, 1 channel, unsigned byte

Referenced by vglLoadPGM().

A.1.1.2 int SavePGM (char $*$ filename, int $w$, int $h$, void $*$ savebuf $)$

Save image data to PGM file, 1 channel, unsigned byte

Referenced by vglSavePGM().

A.1.1.3 int SavePPM (char $*$ filename, int $w$, int $h$, void $*$ savebuf $)$

Save image data to PPM file, 3 channels, unsigned byte

Time to save a VGA image $=3.5 \mathrm{~ms}$

Referenced by vglSavePPM().

A.1.1.4 int SaveYUV411 (char $*$ filename, int $w$, int $h$, void $*$ savebuf)

Save compressed YUV411 image data to file.

Requires one half of the disk space required to save an uncompressed PPM.

A.1.1.5 void vglBaricenterVga (VglImage $* s r c$, double $* x_{-} a v g$, double $*$ y_avg, double $*$ pix_count)

Calculates baricenter of vga image. 
The resuld is stored in image $R G B$ with one pixel. $R=M(0,0)=\operatorname{sum}(f(x, y)) G=$ $\mathrm{M}(1,0)=\operatorname{sum}(\mathrm{x} * \mathrm{f}(\mathrm{x}, \mathrm{y})) \mathrm{B}=\mathrm{M}(0,1)=\operatorname{sum}(\mathrm{y} * \mathrm{f}(\mathrm{x}, \mathrm{y}))$

Reference:

William K. Pratt, Digital Image Processing, Second Edition

References vglBaricenterInit(), vglCreateImage(), vglDownload(), vglSelfSum22(), vglSelfSum3v(), vglSelfSum4h(), vglSelfSum5h(), and vglSelfSum5v().

\section{A.1.1.6 void vglCErodeCross3 (VglImage $*$ src, VglImage $*$ mask, VglImage $*$ dst, VglImage $*$ buf, int times)}

Morpological conditional erosion by cross structuring element 3x3. A buffer is required. Source and destination may be the same.

The structuring element is a $3 \times 3$ cross. The parameter "times" indicates how many times the erosion will be applied.

References vglErodeCross3(), and $\operatorname{vglOr}()$.

\section{A.1.1.7 void vglClear (VglImage $*$ image, float $r$, float $g$, float $b$, float $a$ )}

Referenced by vglDistTransform5(), vglDistTransformCross3(), and vglDistTransformSq3().

\section{A.1.1.8 void vglCloseSq3 (VglImage $*$ src, VglImage $*$ dst, VglImage $*$ buf, int times)}

Morphological closing by square structuring element. A buffer is required. Source and destination may be the same. 
The structuring element is a $3 \times 3$ square. The parameter "times" indicates how many times the closing will be applied.

References vglDilateSq3(), and vglErodeSq3().

\section{A.1.1.9 VglImage $*$ vglCopyCreateImage (IplImage $*$ img_in, int dim3, int has_mipmap)}

Create image with same format and data as img_in

References vglCreateImage(), and vglUpload().

\section{A.1.1.10 VglImage $*$ vglCopyCreateImage (VglImage $*$ img_in)}

Create image with same format and data as img_in.

References $\operatorname{vglCopy}()$, and vglCreateImage().

\section{A.1.1.11 void vglCopyImageTex (VglImage $* s r c, \quad$ VglImage $* d s t)$}

Copy data from src texture to dst texture

\section{A.1.1.12 void vglCopyImageTexFS (VglImage $*$ src, VglImage $* d s t)$}

Copy data from src texture to dst texture using a fragment shader

\section{A.1.1.13 void vglCopyImageTexVFS (VglImage $* s r c$, VglImage $*$ dst)}

Copy data from src texture to dst texture using a fragment shader and a vertex shader 
A.1.1.14 VglImage* vglCreateImage (CvSize size, int depth, int nChannels, int dim3, int has_mipmap)

Create image as described by the parameters

References vglUpload().

\section{A.1.1.15 VglImage* vglCreateImage (IplImage $*$ img_in, int dim3, int has_mipmap)}

Create image with same format as img_in

References vglCreateImage().

\section{A.1.1.16 VglImage $*$ vglCreateImage (VglImage $* \mathbf{i m g}$ in)}

Create image with same format as img_in

Referenced by vglBaricenterVga(), vglCopyCreateImage(), vglCreateImage(), and vgl$\operatorname{LoadPGM}()$.

\section{A.1.1.17 void vglDistTransform5 (VglImage $*$ src, VglImage $* d s t$, VglImage $*$ buf, VglImage $*$ buf2, int times)}

Distance transform given by alternating an elementary cross and a square $3 \times 3$.

Perform successive erorions on input image thresholded to $1 / 256$. The sum of the erosions results is returned as the distance transform result.

References vglClear(), vglCopy(), vglErodeCross3(), vglErodeSq3(), vglSum(), and $\operatorname{vglThresh}()$. 


\section{A.1.1.18 void vglDistTransformCross3 (VglImage $*$ src, VglImage $*$ dst,} VglImage $* b u f, \quad$ VglImage $*$ buf', int times)

Distance transform given by elementary cross.

Perform successive erorions on input image thresholded to $1 / 256$. The sum of the erosions results is returned as the distance transform result.

References vglClear(), vglErodeCross3(), vglSum(), and vglThresh().

\section{A.1.1.19 void vglDistTransformSq3 (VglImage $*$ src, VglImage $* d s t$, VglImage $* b u f, \quad$ VglImage $*$ buf2, int times)}

Distance transform given by square $3 \times 3$.

Perform successive erorions on input image thresholded to $1 / 256$. The sum of the erosions results is returned as the distance transform result.

References vglClear(), vglErodeSq3(), vglSum(), and vglThresh().

\section{A.1.1.20 void vglDownload (VglImage $*$ image)}

Force transfer of image from GPU to RAM. Add RAM as valid context.

Transfer done by glGetTexImage. Color order is compatible with iplImage, that is, BGR.

Time to transfer a VGA image $=2.5 \mathrm{~ms}$

References vglPrintImageInfo().

Referenced by vglBaricenterVga(). 


\section{A.1.1.21 void vglDownloadFaster (VglImage $*$ image)}

Force transfer of image from GPU to RAM. Add RAM as valid context.

Transfer done by glReadPixels. Color order is compatible with iplImage, that is, BGR.

Time to transfer a VGA image $=1.0$ to $1.5 \mathrm{~ms}$

References vglPrintImageInfo().

\section{A.1.1.22 void vglDownloadFBO (VglImage $*$ image)}

Force transfer of image from FBO to RAM. Add RAM as valid context.

Transfer done by glReadPixels. Color order is compatible with iplImage, that is, BGR.

References vglPrintImageInfo().

\section{A.1.1.23 void vglDownloadPGM (VglImage $*$ image $)$}

Transfer image from GPU to RAM in format suitable for saving as PGM.

Use it imediately before vglSavePGM. It is different from vglDownload in two points. The unpack alignment is 1 and color is grayscale

Time to transfer a VGA image $=10 \mathrm{~ms}$

Referenced by vglSavePGM().

\section{A.1.1.24 void vglDownloadPPM (VglImage $*$ image)}

Transfer image from GPU to RAM in format suitable for saving as PPM.

Use it imediately before vglSavePPM. It is different from vglDownload in two points. The unpack alignment is 1 and color order is RGB 
Time to transfer a VGA image $=3 \mathrm{~ms}$

Referenced by vglSavePPM().

\section{A.1.1.25 void vglErodeSq3Sep (VglImage $*$ src, VglImage $*$ dst, VglImage * buf, int times)}

Morpological erosion by square structuring element $3 \times 3$. A buffer is required. Source and destination may be the same.

The structuring element is a $3 \times 3$ square. The parameter "times" indicates how many times the erosion will be applied.

References vglErodeHL3(), and vglErodeVL3().

\section{A.1.1.26 void vglErodeSq5Sep (VglImage $*$ src, VglImage $*$ dst, VglImage * buf, int times)}

Morpological erosion by square structuring element $5 \times 5$. A buffer is required. Source and destination may be the same.

The structuring element is a $5 \times 5$ square. The parameter "times" indicates how many times the erosion will be applied.

References vglErodeHL5(), and vglErodeVL5().

\section{A.1.1.27 void vglGetLevelDistTransform5 (VglImage $*$ src, VglImage $* d s t$, VglImage $*$ buf, VglImage $*$ buf2, int times)}

Get level curve of distance transform5

Perform successive erorions on input image thresholded to $1 / 256$. The returned image 
is the difference between the results obtained in the iterations "times" and "times" - 1 .

References vglAbsDiff(), vglCopy(), vglErodeCross3(), and vglErodeSq3().

\section{A.1.1.28 void vglHorizontalFlip2 (VglImage $*$ src, VglImage $*$ dst)}

Flip image horizontally, that is, left becomes right.

Image flip done by texture mapping, that is, by the fixed pipeline.

\section{A.1.1.29 int vglInit (int $w$, int $h$ )}

Initialize GLUT and create output window with size (w, h).

\section{A.1.1.30 int vglInit ()}

Initialize GLUT and create output window with default size (1280, 960).

Referenced by vglUpload().

\section{A.1.1.31 void vglInOut_model (VglImage $*$ dst, $\quad$ VglImage $*$ dst1)}

Test and model for IN_OUT semantics.

First parameter is input and output. Second parameter is output.

\section{A.1.1.32 VglImage* vglLoadImage (char $*$ filename, int iscolor, int has_mipmap)}

Load image from file to new VglImage.

This function uses cvLoadImage to read image file. 
References vglUpload().

\section{A.1.1.33 VglImage $*$ vglLoadPGM (char $*$ filename)}

Load image from PGM file, 1 channel, unsigned byte

References LoadPGM(), and vglCreateImage().

\section{A.1.1.34 void vglMultiInput_model (VglImage $* \operatorname{srcO}, \quad$ VglImage $* \operatorname{src} 1$, VglImage $*$ dst)}

Test and model for functions with multiple input images.

First and second parameters are input. Third parameter is output.

\section{A.1.1.35 void vglMultiOutput_model (VglImage $*$ src, VglImage $* d s t$, VglImage $*$ dst1)}

Test and model for functions with multiple output images.

First parameter is input. Second and third parameters are output.

\section{A.1.1.36 void vglOpenSq3 (VglImage $*$ src, VglImage $*$ dst, VglImage $*$ buf, int times)}

Morpological opening by square structuring element. Opening is an erosion followed by a dilation. A buffer is required. Source and destination may be the same.

The structuring element is a $3 \times 3$ square. The parameter "times" indicates how many times the erosion will be applied.

References vglDilateSq3(), and vglErodeSq3(). 


\section{A.1.1.37 void vglPrintImageInfo (VglImage $*$ image)}

Print information about image.

Print width, height, depth, number of channels, OpenGL texture handler, OpenGL FBO handler, and current valid context (RAM, GPU or FBO).

Referenced by $\operatorname{vglDownload}(), \operatorname{vglDownloadFaster}(), \operatorname{vglDownloadFBO}()$, and $\operatorname{vglU}$ $\operatorname{pload}()$.

\section{A.1.1.38 void vglReleaseImage (VglImage $* * p_{-}$image)}

Release memory occupied by image in RAM and GPU

\section{A.1.1.39 void vglReplaceIpl (VglImage $*$ image, IplImage $\left.* n e w \_i p l\right)$}

Replace IplImage, stored inside a VglImage, with new IplImage.

Both new and old images must have exactly the same properties, dimensions, depth, type etc. Is useful when grabbing frames from a camera.

References vglUpload().

\section{A.1.1.40 int vglSavePGM (VglImage $*$ img, char $*$ filename)}

Save image to PGM file, 1 channel, unsigned byte

References SavePGM(), and $\operatorname{vglDownloadPGM().~}$

\section{A.1.1.41 int vglSavePPM (VglImage $*$ img, char $*$ filename $)$}

Save image to PPM file, 3 channels, unsigned byte 
References SavePPM(), and $\operatorname{vglDownloadPPM}()$.

\section{A.1.1.42 void vglThinBernard (VglImage $*$ src, VglImage $*$ dst, VglImage * buf, int times)}

Structuring element thinning. Algorithm by Bernard and Manzanera 1999.

Receive as input the image to be thinned. The second image is an auxiliary image. The third image stores the result. Both the second and third images must have the same size and type as the first input image.

The fourth parameter is the number of iterations.

Reference:

M. Couprie, Note on fifteen 2D parallel thinning algorithms, 2006

T. M. Bernard and A. Manzanera, Improved low complexity fully parallel thinning algorithms, 1999

References $\operatorname{vglCopy}(), \operatorname{vglErodeCross} 3()$, and vglThinBernardAux().

\section{A.1.1.43 void vglThinChin (VglImage $* s r c, \quad$ VglImage $*$ dst, $\quad$ VglImage $*$ buf, int times)}

Structuring element thinning. Algorithm by Chin, Wan Stover and Iverson, 1987.

Receive as input the image to be thinned, buffer image and number of times to iterate.

Neighborhood pixels are indexed as follows:

$$
\left(\begin{array}{ccc}
P 3 & P 2 & P 1 \\
P 4 & P 8 & P 0 \\
P 5 & P 6 & P 7
\end{array}\right)
$$


Reference:

M. Couprie, Note on fifteen 2D parallel thinning algorithms, 2006

R. T. Chin et al., A one-pass thinning algorithm and its parallel implementation, 1987 References $\operatorname{vglCopy}()$, and vglThinChinAux().

\section{A.1.1.44 void vglUpload (VglImage $*$ image, int swapRGB)}

Send image data from RAM to GPU. Add GPU as valid context.

If swapRGB is true, channels $\mathrm{R}$ and $\mathrm{B}$ are swapped.

References vglInit(), and vglPrintImageInfo().

Referenced by vglCopyCreateImage(), vglCreateImage(), vglLoadImage(), and vglReplaceIpl().

\section{A.1.1.45 void vglVerticalFlip2 (VglImage $*$ src, VglImage $*$ dst)}

Flip image vertically, that is, top becomes bottom.

Image flip done by texture mapping, that is, by the fixed pipeline.

\section{A.2 src/glsl2cpp_BG.h File Reference}

\#include "vglimage.h" 


\section{Functions}

- void vglDetectFGSimpleBGModel (VglImage *img_in, VglImage *average, VglImage $*$ variance, VglImage $*$ foreground, float std_thresh)

- void vglTrainSimpleBGModel (VglImage $*$ img_in, VglImage *average, VglImage *variance, float weight)

- void vglUpdatePartialSimpleBGModel (VglImage $*$ img_in, VglImage $*$ foregorundClose, VglImage $*$ average, VglImage $*$ variance, float weight)

\section{A.2.1 Function Documentation}

\section{A.2.1.1 void vglDetectFGSimpleBGModel (VglImage $*$ img_in, VglImage * average, VglImage $*$ variance, VglImage $*$ foreground, float std_thresh)}

Detects foreground pixels.

\section{A.2.1.2 void vglTrainSimpleBGModel (VglImage $*$ img_in, VglImage $*$ average, VglImage $*$ variance, float weight)}

Updates average and variance of background model.

\section{A.2.1.3 void vglUpdatePartialSimpleBGModel (VglImage $* i m g \_i n$, VglImage $*$ foregorundClose, VglImage $*$ average, VglImage $*$ variance, float weight)}

Updates average and variance of background model only in pixels that are classified as background. 


\section{A.3 src/glsl2cpp_shaders.h File Reference}

\#include "vglimage.h"

\section{Functions}

- void vgl1to3Channels (VglImage $*$ src, VglImage $*$ dst)

- void vglAbsDiff (VglImage $* \operatorname{src} 0$, VglImage $* \operatorname{src} 1$, VglImage $*$ dst)

- $\operatorname{void}$ vglAnd (VglImage $*$ src0, VglImage $* \operatorname{src} 1$, VglImage $*$ dst)

- void vglBaricenterInit (VglImage $*$ src, VglImage $*$ dst)

- $\operatorname{void}$ vglClear2 (VglImage $*$ src_dst, float $\mathrm{r}$, float g, float b, float $\mathrm{a}=0.0$ )

- void vglContrast (VglImage $*$ src, VglImage $*$ dst, float factor)

- void vglCoordToColor (VglImage $*$ dst)

- void vglCopy (VglImage $*$ src, VglImage $*$ dst)

- void vglCrossingNumber (VglImage $*$ src, VglImage $*$ dst)

- void vglDeleteSkeletonCorners (VglImage $*$ src, VglImage $*$ dst, int step)

- void vglDeleteSkeletonWarts (VglImage $*$ src, VglImage $*$ dst)

- void vglDeleteSkeletonWarts2 (VglImage $*$ src, VglImage $*$ dst)

- void vglDiff (VglImage $*$ src0, VglImage $*$ src1, VglImage $*$ dst)

- void vglDilateCross3 (VglImage $*$ src, VglImage $*$ dst)

- void vglDilateSq3 (VglImage $*$ src, VglImage $*$ dst)

- void vglErodeCross3 (VglImage $*$ src, VglImage $*$ dst)

- void vglErodeHL3 (VglImage $*$ src, VglImage $*$ dst)

- void vglErodeHL5 (VglImage $*$ src, VglImage $*$ dst)

- void vglErodeHL7 (VglImage $*$ src, VglImage $*$ dst)

- void vglErodeSq3 (VglImage $*$ src, VglImage $*$ dst) 
- void vglErodeSq3off (VglImage $*$ src, VglImage $*$ dst)

- void vglErodeSq5 (VglImage $*$ src, VglImage $*$ dst)

- void vglErodeSq5off (VglImage $*$ src, VglImage $*$ dst)

- void vglErodeSq7 (VglImage $*$ src, VglImage $*$ dst)

- void vglErodeSqSide (VglImage $*$ src, VglImage $*$ dst, int side)

- void vglErodeVL3 (VglImage $*$ src, VglImage $*$ dst)

- void vglErodeVL5 (VglImage $*$ src, VglImage $*$ dst)

- void vglErodeVL7 (VglImage $*$ src, VglImage $*$ dst)

- void vglFeaturePoints (VglImage $*$ src, VglImage $*$ dst, int type)

- void vglGaussianBlurSq3 (VglImage $*$ src, VglImage $*$ dst)

- $\operatorname{void}$ vglGray (VglImage $*$ src, VglImage $*$ dst)

- void vglHorizontalFlip (VglImage $*$ src, VglImage $*$ dst)

- void vglJulia (VglImage $*$ dst, float $\mathrm{ox}=0.0$, float $\mathrm{oy}=0.0$, float half_win $=1.0$, float c_real $=-1.36$, float $\mathrm{c} \_$imag $=.11$ )

- void vglLaplaceSq3 (VglImage $*$ src, VglImage $*$ dst)

- $\operatorname{void}$ vglMandel (VglImage $*$ dst, float ox $=0.0$, float oy=0.0, float half_win=1.0)

- void vglMipmap (VglImage $*$ src, VglImage $*$ dst, float lod)

- void vglMulScalar (VglImage $*$ src, VglImage $*$ dst, float factor)

- void vglNoise (VglImage $*$ src, VglImage $*$ dst)

- $\operatorname{void} \operatorname{vglNot}($ VglImage $*$ src, VglImage $*$ dst)

- void vglOr (VglImage $* \operatorname{src} 0$, VglImage $* \operatorname{src} 1$, VglImage $*$ dst)

- void vglRescale (VglImage $*$ src, VglImage $*$ dst, float $\mathrm{x} 0$, float y0, float $\mathrm{x} 1$, float y1)

- void vglRgbToHsl (VglImage $*$ src, VglImage $*$ dst)

- void vglRgbToHsv (VglImage $*$ src, VglImage $*$ dst)

- void vglRgbToXyz (VglImage $*$ src, VglImage $*$ dst)

- void vglRobertsGradient (VglImage $*$ src, VglImage $*$ dst) 
- void vglSelfSum22 (VglImage $*$ src, VglImage $*$ dst)

- void vglSelfSum3v (VglImage $*$ src, VglImage $*$ dst)

- void vglSelfSum4h (VglImage $*$ src, VglImage $*$ dst)

- void vglSelfSum5h (VglImage $*$ src, VglImage $*$ dst)

- void vglSelfSum5v (VglImage $*$ src, VglImage $*$ dst)

- void vglSharpenSq3 (VglImage $*$ src, VglImage $*$ dst)

- void vglSobelGradient (VglImage $*$ src, VglImage $*$ dst)

- void vglSobelXSq3 (VglImage $*$ src, VglImage $*$ dst)

- void vglSobelYSq3 (VglImage $*$ src, VglImage $*$ dst)

- void vglSum (VglImage $* \operatorname{src0}$, VglImage $* \operatorname{src} 1$, VglImage $*$ dst)

- void vglSumWeighted (VglImage $*$ src0, VglImage $*$ src1, VglImage $*$ dst, float weight $=.5)$

- void vglSwapRGB (VglImage $*$ src, VglImage $*$ dst)

- void vglTestInOut (VglImage $*$ src_dst, float $\mathrm{r}$, float $\mathrm{g}$, float b, float a=0.0)

- void vglTestInOut2 (VglImage $*$ src_dst, VglImage $*$ dst)

- void vglTestMultiInput (VglImage $*$ src0, VglImage $* \operatorname{src1}$, VglImage $*$ dst, float weight $=.5$ )

- void vglTestMultiOutput (VglImage $*$ src, VglImage $*$ dst, VglImage $*$ dst1)

- void vglThinBernardAux (VglImage $*$ src, VglImage $*$ eroded, VglImage $*$ dst)

- void vglThinChinAux (VglImage $*$ src, VglImage $*$ dst)

- void vglThresh (VglImage $*$ src, VglImage $*$ dst, float thresh, float top $=1.0$ )

- $\operatorname{void}$ vglThreshLevelSet (VglImage $*$ src, VglImage $*$ dst, float thresh, float top=1.0)

- void vglVerticalFlip (VglImage $*$ src, VglImage $*$ dst)

- void vglWhiteRohrerEdge (VglImage $*$ src, VglImage $*$ dst, float radius)

- void vglXGY (VglImage $*$ src, VglImage $*$ dst) 


\section{A.3.1 Function Documentation}

\section{A.3.1.1 void vgl1to3Channels (VglImage $*$ src, VglImage $* d s t$ )}

Convert grayscale image to RGB.

\section{A.3.1.2 void vglAbsDiff (VglImage $* \operatorname{src} 0, \quad$ VglImage $*$ src1, VglImage $*$ $d s t)$}

Absolute difference between two images.

Referenced by vglGetLevelDistTransform5().

\section{A.3.1.3 void vglAnd (VglImage $* \operatorname{src0}, \quad$ VglImage $* \operatorname{src} 1, \quad$ VglImage $* d s t)$}

Logical AND between two images.

\section{A.3.1.4 void vglBaricenterInit (VglImage $*$ src, VglImage $* d s t)$}

Initialize image to be used in baricenter calculation. The initialization is done by storing the values $(1, \mathrm{x}, \mathrm{y})$ in each output pixel so that the summation over th whole image gives the three moments of the image.

$$
\begin{aligned}
& \mathrm{R}=\mathrm{f}(\mathrm{x}, \mathrm{y}) \\
& \mathrm{G}=\mathrm{x} * \mathrm{f}(\mathrm{x}, \mathrm{y}) \\
& \mathrm{B}=\mathrm{y} * \mathrm{f}(\mathrm{x}, \mathrm{y})
\end{aligned}
$$

Referenced by vglBaricenterVga(). 
A.3.1.5 void vglClear2 (VglImage $* s r c \_d s t$, float $r$, float $g$, float $b$, float $a$ $=0.0)$

Clear image with given color.

\section{A.3.1.6 void vglContrast (VglImage $*$ src, VglImage $*$ dst, float factor)}

Changes contrast of image by given factor.

\section{A.3.1.7 void vglCoordToColor (VglImage $* d s t)$}

Shows coordinates of pixels as colors. Red is horizontal and green is vertical. Coordinates and colors are defined by OpenGL, that is, between 0 and 1.

\section{A.3.1.8 void vglCopy (VglImage $*$ src, $\quad$ VglImage $*$ dst $)$}

Direct copy from src to dst.

Referenced by vglCopyCreateImage(), vglDistTransform5(), vglGetLevelDistTransform5(), $\operatorname{vglThinBernard}()$, and $\operatorname{vglThinChin}()$.

\section{A.3.1.9 void vglCrossingNumber (VglImage $*$ src, VglImage $* d s t)$}

Crossing number is defined as the number of ocurrences of the pattern 01 in the neihborhood of a pixel.

Neighborhood of pixel $\mathrm{P}$ is indexed as follows:

$$
\left(\begin{array}{ccc}
P 3 & P 2 & P 1 \\
P 4 & P & P 0 / 8 \\
P 5 & P 6 & P 7
\end{array}\right)
$$


References:

M. Couprie, Note on fifteen 2D parallel thinning algorithms, 2006

T. M. Bernard and A. Manzanera, Improved low complexity fully parallel thinning algorithms, 1999

\section{A.3.1.10 void vglDeleteSkeletonCorners (VglImage $*$ src, VglImage $* d s t$, int step)}

Deletes corner from skeleton.

Receive as input the image with the skeleton to be thinned. Receives also the step. must be called once with step 1 and once with step 2 .

Neighborhood pixels is indexed as follows:

$$
\left(\begin{array}{ccc}
P 3 & P 2 & P 1 \\
P 4 & P 8 & P 0 \\
P 5 & P 6 & P 7
\end{array}\right)
$$

Pixels deleted are the ones that mach the pattern and its rotations by 90deg.

$$
\left(\begin{array}{lll}
0 & 0 & x \\
0 & 1 & 1 \\
x & 1 & 0
\end{array}\right)
$$

References:

M. Couprie, Note on fifteen 2D parallel thinning algorithms, 2006

T. M. Bernard and A. Manzanera, Improved low complexity fully parallel thinning algorithms, 1999 


\section{A.3.1.11 void vglDeleteSkeletonWarts (VglImage $*$ src, VglImage $*$ dst)}

Deletes warts from skeleton. Receive as input the image with the skeleton to be thinned. Neighborhood pixels are indexed as follows:

$$
\left(\begin{array}{ccc}
P 3 & P 2 & P 1 \\
P 4 & P & P 0 / 8 \\
P 5 & P 6 & P 7
\end{array}\right)
$$

Pixels deleted are the ones that mach the pattern and its rotations by $45 \mathrm{deg}$.

$$
\left(\begin{array}{lll}
1 & 0 & 0 \\
1 & 1 & 0 \\
1 & 0 & 0
\end{array}\right)
$$

That is the same as delete the pixels with crossing number $=1$ and neighbor number $=3$.

References:

Ke Liu et al., Identification of fork points on the skeletons of handwritten chinese characters

\section{A.3.1.12 void vglDeleteSkeletonWarts2 (VglImage $*$ src, VglImage $* d s t)$}

Deletes warts from skeleton. Receive as input the image with the skeleton to be thinned. Neighborhood pixels are indexed as follows:

$$
\left(\begin{array}{ccc}
P 3 & P 2 & P 1 \\
P 4 & P & P 0 / 8 \\
P 5 & P 6 & P 7
\end{array}\right)
$$

Pixels deleted are the ones that mach the pattern and its rotations by $45 \mathrm{deg}$. 


$$
\left(\begin{array}{lll}
1 & 0 & 0 \\
1 & 1 & 0 \\
1 & 0 & 0
\end{array}\right),\left(\begin{array}{lll}
1 & 1 & 0 \\
1 & 1 & 0 \\
1 & 0 & 0
\end{array}\right),\left(\begin{array}{lll}
1 & 1 & 0 \\
1 & 1 & 0 \\
1 & 1 & 0
\end{array}\right),\left(\begin{array}{lll}
1 & 1 & 1 \\
1 & 1 & 0 \\
1 & 1 & 0
\end{array}\right),\left(\begin{array}{lll}
1 & 1 & 1 \\
1 & 1 & 0 \\
1 & 1 & 1
\end{array}\right)
$$

That is the same as delete the pixels with crossing number $=1$ and neighbor number $>=3$.

\section{References:}

Ke Liu et al., Identification of fork points on the skeletons of handwritten chinese characters

\section{A.3.1.13 void vglDiff (VglImage $* \operatorname{src0}, \quad$ VglImage $* \operatorname{src} 1, \quad$ VglImage $* d s t)$}

Image src0 minus src1.

\section{A.3.1.14 void vglDilateCross3 (VglImage $*$ src, VglImage $* d s t)$}

Dilation of image by $3 \times 3$ cross structuring element.

\section{A.3.1.15 void vglDilateSq3 (VglImage $*$ src, VglImage $*$ dst)}

Dilation of image by $3 \times 3$ square structuring element.

Referenced by vglCloseSq3(), and vglOpenSq3().

\section{A.3.1.16 void vglErodeCross3 (VglImage $*$ src, VglImage $*$ dst)}

Erosion of image by $3 \times 3$ cross structuring element.

Referenced by vglCErodeCross3(), vglDistTransform5(), vglDistTransformCross3(), $\operatorname{vglGetLevelDistTransform5(),~and~} \operatorname{vglThinBernard}()$. 


\section{A.3.1.17 void vglErodeHL3 (VglImage $* s r c, \quad$ VglImage $* d s t$ )}

Erosion of image by horizontal line with 3 pixels.

Referenced by vglErodeSq3Sep().

\section{A.3.1.18 void vglErodeHL5 (VglImage $*$ src, VglImage $* d s t$ )}

Erosion of image by horizontal line with 5 pixels.

Referenced by vglErodeSq5Sep().

\section{A.3.1.19 void vglErodeHL7 (VglImage $*$ src, VglImage $*$ dst)}

Erosion of image by horizontal line with 7 pixels.

\section{A.3.1.20 void vglErodeSq3 (VglImage $*$ src, VglImage $* d s t$ )}

Erosion of image by $3 \times 3$ square structuring element.

Referenced by vglCloseSq3(), vglDistTransform5(), vglDistTransformSq3(), vglGetLevelDistTransform5(), and vglOpenSq3().

\section{A.3.1.21 void vglErodeSq3off (VglImage $*$ src, VglImage $*$ dst)}

Erosion of image by $3 \times 3$ square structuring element. Uses an offset array with 9 elements. Slower than vglErodeSq3.

\section{A.3.1.22 void vglErodeSq5 (VglImage $*$ src, VglImage $* d s t$ )}

Erosion of image by $5 \times 5$ square structuring element. 


\section{A.3.1.23 void vglErodeSq5off (VglImage $*$ src, VglImage $*$ dst $)$}

Erosion of image by $3 \times 3$ square structuring element. Uses an offset array with 25 elements. Slower than vglErodeSq5.

\section{A.3.1.24 void vglErodeSq7 (VglImage $* s r c, \quad$ VglImage $* d s t)$}

Erosion of image by $7 \times 7$ square structuring element.

\section{A.3.1.25 void vglErodeSqSide (VglImage $*$ src, VglImage $*$ dst, int side)}

Erosion of image by square structuring element. The parameter "side" is the dimension of the square side in pixels.

\section{A.3.1.26 void vglErodeVL3 (VglImage $*$ src, VglImage $* d s t)$}

Erosion of image by vertical line with 3 pixels.

Referenced by vglErodeSq3Sep () .

\section{A.3.1.27 void vglErodeVL5 (VglImage $*$ src, VglImage $* d s t)$}

Erosion of image by vertical line with 5 pixels.

Referenced by vglErodeSq5Sep () .

\section{A.3.1.28 void vglErodeVL7 (VglImage $*$ src, VglImage $* d s t)$}

Erosion of image by vertical line with 7 pixels. 


\section{A.3.1.29 void vglFeaturePoints (VglImage $*$ src, VglImage $*$ dst, int type)}

Feature Points are defined as function of the crossing number and number of neighbors of a pixel.

The number of neighbors is indicated as $\mathrm{Nb}$. Crossing number is defined as

$\mathrm{Nc}=$ number of occurrences of the pattern 01 in the neighborhood of $\mathrm{P}$

Neighborhood pixels are indexed as follows:

$$
\left(\begin{array}{ccc}
P 3 & P 2 & P 1 \\
P 4 & P & P 0 \\
P 5 & P 6 & P 7
\end{array}\right)
$$

All the ending points are feature points. Are defined as $\mathrm{Se}=\{\mathrm{P} \mid \mathrm{Nc}(\mathrm{P})=1\}$.

Feature points type 1 , denoted as $\mathrm{S} 1$, are defined as $\mathrm{S} 1=\{\mathrm{P} \mid \mathrm{Nc}(\mathrm{P})>=3\}$.

Feature points type 2, denoted as $\mathrm{S} 2$, are defined as $\mathrm{S} 1=\{\mathrm{P} \mid \mathrm{Nb}(\mathrm{P})>=3\}$.

Feature points type 3, denoted as $\mathrm{S} 3$, are defined as $\mathrm{S} 3=\{\mathrm{P} \mid \mathrm{Nc}(\mathrm{P})>=3$ or $\mathrm{Nb}(\mathrm{P})$ $>=4\}$.

References:

Ke Liu et al., Identification of fork points on the skeletons of handwritten chinese characters

\section{A.3.1.30 void vglGaussianBlurSq3 (VglImage $*$ src, VglImage $* d s t$ )}

Blurs image by $3 \times 3$ square gaussian structuring element. 


\section{A.3.1.31 void vglGray (VglImage $*$ src, VglImage $*$ dst)}

Convert image to grayscale by calculating the scalar product of (r, g, b) and (.2125, .7154, $.0721)$.

\section{A.3.1.32 void vglHorizontalFlip (VglImage $*$ src, VglImage $*$ dst)}

Flip image horizontally i.e. left becomes right.

A.3.1.33 void vglJulia (VglImage $*$ dst, float $o x=0.0$, float $o y=0.0$, float $h a l f_{-} w i n=1.0$, float $c_{-}$real $=-1.36$, float $\left.c_{-} i m a g=.11\right)$

Calculate Julia set.

A.3.1.34 void vglLaplaceSq3 (VglImage $*$ src, VglImage $* d s t)$

Laplacian of image by $3 \times 3$ square structuring element.

A.3.1.35 void vglMandel (VglImage $* d s t$, float $o x=0.0$, float $o y=0.0$, float half_win $_{-}=1.0$ )

Calculate Mandelbrot set.

A.3.1.36 void vglMipmap (VglImage $*$ src, VglImage $*$ dst, float lod)

Get specified level of detail. 
A.3.1.37 void vglMulScalar (VglImage $*$ src, VglImage $*$ dst, float factor)

Multiply image by scalar.

A.3.1.38 void vglNoise (VglImage $*$ src, VglImage $* d s t)$

Add gaussian noise to image.

A.3.1.39 void vglNot (VglImage $*$ src, $\quad$ VglImage $* d s t)$

Inverts image.

A.3.1.40 void vglOr (VglImage $* \operatorname{src} 0, \quad$ VglImage $* \operatorname{src1}, \quad$ VglImage $* d s t)$

Logical OR between two images.

Referenced by vglCErodeCross3().

A.3.1.41 void vglRescale (VglImage $*$ src, VglImage $*$ dst, float $x 0$, float $y 0$, float $x 1$, float $y 1$ )

Rescales corners of image to given corners.

A.3.1.42 void vglRgbToHsl (VglImage $*$ src, VglImage $* d s t)$

Converts image RGB to HSL color space.

A.3.1.43 void vglRgbToHsv (VglImage $*$ src, VglImage $* d s t)$

Converts image RGB to HSV color space. 


\section{A.3.1.44 void vglRgbToXyz (VglImage $*$ src, VglImage $* d s t)$}

Converts image RGB to XYZ color space.

\section{A.3.1.45 void vglRobertsGradient (VglImage $*$ src, VglImage $* d s t)$}

Roberts gradient of image.

\section{A.3.1.46 void vglSelfSum22 (VglImage $* s r c, \quad$ VglImage $* d s t)$}

Stores in output pixel the sum of 4 adjacent pixels of the input image. The width and height of the output image must be half of the input image.

Referenced by vglBaricenterVga().

\section{A.3.1.47 void vglSelfSum3v (VglImage $*$ src, $\quad$ VglImage $* d s t)$}

Stores in output pixel the sum of 3 adjacent pixels of the input image. The height of the output image must be $1 / 3$ th of the input image.

Referenced by vglBaricenterVga().

\section{A.3.1.48 void vglSelfSum4h (VglImage $*$ src, VglImage $* d s t)$}

Stores in output pixel the sum of 4 adjacent pixels of the input image. The width of the output image must be $1 / 4$ th of the input image.

Referenced by vglBaricenterVga(). 


\section{A.3.1.49 void vglSelfSum5h (VglImage $*$ src, VglImage $* d s t)$}

Stores in output pixel the sum of 5 adjacent pixels of the input image. The width of the output image must be $1 / 5$ th of the input image.

Referenced by vglBaricenterVga().

\section{A.3.1.50 void vglSelfSum5v (VglImage $*$ src, VglImage $*$ dst)}

Stores in output pixel the sum of 5 adjacent pixels of the input image. The height of the output image must be $1 / 5$ th of the input image.

Referenced by vglBaricenterVga().

\section{A.3.1.51 void vglSharpenSq3 (VglImage $*$ src, VglImage $* d s t)$}

Sharpens image using 3x3 square window.

\section{A.3.1.52 void vglSobelGradient (VglImage $* s r c, \quad$ VglImage $* d s t)$}

Sobel gradient of image.

\section{A.3.1.53 void vglSobelXSq3 (VglImage $* s r c$, VglImage $* d s t$ )}

Sobel edge filtering in $\mathrm{X}$ direction.

\section{A.3.1.54 void vglSobelYSq3 (VglImage $* s r c$, VglImage $* d s t)$}

Sobel edge filtering in $\mathrm{Y}$ direction. 
A.3.1.55 void vglSum (VglImage $* \operatorname{src0}, \quad$ VglImage $* \operatorname{src1}, \quad$ VglImage $* d s t)$

Sum of two images.

Referenced by vglDistTransform5(), vglDistTransformCross3(), and vglDistTransformSq3().

\section{A.3.1.56 void vglSumWeighted (VglImage $*$ src0, VglImage $*$ src1, VglImage $*$ dst, float weight $=.5)$}

Weighted sum of two images. The first image is multiplied by weight, and the second, by 1 - weight. Default weight is 0.5 .

\section{A.3.1.57 void vglSwapRGB (VglImage $*$ src, VglImage $* d s t)$}

Convert image from RGB to BGR and vice versa.
A.3.1.58 void vglTestInOut (VglImage $* s r c_{-} d s t$, float $r$, float $g$, float $b$, float $a=0.0)$

Test and model for IN_OUT semantics.

\section{A.3.1.59 void vglTestInOut2 (VglImage $*$ src_dst, $\quad$ VglImage $* d s t)$}

Test and model for IN_OUT semantics, with double output.

\section{A.3.1.60 void vglTestMultiInput (VglImage $*$ srco, VglImage $*$ src1, VglImage $*$ dst, float weight $=.5$ )}

Test and model for multiple input functions. 


\section{A.3.1.61 void vglTestMultiOutput (VglImage $*$ src, VglImage $* d s t$, VglImage $*$ dst1)}

Test and model for multiple output functions.

\section{A.3.1.62 void vglThinBernardAux (VglImage $*$ src, VglImage $*$ eroded, VglImage $* d s t)$}

Return one step of thinning. Algorithm by Bernard and Manzanera 1999. Receive as input the image to be thinned and its erosion by a elementary cross structuring element. Neighborhood pixels are indexed as follows:

$$
\left(\begin{array}{ccc}
P 3 & P 2 & P 1 \\
P 4 & P 8 & P 0 \\
P 5 & P 6 & P 7
\end{array}\right)
$$

References:

M. Couprie, Note on fifteen 2D parallel thinning algorithms, 2006

T. M. Bernard and A. Manzanera, Improved low complexity fully parallel thinning algorithms, 1999

Referenced by vglThinBernard().

\section{A.3.1.63 void vglThinChinAux (VglImage $*$ src, VglImage $*$ dst)}

Return one step of thinning. Algorithm by Chin, Wan Stover and Iverson, 1987. Receive as input the image to be thinned, buffer image and number of times to iterate. Neighborhood pixels are indexed as follows: 


$$
\left(\begin{array}{ccccc}
x & x & P 10 & x & x \\
x & P 3 & P 2 & P 1 & x \\
P 11 & P 4 & P 0 & P 8 & P 9 \\
x & P 5 & P 6 & P 7 & x \\
x & x & P 12 & x & x
\end{array}\right)
$$

References:

M. Couprie, Note on fifteen 2D parallel thinning algorithms, 2006

R. T. Chin et al., A one-pass thinning algorithm and its parallel implementation, 1987

Referenced by vglThinChin().

\section{A.3.1.64 void vglThresh (VglImage $*$ src, VglImage $*$ dst, float thresh, float top $=1.0$ )}

Threshold of image. If value is greater than threshold, output is top, else, output is 0 .

Default top value is 1 .

Referenced by vglDistTransform5(), vglDistTransformCross3(), and vglDistTransformSq3().

\section{A.3.1.65 void vglThreshLevelSet (VglImage $*$ src, VglImage $*$ dst, float thresh, float top $=1.0$ )}

Threshold of image. If value is equal to level, output is top, else, output is 0. Default top value is 1 . Use after some Distance Transform to get a single distance level set. 


\section{A.3.1.66 void vglVerticalFlip (VglImage $* s r c, \quad$ VglImage $*$ dst)}

Flip image vertically i.e. top becomes bottom.

\section{A.3.1.67 void vglWhiteRohrerEdge (VglImage $* s r c$, VglImage $*$ dst, float radius)}

Finds edge by using a White-Rohrer mask.

\section{A.3.1.68 void vglXGY (VglImage $*$ src, VglImage $* d s t)$}

Stores sobel edge filtering in $\mathrm{X}$ direction in red channel, grayscale in green channel, and sobel edge filtering in $\mathrm{Y}$ direction in blue channel.

\section{A.4 src/glsl2cpp_Stereo.h File Reference}

\#include "vglimage.h"

\section{Functions}

- void vglAbsDiffDisparity (VglImage $*$ img_ref, VglImage $*$ img_2, VglImage $*$ dst, float disparity)

- void vglAbsDiffDisparityMipmap (VglImage *img_ref, VglImage *img_2, VglImage $*$ dst, float disparity, float max_lod)

- void vglFindDisparity (VglImage $*$ img_dif, VglImage $*$ img_disp, float disparity)

- void vglFindDisparityDiff (VglImage $*$ img_sum, VglImage $*$ img_disp, VglImage *img_best, float disparity) 
- void vglGreenDiffDisparity (VglImage $*$ img_ref, VglImage $*$ img_2, VglImage $*$ dst, float disparity)

- void vglHomography (VglImage $*$ img_src, VglImage $*$ img_dst, float $*$ f_homo)

- void vglMapTo3D (VglImage *img_map, VglImage *img_3d, float f, float b, float $\mathrm{D}$, float disp_k=0.0, float $\mathrm{h}=10.0$ )

- void vglMeanMipmap (VglImage $*$ img_dif, VglImage $*$ img_out, float max_lod)

- void vglMeanSq3 (VglImage $*$ img_dif, VglImage $*$ img_out)

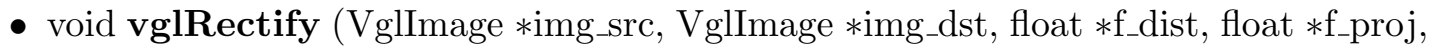
float $*$ f_homo)

- void vglUndistort (VglImage $*$ img_src, VglImage $*$ img_dst, float $* \mathrm{f}_{-}$dist, float $* \mathrm{f}_{-}$proj)

\section{A.4.1 Function Documentation}

\section{A.4.1.1 void vglAbsDiffDisparity (VglImage $* \mathbf{i m g \_ r e f , ~ V g l I m a g e ~} * \boldsymbol{i m g}$ 2 $_{-}$ VglImage $*$ dst, float disparity)}

Calculate absolute difference between img_ref and img_2. Disparities considered are in the closed interval $[4 *$ disparity, $4 *$ disparity +3$]$.

The four differences are stored in the RGBA image dst.

\section{A.4.1.2 void vglAbsDiffDisparityMipmap (VglImage $*$ img_ref, VglImage $*$ $i m g_{-2}, \quad$ VglImage $*$ dst, float disparity, float $\left.\max \_l o d\right)$}

Calculates average absolute difference between img_ref and img_2 at levels of detail in [0, max_lod]. Disparities considered are in the closed interval [ $4 *$ disparity, $4 *$ disparity +3$]$.

The four differences are stored in the RGBA image dst. 


\section{A.4.1.3 void vglFindDisparity (VglImage $*$ img_dif, VglImage $* i m g_{-}$disp, float disparity)}

Find best disparity. The first input image, img_dif, contains absolute differences between a pair of images at disparities [ $4 *$ disparity, $4 *$ disparity +3$]$.

The second input image contains the smallest differences found in channel $\mathrm{R}$, and corresponding disparity value in channel A, Is also an output image, and is updated whenever a smaller difference is found.

\section{A.4.1.4 void vglFindDisparityDiff (VglImage $*$ img_sum, VglImage $*$ img_disp, VglImage $*$ img_best, float disparity)}

Do the same as vglFindDisparity, but the smallest difference is stored in img_best, and corresponding disparity in img_disp. Both are input and output images.

\section{A.4.1.5 void vglGreenDiffDisparity (VglImage $* \boldsymbol{i m g} g_{-}$f, VglImage $* \boldsymbol{i m g}$ 2, VglImage $*$ dst, float disparity)}

Calculate absolute difference between green channel of img_ref and img_2. Disparities considered are in the closed interval [ $4 *$ disparity, $4 *$ disparity +3 ].

The four differences are stored in the RGBA image dst.

\section{A.4.1.6 void vglHomography (VglImage $* i m g_{-} s r c, \quad$ VglImage $* i m g_{-} d s t$, float $* f_{-}$homo)}

Apply homography in img_src and stores result in img_dst.

Important: for matrices the components are written in column major order: 


$$
\operatorname{mat} 2 \mathrm{~m}=\operatorname{mat} 2(1,2,3,4) \Leftrightarrow \mathrm{m}=\left(\begin{array}{ll}
1 & 3 \\
2 & 4
\end{array}\right)
$$

In $\mathrm{C}$ we build the matrix in line major order, then we must transpose tbe matrix before using it in OpenGL context.

\section{A.4.1.7 void vglMapTo3D (VglImage $* i m g \_m a p, \quad$ VglImage $* i m g \_3 d$, float} $f$, float $b$, float $D$, float $d i s p_{-} k=0.0$, float $h=10.0$ )

Convert depth map to affine reconstruction

This algorithm ignores the infinite homography.

img_map: input depth map

img_3d: output reconstruction

f: focal length in pixels

b: baseline in $\mathrm{cm}$

D: fixation point or maximum depth

is_float: if true, output image will store $\mathrm{z}$ in $\mathrm{cm}$. If false output image will store $\mathrm{z}$ as $255 *($ depth / D). If depth $==D$, it is mapped to $z=0$.

disp_k: If set, single disparity will be used.

h: height of camera in $\mathrm{cm}$

\section{A.4.1.8 void vglMeanMipmap (VglImage $*$ img_dif, $\quad$ VglImage $*$ img_out, float $\left.\max \_l o d\right)$}

Mean of pixel values of levels of detail in [0, max_lod]. Result is stored in img_out. 


\section{A.4.1.9 void vglMeanSq3 (VglImage $*$ img_dif, $\quad$ VglImage $*$ img_out)}

Mean filter with a 3x3 square mask.

\section{A.4.1.10 void vglRectify (VglImage $* i m g_{-} s r c$, VglImage $* \mathbf{i m g}$ dst $_{\text {, }}$ float $*$ $f_{-} d i s t$, float $* f_{-}$proj, float $* f_{-}$homo $)$}

Undistort, correct projection and rectify img_src and stores result in img_dst, for use with stereo algorithm.

The input float array f_dist contains the coefficient of radial distortion, and f_proj contains the intrinsinc parameters of the camera: center of projection ( $\mathrm{x}$ and $\mathrm{y}$ ); focal length in pixels ( $\mathrm{x}$ and $\mathrm{y})$. The focal lengths are the same when the pixels are square.

The input float array f_homo contains the homography that rectifies the image.

Important: for matrices the components are written in column major order:

$$
\operatorname{mat} 2 \mathrm{~m}=\operatorname{mat} 2(1,2,3,4) \Leftrightarrow \mathrm{m}=\left(\begin{array}{ll}
1 & 3 \\
2 & 4
\end{array}\right)
$$

In $\mathrm{C}$ we build the matrix in line major order, then we must transpose tbe matrix before using it in OpenGL context.

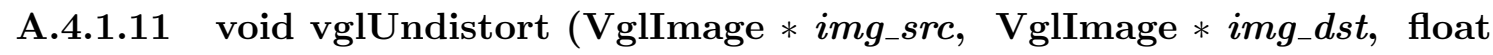 $* f_{-}$dist, float $* f_{-}$proj)}

Correct camera lens distortion of img_src and stores the result in img_dst.

The input float array f_dist contains the coefficient of radial distortion, and f_proj contains the intrinsinc parameters of the camera: center of projection ( $\mathrm{x}$ and $\mathrm{y}$ ); focal length in pixels ( $\mathrm{x}$ and $\mathrm{y})$. The focal lengths are the same when the pixels are square. 
Reference:

http://www. cognotics.com/opencv/docs/1.0/ref/opencvref_cv.htm\#cv_3d 


\section{Referências Bibliográficas}

[1] Aggarwal, J. K., \& Cai, Q. Human motion analysis: A review. Computer Vision and Image Understanding 73 (1999), 428-440. Citado na pág. 1

[2] Aggarwal, J. K., Cai, Q., Liao, W., \& Sabata, B. Articulated and elastic nonrigid motion: A review. In IEEE Workshop on Motion of Non-Rigid and Articulated Objects (1994), pp. 2-14. Citado na pág. 1

[3] Aggarwal, J. K., \& Park, S. Human motion: modeling and recognition of actions and interactions. In 2nd International Symposium on 3D Data Processing, Visualization and Transmission, (3DPVT'04) (2004), pp. 640-647. Citado na pág. 35

[4] Aran, O., \& Akarun, L. Recognizing two handed gestures with generative, discriminative and ensemble methods via fisher kernels. In MRCS (2006), pp. 159-166. Citado na pág. 25

[5] Arulampalam, S., Maskell, S., \& Gordon, N. A tutorial on particle filters for online nonlinear/non-gaussian bayesian tracking. IEEE Transactions on Signal Processing 50 (2002), 174-188. Citado na pág. 34

[6] Bailador, G., Roggen, D., Tröster, G., \& Trivino, G. Real time gesture recognition using continuous time recurrent neural networks. In 2nd international conference on Body area networks (2007), pp. 1-8. Citado na pág. 25

[7] Banon, G. J. F., \& Barrera, J. Bases da Morfologia Matemática para Análise de Imagens Binárias. IX Escola de Computação, Pernambuco, Julho 1994. Citado na pág. 66, 68, 106

[8] Bavel, Z. Introduction to the theory of automata. Reston Publishing Company, Inc., Reston, Virginia, USA, 1983. Citado na pág. 26

[9] Bernard, T. M., \& Manzanera, A. Improved low complexity fully parallel thinning algorithm. In ICIAP '99: Proceedings of the 10th International Conference 
on Image Analysis and Processing (Washington, DC, USA, 1999), IEEE Computer Society, p. 215. Citado na pág. 69, 106

[10] Bertrand, G., \& Couprie, M. New 2D parallel thinning algorithms based on critical kernels. In IWCIA (2006), pp. 45-59. Citado na pág. 69

[11] Bettens, F., \& Todoroff, T. Real-time dtw-based gesture recognition external object for max/msp and puredata. In Proceedings of the SMC 2009 - 6th Sound and Music Computing Conference (2009), pp. 30-35. Citado na pág. 25

[12] Bideau, B., Multon, F., Kulpa, R., Fradet, L., \& Arnaldi, B. Virtual reality applied to sports: do handball goalkeepers react realistically to simulated synthetic opponents? In VRCAI '04: Proceedings of the 2004 ACM SIGGRAPH international conference on Virtual Reality continuum and its applications in industry (New York, NY, USA, 2004), ACM, pp. 210-216. Citado na pág. 33

[13] Black, M. J., \& Jepson, A. D. A probabilistic framework for matching temporal trajectories: Condensation-based recognition of gestures and expressions. In ECCV '98: Proceedings of the 5th European Conference on Computer Vision-Volume I (London, UK, 1998), Springer-Verlag, pp. 909-924. Citado na pág. 25

[14] Bobick, A. F., \& Wilson, A. D. A state-based approach to the representation and recognition of gesture. IEEE Transactions on Pattern Analysis and Machine Intelligence 19, 12 (1997), 1325-1337. Citado na pág. 26

[15] Bray, J. Markerless based human motion capture: A survey. Technical report, Department of Systems Engineering, Brunel University, 2003. Citado na pág. 1

[16] Burdea, G. C., \& Coiffet, P. Virtual Reality Technology. John Wiley \& Sons, Inc., New York, NY, USA, 2003. Citado na pág. 29

[17] Cappé, O., Moulines, E., \& Ryden, T. Inference in Hidden Markov Models (Springer Series in Statistics). Springer-Verlag New York, Inc., Secaucus, NJ, USA, 2005. Citado na pág. 28

[18] Card, S. K., Newell, A., \& Moran, T. P. The Psychology of Human-Computer Interaction. Lawrence Erlbaum Associates, Inc., Mahwah, NJ, USA, 1983. Citado na pág. 22

[19] Card, S. K., Robertson, G. G., \& Mackinlay, J. D. The information visualizer, an information workspace. In SIGCHI Conference on Human Factors in Computing Systems (New York, NY, USA, 1991), ACM, pp. 181-186. Citado na pág. 22 
[20] Chen, Y., Lee, J., Parent, R., \& Machiraju, R. Markerless monocular motion capture using image features and physical constraints. In CGI '05: Proceedings of the Computer Graphics International 2005 (Washington, DC, USA, 2005), IEEE Computer Society, pp. 36-43. Citado na pág. 24

[21] Chengkai, W., Baozong, Y., \& Zhenjiang, M. Markerless human body motion capture using markov random field and dynamic graph cuts. The Visual Computer 24, 5 (May 2008), 373-380. Citado na pág. 24

[22] Chin, R. T., Wan, H.-K., Strover, D. L., \& Iverson, R. D. A one-pass thinning algorithm and its parallel implementation. Comput. Vision Graph. Image Process. 40, 1 (1987), 30-40. Citado na pág. 69

[23] Chu, C.-W., \& Cohen, I. Posture and gesture recognition using 3d body shapes decomposition. In Conference on Computer Vision and Pattern Recognition (CVPR'05) - Workshops (Washington, DC, USA, Janeiro 2006), IEEE Computer Society, p. 69. Citado na pág. 24

[24] Chu, C. W., Jenkins, O. C., \& Mataric, M. J. Markerless kinematic model and motion capture from volume sequences. In Conference on Computer Vision and Pattern Recognition (CVPR'03) (Los Alamitos, CA, USA, 2003), vol. 2, IEEE Computer Society, pp. $475+$. Citado na pág. 24

[25] Chu, C.-W., \& Nevatia, R. Real time body pose tracking in an immersive training environment. In ICCV-HCI (2007), M. S. Lew, N. Sebe, T. S. Huang, \& E. M. Bakker, Eds., vol. 4796 of Lecture Notes in Computer Science, Springer, pp. 146-156. Citado na pág. 34

[26] Correa, P., Czyz, J., Umeda, T., Marques, F., Marichal, X., \& Macq, B. Silhouette-based probabilistic $2 \mathrm{~d}$ human motion estimation for real-time applications. In Image Processing, 2005. ICIP 2005. IEEE International Conference on (2005), vol. 3, pp. III-836-9. Citado na pág. 65

[27] Correa, P., Marqués, F., Marichal, X., \& Macq, B. 3D posture estimation using geodesic distance maps. Multimedia Tools Appl. 38, 3 (2008), 365-384. Citado na pág. 65, 106, 132

[28] Couprie, M. Note on fifteen 2D parallel thinning algorithms. Technical report, Université de Marne-la-Vallée, 2005. Citado na pág. 69

[29] Das, S. R., Wilson, R. C., Lazarewicz, M. T., \& Finkel, L. H. Gait recognition by two-stage principal component analysis. IEEE International Conference on Automatic Face and Gesture Recognition (2006), 579-584. Citado na pág. 25 
[30] Davis, J. W., \& Bobick, A. F. The representation and recognition of human movement using temporal templates. In Conference on Computer Vision and Pattern Recognition (CVPR'97) (Washington, DC, USA, 1997), IEEE Computer Society, pp. $928+$. Citado na pág. 25

[31] Davis, J. W., \& Bobick, A. F. Virtual pat: A virtual personal aerobics trainer. In Workshop on Perceptual User Interfaces (1998), pp. 13-18. Citado na pág. 25

[32] Davis, J. W., \& Shah, M. Visual gesture recognition. Vision, Image and Signal Processing, IEE Proceedings - 141, 2 (Abril 1994), 101-106. Citado na pág. 25, 26, 107

[33] Davison, A. J., Deutscher, J., \& Reid, I. D. Markerless motion capture of complex full-body movement for character animation. In Proceedings of the Eurographic workshop on Computer animation and simulation (New York, NY, USA, 2001), Springer-Verlag New York, Inc., pp. 3-14. Citado na pág. 24

[34] Duda, R. O., Hart, P. E., \& Stork, D. G. Pattern Classification, 2a ed. John Willey \& Sons, 2001. Citado na pág. 28

[35] Elgammal, A., Shet, V., Yacoob, Y., \& Davis, L. S. Learning dynamics for exemplar-based gesture recognition. In in IEEE Computer Society Conference on Computer Vision and Pattern Recognition (2003), pp. 571-578. Citado na pág. 23, 79

[36] Farrugia, J. P., Horain, P., Guehenneux, E., \& Alusse, Y. GPuCV: A framework for image processing acceleration with graphics processors. In Multimedia and Expo, 2006 IEEE International Conference on (2006), pp. 585-588. Citado na pág. $42,49,59$

[37] Faugeras, O. Three-dimensional computer vision: Geometric viewpoint. MIT Press, Cambridge, MA, USA, 1993. Citado na pág. 18

[38] Faugeras, O., Luong, Q.-T., \& Papadopoulou, T. The Geometry of Multiple Images: The Laws That Govern The Formation of Images of A Scene and Some of Their Applications. MIT Press, Cambridge, MA, USA, 2001. Citado na pág. 15, 16

[39] Fernando, R., \& Kilgard, M. J. The Cg Tutorial: The Definitive Guide to Programmable Real-Time Graphics. Addison-Wesley Longman Publishing Co., Inc., Boston, MA, USA, 2003. Citado na pág. 43

[40] Freeman, W. T., Anderson, D. B., Beardsley, P. A., Dodge, C. N., Roth, M., Weissman, C. D., Yerazunis, W. S., Kage, H., Kyuma, K., Miyake, Y., \& TANAKA, K. Computer vision for interactive computer graphics. IEEE Comput. Graph. Appl. 18, 3 (1998), 42-53. Citado na pág. 30 
[41] Freeman, W. T., Beardsley, P. A., Kage, H., Tanaka, K., Kyuma, K., \& Weissman, C. D. Computer vision for computer interaction. SIGGRAPH Comput. Graph. 33, 4 (2000), 65-68. Citado na pág. 30

[42] Freeman, W. T., Tanaka, K., Ohta, J., \& Kyuma, K. Computer vision for computer games. In 2nd International Conference on Automatic Face and Gesture Recognition (FG'96) (Washington, DC, USA, 1996), IEEE Computer Society, p. 100. Citado na pág. 30

[43] Fung, J., \& MAnn, S. OpenVIDIA: parallel GPU computer vision. In MULTIMEDIA '05: Proceedings of the 13th annual ACM international conference on Multimedia (New York, NY, USA, 2005), ACM, pp. 849-852. Citado na pág. 42, 49

[44] Gaitanis, K., Correa, P., \& Macq, B. Human action recognition using silhouette based feature extraction and dynamic bayesian networks. Scientific Commons (2008). Citado na pág. 65

[45] Gavrila, D. The visual analysis of human movement: A survey. Computer Vision and Image Understanding 73, 1 (1999), 82-98. Citado na pág. 1

[46] GILL, A. Introduction to the theory of finite-state machines. McGraw-Hill, New York, 1962. Citado na pág. 26

[47] Guo, Y., Xu, G., \& Tsusi, S. Understanding human motion patterns. International Conference on Pattern Recognition (ICPR'94) (Outubro 1994). Citado na pág. 35

[48] Hämäläınen, P., Ilmonen, T., Höysniemi, J., Lindholm, M., \& Nykänen, A. Martial arts in artificial reality. In SIGCHI Conference on Human Factors in Computing Systems (New York, NY, USA, 2005), ACM, pp. 781-790. Citado na pág. 33

[49] Hartley, R., \& Zisserman, A. Multiple view geometry in computer vision. Cambridge University Press, New York, NY, USA, 2000. Citado na pág. 13, 15, 16

[50] Hong, D., \& Woo, W. A 3D vision-based ambient user interface. International Journal of Human Computer Interaction 20, 3 (july 2006), 271-284. Citado na pág. 34

[51] Hong, P., Huang, T. S., \& Turk, M. Constructing finite state machines for fast gesture recognition. International Conference on Pattern Recognition 3 (2000), 3695. Citado na pág. 25, 26, 61

[52] Hong, P., Turk, M., \& Huang, T. Gesture modeling and recognition using finite state machines. In Fourth IEEE International Conference on Automatic Face and Gesture Recognition (2000), pp. 410-415. Citado na pág. 25, 26, 61 
[53] Hu, M. K. Visual pattern recognition by moment invariants. IRE Transactions on Information Theory IT-8 (Fevereiro 1962), 179-187. Citado na pág. 24

[54] Imasawa, S., Ohya, J., Takahashi, K., Sakaguchi, T., Kawato, S., Ebihara, K., \& Morishima, S. Real-time, 3d estimation of human body postures from trinocular images. In International Workshop on Modelling People (MPEOPLE '99) (Washington, DC, USA, 1999), IEEE Computer Society, p. 3. Citado na pág. 24

[55] Jaimes, A., \& Sebe, N. Multimodal human-computer interaction: A survey. Computer Vision and Image Understanding 108, 1-2 (2007), 116-134. Citado na pág. 22

[56] Johansson, G. Visual motion perception. Scientific American (Junho 1975), 7688. Citado na pág. 35

[57] JuAng, C.-F., \& Ku, K.-C. A recurrent fuzzy network for fuzzy temporal sequence processing and gesture recognition. IEEE Transactions on Systems, Man, and Cybernetics, Part B: Cybernetics 35, 4 (Agosto 2005), 646-658. Citado na pág. 25

[58] Kadous, M. W. Temporal Classification: Extending the Classification Paradigm to Multivariate Time Series. PhD thesis, School of Computer Science \& Engineering, University of New South Wales, 2002. Citado na pág. 25

[59] Keogh, E. J., \& Pazzani, M. J. Scaling up dynamic time warping to massive dataset. In 3rd European Conferece on Principles and Practice of Knowledge Discovery in Databases (1999), pp. 1-11. Citado na pág. 25

[60] Kilner, J., Guillemaut, J.-Y., \& Hilton., A. 3d action matching with keypose detection. In ICCV Workshop on Search in 3D and Video (S3DV 2009) (Kyoto, JapÃ£o, Setembro 2009). Citado na pág. 36

[61] KIm, J.-M., \& Song, M.-K. Three dimensional gesture recognition using PCA of stereo images and modified matching algorithm. Fourth International Conference on Fuzzy Systems and Knowledge Discovery 4 (2008), 116-120. Citado na pág. 25

[62] Kisacanin, B., Pavlovic, V., \& Huang, T. S., Eds. Real-Time Vision for Human-Computer Interaction. Springer-Verlag New York, Inc., Secaucus, NJ, USA, 2005. Citado na pág. 22

[63] Kohavi, R., \& John, G. H. Wrappers for feature subset selection. Artif. Intell. 97, 1-2 (1997), 273-324. Citado na pág. 37 
[64] Kohler, M., Oter, S. S., \& Uller, H. M. The ARGUS-architecture for global computer vision-based interaction and its application in domestic environments. In 8th International Conference on Human-Computer Interaction) (august 1999), Lawrence Erlbaum Associates. Citado na pág. 24

[65] Krueger, M. W. Artificial Reality II. Addison-Wesley, 1991. Citado na pág. 29

[66] Lee, J., Cakmak, M., DePalma, N., \& Christensen, H. I. Gesture recognition with temporally local to global representations. Computer sciences technical report, Georgia Institute of Technology, 2010. Citado na pág. 37

[67] Lee, J., Chai, J., Reitsma, P. S. A., Hodgins, J. K., \& Pollard, N. S. Interactive control of avatars animated with human motion data. ACM Trans. Graph. 21, 3 (2002), 491-500. Citado na pág. 88, 106

[68] Lee, M. W., \& Cohen, I. Human upper body pose estimation in static images. In 8th European Conference on Computer Vision (Prague, Czech Republic, Maio 2004), T. Pajdla \& J. Matas, Eds., vol. 3022 of Lecture Notes in Computer Science, Springer. Citado na pág. 24

[69] Levenshtein, V. I. Binary codes capable of correcting deletions, insertions, and reversals. Soviet Physics Doklady 10, 8 (1966), 707-710. Citado na pág. 99

[70] Li, J., Wan, C., Zhang, D., Miao, Z., \& Yuan, B. Markerless human motion capture by markov random field and dynamic graph cuts with color constraints. Science in China Series F: Information Sciences 52, 2 (2009), 252-259. Citado na pág. 24

[71] Li, Z., \& JARvis, R. Real time hand gesture recognition using a range camera. In Australasian Conference on Robotics and Automation (Dezembro 2009). Citado na pág. $27,88,98$

[72] Lv, F., \& Nevatia, R. Single view human action recognition using key pose matching and viterbi path searching. Citado na pág. 36

[73] Maes, P., Darrell, T., Blumberg, B., \& Pentland, A. The Alive system: Full-body interaction with autonomous agents. In Proceedings of the Computer Animation (Washington, DC, USA, 1995), IEEE Computer Society, p. 11. Citado na pág. 30

[74] Mamania, V., Shaji, A., \& Chandran, S. Markerless motion capture from monocular videos. In ICVGIP (2004), pp. 126-132. Citado na pág. 24 
[75] Mcmillan, L., , Mcmillan, L., \& Bishop, G. Head-tracked stereoscopic display using image warping. Proceedings of SPIE 2409. Citado na pág. 134

[76] Michoud, B., Gulllou, E., \& Bouakaz, S. Real-time and markerless 3d human motion capture using multiple views. In ICCV Workshop on Human Motion (WHM'2007) (2007), A. M. Elgammal, B. Rosenhahn, \& R. Klette, Eds., vol. 4814 of Lecture Notes in Computer Science, Springer, pp. 88-103. Citado na pág. 24

[77] Mitra, S., \& Acharya, T. Gesture recognition: A survey. IEEE Transactions on Systems, Man, and Cybernetics, Part C: Applications and Reviews 37, 3 (2007), 311-324. Citado na pág. 1, 23

[78] Moeslund, T. B., \& Granum, E. A survey of computer vision-based human motion capture. Computer Vision and Image Understanding 81, 3 (2001), 231-268. Citado na pág. 1, 35

[79] Moeslund, T. B., Hilton, A., \& Krüger, V. A survey of advances in visionbased human motion capture and analysis. Computer Vision and Image Understanding 104, 2-3 (2006), 90-126. Citado na pág. 1, 35

[80] Mueller, F., \& Group, H. C. Breakout for two: An example of an exertion interface for sports over a distance. Citado na pág. 33

[81] Murakami, K., \& Taguchi, H. Gesture recognition using recurrent neural networks. In SIGCHI Conference on Human Factors in Computing Systems (New York, NY, USA, 1991), ACM, pp. 237-242. Citado na pág. 25

[82] Myers, C. S., \& Rabiner, L. R. A comparative study of several dynamic time warping algorithms for connected word recognition. The Bell System Technical Journal 60, 7 (1981), 1389-1409. Citado na pág. 25

[83] NVIDIA corporation. http://www.nvidia.com/. Citado na pág. 41, 47

[84] Ogale, A. S., Karapurkar, A., \& Aloimonos, Y. View-invariant modeling and recognition of human actions using grammars. In ICCV Workshop on Dynamical Vision (WDV'05) (2005). Citado na pág. 88

[85] Okada, R., \& Stenger, B. A single camera motion capture system for humancomputer interaction. IEICE - Trans. Inf. Syst. E91-D, 7 (2008), 1855-1862. Citado na pág. 24,36

[86] OpenCV reference manual. http://opencv.willowgarage.com/documentation/ index.html. Citado na pág. 8, 16, 48 
[87] OpenGL. http://www.opengl.org/. Citado na pág. 43

[88] Owens, J. D., Luebke, D., Govindaraju, N., Harris, M., KrÃ $\frac{1}{4}$ Ger, J., Lefohn, A. E., \& Purcell, T. J. A survey of general-purpose computation on graphics hardware. In Eurographics 2005, State of the Art Reports (Agosto 2005), pp. 21-51. Citado na pág. 41

[89] Penner, E., \& Parker, J. R. The virtual window simulator. In Conference on Future Play (2007), ACM, pp. 54-60. Citado na pág. 134

[90] Rabiner, L. R. A tutorial on hidden markov models and selected applications in speech recognition. In Proceedings of the IEEE (1989), pp. 257-286. Citado na pág. 25

[91] Rosales, R., Athitsos, V., Sigal, L., \& Sclaroff, S. 3d hand pose reconstruction using specialized mappings. In International Conference on Computer Vision (ICCV'01) (2001), pp. 378-385. Citado na pág. 88, 106

[92] Rosales, R., \& Sclaroff, S. Learning and synthesizing human body motion and posture. In FG'00: Proceedings of the Fourth IEEE International Conference on Automatic Face and Gesture Recognition (Washington, DC, USA, 2000), IEEE Computer Society, p. 506. Citado na pág. 88, 106

[93] Rost, R. J. OpenGL(R) Shading Language, 2a ed. Addison-Wesley, 2005. Citado na pág. 45

[94] Saboune, J., \& Charpillet, F. Markerless human motion tracking from a single camera using interval particle filtering. International Journal on Artificial Intelligence Tools 16, 4 (2007), 593-609. Citado na pág. 35

[95] Savelsbergh, G. J. P., Williams, A. M., Kamp, J. V. D., \& Ward, P. Visual search, anticipation and expertise in soccer goalkeepers. Journal of Sports Sciences

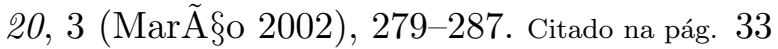

[96] Scharstein, D., \& Szeliski, R. A taxonomy and evaluation of dense two-frame stereo correspondence algorithms. International Journal of Computer Vision 47, 1-3 (2002), 7-42. Citado na pág. 18

[97] Shneiderman, B., \& Plaisant, C. Designing the User Interface: Strategies for Effective Human-Computer Interaction, 4⿳亠丷a ed. Pearson Addison Wesley, 2004. Citado na pág. 136

[98] Starner, T., \& Pentland, A. Visual recognition of american sign language using hidden markov models. In International Workshop on Automatic Face and Gesture Recognition (1995), pp. 189-194. Citado na pág. 25 
[99] Sutherland, I. A head-mounted three-dimensional display. In Fall Joint Computer Conference (1968), pp. 757-764. Citado na pág. 29

[100] Thome, N., Merad, D., \& Miguet, S. Learning articulated appearance models for tracking humans: A spectral graph matching approach. Signal Processing: Image Communication 23, 10 (2008), 769-787. Citado na pág. 133

[101] Tong, M., Liu, Y., \& Huang, T. S. 3d human model and joint parameter estimation from monocular image. Pattern Recogn. Lett. 28, 7 (2007), 797-805. Citado na pág. 24

[102] Tresadern, P., \& Reid, I. An evaluation of shape descriptors for image retrieval in human pose estimation. In 18th British Machine Vision Conference, pp. 800-809. Citado na pág. 36,88

[103] Turk, M. Computer vision in the interface. Communications of the ACM 47, 1 (2004), 60-67. Citado na pág. 22

[104] Turk, M. RTV4HCI: A historical overview. In Real-Time Vision for HumanComputer Interaction, B. Kisacanin, V. Pavlovic, \& T. S. Huang, Eds. SpringerVerlag New York, Inc., Secaucus, NJ, USA, 2005. Citado na pág. 22

[105] Turk, M., \& KÖLsch, M. Perceptual interfaces. In Emerging Topics in Computer Vision, G. Medioni \& S. B. Kang, Eds. Prentice Hall, 2004. Citado na pág. 22

[106] VApnik, V. N. Statistical Learning Theory. Wiley-Interscience, 1998. Citado na pág. 99

[107] Verma, R., \& Dev, A. Vision based hand gesture recognition using finite state machines and fuzzy logic. In International Conference on Ultra Modern Telecommunications (ICUMT'2009) (Outubro 2009), pp. 1-6. Citado na pág. 26

[108] Warren, J. Unencumbered full body interaction in video games. Master's thesis, Parsons School of Design, Abril 2003. Citado na pág. 31

[109] Weinland, D., \& Boyer, E. Action recognition using exemplar-based embedding. In Conference on Computer Vision and Pattern Recognition, (CVPR'08) (June 2008), pp. 1-7. Citado na pág. 36

[110] Wren, C., Azarbayejani, A., Darrell, T., \& Pentl, A. Pfinder: Real-time tracking of the human body. IEEE Transactions on Pattern Analysis and Machine Intelligence 19 (1997), 780-785. Citado na pág. 31

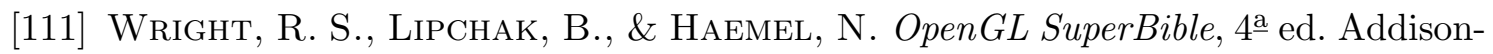
Wesley, 2007. Citado na pág. 55 
[112] Yamato, J., OhyA, J., \& Ishis, K. Recognizing human action in time-sequential images using hidden markov model. In IEEE Computer Society Conference on Computer Vision and Pattern Recognition (1992), pp. 379-385. Citado na pág. 25

[113] Yang, R., \& Pollefeys, M. Multi-resolution real-time stereo on commodity graphics hardware. In IEEE Computer Society Conference on Computer Vision and Pattern Recognition (2003). Citado na pág. 18

[114] Yoo, J. H., \& Nixon, M. S. Markerless human gait analysis via image sequences. In International Society of Biomechanics XIXth Congress (Dunedin, Nova Zelândia, 2003). Citado na pág. 35

[115] Zheng, J. Y., \& Suezaki, S. A model based approach in extracting and generating human motion. In International Conference on Pattern Recognition (ICPR'98) (Agosto 1998), vol. 2, pp. 1201-1205. Citado na pág. 88 


\section{Índice Remissivo}

3DV Systems, 32, 34

annealed particle filtering, 24

artificial retina, 30

baricentro, 66

barrel, 8, 65

baseline, 10, 67, 84-86, 88

blob, 66-69, 71, 91, 106

Cell, 36

$\mathrm{Cg}, 43$

chromakey, 23, 31

coeficientes de distorção radial, 8

CSV, 97

CUDA, 42, 44, 45, 47-49

cvCalibrateCamera, 8

cvDrawChessboardCornerGuesses, 9

cvFindChessboardCornerGuesses, 8, 13

cvFindFundamentalMatrix, 13

cvFindHomography, 16

cvUndistortOnce, 8

dataset, 4, 83-85, 88

diagrama de Voronoi, 77

Direct3D, 43

disparidade, 9, 10

DTW, 25

Firewire, 84

fragment shader, 43, 44, 46, 47

framebuffer, 47

FSM, 3, 25, 79, 80, 131 gather, 44

GeForce, 41, 44, 47

gl_FragColor, 46

gl_FrontColor, 46

gl_ModelViewMatrix, 46

gl_TexCoord, 46

gl_Vertex, 46

GLSL, 42, 43, 45, 46

glsl2cpp_BG.h vglDetectFGSimpleBGModel, 154

vglTrainSimpleBGModel, 154

vglUpdatePartialSimpleBGModel, 154

glsl2cpp_shaders.h

vgl1to3Channels, 158

vglAbsDiff, 158

vglAnd, 158

vglBaricenterInit, 158

vglClear2, 158

vglContrast, 159

vglCoordToColor, 159

vglCopy, 159

vglCrossingNumber, 159

vglDeleteSkeletonCorners, 160

vglDeleteSkeletonWarts, 160

vglDeleteSkeletonWarts2, 161

vglDiff, 162

vglDilateCross3, 162

vglDilateSq3, 162

vglErodeCross3, 162

vglErodeHL3, 162

vglErodeHL5, 163 
vglErodeHL7, 163

vglErodeSq3, 163

vglErodeSq3off, 163

vglErodeSq5, 163

vglErodeSq5off, 163

vglErodeSq7, 164

vglErodeSqSide, 164

vglErodeVL3, 164

vglErodeVL5, 164

vglErodeVL7, 164

vglFeaturePoints, 164

vglGaussianBlurSq3, 165

vglGray, 165

vglHorizontalFlip, 166

vglJulia, 166

vglLaplaceSq3, 166

vglMandel, 166

vglMipmap, 166

vglMulScalar, 166

vglNoise, 167

vglNot, 167

vglOr, 167

vglRescale, 167

vglRgbToHsl, 167

vglRgbToHsv, 167

vglRgbToXyz, 167

vglRobertsGradient, 168

vglSelfSum22, 168

vglSelfSum3v, 168

vglSelfSum4h, 168

vglSelfSum5h, 168

vglSelfSum5v, 169

vglSharpenSq3, 169

vglSobelGradient, 169

vglSobelXSq3, 169

vglSobelYSq3, 169

vglSum, 169

vglSumWeighted, 170

vglSwapRGB, 170

vglTestInOut, 170
vglTestInOut2, 170

vglTestMultiInput, 170

vglTestMultiOutput, 170

vglThinBernardAux, 171

vglThinChinAux, 171

vglThresh, 172

vglThreshLevelSet, 172

vglVerticalFlip, 172

vglWhiteRohrerEdge, 173

vglXGY, 173

glsl2cpp_Stereo.h

vglAbsDiffDisparity, 174

vglAbsDiffDisparityMipmap, 174

vglFindDisparity, 174

vglFindDisparityDiff, 175

vglGreenDiffDisparity, 175

vglHomography, 175

vglMapTo3D, 176

vglMeanMipmap, 176

vglMeanSq3, 176

vglRectify, 177

vglUndistort, 177

GPU, 3, 39-45, 47, 49, 51, 52, 59

groundtruth, 97-101, 103

hardware, 30, 40, 41, 45, 47

HLSL, 43

HMM, 25, 27, 28, 37, 77, 131

HOG, 37

Intel, 32, 41

keyframe, 36, 37, 77, 78, 88, 95, 103, 105, 131

keypoint, 77, 88, 92, 94, 95, 105, 107, 131, 132

LoadPGM

vglImage.h, 142

matriz fundamental, 12, 13 
Microsoft, 32, 43

nvcc, 47

NVIDIA, 41-44

OpenGL, 41-43, 45, 46, 51

PCA, 25

pincushion, 8

pinhole, $4-8$

pipeline, 4, 18, 41, 42, 45, 47, 61, 65, 66, 68, $70,105,106$

pixelbuffer, 54

pontos correspondentes, 9

restrição epipolar, 11

RNN, 25

\section{SavePGM}

vglImage.h, 142

SavePPM

vglImage.h, 142

SaveYUV411

vglImage.h, 142

scatter, 44

shader, 42-44, 49

sistema de coordenadas da câmera, 6

sistema de coordenadas da imagem, 7, 15

src/glsl2cpp_BG.h, 153

src/glsl2cpp_shaders.h, 155

src/glsl2cpp_Stereo.h, 173

src/vglImage.h, 139

template matching, 24

thread, 40, 47, 48

thresholding, 72

top hat, 72,106

vertex shader, $43,44,46$

VGA, 84

vgl1to3Channels

glsl2cpp_shaders.h, 158
vglAbsDiff

glsl2cpp_shaders.h, 158

vglAbsDiffDisparity glsl2cpp_Stereo.h, 174

vglAbsDiffDisparityMipmap glsl2cpp_Stereo.h, 174

vglAnd glsl2cpp_shaders.h, 158

vglBaricenterInit glsl2cpp_shaders.h, 158

vglBaricenterVga vglImage.h, 142

vglCErodeCross3

vglImage.h, 143

vglClear vglImage.h, 143

vglClear2 glsl2cpp_shaders.h, 158

vglCloseSq3

vglImage.h, 143

vglContrast

glsl2cpp_shaders.h, 159

vglCoordToColor glsl2cpp_shaders.h, 159

vglCopy

glsl2cpp_shaders.h, 159

vglCopyCreateImage

vglImage.h, 144

vglCopyImageTex vglImage.h, 144

vglCopyImageTexFS

vglImage.h, 144

vglCopyImageTexVFS

vglImage.h, 144

vglCreateImage

vglImage.h, 144, 145

vglCrossingNumber glsl2cpp_shaders.h, 159

vglDeleteSkeletonCorners glsl2cpp_shaders.h, 160 
vglDeleteSkeletonWarts glsl2cpp_shaders.h, 160

vglDeleteSkeletonWarts2 glsl2cpp_shaders.h, 161

vglDetectFGSimpleBGModel glsl2cpp_BG.h, 154

$\operatorname{vglDiff}$

glsl2cpp_shaders.h, 162

vglDilateCross3

glsl2cpp_shaders.h, 162

vglDilateSq3

glsl2cpp_shaders.h, 162

vglDistTransform5

vglImage.h, 145

vglDistTransformCross3

vglImage.h, 145

vglDistTransformSq3

vglImage.h, 146

vglDownload

vglImage.h, 146

vglDownloadFaster

vglImage.h, 146

vglDownloadFBO

vglImage.h, 147

vglDownloadPGM

vglImage.h, 147

vglDownloadPPM

vglImage.h, 147

vglErodeCross3

glsl2cpp_shaders.h, 162

vglErodeHL3

glsl2cpp_shaders.h, 162

vglErodeHL5

glsl2cpp_shaders.h, 163

vglErodeHL7

glsl2cpp_shaders.h, 163

vglErodeSq3

glsl2cpp_shaders.h, 163

vglErodeSq3off

glsl2cpp_shaders.h, 163
vglErodeSq3Sep

vglImage.h, 148

vglErodeSq 5

glsl2cpp_shaders.h, 163

vglErodeSq5off

glsl2cpp_shaders.h, 163

vglErodeSq5Sep

vglImage.h, 148

vglErodeSq7

glsl2cpp_shaders.h, 164

vglErodeSqSide

glsl2cpp_shaders.h, 164

vglErodeVL3

glsl2cpp_shaders.h, 164

vglErodeVL5

glsl2cpp_shaders.h, 164

vglErodeVL7

glsl2cpp_shaders.h, 164

vglFeaturePoints

glsl2cpp_shaders.h, 164

vglFindDisparity

glsl2cpp_Stereo.h, 174

vglFindDisparityDiff

glsl2cpp_Stereo.h, 175

vglGaussianBlurSq3

glsl2cpp_shaders.h, 165

vglGetLevelDistTransform5

vglImage.h, 148

vglGray

glsl2cpp_shaders.h, 165

vglGreenDiffDisparity glsl2cpp_Stereo.h, 175

vglHomography glsl2cpp_Stereo.h, 175

vglHorizontalFlip glsl2cpp_shaders.h, 166

vglHorizontalFlip2

vglImage.h, 149

vglImage.h

LoadPGM, 142 
SavePGM, 142

SavePPM, 142

SaveYUV411, 142

vglBaricenterVga, 142

vglCErodeCross3, 143

vglClear, 143

vglCloseSq3, 143

vglCopyCreateImage, 144

vglCopyImageTex, 144

vglCopyImageTexFS, 144

vglCopyImageTexVFS, 144

vglCreateImage, 144, 145

vglDistTransform5, 145

vglDistTransformCross3, 145

vglDistTransformSq3, 146

vglDownload, 146

vglDownloadFaster, 146

vglDownloadFBO, 147

vglDownloadPGM, 147

vglDownloadPPM, 147

vglErodeSq3Sep, 148

vglErodeSq5Sep, 148

vglGetLevelDistTransform5, 148

vglHorizontalFlip2, 149

vglInit, 149

vglInOut_model, 149

vglLoadImage, 149

vglLoadPGM, 150

vglMultiInput_model, 150

vglMultiOutput_model, 150

vglOpenSq3, 150

vglPrintImageInfo, 150

vglReleaseImage, 151

vglReplaceIpl, 151

vglSavePGM, 151

vglSavePPM, 151

vglThinBernard, 152

vglThinChin, 152

vglUpload, 153

vglVerticalFlip2, 153
vglInit

vglImage.h, 149

vglInOut_model

vglImage.h, 149

vglJulia

glsl2cpp_shaders.h, 166

vglLaplaceSq3

glsl2cpp_shaders.h, 166

vglLoadImage

vglImage.h, 149

vglLoadPGM

vglImage.h, 150

vglMandel

glsl2cpp_shaders.h, 166

vglMapTo3D

glsl2cpp_Stereo.h, 176

vglMeanMipmap

glsl2cpp_Stereo.h, 176

vglMeanSq3

glsl2cpp_Stereo.h, 176

vglMipmap

glsl2cpp_shaders.h, 166

vglMulScalar glsl2cpp_shaders.h, 166

vglMultiInput_model

vglImage.h, 150

vglMultiOutput_model

vglImage.h, 150

vglNoise

glsl2cpp_shaders.h, 167

vglNot

glsl2cpp_shaders.h, 167

vglOpenSq3

vglImage.h, 150

vglOr

glsl2cpp_shaders.h, 167

vglPrintImageInfo

vglImage.h, 150

vglRectify

glsl2cpp_Stereo.h, 177 
vglReleaseImage

vglImage.h, 151

vglReplaceIpl

vglImage.h, 151

vglRescale glsl2cpp_shaders.h, 167

vglRgbToHsl glsl2cpp_shaders.h, 167

vglRgbToHsv glsl2cpp_shaders.h, 167

vglRgbToXyz glsl2cpp_shaders.h, 167

vglRobertsGradient glsl2cpp_shaders.h, 168

vglSavePGM

vglImage.h, 151

vglSavePPM

vglImage.h, 151

vglSelfSum22

glsl2cpp_shaders.h, 168

vglSelfSum3v

glsl2cpp_shaders.h, 168

vglSelfSum4h

glsl2cpp_shaders.h, 168

vglSelfSum5h

glsl2cpp_shaders.h, 168

vglSelfSum5v

glsl2cpp_shaders.h, 169

vglSharpenSq3

glsl2cpp_shaders.h, 169

vglSobelGradient

glsl2cpp_shaders.h, 169

vglSobelXSq3

glsl2cpp_shaders.h, 169

vglSobelYSq3

glsl2cpp_shaders.h, 169

vglSum

glsl2cpp_shaders.h, 169

vglSumWeighted

glsl2cpp_shaders.h, 170
vglSwapRGB

glsl2cpp_shaders.h, 170

vglTestInOut

glsl2cpp_shaders.h, 170

vglTestInOut2

glsl2cpp_shaders.h, 170

vglTestMultiInput glsl2cpp_shaders.h, 170

vglTestMultiOutput glsl2cpp_shaders.h, 170

vglThinBernard

vglImage.h, 152

vglThinBernardAux

glsl2cpp_shaders.h, 171

vglThinChin

vglImage.h, 152

vglThinChinAux

glsl2cpp_shaders.h, 171

vglThresh

glsl2cpp_shaders.h, 172

vglThreshLevelSet

glsl2cpp_shaders.h, 172

vglTrainSimpleBGModel

glsl2cpp_BG.h, 154

vglUndistort glsl2cpp_Stereo.h, 177

vglUpdatePartialSimpleBGModel glsl2cpp_BG.h, 154

vglUpload vglImage.h, 153

vglVerticalFlip glsl2cpp_shaders.h, 172

vglVerticalFlip2

vglImage.h, 153

vglWhiteRohrerEdge glsl2cpp_shaders.h, 173

$\operatorname{vglXGY}$

glsl2cpp_shaders.h, 173

Videodesk, 30

Videoplace, 29-31 
Xeon, 41

ZCam, 33, 34 